\title{
Appalachian Adolescents' Identity and Agency: An Ethnographic Exploration of How Local Culture and Social Class Matter in the Postsecondary Transition
}

Brandi Slider Weekley

Follow this and additional works at: https://researchrepository.wvu.edu/etd

\section{Recommended Citation}

Weekley, Brandi Slider, "Appalachian Adolescents' Identity and Agency: An Ethnographic Exploration of How Local Culture and Social Class Matter in the Postsecondary Transition" (2015). Graduate Theses, Dissertations, and Problem Reports. 6929.

https://researchrepository.wvu.edu/etd/6929

This Dissertation is protected by copyright and/or related rights. It has been brought to you by the The Research Repository @ WVU with permission from the rights-holder(s). You are free to use this Dissertation in any way that is permitted by the copyright and related rights legislation that applies to your use. For other uses you must obtain permission from the rights-holder(s) directly, unless additional rights are indicated by a Creative Commons license in the record and/ or on the work itself. This Dissertation has been accepted for inclusion in WVU Graduate Theses, Dissertations, and Problem Reports collection by an authorized administrator of The Research Repository @ WVU.

For more information, please contact researchrepository@mail.wvu.edu. 
Appalachian Adolescents' Identity and Agency: An Ethnographic Exploration of How Local Culture and Social Class Matter in the Postsecondary Transition

\author{
Brandi Slider Weekley \\ Dissertation submitted \\ to the College of Education and Human Services \\ at West Virginia University \\ in partial fulfillment of the requirements for the degree of \\ Doctor of Philosophy in \\ Education, Interdisciplinary
Melissa Sherfinski, Ph.D. Co-Chair
Audra Slocum, Ph.D. Co-Chair
Sharon Hayes, Ph.D.
Carol Markstrom, Ph.D.
Samuel F. Stack, Ph.D. \\ Department of Curriculum \& Instruction/Literacy Studies
}

\author{
Morgantown, West Virginia \\ 2015
}

Keywords: Appalachia, Education, Social Class, Identity, Postsecondary Transition

Copyright 2015 Brandi Slider Weekley 


\section{ABSTRACT \\ Appalachian Adolescents' Identity and Agency: An Ethnographic Exploration of How Local Culture and Social Class Matter in the Postsecondary Transition}

\section{Brandi Slider Weekley}

This study details a one year critical, ethnographic examination of the postsecondary transitions of six West Virginia high school seniors. The work explores how social class and local culture mattered in the postsecondary transition for students from a range of social and economic backgrounds. Figured Worlds Theory (Holland, et al., 1998) was used to explore how students' identities were constructed from the world around them and enacted as students agentively moved through the postsecondary transition. Attention was paid to the hollowing out of rural spaces and how this happens in West Virginia as a product of deindustrialization and educational policy and practices that are all forwarded by globalization and neoliberalism.

Two West Virginia high schools were selected to show a range of experiences: one high income, suburban school and the other a low income, rural school. Convenience sampling was used to purposefully select three seniors at each site who came from a low, middle, and high income background, respectively. Students participated for one year, during the spring of their senior year in high school through the fall of their freshman year in college. Participant observation was used as the main data gathering tool in schools and communities. Each student participated in two semi-structured interviews: the first, during their senior year and the second during the fall of their freshman year of college. The interviews explored participants' identities, views on their communities, and their postsecondary plans and outcomes. Students participated in focus groups that explored Appalachian identity, culture, and dialect, as well as race. The final focus group utilized photovoice as students shared images of their communities and lives to show how they constructed their own and community identities. Semi-structured interviews were completed with parents to learn about their support and involvement in their children's education. Questionnaires were completed by guidance counselors and teachers to capture their educational approaches and demographic backgrounds.

All data were compiled into a primary record that was analyzed using NVIVO qualitative software. Drawing from grounded theory, open codes were developed from the primary record and theoretical background to develop analytic themes. These themes were used to sort the primary record and all other data sources. All data were used in triangulation to explore the connections and contradictions between sources. Data analysis was approached through a critical ethnographic framework that focused on constructing and drawing meaning from participants' experiences (Carspecken, 1996).

Major findings of the study revealed differences between how social class was constructed at the two sites. These differences mediated the ways that class influenced students' lives and thus positioned them differently within the postsecondary transition. Values within the rural community supported a broad range of students and countered discourses of competition during the postsecondary transition. In the suburban community, discourses of competition and achievement served to other students who did not excel and did not as strongly support students in the postsecondary transition.

Students and families depended on the schools as their main source of information during the postsecondary transition and though schools provided some support, there were lacunae 
between what was provided and what participants needed. Further, schools' support for the postsecondary transition was narrowly focused on baccalaureate choices, despite rhetoric that purported to support college and career readiness. While all participants found gaps in the postsecondary transition advising process, students from first generation backgrounds were the most disadvantaged by the lack of structural support from schools. School counselors were aware of this gap; however, because of heavy workloads and standardization and accountability pushdown, they were not positioned to broaden their reach to include more students.

Despite these barriers, students and families showed great agency through the postsecondary transition as they worked to achieve their goals. Students' and parents' work disrupted discourses that position first generation, low-income, and Appalachian students and families as deficient in the postsecondary transition process. Further, participants' attachment to family and place disrupted the hollowing out narrative that success is found elsewhere and students who stay in rural places are settling for less than the best. However, these commitments were challenged by a lack of infrastructure that would allow young adults to remain locally.

The participants' stories pushed against neoliberal narratives that hide structures within the social, economic, and educational systems that contribute to inequitable educational and life outcomes. This work contributes a critical, strengths based perspective of low income and Appalachian adolescents to the educational literature. Further, the work offers perspectives that may be helpful in constructing educational policy geared towards the postsecondary transition and guidance, as well as information that can contribute to stable and sustainable Appalachian communities. 
To Chaddy Patty, Mom \& Dad.

It's been a long road. 


\section{Table of Contents}

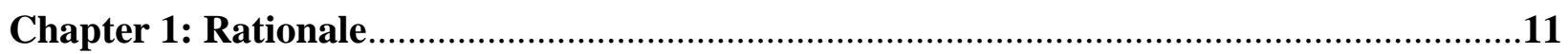

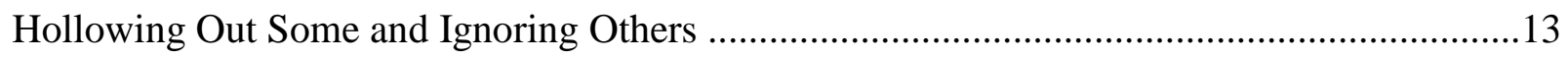

Context of the Practices of Hollowing Out in West Virginia ....................................................16

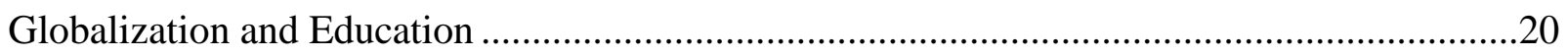

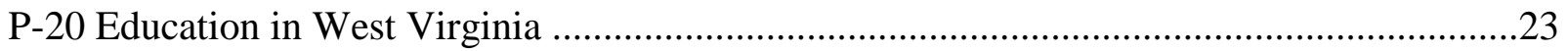

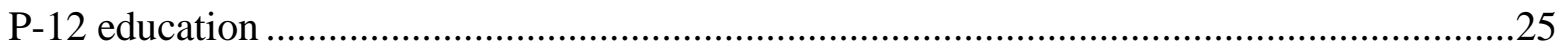

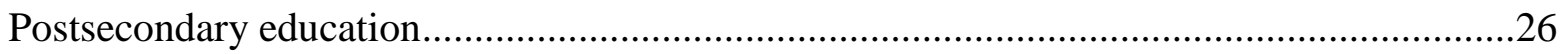

What Factors Influence the Postsecondary Transition? ..........................................................28

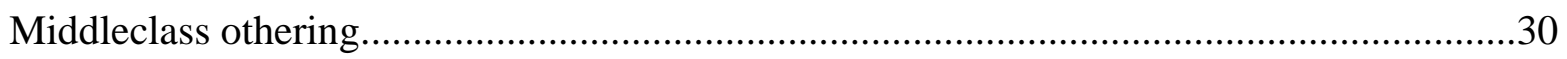

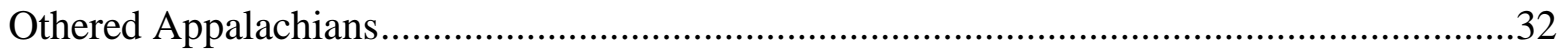

Middleclass othering of Appalachian students and families ...................................................35

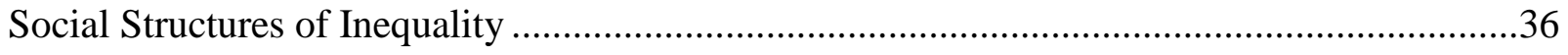

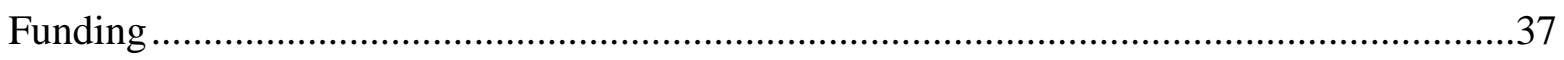

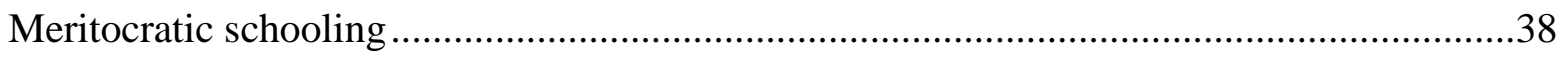

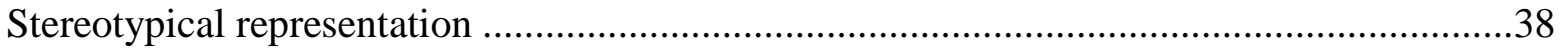

Biased preparation and guidance ......................................................................................

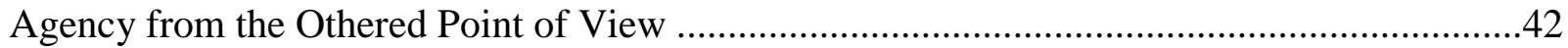

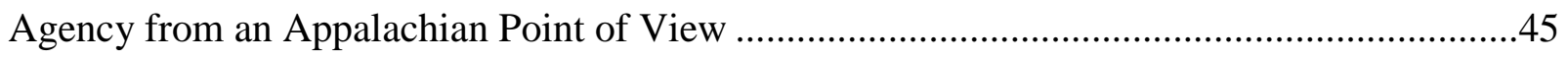

Ties to Place and Family and Appalachian Students' Postsecondary Trajectories .....................47

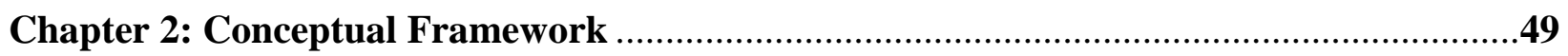

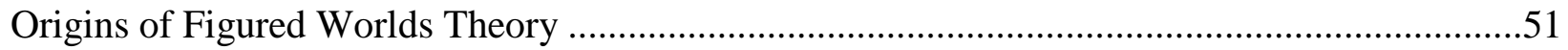

The Social Construction of Figured Worlds ………………..........................................................54

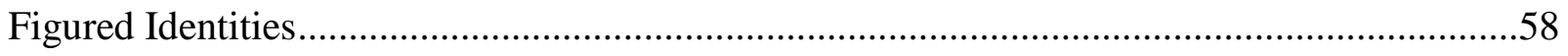

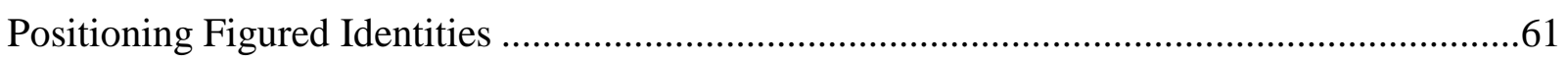

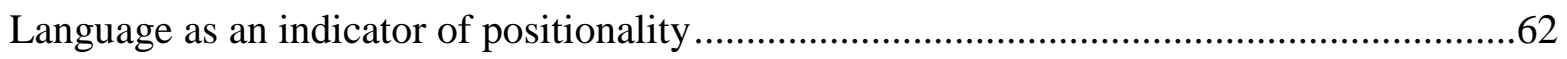

Habitus as identity foundation and indicative of position ...................................................64

The Dialogue between Figured Worlds and Identities ...............................................................66

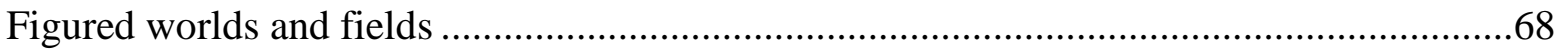

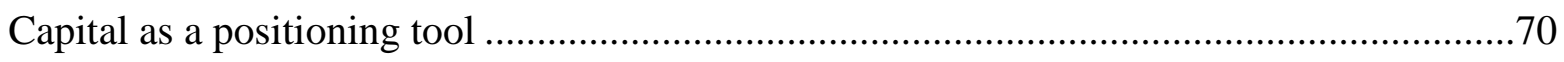

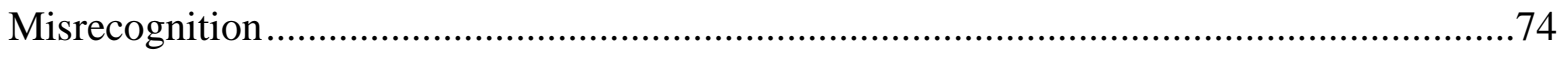

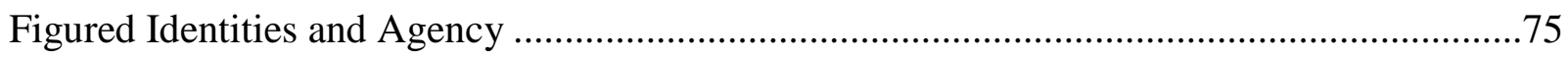




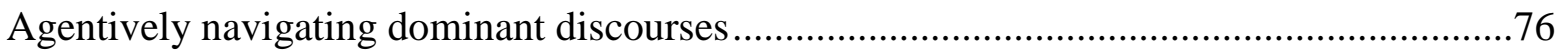

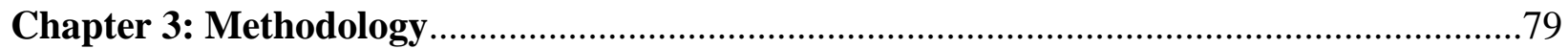

Recognizing Class, Race, and Gender in Rural Appalachia-Researcher Positionality ..............79

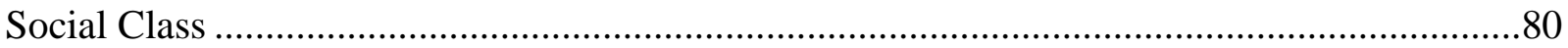

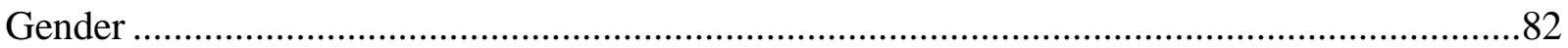

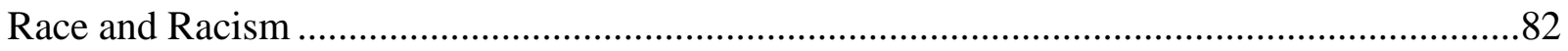

Where this Places Me

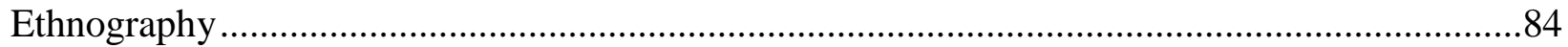

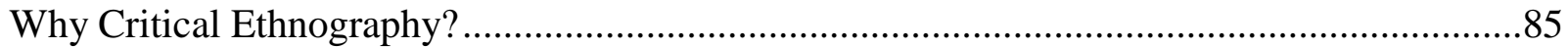

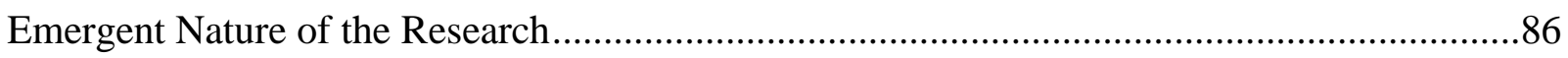

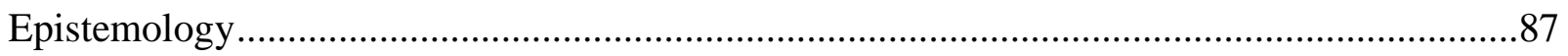

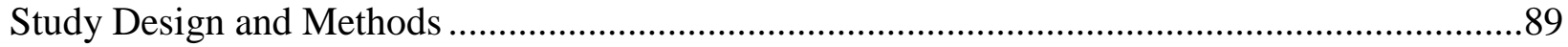

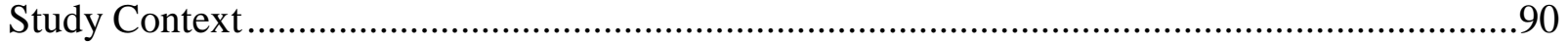

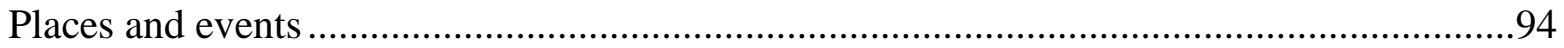

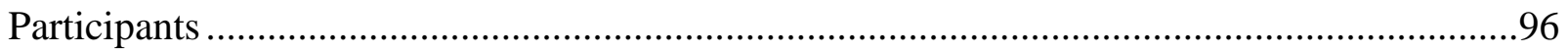

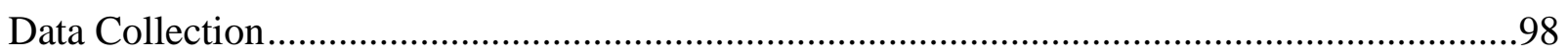

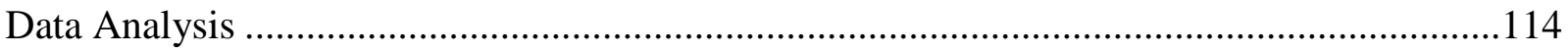

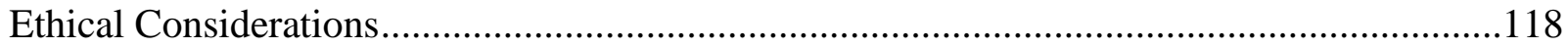

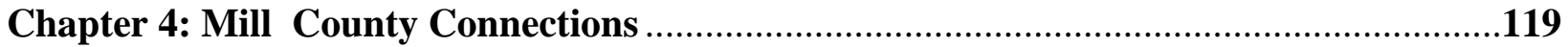

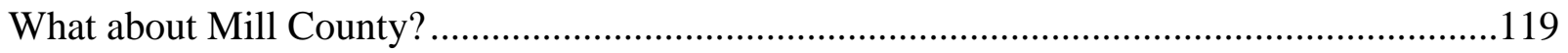

From past to present: Where blue-collar is middleclass ...............................................123

Processing deindustrialization: Adapting (long standing) identities to changing

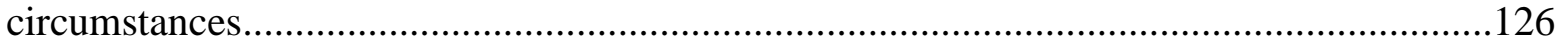

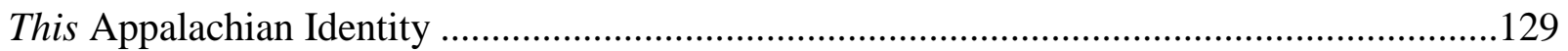

The Challenges of Education: An Appalachian Community within a Neoliberal Context .....135

Finding Success within Stringent Barriers ..............................................................142

Mill County High: An Appalachian High School...............................................................144

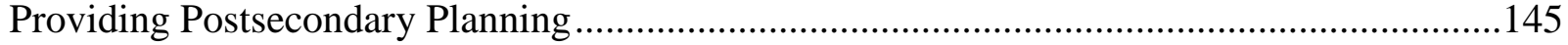

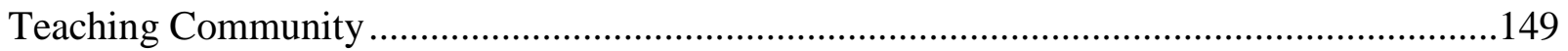

A Day in the Life: Constructing School at MCHS ........................................................153

Constructing Connections: School, Community, and Spare Time .....................................156

Cracks in the Community: Social (In)Justice ..................................................................159

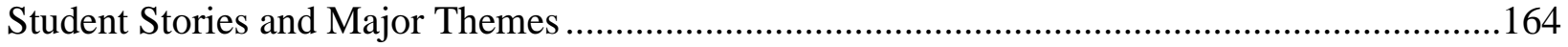


Networks of Support: The Kids Know if they Need Somethin' I'll be Right There 166

Being Present: Relationships and Experience .173

Disrupting Dominant Discourses

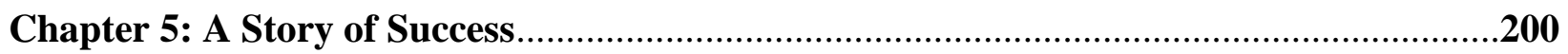

Community History: Present — Not Past .........................................................................200

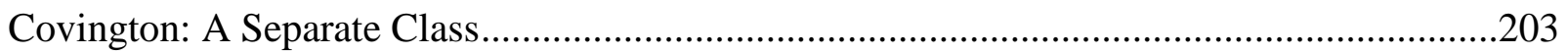

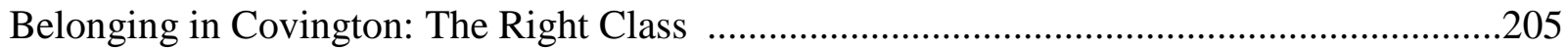

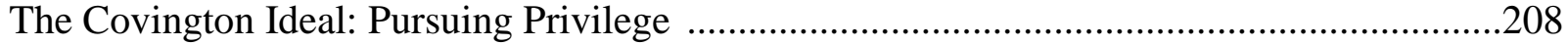

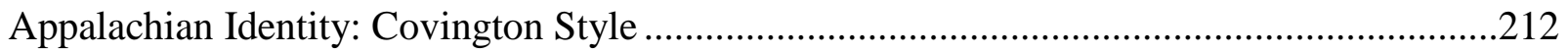

Covington High: Succeeding at the Competition ...........................................................224

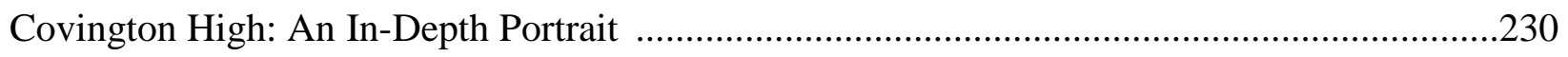

Teacher Business: Maintaining Status with Concerns .................................................236

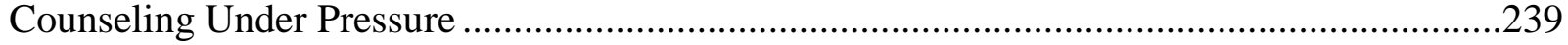

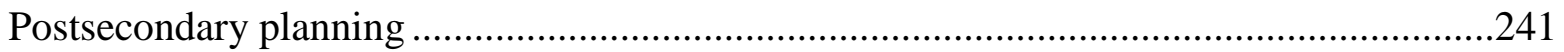

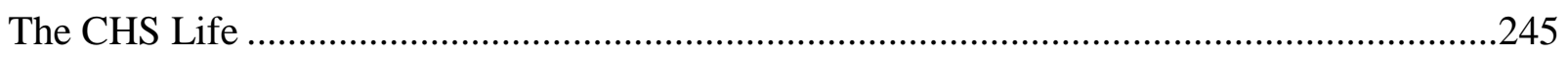

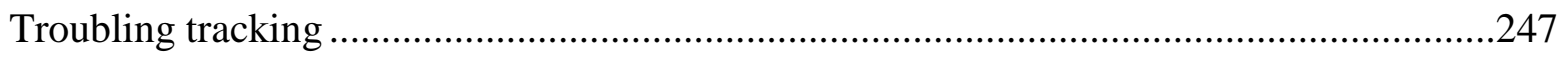

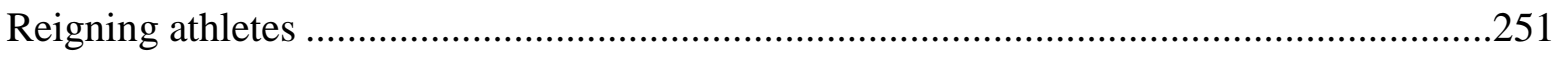

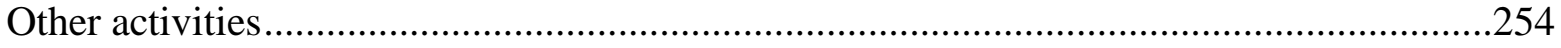

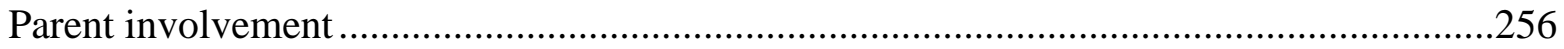

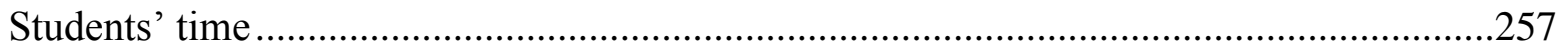

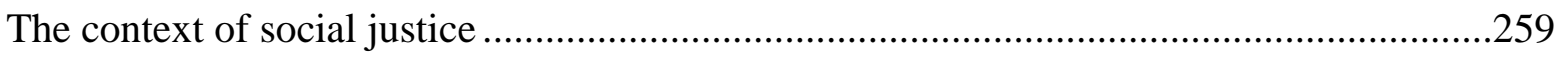

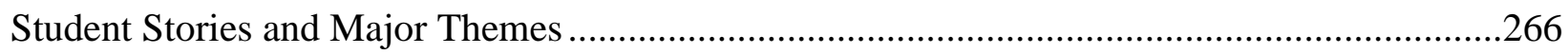

Success at Othering: Community and School Practices.................................................266

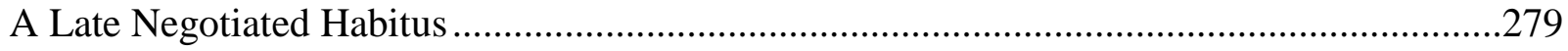

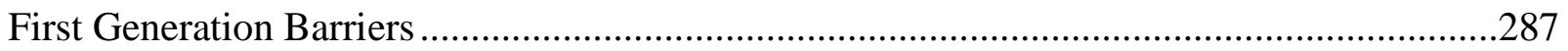

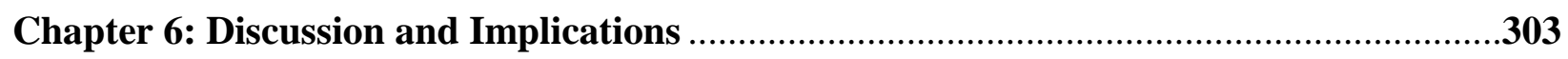

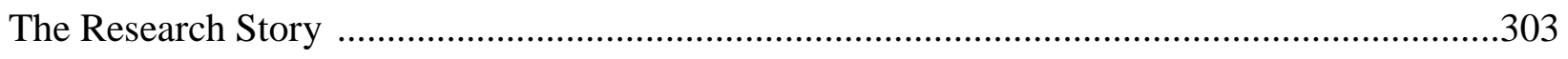

The Relativeness of Social Class and Social Class Experiences ..........................................304

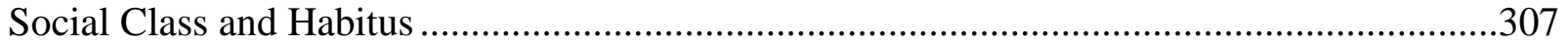

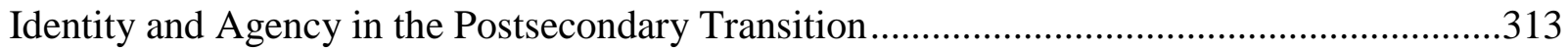

Agency Beyond Bound Spaces: Figured Worlds Theory ................................................315

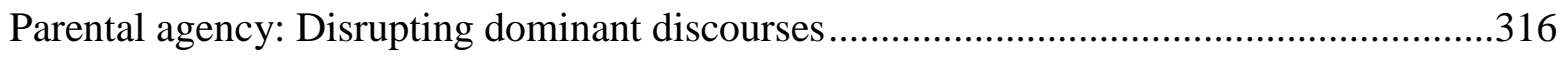


Disrupting Social Reproduction: Othered Capital as Unrecognized capital ......................319

Social Reproduction: A Flawed System Reproduces Social Inequalities .............................322

Academic preparation translated to institutionalized capital.........................................327

Reproducing the Decline of Rural Communities ........................................................328

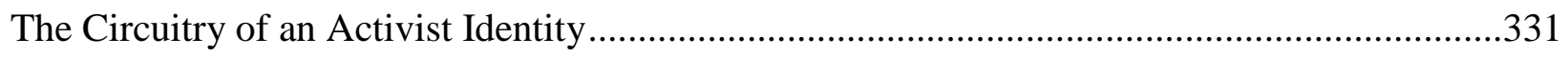

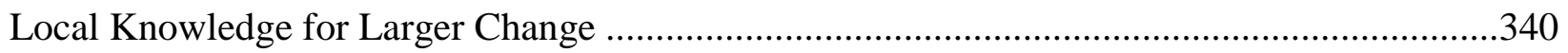

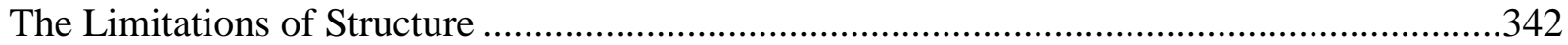

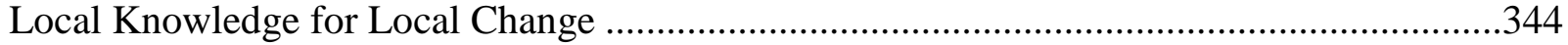

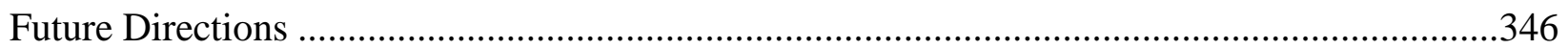

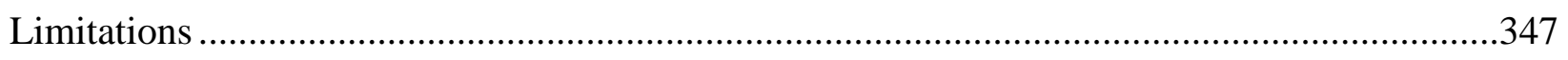

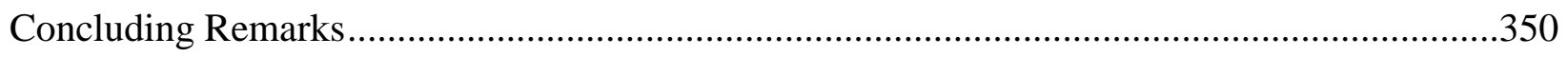

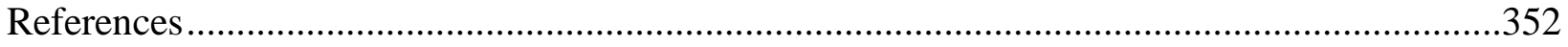

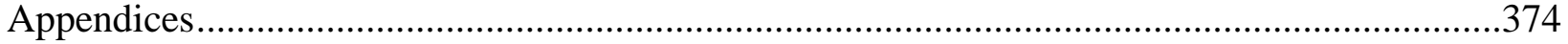




\section{List of Tables}

Table 1 Key theoretical mechanisms of identity and agency processes .....................................53

Table 2 Community characteristics taken from the 2010 U.S. Census......................................93

Table 3 School activity, demographic, and other education information ...................................93

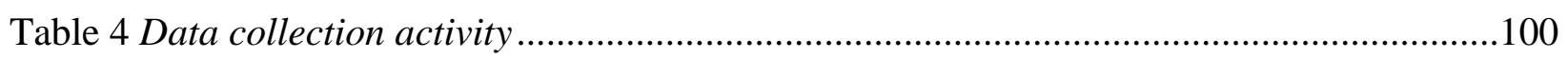

Table 5 Income and education comparisons of Mill County and West Virginia ........................126

Table 6 Postsecondary advising activities at MCHS ..............................................................147

Table 7 Achievement test scores at MCHS in comparison to West Virginia .............................152

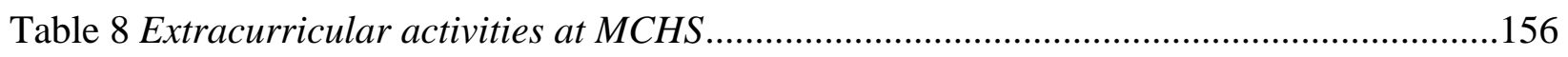

Table 9 Background information for students and families in Mill County ..............................165

Table 10 Income and education comparisons of Covington to other local areas .....................202

Table 11 Background information for students and families in Covington..............................212

Table 12 Achievement test scores at CHS in comparison to West Virginia ..............................228

Table 12 Postsecondary advising activities at CHS .............................................................242

Table 14 Postsecondary institutions visiting CHS during lunch ...........................................244 


\section{List of Figures}

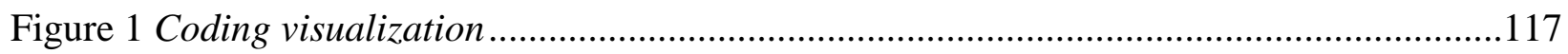

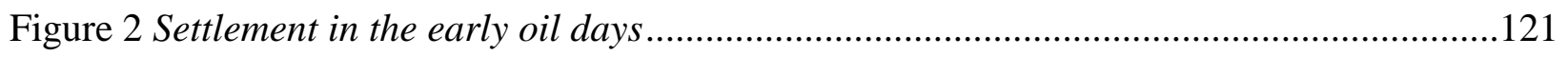

Figure 3 Mansions from the early oil boom in Settlement ….................................................121

Figure 4 Building the first public county high school in Millsdale, West Virginia ....................122

Figure 5 The finished Mill County High School ......................................................................123

Figure 6 New "shellionaire” home in Millsdale...................................................................123

Figure 7 Former boarding house from the early oil days in Mill County .................................124

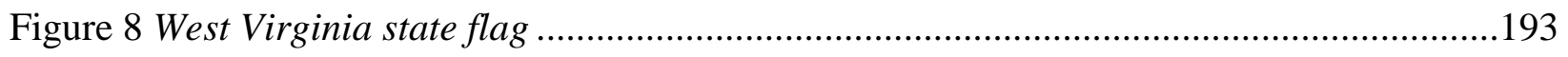

Figure 9 Home for sale in wealthy Covington neighborhood .................................................205

Figure 10 Selene's depiction of her community's focus......................................................235

Figure 11 Fantasia's presentation of how differently she dresses between home and school ....261 


\section{Chapter 1: Rationale}

Secondary education and adolescence are critical time periods for developing ideas and actions regarding the life trajectory. In high school, students are differentially prepared for postsecondary options, impacting their lives in important ways. Because of the inequitable outcomes experienced by different groups of students, understanding the processes of how secondary schooling directs students is imperative. This dissertation is about how educational inequalities are perpetuated into inequitable life outcomes in West Virginia, the state that I have always called home.

In this chapter the hollowing out of rural areas is explored as the young and educated leave more often than they stay. I look at what this means for West Virginians and how the economic and political contexts of the state contribute to this effect. Then, the connections between hollowing out and globalization are made, as well as where West Virginia's P-20 educational practices fit within this framework. Next, current research on social class factors that impact postsecondary trajectories and how these discourses fit within inequitable social structures are described. Following this, the concerning ways that biased preparation and guidance at the school level and how these contribute to inequalities are highlighted. This research is then connected to the small body of work that has been done regarding Appalachian adolescents' postsecondary trajectories to show the similarities between this and the larger body of work on the postsecondary transition. This section is followed by an introduction to the complications of Appalachian cultural traits and how these are negotiated in the postsecondary transition.

The postsecondary transition is a major point during the period adolescence. Adolescence is described by sociologist Nancy Lesko (2012a, 2012b) as a time "out of time;" a period when adolescents are neither adults nor children but are in a liminal period of progress and maturation. 
Students are placed as out of time by educators and adults and monitored to ensure they make the “right" decisions. Through this lens, adolescents are expected to abide by guidance counselors' and educators' advice on postsecondary planning and action. By following adult guidance, students are expected to develop an "active mastery" of the process of becoming. When students choose outside of established boundaries, their decisions are labeled as not in their own best interest (Burnell, 2003; Lee \& Vagle, 2010; Lesko, 2012b). This tension between adult control and student agency permeates the postsecondary trajectory. As constructed, adolescence is a crucial time period when lasting life decisions are made.

Despite the postsecondary transition being very important in life trajectories, research shows that students are differently prepared and guided towards postsecondary options along social class lines (Hallinan \& Oakes, 2011). Students from the middle and upper middleclass are more likely than their working-class and poor peers to be prepared by schools for baccalaureate programs (McDonough, 1997). This is true even when working-class and poor students have high achievement levels (Burnell, 2003; Stephan, Rosenbaum, \& Person, 2009). This discrepancy is exacerbated when students who are labeled low achieving (often working-class and poor) are given less and lower quality postsecondary guidance, leaving them in vulnerable positions after graduation (Carr \& Kefalas, 2009; McDonough, 1997, 2005).

Educational institutions have strong impacts on who is directed to specific outcomes, but students also have agency in this process. Important aspects to consider when examining postsecondary trajectories are the sources of students' agency and how it is exercised. Students are neither puppets of educational institutions nor are they entirely independent of the school and local contexts. To examine what these practices mean, the major research question for this project is: What are the implications of habitus and identity in the postsecondary transition? 
There are two attendant questions: (1) How does habitus inform identity? and (2) How is identity implicated in the postsecondary trajectory? To explore these research questions, this project will examine the interaction of school processes and students' agency and how these lead to postsecondary decisions and trajectories. I will focus on social class as it informs school, educator, and student identities, as well as relevant Appalachian cultural values through the use of habitus. Habitus is the embodiment, physically and cognitively, of a person's classed experiences that shapes how they access and utilize capital within the various spaces of their life (Bourdieu, 1977, 1984; Maton, 2012). I hope to learn which school practices are helpful and which are harmful and how these are informing the choices that students make. I will continue to work with students after graduation to see how their preparation and choices are actualized. These issues are important in West Virginia because many students come from working-class and poor backgrounds. An additional layer of complexity is added when considering Appalachian traits of close ties to place and family that run across the social class spectrum.

\section{Hollowing Out Some and Ignoring Others}

This section begins with an excerpt from a letter, Dear West Virginia (Headley, 2012), as the young author left in pursuit of a career. The letter poignantly illustrates the emotion that comes with being a West Virginian student positioned to choose his future in a place that has limited structural support for careers outside of industry. In this case, the author chose to participate in "hollowing out" the state by taking his talents and college degree westward in search of a career:

The question is, did I begin to stand out because I knew I was going to leave? Or did I know I was going to leave because I was beginning to stand out? You see, I've never had a problem being from West Virginia. I just had some difficulty 
being in West Virginia. You probably didn't see it, because my back was to you as I drove, but I cried when I left...I cried because I missed [the state] already. I cried because I'd never been away...for longer than two weeks. I cried because I was afraid. Because if I wasn't a West Virginian, then what was I?

Hollowing out, the phenomenon so moving for the young writer quoted above, refers to the pattern of people leaving and to the precipitating processes-steering secondary students from privileged backgrounds to baccalaureate programs while not steering less privileged students anywhere (Engberg \& Wolniak, 2010; Stephan, et al., 2009).

Carr and Kefalas (2009) have noted that of all the states, West Virginia has the highest number of students who leave after graduating from college. While this study looks at effects after postsecondary decisions have been made, it is especially important since West Virginia secondary education policy gears all students towards baccalaureate programs (Edvantia, 2011). State data (West Virginia Higher Education Policy Commission [WVHEPC], 2011) indicate that high school graduates enroll at higher rates than students nationally in 4-year schools but at lower rates in 2-year schools. Concurrently, U.S. Census (2010) data show that West Virginia has a lower baccalaureate attainment rate (17.6\%) than the rest of the country (28.2\%).

As I will discuss, this exodus of educated students is precipitated by the current practices of gearing all students towards 4-year degrees, which sorts students from less privileged backgrounds out of this pathway. When I see West Virginia's low adolescent and young adult labor participation rates (those aged 16-24 who are working) (O’Leary \& Boettner, 2012), I am concerned that graduates who move directly to work face high levels of structural unemployment (O'Leary \& Boettner, 2012) and few job opportunities that offer living wages (McDonough, Gildersleeve, \& McClafferty Jarsky, 2010; U.S. Department of Labor, 2013). This is particularly 
troubling because West Virginian students enroll in 2-year schools at less than half the national average (WVHEPC, 2011; National Center for Education Statistics, 2012).

These sorting processes direct high achievers from privileged class backgrounds to baccalaureate programs (Carr \& Kefalas, 2009) while students with lower achievement and less class privilege are excluded from baccalaureate trajectories and given few other options (Carr \& Kefalas, 2009). Stephan et al. (2009) and Klasik (2012) reported similar results when looking at socioeconomic status (SES), achievement, and postsecondary trajectories. These practices are problematic given the conflation of achievement and ability with social class (Brantlinger, 2003; Delpit, 2006; Rist, 2000). These patterns are indicative of privileged students being given more and better guidance to prepare and attend postsecondary education (Lareau, 2003; McDonough, 1997). Inequitable guidance creates difficulties for students when schools do not adequately facilitate the postsecondary choice process.

Carr and Kefalas (2009) presented their findings to the local school board in the community where they completed their ethnography of rural schooling. Their work showed that: (1) schools over-invested in some students, (2) under-invested in others, and (3) sent overinvested graduates off to "succeed elsewhere." The school board in this study recognized this pattern but justified the actions because their views of opportunity and success were narrow and largely focused on economic attainment and prestigious jobs. These views and patterns of practice contribute to the under-valuing of many students and the contributions they can make to their communities.

Educators, in particular rural educators (Howley \& Howley, 2010), are trained to classify success according to middleclass, urban standards, effectively excluding othered students from “success" (Brantlinger, 2003; Delpit, 2006; Graue \& Sherfinski, 2011). Along with other 
educators (Graue \& Sherfinski, 2011; Lareau, 2003), I believe that standard definitions of success are too narrow; that many more students and families have the potential to do great things, if they are allowed. This work proposes that schools broaden their perspectives for what constitutes success, for example by valuing and supporting pathways to blue-collar jobs, encouraging careers that are needed locally but that may not be prestigious or lucrative, and to supporting the community locally. If goals are re-conceptualized, perhaps students can be engaged in more effective postsecondary preparation, giving them greater opportunities for a high quality, satisfactory life.

\section{Context of the Practices of Hollowing Out in West Virginia}

In this section, I focus on the neoliberal, economic perspectives of globalization and their impacts on West Virginia. I do this because globalization has been "strongly shaped by broader economic regimes and ideologies" (Howley \& Howley, 2010) and education has not escaped these effects. These practices have been particularly detrimental to rural areas and West Virginia, shaping the landscape of education and students' and families' contexts, particularly as the state has seen massive job losses with deindustrialization.

West Virginia is a state known for economic struggle and hardship. Although there are various economic revenues in West Virginia, the most prominent have been industrial, and, in particular, extractive industries. Though West Virginia is a state rich in natural resources, most of the economic benefits of these resources have not stayed in state due to absentee corporate ownership and political maneuvering (Boettner, 2013b; Rasmussen, 1996). Industries and the communities they once supported have been radically changed by neoliberal policies of globalization (Carr \& Kefalas, 2009; Howley \& Howley, 2010; McDonough, et al., 2010). 
The disappearance of living-wage blue-collar jobs is an outgrowth of globalization as industry has shifted manufacturing to countries with lower wages and fewer environmental regulations (Bell \& York, 2010; Boettner, 2013a; Ludke, Obermiller, \& Rademacher, 2012; WVDHEPC, 2007). A recent estimate shows that coal companies, which claim to be the backbone of West Virginia's economy, only employ 3\% of the state's workforce and contribute just $16 \%$ to the state's tax revenue (Blaacker, Woods, \& Oliver, 2012). While this is not a trivial amount, it is a weak backbone for an entire economy. Shrinking mining employment is due to a combination of globalization and mechanization, in particular long-wall mining which needs fewer workers yet mines more coal (Bell \& York, 2010; O’Leary \& Boettner, 2012).

Analysis from the West Virginia Budget and Policy Center indicates that West Virginia has been hard hit by deindustrialization and has recovered slower than the rest of the country (Boettner, 2013a). The manufacturing economy with living-wage jobs has been replaced by a service sector economy with low-paying jobs (Oberhauser, 2005). In the 1970's Weirton Steel was the largest employer in the state and paid average or above average wages. In contrast, WalMart is now the largest employer in the state, paying poverty level wages to the majority of its employees (Boettner, 2013a; Woodman, 2012).

Deindustrialization and globalization continue to cause job losses in the industrial sector, even as state leaders continue to look myopically towards coal and other industry as a way to increase economic development and maintain power (Bell \& York, 2010; Blaacker et al., 2012; Ludke, et al., 2012). For instance, West Virginia has created corporate tax cuts over the past five years to eliminate the business franchise tax and continue lowering the corporate net income tax (Boettner, 2013b; O'Leary, 2013). These cuts decrease the effective cost of doing business from $.2 \%$ to $.1 \%$ of corporations' total operating budgets while shifting the burden of responsibility for 
deficits to the public (Boettner, 2013b). For example, in tandem with the mentioned corporate tax cuts, West Virginia has made a 9\% (\$34.8 million) cut to the higher education budget that has been passed on to students and parents as tuition hikes at all public state institutions (Associated Press, 2013; Boettner, 2013b). At the time of this writing, due to a budget shortfall because of low natural gas prices, West Virginia has recently enacted drastic budget cuts to all state services including P-20 education and healthcare (Office of the Governor, 2015).

Despite industry's repeated failure to provide the economic support to the state that it claims, rhetoric, particularly by elected representatives, continues to present industry as the future of the state. The Department of Commerce produces $E d g e$ magazine to promote business and the inaugural 2012 issue featured the Comeback Cracker, a multi-billion dollar project to put West Virginia at the center of energy production via natural gas. Much was done to entice the corporation to build in West Virginia, including massive tax incentives, but the company chose to build in Pennsylvania. The latest issue of Edge featured Governor Earl Ray Tomblin announcing at an industry press conference, "The world is hungry for West Virginia's energy. With coal and gas as our core strength, the Mountain State's energy diversity powers the nation and the world" (Bond, 2013, p. 33). However, once natural gas prices plummeted in 2015, this "comeback cracker" has been put on indefinite hold and will not be bringing the projected benefits to the area (Marcellus Drilling News, 2015).

West Virginia's politicians have a long history of enmeshment with extractive corporations. Francis H. Pierpont, the first interim governor of West Virginia was the co-founder of Consolidation Coal Company, known today as Consol Energy (Tinnell, 2013). A few years prior (1861) to West Virginia becoming a state (1863), Johnson Newlon Camden, an employee of John D. Rockefeller, began buying land to establish Standard Oil as a presence in the area 
(Miller, 2012). Camden then became a lobbyist for Standard Oil in D.C. and eventually returned to West Virginia to become a senator, “one of the first of West Virginia's political leaders to use his public position to serve his industry, a prototype of some who followed" (Miller, 2012, n. p.). The Rockefellers have maintained power in the state for over a century as West Virginia's lifetime politician and recently retired senator is John D. Rockefeller's great-grandson, Jay Rockefeller.

Despite the challenges of deindustrialization and politicians who are friendlier towards businesses than state constituents, there is new grassroots work going on in West Virginia that provides an alternative narrative to the dichotomous stay and struggle or leave and thrive. Terman (2015) has new research showing that despite the initial exodus of college educated graduates leaving West Virginia, after time spent living outside of the state, younger people are beginning to return. In Terman's study, young adults returned to West Virginia for a variety of reasons: some had started families they were interested in raising here, others had family obligations that required them return, and some were forced to return because of the economic downturn. Terman's research shows that despite more young people still leaving, some are coming back to the area. Terman's research is coupled with a rise in community level organizations created by, and often geared towards, young people who envision a different future for West Virginia. These grassroots groups have begun to gain momentum, working on policy issues such as living wage work, technology infrastructure, and diversifying the economy. Organizations like Generation West Virginia (generationwv.org), The West Virginia Community Development Hub (wvhub.org), Create West Virginia (createwv.org, and Our Children, Our Future (ocofwv.org) are creating alternative discourses outside of a capitulation to globalization as the only option. 


\section{Globalization and Education}

Globalization, bolstered by market-based policies, pushes for competition in education between students and schools at local and global levels. Within the framework of globalization and "market-based, capitalist contexts," education is viewed as the place where "children are educated as commodities that can be bought and sold in the market or at the very least as participants contributing to and subjected to Global capitalism” (Lee \& Vagle, 2010, p. 6). As these policies infiltrate education, parents and students are set up as education consumers (Graue \& Sherfinski, 2011). This push comes with the rationalization that a market climate in all spaces fosters the best performance leading to the greatest social good.

American public education has been tied to the interests of business since its inception and that link is still apparent and becoming stronger (Brown, 2010; Schafft \& Jackson, 2010). At the turn of the $20^{\text {th }}$ century, as public education became available for all children, the purposes of education shifted. Educational goals changed from an emphasis on moral goals to those that would serve an industrializing nation and society focused on economics (Urban \& Wagoner, 2009). Parallel to this shift, was the creation of the differentiated curriculum in high school that separated students who would attend college from those who should be prepared for work (Frasier, 2010). Discussions at the time, similar to those heard today, focused on curricular goals and how students should be prepared for either college or a career, as well as the choice students should have in this decision (Frasier, 2010). At the time, there was also a push to standardize public education, at both the elementary and secondary levels, so that students would receive a quality education, which is, again, rhetoric that is often heard today.

In addition to the increases in a focus on public education and curriculum concerns, the industrialization of the nation had other impacts on education. For instance, as adult workers 
pushed for rights in industrial work to make a decent living and fair wages, child labor laws were enacted to open more positions for adults (McMahan, 2009). In response, schooling became compulsory and as truancy laws became more routinely enforced, more students attended school (McMahan, 2009).

As this historical view shows, schooling has long been tied to the national economy, however the explicit link to economic ends has increased exponentially since the 1980's (Conklin \& Lee, 2010). An emphasis on high stakes testing, international comparisons, and improvement through competition and accountability push neoliberal policies and globalization agendas on students. This focus on economic goals is highlighted in reports like A Nation at Risk and reform policies like No Child Left Behind Act (NCLB) and Race to the Top (Conklin \& Lee, 2010). Race to the Top is the most recent competitive reform tied to market proficiency as demonstrated in its first goal, "Adopting standards and assessments that prepare students to succeed in college and the workplace and to compete in the global economy" (United States Department of Education, 2013). As educational outcomes have become increasingly tied to competition and economic outcomes, the concurrent standardization and accountability measures used to assess these goals have led to universal policies that do not benefit all schools and students equally.

Policies of globalization ignore the importance of the connection between local schools and communities and sacrifice this for global connections (Buras, Randels, Salaam, \& SAC, 2010; Schafft \& Jackson, 2010). As students, particularly those in rural areas, are prepared to participate as global citizens, they are often prepared for lives in urban and suburban spaces and not their rural communities. Additionally, successful assimilation into the global community is based on the assumption of a homogenous consumer culture that is detrimental to many students, 
particularly those from lower income backgrounds who are excluded from participating and ostracized for what they do not have (Brantlinger, 2003; Buras, et al., 2010; Schafft \& Jackson, 2010). The values of rural Appalachian individuals are often different than those proffered by global education policies creating difficulties for these students, families, and communities.

For rural schools, globalization means that the local is devalued; the only value lies in those who leave in order to participate in the larger economy elsewhere (Schafft \& Jackson, 2010). Like rural schools nationally, (Burnell, 2003; Carr \& Kefalas, 2009; Hektner, 1995; McDonough, et al., 2010) schooling in Appalachia often educates students out of their small communities (Bryan \& Simmons, 2009; DeYoung, 2007; Locklear, 2011; Wright, 2012). In some cases when students adopt the middleclass values of schools they become mismatched with their rural places and leave for cultural reasons. Also, when students are prepared for pathways that lead them to jobs that do not exist in their communities they leave the area to find adequate or desirable employment.

The impacts of globalization on the local school are complicated. For example, the deindustrialization that has accompanied globalization has drained many rural communities of the manufacturing and industrial jobs that once provided a good living for people with only high school degrees. At the same time, at least some postsecondary training has become important in gaining stable and adequate employment (Klasik, 2012). However, rural places often do not have an employment base that requires more advanced degrees (Carr \& Kefalas, 2009). Globalization hits rural communities with a double whammy, not only do they lose employment base, but the knowledge and technology sector jobs that have increased are not located in their areas, and the service sector jobs that have replaced manufacturing do not provide a living wage. In these situations, schools are faced with difficult choices; it would seem unethical to only prepare 
students for available local jobs as they diminish and those that are available pay poverty level wages. However, training students for jobs that provide an opportunity for stable employment and adequate income often means that students will need to leave the area to find that type of work.

As schools logically prepare students for the best possible outcomes, i.e. finding employment that provides satisfaction and an adequate income and benefits, these pathways often lead to college training. However, as described in the following sections, the students who are the most likely to successfully transition to college are middleclass students, while students from lower classes are excluded from these pathways. Moreover, pathways to technical training that could provide pathways for students to remain locally and contribute to community are subsumed under college prep practices and lack structural support from schools. As schools and communities, across the rural-urban spectrum, become swept up in discourses of globalization and the increasing needs for college education, students and communities that do not fit this model are marginalized. The impacts of globalization are assumed to be imminent, leaving out space for alternative dialogues that position rural schools, students, and communities as relevant and sustainable participants in a global world (Theobald \& Wood, 2010).

\section{P-20 Education in West Virginia}

The heavy hand of neoliberal globalization stretches over West Virginia's education, as illustrated in a recent "efficiency audit" (Public Works, LLC., 2012). The West Virginia Governor's Office commissioned Public Works to examine the state's education system because of consistently ranking at the bottom in many educational outcomes; in particular, West Virginia's poor showing on the National Assessment of Educational Proficiency was impetus for the independent audit (Public Works, LLC., 2012). The two main goals of the audit were to, 
"Identify savings and efficiencies and service-delivery improvements that can be instituted to make the best use of West Virginia's educational spending and to increase student achievement" (Public Works, LLC., 2012, p. 2). The report opens with these paragraphs:

At no other time in our nation's history has there been a greater call to transform our educational system. The future of our economy and our democracy depend upon our ability to find better ways to marshal limited resources and to educate our children.

West Virginia's education system, like most in our country, has developed into a structure that satisfies the needs and desires of a wide swath of constituencies and consumers that depend on the outputs of primary and secondary education: businesses that hope to employ West Virginia's graduates; school professionalsteachers, administrators, support personnel, transportation providers, and many others-who devote their time and energy to education; educational policymakers, both elected and appointed, with ideas and aspirations for our schools; the parents who entrust their children-and their hopes for their children's futures-to all school professionals every day; and, of course, the taxpayers who fund this educational system and thus ultimately expect a say in its cost and structure. (Public Works LLC, 2012, p. 1)

The title of this project as an efficiency audit sets the work firmly within the market-oriented framework of globalization. Citizenship goals are subsumed under goals towards economic prosperity from the national to individual levels. These outcomes are framed with language used in business and markets that denies the complexity of the educational process and learning. All 
of these indicate the ideology of neoliberal globalization that is present in West Virginia's education system. The following sections expand on how this ideology manifests in practice.

P-12 education. Similar to trends nationally, in recent years West Virginia's P-12 system has geared students towards baccalaureate degrees to the exclusion of other types of postsecondary education (Edvantia, 2011). Knowing that the postsecondary transition is closely related to social class, the high number of West Virginia children in poverty creates the likelihood that many students are excluded from effective postsecondary planning (Burnell, 2003). Information at the policy level, as this study began in 2013 , indicated a shift towards a broader range of postsecondary options, college and career readiness rather than a college only focus. My dissertation explores how these policies are being enacted in the day-to-day settings of schools.

The recently modified Global 21 Initiative (now Educate WV) used language that largely geared P-12 students towards baccalaureate degrees for economic purposes (Edvantia, 2011). Language in the revised Educate West Virginia standards continues a framework laden with the rhetoric of competition and economic allusions:

Revolutionary changes in technology, the global marketplace and significant social, political and environmental issues dramatically affect what students today must know. The challenge to educators and parents is to provide instruction that is not only relevant and engaging but that also includes the world-class rigor necessary to prepare students to get a job in a culturally diverse, technologically complex and economically competitive world. The program is a systemic approach to help West Virginia not only compete globally but also thrive. From the classroom to the district office to the state Department of Education, the program is a bold acknowledgment that we must change how we operate if we expect 
to change what and how children learn. At its core is the mission to develop self-directed, motivated learners who demonstrate the skills and knowledge that are fundamental to becoming successful adults in the digital world. (West Virginia Department of Education, [WVDE], 2013a, n. p.)

To develop these new standards, forums were held with various stakeholders - teachers, students, and business leaders - in order to "Creat[e] a 21st century education system...that...is connected locally and globally to business, industry, and other key stakeholders" (Edvantia, 2011, p. 3). This language again underscores the neoliberal ends of the P-12 system.

Postsecondary education. Prior to 2013, West Virginia's publicly available postsecondary information myopically focused on a baccalaureate degree as the choice for students, though the language changed in 2013, immediately before this study. Previously, the College Foundation of West Virginia, the website promoted by the state for all postsecondary options, only had information about baccalaureate institutions and programs. To find information about other postsecondary options, an entirely different site had to be accessed, and the links were very difficult to find (CFWV, 2012). This ethos is coupled with rhetoric from business and education communities that more education is needed to meet state employment needs (Edvantia, 2013; Kersey, 2012; WVHEPC, 2007).

These calls from the business community and politicians for more skilled workers mirror the national rhetoric about a shortage of educated workers. However, Rosenbaum (2001) casts doubt on these claims indicating that skills are not in short supply, rather employers use degree attainment as a sorting mechanism for hiring. Rosenbaum's work highlights the disaster of high schools gearing all students towards 4-year programs while simultaneously not providing structures for all students to qualify for such programs (Rosenbaum, 2011). This singular focus 
causes a "cooling out" effect for lower social class students; they do not qualify for baccalaureate work but have made no alternative plans (Rosenbaum, Muller, \& Krei, 1996; Rosenbaum, 2011).

Problematic practices are also found in "universal" policies that claim to offer access to all, though often the access is limited to a select group. To increase college attendance, West Virginia offers the PROMISE Scholarship, a universal access scholarship funded by state lottery profits. When the PROMISE began in 2002, it offered full tuition coverage to any state school, valued at $\$ 4,750$. The stipend could be used towards private institution tuition as well. The scholarship is limited to students with a 3.0 grade point average and a minimum SAT score of 1000 or ACT score of 21 (Scott-Clayton, 2011). Recently the scholarship has changed; while it still offers a maximum of $\$ 4,750$ to students, theachievement requirements are more competitive. Students still need an overall 3.0 GPA, in addition to completing "minimum core class requirements" (4 English, 4 Math, 4 Social Science, and 3 Natural Science credits) with a 3.0 average in these core classes (CFWV, 2013b). Additionally, students now need a 1020 on the SAT with minimum scores in Math and Critical Reading or a 22 on the ACT with minimum requirements in English, Math, Science and Reading (CFWV, 2013b).

In theory, the PROMISE Scholarship is open to all students who meet these markers; in practice it does not offer universal access. Knowing that students from more privileged backgrounds are more likely to meet these requirements, students from less privileged backgrounds are less likely to benefit from this "universal" program. Similar to other merit scholarships, like the Georgia HOPE scholarship, the PROMISE is restricting access to those who need it while benefiting already privileged students (Cornwell \& Mustard, 2007).

A push towards baccalaureate programs and the narrowing of access to the PROMISE Scholarship have been accompanied by increases in tuition statewide. The document detailing 
these tuition increases downplays the barriers the increases present to students by comparing the low tuition rates of West Virginia schools with the much higher rates of neighboring states' institutions (WVHEPC, 2013). The recent federal government sequester and state budget cuts have led to a 6-9\% tuition increase for all West Virginia state schools in 2014 (Associated Press, 2013). These increases come despite a legislative mandate that the 6-year plan for higher education should "contain costs and maintain affordability of higher education" (WVHEPC, 2007, p. 3).

Rosenbaum's $(2001,2011)$ research points to the misguidedness of the strong push towards baccalaureate work to the exclusion of other options. While these trends are discouraging, hopeful possibilities exist. West Virginia's Department of Education website now includes language that includes an array of postsecondary options. Documents from higher education groups also include broader information on postsecondary schooling (CFWV, 2013a; WVHEPC, 2013). These are very recent changes that have paralleled national conversations around college and career readiness and I hope that they represent more possibilities for more students, particularly in light of the fact that most job openings in West Virginia call for subbaccalaureate training (U.S. Department of Labor, 2013).

\section{What Factors Influence the Postsecondary Transition?}

Factors influencing postsecondary trajectories are largely attributed to families and students, namely: parental education and occupation, family income, parental involvement, ability, capital, etc. (Ali \& Saunders, 2006; Epstein, 2007; Hossler \& Gallagher, 1987, 1992;

Klasik, 2012; Lopez Turley, 2006). These researchers use a perspective that situates both families and students as deficient and in need of remediation while using the language of helping professionals. Though they do not overtly blame parents and students for educational disparities, 
the researchers place the parents and students as lacking money, education, capital, etc. that would allow them to adequately support their education. Lightfoot (2001) describes this "benevolent" deficit language, stating that "[it] creates possibilities for helping the parents of children at risk but limits the possibility that we will see them as equal partners in this enterprise" (p. 95). Lightfoot goes on to describe the inadequacy of a benevolent deficit lens, noting that when discourses remain the same, such as by using deficit language, new ideas and frameworks for viewing families are difficult to take hold, even if educators genuinely desire to change.

The scholars mentioned in the previous paragraph draw upon developmental psychology frameworks to ground their work. While the generalities of psychological development are important, these frameworks are limited as they often fail to recognize assets of marginalized groups and consistently position low income and people of color as delayed or aberrant (Lee \& Vagle, 2010a; Lee \& Vagle, 2010b; Vagle \& Parks, 2010). Despite these shortcomings, developmental theories are seminal theories that provide cornerstones of the educational research literature (Brice Heath, 1983; Lee \& Vagle, 2010b; Vagle \& Parks, 2010). While Urie Bronfenbrenner's ecological theory of human development provides a framework that offers the potential for understanding students' and families' educational participation and outcomes within a critical framework, it is not often used in this way. These lacunae call for expanding the frameworks used to study education as well as frames that provide tools to question the power of dominant norms. A critical cultural perspective can help to deconstruct theories that have cultural and racial biases (Lee \& Vagle, 2010a) as well as provide a conceptualization of trajectory that is more broadly focused, which can enable educators to "inhibit proscriptive life trajectories" (Brown, 2010, p. 184). Critical researchers indicate that an acceptance of difference and diversity is not the problem with developmental psychological theories, rather, the problem lies in 
difference constructed around privilege with Whiteness and middleclass as the norms (Brown, 2010; Vagle \& Parks, 2010). A critical cultural perspective expands to show development as a “cultural process" informed by relationships of power and inequality, both presently and historically (Brown, 2010).

Middleclass othering. As mentioned, the factors most prevalent in research on postsecondary trajectories are: parental education and occupation, family income, race, parental involvement, ability, and capital (Ali \& Saunders, 2006; Epstein, 2007; Hossler \& Gallagher, 1987, 1992; Klasik, 2012; Lopez Turley, 2006). When considered alone, these factors appear to be isolated, individual descriptors; however, when these factors are examined in combination, they are best conceptualized as social class. This section describes how this middleclass standpoint "others" lower class parents by placing them as deficit and in need of help.

Schools are middleclass institutions (Anyon, 1981; Bourdieu \& Passeron, 1990; Brantlinger, 2003) and Epstein (2007) positions them as experts in knowing how to "help" parents. From this expert standpoint, parents lack knowledge and the wherewithal to support their children's education appropriately, largely because of the capital they lack. Epstein (2007, p. 16) describes that, "only some parents - mainly those with more formal educationindependently become involved in their children's...education." This statement excludes the formally educated from needing help, and thus covertly implicates Others (Lightfoot, 2001), largely low income parents with less formal education. The omission also implicates minority parents (Brown, 2010; Lightfoot, 2001) who often have less formal education than Whites. As parental participation is constructed, othered parents are unable to participate in the expected and accepted ways defined by schools (Epstein, 2007), doubly implicating racial Others as race and social class are impossible to extricate. 
SES is an important factor in the postsecondary transition and Galotti and Mark (1994) found that parents were the most important source students utilized for information on college. Their work indicated that parents who had lower education levels, and who were often lowerincome, perceived cost as a barrier to their children's postsecondary attendance. One solution the researchers offered was to give parents more education for how they could access information on financial aid and personally fund college. The work implies that if parents knew more they could better support their children's college attendance. Their work fails to address the structural issues that cause poverty and cause parents to not be able to pay for college.

Cabrera and LaNasa (2001) indicate the importance of parental involvement in planning for college, noting that parents from lower social classes lack "first hand exposure to postsecondary education" (p. 142). This research construes parents as uninvolved with their children's schooling and as having lower educational expectations due to ignorance about the benefits that come from a college education. The authors note that if parents have more information on college costs, it "may suffice to motivate [parents] to start saving for their children's postsecondary education" (p. 142). Again, the work fails to acknowledge the structural causes of poverty and "benevolently" places parents as ignorant and in need of help by education experts.

Other researchers support the importance of SES in determining who goes to college while emphasizing the lack of capital parents bring, particularly in economic resources and experience with higher education (Engberg \& Wolniak 2010; Plank \& Jordan, 2001). Mirroring the seminal work of Hossler and Gallagher (1987, 1992), Klasik (2012) emphasizes that low income and minority families' positions disadvantage students preparing for and applying to postsecondary education. Klasik (2012) does focus on schools' responsibilities but it is in ways 
that align with increasing parental involvement in and support for education. All of these researchers compassionately view parents through the deficit lens proffered by Epstein (2007).

Lopez Turley's (2006) study of parents' preferences for where their children live during college again places othered families as barriers to postsecondary success. In her study, some parents encouraged their high achieving students to attend college wherever it best suited them while other parents encouraged their high achieving students to remain at home during college. Parents who wanted their students to stay at home were more likely to be minorities, less educated, and have less prestigious, lower paying jobs. The study found that the push to stay at home limited and sometimes eliminated children's opportunities for attending college. While the study was quantitative and did not address reasons for preferences, the author goes on to interpret parents' preferences for children to remain at home as a fear that they would be unable to help their children in distant places, particularly in unfamiliar college settings. She provides the caveat that parents may have had other reasons for wanting their children to remain home, however these are not explored. Like others, Lopez Turley does not position these parents as bad, rather as lacking the necessary capital to move their children to college.

Othered Appalachians. The body of work in the previous section focuses on minority groups as "othered." The following works on Appalachia focus on poor, rural, White students to the exclusion of those in the region who represent a more diverse group, which is typical of research in Appalachia, which often focuses on groups stereotypically associated with the region (Anglin, 2004). Though ethnic and racial categories differ between these bodies of work, commonalities include a focus on low social class and deficit frameworks. The majority of educational research on and in Appalachia places low income students and families as in need of help from institutions and institutional experts. Students in Appalachia and West Virginia face 
similar constraints to students attending poor urban schools (Brown, Copeland, Costello, Erkanli, \& Worthman, 2009), particularly as both places have higher poverty levels than national norms (Ludke et al., 2012; U.S. Census Bureau, 2010).

Broader discourses that situate Appalachians as deviant in comparison to middleclass Americans are important to consider, particularly within the historical context of how Appalachia has been created and situated in the American consciousness. To understand the idea of Appalachia, there needs to be an understanding of how the region has been positioned by those who created it and the context within which it was created (Batteau, 1990; Ledford, 1999a; Shapiro, 1978; Wagner, Batteau, \& Green, 1983). While Appalachia is a federally defined, geographic region that stretches across the Appalachian Mountain Chain, there has never been a coherent group of people or culture that is truly Appalachian. Rather, the creation of Appalachians and Appalachia have come from the dialogue between lived Appalachia and described Appalachia (Batteau, 1990). Appalachia has been created as a means to achieve gain for others, and so it has been constructed through archetypal myths that develop an illusion of the region by those looking to further their own agendas or interests in economic gains related to natural resources (Batteau, 1990; Shapiro, 1978). The region has been created as a stereotype, filled with negative imagery of hillbillies with nefarious dispositions and practices who need to be controlled (Street, 1991; Whisnant, 1983). Often, problems identified as specific to Appalachia, such as poverty, ignorance, and racism are actually problems of America writ-large; however, these discourses have served to set Appalachia as a place apart so that Americans can extricate themselves from responsibility for racism (Noe, 1999) and other social ills. Understanding the historical context of Appalachia and how it has been created helps to understand broader social issues in America related to power inequalities (Batteau, 1990) and 
why Appalachians are persistently characterized as stereotypes.

Critical Appalachian scholarship (Anglin, 2002; Billings, Norman, \& Ledford, 1999;

Cunningham, 2012) speaks back to stereotypical descriptions of the region and people who live there, but aberrant cultural traits continue to be cited as causes of regional/national disparities, including educational outcomes. Assumptions of deviance are even held by those in the region (Towers, 2005) with many viewing the "place" of Appalachia as "somewhere else" because representations of Appalachia are often so far from lived realities (Shelby, 1999).

The conceptual creation of Appalachia (Batteau, 1990) and the range of diversity within the region contradict the notion of one particular ethnicity of Appalachians (Cunningham, 2012), though this has often been used as a reason for "intervention" in the region (Whisnant, 1983). However, there are commonalities particular to areas in the region that are culturally relevant when considering social outcomes. Susan Keefe, an Appalachian researcher, presents characteristics of Appalachian identity as determined not so much by one set of traits, but rather as "differences in strength of presence of a trait" (p. 129). While there are some problems with Keefe's (1998) depiction of largely rural people living in the mountains, she presents Appalachian-ness as being constructed around "otherness." It is a "consciousness... as a people with a single historical experience, a shared relationship to the outside world, and a common destiny" (p. 140). Keefe (1998) elaborates that negative discourses "have had an impact on Appalachian peoples' identity, forcing them to deal with the pervasive negative stereotypes" ( $p$. 143). The coinciding experiences of being othered are something that crosses Appalachian experience across borders, ethnicities, and social classes (Obermiller, 1977; Obermiller \& Maloney, 2011). This experience is something Appalachian students share with othered students in the dominant education literature. As the following review shows, the same deficit 
perspectives applied to othered students nationally are applied in nearly identical ways to Appalachian students. In these cases, minority racial status is replaced by similarly disadvantageous Appalachian cultural traits. In these works, minority racial status is only replaced by cultural traits because Appalachian research has almost entirely focused on White students, not because cultural traits are more important than race.

Middleclass othering of Appalachian students and families. Ali and Saunders (2006) found that Appalachian students' expectations and parental support for postsecondary education were definitive factors in postsecondary planning and choice. Their work found that parents' poverty, unemployment, and lack of postsecondary experience reinforced students not entering postsecondary education. The parents supported what they knew, staying at home and being around family, ostensibly remaining in poverty, which passed on their (lack of) capital to their children. Similar to Epstein (2007), Ali and Saunders (2006) propose that schools reach out to parents to inform them of possibilities and to give them information about college. The authors pose that through these mechanisms families' economic and educational deficits can be alleviated and students can move more successfully to college.

Other researchers cite similar findings that indicate parents' lack of postsecondary education as barriers to Appalachian students' college attendance (Ali \& Saunders, 2009; Baldwin, 2000; Brown, et al., 2009). Diverse factors preventing students' transition to postsecondary schooling included low parental support for education, cultural deficits that do not value education, and lack of financial resources to support college attendance. Similar to the dominant literature, these researchers describe the need to reach out to families so they can be taught the 'right' paths for their children in order to facilitate postsecondary transitions. 
In Appalachia, cultural traits are framed from deficit perspectives and indicated as reasons for poverty (Ali \& Saunders, 2006, 2009) and low educational attainment (Wallace \& DieKroger, 2000). Strong ties to place were indicated as barriers in the postsecondary transition (Ali \& Saunders, 2009; Wallace \& DieKroger, 2000), particularly for males (Brown, et al., 2009; Chenoweth \& Galliher, 2004). In research largely conducted in central Appalachia, ties to family and place are some of the few established cultural traits (Keefe, 1998; Stanley, 2012; The Rural and Appalachian Youth and Families Consortium, 1996), which, viewed from a modern perspective, are as barriers to successful postsecondary transitions.

These works show the similarities between narratives of Appalachian and othered students elsewhere. The presentation of Appalachian families is congruent with Epstein's (2007) recommendations for 'appropriate' parent support and school interaction, negating possibilities for positive agency from families or students (Buras, et al., 2010). Wallace and DieKroger (2000) detail Appalachian cultural "problems":

Appalachian culture has traditionally valued loyalty to family and community, hard work, self-reliance, strong sense of religion, and resistance to change. While most of these values seem positive, they may be a factor in perpetuating negative perceptions of higher education. (n. p., emphasis added)

Similar to the dominant literature, these works fail to discuss institutional barriers (Bradner, 2008) and the consequences of cultural stereotypes and deficit narratives (Anglin, 2004) on students' outcomes.

\section{Social Structures of Inequality}

Privileged perspectives, like those reviewed, obscure the structures that work differently for othered groups with less power. As the middleclass structure of education unequally benefits 
those from the middleclass, the consequences for those who do not benefit are ignored or minimized (Brantlinger, 2003). This willful neglect manifests in theories like the culture of poverty, popularly used by pseudo-educator Ruby Payne, which blame the disenfranchised for their positions so that the powerful do not have to take responsibility for the results of their actions (Bickel \& McDonough, 1997). The following are important ways that inequality is structured, though by no means do I cover all structural inequalities, such as West Virginia's high stakes testing and "universal" merit scholarships.

Funding. A glaring omission of deficit discourses is the way that inequitably funded schools contribute to and exacerbate poverty (Buras, et al., 2010). Using property taxes to fund public schools assures that the money of the wealthy benefits only their children (Brantlinger, 2003; Buras, et al., 2010; Kahn \& Minnick, 2005). This is especially important in West Virginia considering the influence of industry on the assessment of property taxes (Rasmussen, 1996; Boettner, 2013b) and the state's low property tax rates (44th in the nation) (Boettner, 2013b). Under-funded schools, as arranged by the powerful (Buras, et al., 2010; Graue, Kroeger, \& Prager, 2001), function in conditions that more powerful parents would hotly contest (Brantlinger, 2003). These are the schools most often labeled failing by NCLB (Lauen, 2011), have many teachers working outside of their subject areas, low teacher pay, high teacher turnover, inadequate materials, and overcrowded classrooms (Brantlinger, 2003; Buras et al., 2010). It seems unfair to ask students to participate and perform equally when they are not provided the same opportunities for participation; yet these inequalities are not factored into accountability policies and school labeling. In fact, NCLB penalizes struggling (i.e., low income) schools with labels of failing and then uses a punishment model to "motivate" these schools by threatening closure and funding cuts if adequate yearly progress is not met (Lauen, 2011). 
Meritocratic schooling. American public schools are embedded within a history of inequality and tension that characterizes American society (Buras et al., 2010) where ideologies of individualism and personal merit are salient (Brown, 2010; Graue et al., 2001). Although the rhetoric surrounding public schools is a free and equal education for all, the outcomes are much less so (Auerbach, 2007; Brantlinger, 2003; Delpit, 2006). Schools are presented as meritocracies that equally reward the efforts of the natively inclined and hard working. In practice, schools are far from this, unequally rewarding some "traits" more than others, "high intelligence, athletic competence, [perceived] work ethic, and other types of student merit," which also happen to be typical traits of privileged, White students (Brantlinger, 2003, p. 1). The idiom, "born on third, think they hit a triple" captures the ideology of the dominant regarding their success in education (and life in general) (Buras et al., 2010).

Stereotypical representation. Narratives of deficit and stereotypes position the poor and minorities as responsible for or deserving of their plight (Lightfoot, 2001; Schnee \& Bose, 2010). These narratives omit the failures of society that have positioned particular communities in such ways (Buras et al., 2010). Deficit narratives and stereotypes are especially salient in West Virginia where $24 \%$ of children live in poverty (National Center for Children in Poverty, 2013). Rhetoric in and about West Virginia constantly swirls around blaming poor children and families for their failures (Latimer, 2006; Towers, 2005).

For example, a state newspaper detailed the first meeting of the West Virginia Senate Child and Poverty Committee, "a newly created special study committee" to address high poverty, drop-out, and teenage pregnancy rates (Miller, 2013). A large part of the meeting was spent discussing how to combat teenage pregnancy in order to lower poverty rates. The Senate Finance Chairman explained that, "Current practices [surrounding teenage pregnancy] in West 
Virginia provide an incentive to get young girls to become pregnant because the state provides the new mother with an apartment if she is not married" (Miller, 2013, n. p.). Another presenter detailed the impacts of "toxic stress on children" indicating that, "Toxic stress is the problem for too many children...It happens in poor families, most of the time” (Meyer, 2013, n. p.). The newspaper reporting this meeting added a suggestion based on the presentation: "How do we limit the exposure of children affected by such stress to the toxic environments that cause it? By getting them out of their homes and, frankly, in contact with less stressful people as much as possible" (Meyer, 2013, n. p.).

These views are reinforced by state representatives like Gayle Manchin, wife of Senator (former governor) Joe Manchin, and, at the time of this study, president of the state board of education (WVDE, 2013b). Gayle Manchin started West Virginia Partnership to Assure Student Success (WVPASS) which is affiliated with the State Department of Education, and offers a Ruby Payne, Culture of Poverty Framework training for “educating professionals and community leaders about the effects of class and poverty on society" (WVPASS, 2013A). The organization partnered with some state colleges to "design and pilot a national Ruby Payne PreService Teacher Education Program" (WVPASS, 2013a). The deleterious effects of Ruby Payne's pseudo-research are legitimized through organizations like this that either misunderstand or willfully misrepresent the experiences of othered people (Bomer, Dworin, May, \& Semingson, 2008; Gorski, 2006, 2008). Unfortunately many of the board members of WVPASS include leaders of state welfare agencies, various state department representatives, multiple postsecondary leaders, and representatives from K-12 education (WVPASS, 2013b). Work like Ruby Payne's blames poverty on the people in poverty, leading to ineffective programming and discriminatory views and treatment. 
Biased preparation and guidance. High school guidance counseling and most preservice teacher education is based on developmental theories and middleclass modes of interaction (McDonough, 2005; Stephan, 2013). It is also modeled on one to one interactions with students asking questions and counselors responding, a tradition that heavily favors White, middleclass students (Stephan, 2013). This history incites many issues considering the research that shows guidance is not adequately serving all students in the postsecondary transition (Hallinan \& Oakes, 2011; McDonough, 1997; Oakes \& Guiton, 1995; Rosenbaum, 2001; Rosenbaum, et al., 1996). This is a main concern of mine for the study. I am interested in the ways that students are prepared by schools for the postsecondary transition. I want to see how the students utilize this preparation as they transition to either work or postsecondary education after graduation.

Though coursework and postsecondary advising are separately detailed here, I understand that they are related as coursework largely determines what postsecondary options are available. I focus on guidance counselors as they are the 'official' educators involved in the advising activities. I understand that other educators may assist in this process, though it is in less systematic ways (Blumberg Corwin, Venegas, Maya Oliverez, \& Colyar, 2004).

Research shows that schools and guidance counselors shape programs and advice on students' social class status (Perna et al., 2008; Yonezawa, Wells, \& Serna, 2002), which is also implicated in the construction of ability. Though ability and achievement are socially constructed (Jaeger, 2011; Yonezawa et al., 2002) they are viewed as innate traits (Hallinan \& Oakes, 2011; Oakes \& Guiton, 1995; Rubin, 2003) and are the official reasons for placing students in tracked curricula. Yonezawa et al. (2002) describe the power of ability to inform educators' and even 
students' own views of their potential and lament the entrenchment of this construction as it appears justifiable and the best way to serve all students' academic needs.

The biased construction of ability and achievement excludes othered students from academic coursework, leading to de facto limitation of postsecondary options (Brantlinger, 2003; Delpit, 2006; Hallinan \& Oakes, 2011; Rubin, 2003). If students do not begin the college prep track early, they lack the prerequisites for attending baccalaureate programs (Blumberg, et al., 2004). While tracking is now more flexible, it is much harder for students to move from low to high tracked courses (Yonezawa et al., 2002).

These biases are compounded by structural factors limiting guidance counseling. Due to mental health training and not college counseling training, counselors may not be well versed in the postsecondary application process or financial aid systems (McDonough, 1997, 2005). A dearth of counselors nationally, but especially in urban, rural, and low SES areas, has led to unacceptably high counselor-student ratios (Blumberg Corwin, et al., 2004; Klasik, 2012; McDonough, 2005; Perna, et al., 2008). This leaves minimal time to spend on postsecondary advising and at some schools, typically low income and minority schools, postsecondary advising is not a priority (Klasik, 2012; Perna et al., 2008).

Further problems occur when the roles and expectations for counselors' are unclear (McDonough, 1997, 2005; Stephan, 2013). Parents and students assume the responsibility of advising lies with counselors, while counselors view their role as personal and psychological advisors. In contrast, administrators ask counselors to fill multiple roles including test administration, administrative tasks, substituting, and miscellaneous duties across the school (Blumberg Corwin, et al., 2004; McDonough, 2005). 
These issues are integral to my work. How can students' actual needs be understood and met? What are the dialogues between counselors, administrators, and educational researchers? How can those dialogues be expanded to include families and students to use the knowledge of all of these groups? What can be done to most effectively transition students to their desired outcomes?

\section{Agency from the Othered Point of View}

Despite the majority of research being deficit oriented, there is research pushing back against these deficit narratives. The current market based forms and reforms in education place parents and students as consumers on an "input-output model" where families get out, "in terms of family practice," what they put in (Graue \& Sherfinski, 2011, p. 270). However, a critical view sees the already present raced, classed, and gendered power imbalances that favor the middleclass (Tveit, 2009). Middleclass families' capital is easily recognized by schools because they are middleclass institutions. However, critical researchers pose that working-class and poor parents also have capital but it is not recognized by schools, which renders it less helpful in cultivating school success, as currently conceptualized (Gonzalez, Moll, \& Amanti, 2005).

When middleclass capital is viewed as the only useful school capital it is "normalized" and frames othered parents in a deficit way (Rios-Aguilar, Kiyama, Gravitt, \& Moll, 2011). New research presents the necessity of expanding the view of capital to include the ways that othered families support and care about their children's education (Graue \& Oen, 2009; Schnee \& Bose, 2010; Tveit, 2009). The following works exhibit specific projects that speak to othered capital that is un/mis-recognized by schools.

Dominant perspectives, many cited previously, fallaciously place families as uninvolved in children's education (Auerbach, 2007). An alternative as to why parents do (not) participate in 
their children's education is offered by Doucet (2011). Doucet worked with Haitian immigrant families who deliberately refrained from participating with school based activities to protect their children from the school. Families described protecting their children from "Americanization," which translated to White, middleclass values. Doucet's study complicates the binary of involved/uninvolved parents (Lightfoot, 2001) showing that parents were participating in their children's education by resisting school efforts to build bridges to the home. Doucet (2011) argues that bridge building is "not value neutral" (p. 2728) and the uniform acceptance of White, middleclass norms needs challenged (Auerbach, 2007). Parents were concerned about how schools engaged them and their children in dictating what and how things should be done. In ways not recognized as valid by the schools, the Haitian parents attempted to "negotiat[e] a seat at the table" so that educators would listen to their concerns and wishes (Doucet, 2011, p. 2725). Camille Cooper (2009) echoes parents' concerns in her work with African American mothers. Cooper points out that while most schools, legal mandates, and educational research call for parents to be involved as "partners" what is actually required is "deferential parental involvement" (p. 380), where parents defer to school expertise by participating in prescribed ways. Similar to Doucet (2011), Cooper voiced that when parents do not participate in prescribed ways they are accused of not participating. In Cooper's work, African American mothers shared about their experiences with the biased views of educators. The mothers indicated the racial privilege of Whites whose stereotypes are positive and assume a value for education; while stereotypes of poor, Black mothers positioned them as "lack[ing] the ability and willingness to meaningfully contribute to their children's education" (p. 381). As mothers voiced concern about their children's education, particularly their need and effort to protect and guide their children 
through the "lived experiences... and...consciousness of racism" (p. 389), they positioned themselves as caring in ways that went unrecognized by schools.

Cooper's (2009) work is supported by other works that demonstrate the ways that othered parents' support and participation in education goes unrecognized by schools. Document analysis by Tveit (2009) indicated parents supporting their children's education by “monitoring [students'] progress, encouraging the child to work alone, assisting the child, seeking help from friends, or sitting with the child while working...[and] provid[ing] learning opportunities outside school" (p. 290). Lightfoot's work (2001) goes on to elaborate more ways that othered parents' support goes unrecognized by schools as standards of "appropriateness" are set around a White, middleclass model. Lightfoot's (2001) work in urban schools shows parents involved in ways that vary from typical descriptions, emphasizing the need to understand why parents do certain things. Similar to Doucet (2011), Lightfoot indicates that understanding parents' reasoning behind their actions helps to show their support of children's schooling and that "parent actions, including those which may be perceived as suggesting a lack of engagement, are intentional and purposeful” (p. 94). Calabrese Barton, Drake, Perez, St. Louis, and George (2004) further support the necessity of understanding parents' intentions and what they do to "impact" (p. 11) their children's education in positive ways.

In contrast to mainstream educational research, there is research that offers frameworks for viewing parents in empowering ways. Doucet and Vukovic (2011) propose a RESPECT framework for engaging families and children more effectively: "Rethink family roles, examine biases, share power, practice empathy, expand notions of involvement, communicate, tap into families funds of knowledge" (p. 1). The authors pose that by "humanizing" parents, schools can access untapped potential; particularly important knowing that parent beliefs and hopes for 
education are stronger predictors of student achievement than traditionally depicted parental involvement (Doucet \& Vukovic, 2011). Other researchers illustrate the necessity of asking parents what they need from the schools and what they can contribute (Auerbach, 2007). These type of actions help to build relationships on mutually constructed trust rather than condescending stereotypes of parents (Fann, McClafferty Jarsky, \& McDonough, 2009; Graue \& Oen, 2009). If parents are to be viewed as anything other than liabilities, these changes must take place (Graue et al., 2001; Graue \& Sherfinski, 2011).

\section{Agency from an Appalachian Point of View}

Often Appalachian students are placed as creators or victims of difficult circumstances, like poverty and a "backwards" culture. Inaccurate and stereotypical views such as these deny the agency of students and families who make decisions based on their particular lived contexts. Similar to othered students elsewhere, Appalachian students are impacted by larger narratives of deficit (Slocum \& Weekley, 2013; Towers, 2005). Appalachian researchers describe the importance of agency in negotiating representation, "We cannot ignore issues of representation because they determine who gets to speak to, with, and for us about the exploitation of this region and the strategies for our future" (Smith, et al., 2010, p. 61). Paying attention to students' agency provides a space to understand how constraining discourses are mediated.

There is some work that describes the structural constraints facing Appalachian students and how they are agentive within these limitations (Bickel \& McDonough, 1997). Bickel and McDonough (1997) studied high school dropout, teen pregnancy, and violent teen deaths in West Virginia and found that these events were the results of, rather than causes of, limited opportunities. In describing their results, the authors strongly pushed back against discourse that placed students and communities at fault for the challenges they faced, stating, "Our results are 
inconsistent with victim-blaming... and suggest that commonplace explanations of dropping out, teen pregnancy, and violent deaths in Appalachia are simply wrong" (Bickel \& McDonough, 1997, p. 41). The researchers noted the student agency in these decisions indicating that while these may seem like irrational behaviors they are rational choices for students within the context of their very limited economic circumstances and opportunities.

Other works focus on the divergence of Appalachian cultural traits from mainstream middleclass culture as strengths, particularly ties to family and place. In contrast to the deficit oriented work on Appalachian students, more nuanced research shows the complexities of how ties to place and family are negotiated within institutions that do not value these as important (DeYoung, 2007; Howley, 2006). DeYoung (2007) and Howley (2006) indicate that parents understand the importance of education but are troubled knowing that schools teach their children values that conflict with their own, recall the similarity with the Haitian parents mentioned earlier. Ironically, educators in Appalachia are often locals who have chosen the profession in order to remain close to home but through their training have adopted norms that conflict with the local (DeYoung, 2007; Howley \& Howley, 2010).

Bryan and Simmons (2009) studied the contexts and experiences of first generation Appalachian college students' postsecondary transitions. In this work, in contrast to the work on Appalachia from a deficit perspective, students shared that their parents and small communities valued education and had encouraged them to apply for college. Students also noted some of the difficulties in applying to college because their parents were unfamiliar with the process. Bryan and Simmons (2009) demonstrate this complexity:

Though every participant indicated feeling a high level of support from their family when they came to college, it was not necessarily indicative of the 
family understanding the process; it was a showing of support out of love and excitement for the student. (p. 398)

Multiple students voiced their parents' college plans for them from an early age as they hoped that their children would have opportunities they believed education would provide. These stories powerfully speak back to the narratives of parents and children not valuing education.

Bryan and Simmons (2009) and Wright (2012) depict how ties to family and place can be assets rather than liabilities in the transition to postsecondary education. Strong family connections played integral roles in fostering and supporting students' postsecondary decisions (Bryan \& Simmons, 2009). Wright (2012) details how students' tie to place positively informed their postsecondary decisions leading them to seek degrees and education to support their communities. Wright (2012) notes the institutional support from a local community college that helped students to achieve these goals. These works confirm the necessity of schools adapting to the local context. Through culturally supportive programming schools can foster rather than deter students' success and open broader views for what constitutes success.

\section{Ties to Place and Family and Appalachian Students’ Postsecondary Trajectories}

As mentioned, ties to family and place are common across the Appalachian region but are often represented as barriers to postsecondary schooling in research based on mainstream, middleclass norms (Ali \& Saunders, 2006, 2009; Brown, et al., 2009; Chenoweth \& Galliher, 2004; Wallace \& DieKroger, 2000). In non-critical work, these ties are seen as barriers to higher education for multiple reasons; for example, family responsibilities are viewed as distracting students from school work. Also, when students prefer to stay close to their families their options for schooling choices may be limited, particularly in rural areas and so non-critical work posits that students should choose schooling over their families. Conversely, in more critical work, ties 
to place and families can be positioned as beneficial in the postsecondary choice process (Jones, 2013; Slocum \& Weekley, 2013; Wright, 2012). For example, in Bryan and Simmons’ work, students felt strongly supported by their families in making the postsecondary transition. In Wright's work, the local community college structured their education and programming around local needs so that students who wanted to remain locally could pursue their education while maintaining their commitment to strengthening their local communities. Culturally sensitive research, like that of Wright and Bryan and Simmons, demonstrates how cultural practices can be beneficial if institutions and researchers are willing to de-center their standards from mainstream, middleclass norms.

Policies of globalization have strong impacts on local schools and communities. As education and students are framed through neoliberal discourses, they are positioned to participate in the global economy to the detriment of the local. The impacts of globalization and neoliberal discourses manifest in the ways that schools steer students towards college, while excluding other options to support alternative training or work experiences. In rural communities that offer few opportunities to use baccalaureate degrees, and where students may have strong commitments to family and place, students are faced with limited options; should they stay and struggle with what exists or leave and find economic security elsewhere? However, alternatives to this binary are becoming more common, particularly as the young and educated who have left begin to return home (Terman, 2015). In the following methodology chapter I will address these topics are they relate to my research questions. 


\section{Chapter 2: Conceptual Framework}

A life can only be understood in terms of its trajectory through specific social fields.

(Thompson, 2012)

I am interested in how students' social class backgrounds, especially the working and lower classes, are implicated in how they progress through the middleclass school system. This is particularly important in states like West Virginia where many middleclass people work in traditionally blue-collar professions. For example, industrial (coal and chemical) and manufacturing jobs provide positions for people who have only high school degrees, while offering salaries that are often double the income for college educated professionals like teachers. Additionally there are many more job positions in West Virginia that require only a high school degree than require a college degree (U.S. Department of Labor, 2013). I am interested in how these dynamics play out in the ways that schools prepare students for their postsecondary routes and related to how students and families negotiate interactions with the school and after high school graduation. My specific research questions are: What are the implications of habitus and identity in the postsecondary transition? How does habitus inform identity? How is identity implicated in the postsecondary transition?

In order to examine the reciprocal nature of how students' social class status is negotiated within the classed cultures of their schools and communities I utilize Figured Worlds Theory (FWT) (Holland et al., 1998) as my main framework through which to explore my research questions. FWT draws on cultural and social constructivist understandings of identity, positionality, and agency to explain how individuals negotiate relationships within discourse communities that are constructed by and constructive of figured worlds. The cultural viewpoints that FWT pays attention to allow me to understand how habitus is constructed from social class 
positioning. While the social constructivist aspects allow me to see the way that identity is constructed from the social, which in my case I am most interested in social class and Appalachian culture. As FWT marries these theoretical frameworks and expands on them they incorporate agency allowing room for people to move beyond their cultural boundaries. With the breadth to include culture, identity, and agency, FWT allows me a framework through which to examine my research questions.

FWT attends to any cultural aspects of a person's life and how those are constructed and negotiated at the personal level, as well as at group levels as in class practices. FWT also pays attention to positionality, how people are positioned in power relations to one another, to consider how positionality influences individual and group processes. The social constructivist elements of the theory acknowledge that people take on an active role in constructing their worlds, illustrating that individuals are not strictly bound by their culture. That people are not strictly bound by their culture is important as I show how students engage life in improvisational ways that lead to unexpected outcomes. Holland et al.'s (1998) work draws together these elements to enable rich theorizations of practices that are reflective of the complexity of life.

This chapter begins by introducing generally how figured worlds are socially constructed. Then I discuss how this social construction is negotiated at the personal level in identity work. After this I cover the dialogic nature of identity construction and then finish with how the individual acts upon the social in agentive ways. Following this I discuss the nature of positionality and how power plays into the processes of identity construction and agency. 
Finally, I elaborate on the connection between identity and agency and how agency is drawn from the personal and social. Throughout the chapter, concepts are mentioned repeatedly and across different sections, which is due to the overlapping nature of the concepts and aspects of FWT.

\section{Origins of Figured Worlds Theory}

Inspired by applications of cultural and constructivist theorists' import for contemporary anthropology, Holland and her colleagues have developed the work of Lev Vygotsky, Mikhail Bakhtin, and Pierre Bourdieu. Holland et al. illustrate how identity is formed through the interaction of the self with others and the environment, interpreted uniquely, and then enacted in novel and agentive ways. The theory takes into consideration how these founding theorists' constructions work in concert to show the process and dialogic nature of identity construction and agency within the social context of figured worlds, as well as how these processes are situated within the larger societal systems of power. As identity and agency are constructed and enacted, they occur within both independent and overlapping figured worlds that provide a space of shared communication and understanding for the interpretation of actors' meaning. I explain each of these theorists' work in turn, and ask my readers to keep in mind as I explicate Holland et al.'s (1998) theory further that they have theorized beyond these three theorists in order to create a new theory of identity and agency all their own. In this way, readers may notice traces of these theorists creeping into the conversation as I describe Holland and her colleagues' work later on, after briefly introducing key concepts from the three foundational theorists.

Vygotsky's theory is used to illustrate how the social world is constructive of identities through individual interpretation of signs and symbols, via semiotic mediation. For example, as social class constructs people's positions and identities, they learn to identify and understand 
signs and symbols representative of social class. The terms yuppie and trailer trash are both related to the world of social class and are used by people to position themselves and others and have generally understood meanings. However, despite these generally understood meanings these words also have personal meaning as people use them to position themselves or others.

Bakhtin's work is used to show the dialogic nature of how identities are constructed and negotiated as a person responds to the social world, interpreting incoming messages and answering back. Think of a high school student from a working-class background who lives in a nicely kept trailer but does not want to be seen as "trash." In a discursive move to distance herself from this damaging identity, she clarifies the differences between herself, not trash, and others who live in trailers who are different and so "trash." The student is responding to discourses that place her identity, by virtue of her home, as trashy; however, in rebuttal she "answers" the world and has a specific audience in mind, those who would position her as trash. As this student is in response to the world, she is also responding to the world, in anticipation of the world's next response. Bakhtin's work also pays attention to positionality and how power informs the way one is engaged by and engages with the world. For the student I have described, social class status assigns power based on housing structures, so that a peer who does not live in a trailer can assert that those who do are "trash." While the hypothetical student is positioned with less power than the people calling her "trash," she still has power. However she may have more power than those who she can further differentiate herself from who really are "trash," while she just happens to be a person who lives in a trailer. While Bakhtin's work pays close attention to the dialogic nature of positionality and power at the level of the person, Bourdieu's work is drawn upon to illustrate the positional nature of identity development as the social and individual are hierarchically constructed based on the socio-economic world. According to FWT, 
the social and personal are in cycles of response and engagement as identities are constructed and negotiated. Identities are constantly being shaped as people draw from the social, interpret this, and then act on the world in agentive ways.

As a framework, FWT allows me to examine how students interact with cultural discourses at the individual level as mediated by their broader social contexts (Holland et al., 1998) (See Table 1). In this case, the broader social contexts I am most interested in are the school systems, community level processes, and how these are impacted by the neoliberal agenda and globalization. While FWT provides the nuance to examine individual processes, it also provides enough breadth that communities can be framed in ways similar to individuals, as having particular identities and drawing on those identities to act on the world. FWT is a framework that allows me to explore the process of how students' shape their identities as actors within particular figured worlds and agentively enact those identities as they respond to the world around them. In this study, as high school seniors draw on available discourses they construct an understanding of who they are as students and young adults. In this process, students are interpreting their worlds in both inner and external processes that in turn shape at least in part how the world responds to them (Urrietta, 2007b). This happens continuously and dialogically as students are shaped by their world and shape it in response. In the postsecondary transition process, students agentively make decisions about where they will go and what they will do based on their identities within classed and Appalachian contexts.

Table 1

Key theoretical mechanisms of identity and agency processes.

\begin{tabular}{ll}
\hline Theorist & Key Mechanisms \\
\hline Vygotsky & Social interaction \\
Bakhtin & Dialogism \\
Bourdieu & Power analysis via habitus and field
\end{tabular}


In this study, I examined the opportunities that these complex identities afforded for students' agency as they made decisions that shaped their postsecondary trajectories. FWT permits me to highlight the plurality of experiences that lead to student agency as well as to examine how class and culture are implicated in this process. In this chapter, I explain the theoretical framework that Holland and her colleagues have developed from the original theorists discussed above. As I move through this section, the ideas are based on the work of Holland et al. (1998) unless otherwise cited.

\section{The Social Construction of Figured Worlds}

Figured worlds are, "historical phenomena" that are "socially organized and produced via social encounters" and "culturally constructed, activities...dependent upon interaction and intersubjectivity of participants" (Holland et al., 1998, p. 40-41). Figured worlds are both conceptual and material. They are conceptual as they exist only as people have constructed, participated in, and maintained them. Via this conceptuality, figured worlds "supply the contexts of meanings for actions, cultural productions, performances, disputes, and the understandings people come to make of themselves" (p. 60). Figured worlds are made material through participants' production of them, specifically as "manifest in people's activities and practices...narratives and performances that constantiate relative positions" (p. 60). As actions

and practices are produced they bring life to figured worlds. In Holland et al.'s (1998) words, figured worlds are:

A socially and culturally constructed realm of interpretation in which particular characters and actors are recognized, significance is assigned to certain acts, and particular outcomes are valued over others....Figured worlds provide the contexts of meaning and action in which social positions and social relationships are named 
and conducted. They also provide the loci in which people fashion senses of selfthat is develop identities. (p. 52, 60)

Finally, as they are "encountered in day-to-day social activity, lived through practices and activities" (p. 56), figured worlds capture the everyday-ness of the cultural in the personal.

Figured worlds are created around specific sets of circumstances and have entire cultures based around those circumstances. These sets of circumstances are like the "storylines" of figured worlds that serve "as backdrops for interpretation, though they are not prescriptive" (p. 54). In this sense, the storylines provide a general understanding for how activities transpire, or are, at least, expected to occur. As students exist within multiple and overlapping figured worlds that have expectations built around what can be expected and how to move through these worlds. In this study, I am most interested in the figured worlds of the communities and the figured world of the postsecondary transition process as it occurs within the schools and communities where students have expectations for how the transition should progress. As actors gain a generalized understanding for how to engage with a figured world, they develop what the authors call "cultural schema." The authors describe that cultural schema help actors to, "guide attention to, draw inferences about, and reconstruct memories of experience" (p. 29) relative to figured worlds. Discourses become what Vygotsky called a "pivot," a tool to enter a particular figured world. Because actors engage uniquely, these generalized discourses are utilized only as frames or references and not step by step guides for how to participate as members construct their identities and the figured worlds.

Ureitta (2007a) describes figured worlds as "landscapes of action," where people and actions are related in ways that carry a shared meaning understood by the actors of that figured world. Just as actions carry meaning, relationships are also understood and recognized to have 
particular meanings for the actors within figured worlds. In this way the stage of figured worlds "distribute" actors who are set for action and relationships (Holland et al., 1998, p. 41). As actors are distributed across the landscapes of actions of figured worlds, their own actions inform the figured world, a process called "coproduction." For example, in the figured world of the high school there are important actors like guidance counselors, AP teachers, and students in AP and general classes. As a student participates in AP classes and is called "Miss 4.0" by a friend in general track courses and is talked about as a star student by multiple teachers, these actors' actions, by the teacher, student, and friend, are working together to create a specific figured world. In this figured world, participating in AP or general classes has meaning that is produced through relationships such as the friendship between the AP student and her friend who teases her for being "Miss 4.0" and by how the teachers treat students who are and are not in AP classes. As the actors engage in figured worlds they use artifacts, like designation as AP, "Miss 4.0," etc. to define their relationships to the world and to one another. For this project, seeing how students are positioned, i.e. distributed, across figured worlds, helps to see who has (or does not have) access to resources and people to help facilitate the postsecondary transition process. Seeing how access is distributed gives a look into how students are empowered, or not, to move through this process based on how their positions have been coproduced within their figured world. As people engage with one another, they are coproducing the figured world of their high school, where people have expected roles they are likely to fill as they participate in the postsecondary transition process.

Coproduction is indicative of the "process" make-up of figured worlds. Just as there are shared meanings around relationships and actions, there are also specified roles for actors which shape the ways, and are shaped by the ways, that actors participate (Urietta, 2007a). The roles of 
a figured world represent pre-defined positions, or potential identities, associated with the figured world. These roles are relational as actors are always responding to other actors within the figured world and these responses are based on an understanding of positionality. Positionality reflects the understanding of how a role is placed within a figured world, specifically related to power dynamics. Positionality is also relational in the sense that roles are positioned as always in response to other roles. As Holland et al. describe, "personal activity always occurs from a particular place in a social field of ordered and interrelated points or positions of possible activity" (p. 44).

As actors of figured worlds engage in activity they employ artifacts that help to construct the figure world. Like figured worlds, artifacts are both conceptual and material, recalling the past and framing the present through an "ideal or conceptual aspect" (Holland et al., 1998, p. 52). Artifacts, serve as entry points into figured worlds and also are constructive of the figured world. They also symbolize meaning relevant to figured worlds, evoking certain ways of thinking or ways of being when they are encountered. The meaning attached to artifacts is reflective of the positionality of actors as artifacts place people and are used by people to place themselves and others. As actors utilize artifacts as tools of placement in figured worlds, they gain a sort of external control over themselves as well, "learning how to position ourselves for ourselves" (p. 64). In summary:

figured worlds are evinced in practice through the artifacts employed by people in their performances...artifacts...open up figured worlds...they are the means by which figured worlds are evoked, collectively developed, individually learned, and made socially and personally powerful. (Holland et al., 1998, p. 61) 
As actors participate in figured worlds the worlds continue in whole and as parts of society. Activities, too, are definitive in constructing figured worlds where some results are preferred over others. Participants in figured worlds develop competency in using the language and actions symbolic of the world, forming into "communities of practice," (Lave \& Wenger, as cited in Holland et al., p. 56). Individuals move through these systems negotiating the embedded assumptions and meanings in ways that have personal implications. This negotiation iteratively shapes the person and the figured world as dominant discourses are supported or challenged.

As figured worlds are constructed by these multiple components, they are also nested within the larger social and cultural settings giving them a historicity. This nesting within social and cultural frameworks also shapes positionality for actors within figured worlds, where roles and relationships reflect the hierarchical structures of society. As people engage these contextually based roles, relationships, and actions, they interpret what these experiences mean for themselves and use this interpretation to shape their further participation in the figured world. The figured world becomes the stage where actions, roles, and relationships are interpreted at the individual level and, based upon that unique interpretation, engaged by actors; this continues the iterative process that shapes the figured world as it is perpetuated by its members.

\section{Figured Identities}

As identity is conceptualized within FWT, it is difficult to describe in a written, linear way. FWT considers identity to be always in process and in construction, however stable enough that it shapes how a person engages with the world. Also, while identity is used in the singular, the authors imagine the concept as consisting of multiple identities that are contextually based. As people draw on their contexts they place themselves and are placed based on different positions dependent on their lives. 
Identity is both a personal and social concept in that it is a person interpreting their external world via internalized processes. The interaction of the external, that is interpreted internally, and then expressed externally, speaks to the dialogic nature of identity construction. As a person interprets the social world and what it means for them, these meanings form the core of the conscious self, their "self-understandings," their identities. With identities as the core of a person's conscious self, they provides an awareness of who one is to oneself and to the world outside, who a person would like to be, and who they believe they can possibly be. Significantly, the conceptualizations of who one is, to whomever, do not need to be geared towards a singular identity, rather it is possible to hold multiple, sometimes conflicting understandings of the self simultaneously. FWT pays strong attention to the self-understandings that construct identity, as when enacted these also structure the figured world, implicating identity as not only a social product but also a producer of the social. Finally, while identities may be related to large social constructs like gender or class, Holland et al. (1998) conceptualize identities more locally as specific to participants' figured worlds giving them "particularity." In this study, being able to see the "particularity" of people's identities offers an opportunity to see how detailed contexts, such as high school, friends, and family, influence students' identity production outside of larger constructs like social class. For instance, paying attention to the particularities of a students' identity from a low income, first generation background who successfully makes the transition to college, can show details that have served as resources, which would likely be obscured in studies that look at larger patterns. Identifying unexpected resources, or hindrances, provides opportunity to make the postsecondary transition, to whatever pathways, more accessible for students and families. 
Just as figured worlds are processes always active and in production, so too are identities. As identities are produced, people draw from multiple aspects of life including their "history in person, the sediment from past experiences" (Holland et al., 1998, p. 18), and their current cultural milieus and positionality. These varied aspects are made personal, "subjectively taken up" (p. 18), through "heuristic development" (p. 18) as people experientially move through life. Just as figured worlds co-develop with actors, identities form in codevelopment as people marry the personal and social creating new formations. Further, as people form identities, it is not only a means to express themselves to others but also themselves, as understandings "of themselves and for themselves" (p. 4). Understandings "of" themselves allow people to comprehend "who I am" within a given context, and understanding "for" themselves supplies meaning to the "who I am" position. These understandings and meanings are the spaces where "authoring the self" occurs. Authoring the self, can be both conceptual, an internal production, or procedural, an external act (Urietta, 2007b), and are both spaces where identities becomes agentive.

As people author themselves, they use tools similar to those used to construct figured worlds. Tools of identity are similar to the artifacts used in the construction of figured worlds: cultural schema, discourses, objects, and actions. Anything a person uses, directly or indirectly, to position themselves is an identity tool, which, through semiotic mediation, allows them to “create a revised sense of self" (Holland et al. 1998, p. 43). As identities are externalized activities become "improvisational," new productions of identities that can be used as tools that shape further activity. The repetition of improvisations leads to them becoming natural and the process of production moves out of conscious thought. Vygotsky (as cited in Holland et al., 1998, p. 40) terms the naturalization of improvisations "fossilization" and posits that as identity tools become fossilized they become more available as "tools of agency." 


\section{Positioning Figured Identities}

Positionality, how one is positioned by their identities, in figured worlds is associated with power and privilege difference related to social constructs like race/ethnicity, gender, social class, and location. Understanding who does and does not have what power within the figured world of the postsecondary transition is important when considering how to best serve students and families. Positionality matters, because, as Holland et al. pose, "persons look at the world from the positions into which they are persistently cast" (Holland et al., 1998, p. 44). In this section I begin by explaining hierarchical positionality and how people come to embody different positions. Then I look at how language is used in constructing and maintaining positionality. As people draw on their experiences to form their identities, I am interested in how these experiences are classed in nature, so I foreground a description of Bourdieu's (1984) concept of habitus within this section to give an understanding for how classed experiences position actors.

Social positions are limited, and limiting, as people claim higher positions and assume that those in lower positions will act accordingly. As people negotiate these positions, certain knowledge is held as valuable and a person's position within the figured world is indicated by their relationship with that knowledge. Hierarchical positions and the experiences that result from these build different cultural schema within a person. Ascription to schema also becomes an identifier of a person's place in society as it shapes how they move through the world and engage with others. This positioning happens discursively, through dialogue and discourse, but also in the physical sense based on how people have "access to space, associates, activities and genres" (Holland et al., 1998, p. 44). The early years are powerful in constructing the positionality of figured identities, "linking durably in their persons structures of privilege to the 
dispositions of silencing and acceptance that such structures demand" (Holland et al., 1998, p. 136). People's privilege, across their lives, build expectations for how they should engage with people in power positions and for how they can expect to be engaged by these people. For instance, a first generation, working-class college student does not ask questions in her college class because she is afraid of "looking dumb." Her classroom experiences in college are shaped by the experiences she had in high school when teachers, people in more powerful positions, were dismissive of her requests for help. As this student has been silenced across her K-12 experiences, it has shaped the way she that she later disqualifies herself from help in college. Hierarchical positions are not natural but imposed; however, it (typically) remains for those in less powerful positions to these hierarchies as those with more powerful positions are unlikely to change a system that gives them power (Carspecken, 1996). An awareness of positionality is essential, by ignoring it we may "silenc[e]....those who lack privilege and power" (Holland et al., 1998, p. 25). Knowing about how power and privilege influence when students feel privileged to speak up or not, means that reaching out to students who are likely to have been othered by a low status (social class, race, gender, sexual orientation, etc.) may be a helpful pathway for them to gain access to knowledge or help for the postsecondary transition that they may otherwise go without.

Language as an indicator of positionality. How a person perceives themselves in relation to others is reflected in language, which has layers of meaning, including references to power and positionality. Holland et al. point to the importance of language in positionality citing that, "Since utterances organize experience (as the source of the psyche itself), we are strongly affected by the position we are cast into within interactions" (Holland et al., 1998, p. 188). Here Bakhtin (as cited in Holland et al., 1998) is drawn from to indicate that all utterances are dialogic 
in that they are, (1) in response to the external and (2) $a$ response to the external. Moreover, all utterances are characterized by addressivity, that is, there is always an intended audience. Through objectification people make the subjective social, such as when they "move from inner to outer speech" (Bakhtin as cited in Holland et al., 1998, p. 189), and put their own stamp on the world. As people speak to the external their utterances are reflective of positionality. In regards to this study, being able to see how people position themselves and are positioned by language provides a layer to analyze power and how it plays in the postsecondary transition process.

Social position is also marked by specific aspects of language such as dialects, accent, and the "degree of formality" people use in their speech (Holland et al., 1998, p. 127). While words have a basic, dictionary-esque, meaning, this is rudimentary and really the least important aspect of meaning. Layered upon a dictionary level meaning are the ways that words are used within particular discourse communities and also the ways that words are interpreted at the individual level based upon someone's personal context. These contextually based connotations are what are referred to as the "sense" of the word, which changes based on who is using the word or language, what setting it is happening in, and who the intended audience is. The book gives the example of the word coal to show how different the basic "meaning" of a word can be in relation to the "sense" of a word that is based on context. Holland et al. (1998) use the example of coal to illustrate these nuances, which fits nicely with this work as coal has played such an integral part to the identity of West Virginia. The dictionary meaning of coal describes an organic substance, composed of carbon. However, as coal is perceived by the artist, it is a tool for sketching (charcoal), which is much different than for the person in a home using coal as a tool for heating. These examples are both much different than what the word coal elicits in West Virginia for the miner worrying about keeping their job or for the industrialist looking to 
increase their profits. As people speak and interpret what is spoken to them, they draw from their inner selves and the external and use what they have learned from others' language for their own purposes.

Tying language to self and position. Bakhtin describes the self as analogous to the word "I" in language use. When a person uses the word "I" there is a clear understanding of meaning however what "I" means is different for every person. To describe oneself, a person describes how they are and are not like others, whether implicitly or explicitly. As a person describes themselves through language, it is done by drawing upon available discourses so that it can be understood by others, leading a person to take on external descriptors and positions. A person has agency in this construction of self; through language they reveal who they are for themselves, who they are for others, and how they are impacted by others. This is what Bakhtin (as cited in Holland et al., 1998, p. 178) called, the "I-for-myself...I-for-others... and other-inmyself." A person does not express themselves most fully through explicit statements, rather it is through actions, other speech, and negotiations with others that the self is authored. Through this dialogue, a person indicates their values and what they represent. Positionality is always present within this "self-authoring," shaping participation in figured worlds and relationships with others (Holland et al., 1998, p. 173).

Habitus as identity foundation and indicative of position. Holland et al. (1998) utilize Pierre Bourdieu's concept of habitus to help show how identities are constructed based on a person's early life. They describe habitus as "our past, brought to the present" (p. 17), indicating how identity construction corresponds with a person's early life. Habitus also helps to explain how identities are influenced by, and indicative of, the hierarchical nature of positionality specifically related to socioeconomic and political systems (Grenfell, 2012). 
Bourdieu developed the concept of habitus to explain how social class is reproduced through subtle, yet powerful pathways at the individual level (Bourdieu, 1977b, 1984, 2000). Habitus is the disposition(s) that background the behaviors and beliefs that form a person's identities (Bourdieu, 1977b, 1984, 2000; Holland et al., 1998). Essentially habitus is the embodiment of a person's classed position as manifested in internal processes and the ensuing external behaviors.

Bourdieu describes habitus as a "structured and structuring structure" (Bourdieu as quoted in Maton, 2012, p. 50). It is structured in the sense that it is built from our lived experiences and structuring in the sense that the experiences that have built it go on to influence a person's views and actions. In this way habitus is a connection between the personal and the social, what Holland et al. (1998) refer to as "history in person" (p. 58).

The habitus is most strongly formed within the family (Bourdieu, 2000); in an implicit process, life is learned as it is lived. Additionally, Bourdieu considered early schooling experiences to be influential in habitus construction (Bourdieu \& Passeron, 1990), though he did not speak broadly on the influences of secondary schooling. As I explore students' habitus during secondary schooling, this provides an interesting extension to understanding how habitus continues to be negotiated after childhood. Children are experientially taught to participate in society in particular ways based on their various positionalities including classed, raced, and gendered spaces. As people engage in this dialogue with the social, they develop conceptual schema, what Bourdieu (2000) calls "dispositions," that allow them to engage in life in ways that fit with their classed positions. Within FWT, this is an aspect of how people dialogically negotiate the spaces within various figured worlds based on available discourses. 
As the habitus shapes how a person engages with figured worlds, it provides a basis for the discourses they do or do not identify with. Moreover, these particular locations in the social world shapes what possibilities are seen and not seen, based on past experiences (Maton, 2012). These cognitive frameworks are drawn upon in identity work as people shape who they are in response to the social. As people incorporate their history into consciousness, they act on the figured worlds in predictable ways, which is what allows habitus to also be conceptualized as a structure (Maton, 2012).

Bourdieu (2000) describes these actions and reactions as not fully conscious decisions, rather as almost reflexes, based on the past. FWT extends habitus to incorporate the conscious ways that people understand life as grounded in their classed backgrounds. Through incorporating a conscious identity people have agency in constructing their responses to the external, in turn, shaping the world around them. Understanding habitus within the framework of FWT gives sight to the bounds of social class but also how those boundaries can be surpassed because of human agency that is grounded in identity.

\section{The Dialogue between Figured Worlds and Identities}

In this section I begin by detailing the aspects of dialogue that occur as people engage with their environments, each reciprocally influencing the other. Then I describe aspects that are important when thinking about how power is constructed within and across figured worlds. To conclude, I elaborate on Bourdieu's concepts of field, capital, and misrecognition to draw in the socio-economic aspects of power and how they are implicated in identity development. As this study is very concerned with how people are influenced by cultural ties to family and place and social class, being able to see the dialogue between the cultural/social and the participants helps to understand the ways that these artifacts are taken up in discourse and negotiated as 
participants move through the postsecondary transition. Additionally, because I am interested in the pathways of students from working-class and lower backgrounds, students who are not typically positioned with the power associated with higher social classes, it is important to understand how they negotiate a system where they often engage with those who have more power than themselves, such as higher class students and educators.

FWT utilizes Vygotsky (as cited in Holland et al., 1998) to show that a person develops as a result of their surroundings. People learn from those around them and understand who they are from their contextual space and relations. As people internalize limits and possibilities, identities are shaped and shape behavior as people act on the world in ways that support this inner sense. Importantly, as people become more experienced with figured worlds they can more adeptly resist discourses that may be limiting. These inner and outer dialogues are always in flux based on our social contexts, thus the potential for change always remains.

As I have mentioned, when identity is enacted it shapes the external. Bakhtin is drawn upon here to conceptualize the interactive dialogue where identity processes shape the external. Humans use semiotic mediation to recognize and manipulate symbols, "altering the social environment" (Holland et al., 1998, p. 35) and the representation of inner selves. The meanings that are symbolically assigned are socially constructed and understood in specific ways by each person and used according to their own history, "a product of the person-in-practice (Holland et al., 1998, p. 40). This is part of what Bakhtin refers to as heteroglossia, where "specific points of view on the world... are juxtaposed to one another, mutually supplement one another, contradict one another and can be interrelated dialogically” (Bakhtin, as cited in Holland, 1998, p. 170). Heteroglossic discourses occur within a person as well as externally, charging every person to negotiate a multitude of possibilities. Holland et al. elaborate, "the author...creates by 
orchestration, by arranging overheard elements...not by some...ineffable and central source. The author works within, or at least against, a set of constraints that are also a set of possibilities for utterance" (p. 171). As people draw from available heteroglossic discourses, they construct responses available for themselves and for others.

This dialogue represents the interrelatedness of identity, relationships, and context. Identity is a role that has been constructed by those who came before a person and by how a person fills their role within society. Expected roles come from dominant discourses that are applied to society in a universal way: "both interpersonally and institutionally" (Holland et al., 1998, p. 26). Dominant discourses frame acceptable ways of being; however, prescriptive dialogues can be re-framed. Again, codevelopment is in process as society sets expectations that are acted upon by individuals in a mutually constitutive process. These expectations and roles are reflective of positionality, of how the individual is placed, and places themselves, within the positions available in society. As students move through the postsecondary choice process they negotiate their places within the figured worlds of their communities and schools. As they move in these agentive ways, students' actions are mediated by their understandings and adherence to local symbolism. Through their participation in these figured worlds, the students reproduce the local but also produce their own variations on the local.

Figured worlds and fields. As students engage in figured worlds, the figured worlds are constructed with recognition of social fields. Bourdieu's concept of field (Grenfell, 2012) is helpful in understanding positionality and how capital is broadly employed to shape positionality in social spaces. When Holland et al. (1998) utilize Bourdieu's notion of field they note its similarity to the concept of figured worlds; however, there are important differences. Field is used by Bourdieu to show the hierarchical nature of social relationships and how these are 
reflective of the power structures of society and how capital is used to maintain societal structures. In contrast, figured worlds focus more on the everyday actions that make up social relationships which are also informed by the fields that individuals and groups negotiate. Field adds a layer to figured worlds that allows for a richer understanding of how power operates within a figured world.

Fields serve as the contexts where a person's habitus and capital, in combination with other processes, tend to reproduce the social order. Field is the social space surrounding a particular arena and is a way to understand how people are positioned in social spaces as habitus structures their level of and use of capital. Bourdieu likens the concept of field to a sporting game where players are assigned roles with specific rules that must be followed. These are initially difficult but become 'natural' the longer a person plays. Skills that are weak become stronger and players perform more adeptly the longer they practice and play. The conditions of the field - muddy, turf, natural grass - impact how the game is played and what players can do.

However, unlike in literal sporting events, players in the social world do not begin on even ground with a score of zero (Bourdieu, 2000, 2011). Thompson (2012) describes this inequality:

Players who begin with particular forms of capital are advantaged at the outset because the field depends on, as well as produces more of, that capital. Such lucky players are able to use their capital advantage to accumulate more and advance further than others. (p. 67)

Anything can be a social field: high school, college, politics though these are all bound within what Bourdieu refers to as the "fields of power," which are the political and economic fields as they determine the direction and laws of society (Thompson, 2012). Each field has its own form 
of "distinction" determining who is dominant (Thompson, 2012, p. 70) and they overlap and are related, where events in one field create change in other fields (Thompson, 2012).

Thompson (2012) and Bourdieu (2000) note that people are active agents within fields; however, their agency is limited by their positionality. Fields are places of struggle where people vie for positions and access (Bourdieu, 2000) and the powerful assert dominant dialogues of what should be that privilege certain groups by perpetuating myths of Others. This place in the social space is powerful, giving a "sense of place or class unconsciousness" (Bourdieu, as quoted in Crossley, 2012, p. 86).

Capital as a positioning tool. Crossley (2012) describes capital as the "currency" of social class and it influences how people are positioned to engage within fields and figured worlds. As I write about capital I call it "dominant" because of its level of power in society, not because of an inherently higher value. I treat capital as existing as often unrecognized within working-class, poor, and rural communities, referring to it as othered capital. However because of the domination of dominant capital, othered students' capital is not as powerful or even recognized as middleclass, suburban capital (Rios-Aguilar et al., 2011). As I progress through my project I want to expand the view of what capital is and of how students' and families' strengths can be drawn upon in schools rather than seen as barriers. I also want to show what can be deficits in what is considered dominant capital, things such as striving for personal and career success over family, etc. Capital is a concept that can show what students bring to the table and how this is engaged by the middleclass school system.

There are different types of capital and these are not directly transferrable to economic capital but at root they can all be deduced to economic capital (Bourdieu, 1977a). These connections are hidden in order to substantiate dominant capital's value as it is transformed into 
the signification of power and place within fields. Societal stratification is replicated through the ways that dominant capital is acquired (Moore, 2012) as it is amassed over time and embodied or held within the person (Bourdieu, 2011), reflective of history-in-person (Holland et al., 1998). For example, a high school student who has been a very successful student all through school, is recognized by teachers as "talented," conferring capital to the student. As this student has been recognized for years by teachers as talented, the recognition becomes embodied in their person as they understand that they are recognized and that this confers privileges in the school. For instance, when this student needs a letter of recommendation for a scholarship application, they know (embodied capital) that they can approach any of their teachers (social capital) who will write a glowing recommendation (institutionalized capital). Because the student has "amassed over time" the embodied knowledge that teachers view them as talented, they are confident in drawing on the teachers as resources to further their goals. In this way, capital begets capital and it is important in what it is, how it is used, and in how it is recognized (Bourdieu, 2000; Crossley, 2012).

Types of capital. Money and its associated forms are the most basic type of capital. Economic capital can buy access to most other types of capital, even social capital, which gives a person access to people who collectively have more power than any single group member (Bourdieu, 2011). This is often an implicit relationship where money allows investment in social activities and provides access to the free time needed for socializing and building relationships, particularly in exclusive spaces. Cultural capital is the most symbolic form of capital, i.e. the least directly related to money, and thus the most powerful type of capital (Bourdieu, 2011). The logic is that if you cannot buy it, then it must be something people either innately have or do not, setting up a seemingly "natural" hierarchy. Cultural capital is viewed as the property of the 
whole society and includes things like choosing the right literature, art, music, food, and lifestyle, as well as the knowledge of these things (Bourdieu, 1977a). Like other types of capital, cultural capital depends on the time, resources, and access people have to consume and embody this type of capital (Moore, 2012).

Forms of capital. The forms of capital are how the different types of capital are expressed (Moore, 2012). Objectified capital is capital in its material form, works of art, music, clothing, etc., what Moore (2012) calls the "raw materials" of culture (p. 103). Objectified capital signifies a certain amount of economic capital that allows access and an ability to recognize and consume the capital (Bourdieu, 2011). Objectified capital is often misrecognized as culture itself, particularly in regards to dominant objectified capital. Artifacts that reflect social class are important aspects of FWT as they signify who belongs to what identities. For example, when a student takes weekend trip to a museum with their family, they are able to talk about the museum and what they learned in their history class at school the next week. When the teacher recognizes the students as "interested in learning" the student is conferred symbolic capital. However, this trip also represents other artifacts of social class status, such as the economic capital available to take a weekend trip and the cultural capital that recognizes a trip to the museum as valuable. While a trip to a museum is a classed activity, often the recognition of capital is misrecognized as a natural valuing of culture, a trait that seems unrelated to social class.

Embodied capital is the externalization of capital; it is related to access to economic capital which becomes a fundamental part of a person. Embodied capital is the knowledge of how to move through a culture, the way that culture is held within the body (Bourdieu, 2011; Moore, 2012). Bourdieu (2011) describes that embodied capital becomes symbolic capital 
because it is understood "as legitimate competence" (p. 86). It is an understanding of how to act, speak, dress, and choose in specific situations (Moore, 2012). When students are from middleclass backgrounds, their embodied capital matches the capital that is viewed, not as capital, but as a general competence in middleclass schooling. As a students' capital/competence is recognized by school officials, students are rewarded for their match with the school system and offered more capital. When students' embodied capital does not match that of the school, i.e. they are from working-class or poor backgrounds, they are not as easily recognized as being "competent" actors in school. Both of these instances influences how educators engage with students. Embodied capital is a part of the expression of habitus (Bourdieu, 2011; Moore, 2012) and a strong indicator of positionality.

Institutionalized capital is that which is officially sanctioned by institutions as valuable. Economic capital is institutionalized in ownership laws (Bourdieu, 2011). Social capital is institutionalized in elected political positions or other prestigious social positions like the president of the country club. Cultural capital is institutionalized through educational credentials, such as a high GPA, membership in the national honor society, or a high score on the SAT; these are all markers of dominant cultural capital. Institutionalized capital is important, because it is officially recognized by institutions, aspects of institutionalized capital are used as gatekeeping mechanisms to other institutions or capital. For example, GPA and SAT scores are used as gatekeeping tools for students to access higher education and to get funding. Likewise, degrees from various postsecondary institutions are used as gatekeeping tools for employment (Rosenbaum, 2001). 
I am interested in the ways that students utilize their capital, based on their identities. In what ways does capital restrict them or expand their opportunities? How do students draw on capital to facilitate their postsecondary decisions? Habitus structures how capital is typically used; however, students may utilize capital in untried ways. Students trying capital in novel ways is an example of them operating within their Zone of Proximal Development (ZPD), Vygotsky's concept utilized by Holland that I will expand upon later, as they use tools they have mastered in innovative ways, an act of agency.

Misrecognition. Misrecognition is another concept from Bourdieu that helps to show why some social markers that shape dispositions and positionality, like capital, are viewed as better as or higher than others. Misrecognition is the belief of the supremacy of some cultural artifacts and positions over others, not according to an inherent value, rather the value associated with different social classes (Bourdieu, 1984). The social class in control validates their culture as "culture" while the culture of the lower classes is invalidated. The adherence to symbolic power is not explicitly taught but is rooted in unconscious perceptions that are shaped by inequitable structures (Bourdieu, 2000). Bourdieu called this doxa, the truth of misrecognition (Deer, 2012). Doxa is a truth in the sense that it is a common belief that is held to be true rather than an actual fact; it is the known, but unspoken. Doxa supports and reinforces misrecognition which supports the power structure by maintaining its "legitimacy" (Bourdieu, 2000; Deer, 2012, p. 116). Because it is an unexamined truth, doxa is ingrained in the everyday-ness of life, leading to the reproduction of social structures. For example, because West Virginia's population has a low baccalaureate attainment rate and many people in poverty, doxa of residents not valuing education and living in a "culture of poverty," blame West Virginians for these outcomes and hide the structures that perpetuate these situations. As this doxa circulates and is generally 
accepted, efforts by benevolence workers and politicians focus on fixing the people rather than the structures that actually cause these problems. Because these people are "helping to fix the problem," they are legitimated as good, while people misrecognize that it is the actions of the powerful that are actually causing the problems.

As doxa go unexamined, power can be asserted and maintained through misrecognition (Bourdieu \& Passeron, 1990) leading to symbolic violence (Bourdieu, 1984) where people from lower social classes who do not have "culture" may participate in supporting their own domination (Bourdieu, 2000; Schubert, 2012). Symbolic violence happens because to "succeed" in society it is necessary to learn and adopt the system of the powerful, or at least to learn to navigate it effectively. Broad opportunity is limited if the dominant culture is not at least adhered to, whether it is actually valued or not. When a person adopts the dominant culture as their own, though, this may be because they actually believe it is better, which would be symbolic violence; or it may be a form of cultural literacy for understanding what is necessary to move through society in specific ways (Schubert, 2012).

\section{Figured Identities and Agency}

I have already described the social in the individual (identity) and the dialogue involved in this process. Now I move to describing the individual in the social (agency), which, like identity construction, is always negotiated in dialogue. Agency is the enactment of the personal interpretation of the social, which shapes figured worlds. In this way identity is a mediator of agency where self-understandings inform how a person engages with the external. While people are "bounded" (Holland et al., 1998, p. 6) by their contexts, the continuous negotiation of 
identity opens opportunities for people to engage with these contexts in improvisational ways (Urrieta, 2007b), shaping "a place for his own activity" (Holland et al., 1998, p. 211) as they negotiates discourses in accordance with their identities.

As a person negotiates their place within figured worlds their actions are both specific and general; they are specific to the particular person, time, and place and general in terms of history and usual practice (Holland et al., 1998, p. 213). Agency, as "identity in practice" (Holland et al., p. 270), allows the space for contradictions without calling into question the validity of a person's identity. Behavior is treated not as a pure projection of the self, rather a piece of the self to be considered in context.

Agency is an in-process culmination of all that has happened in life. Through practice and increased facility identities become more integrated and complex; a person does not have to think about what to do, they just do it (like driving a car). There is a transition from having to walk mentally through a process to doing it "naturally" as a person becomes more confident in their own agency. When people see themselves as competent actors they come to more closely identify as part of that figured world. Success is satisfying and leads to the desire for further participation as a person's emotional attachment to a figured world increases. In contrast, a lack of success may impede participation.

Agentively navigating dominant discourses. While cultural discourses that fill figured worlds can be oppressive they are the known, so people still frame themselves according to these discourses. It is not that people necessarily agree with the discourses, rather the discourses are the only known frameworks from which to operate. When asked directly, people may agree with oppressive discourses even though their actions may not. These contradictory actions are the site of agency as people rearrange the heteroglossic discourses within their figured worlds. As people 
engage with oppressive metanarratives they develop ways to speak back. This is a form of agency, a way to change dominant discourses. As Holland et al. (1998) posit, "Human agency may be frail, especially among those with little power, but it happens daily and mundanely" (p. 5). Even if people have little power, conflicting actions or just speaking out against discourses show agency.

When personal experiences contrast with dominant discourses it is a place to see and understand the hierarchical nature of society. As people with little power see the mismatch between how they are described and their lived experiences there is space to imagine what they can do to change that. This space of authoring is a political process that Holland et al. (1998) conceptualize as similar to Vygotsky's ZPD. It is the space beyond what others have provided, where a person sorts out their identity and actions are scaffolded by interaction and context. The ZPD offers an opening to act where one may not have total experience but may know about acting on that experience, for example as in when students use capital in novel ways. This opens the space for agency, where new scenes are imagined and energy is put towards action.

Self-authoring draws on semiotic mediation of heteroglossic voices in order to construct the self. As discourses are internalized they are modified to be of the person and become what Bakhtin referred to as internally persuasive discourses where "external or authoritative speech has been married to one's own" (p. 182). Internally persuasive discourse helps to mediate the heteroglossia of the internal and external. In the process of self-authoring, a person draws from the social, makes it their own, and then reasserts themselves without the control of the original authorities. As people gain experience in a discourse or figured world, it allows them to resist other discourses because they have experienced their flaws. 
Drawing on Bakhtin's dialogism, the space where people "improvise" or act in ways that are different from what may be expected is the place of agency. This agency resists others' descriptions allowing for a reorganization of the social world. "[S]elf-direction—plays into both [the] domination by social relations of power and [the] possibilities for (partial) liberation from these forces" (Holland et al., 1998, p. 5). The space of authoring is a response to positionality and the figured context; it is the construction of self relative to the figured world and agency comes through this response. Agency moves the space of authoring from self to the cultural world.

FWT is useful in that it considers the social world a person is embedded within, which in my case makes room for cultural context and social class. It also allows the space for people to "improvise" beyond these boundaries as they interpret their social world to have personal meaning. It is within this space of interpretation that students negotiate their identities and enact these negotiations, shaping the social. Identity processes open the space for possibilities outside of dominant discourses where students exercise agency, placing them more firmly in control of their postsecondary outcomes. This agency offers a view of students as not "victims" of their circumstances or areas, which is where lower income and Appalachian students are often placed. Students and families want to be, and can be, partners in their postsecondary trajectories if they are given the space to do so. FWT makes room for individual agency and for people to move in ways not determined by their social class boundaries. In the next chapter, I detail the methods I will use to explore how students draw on their local classed and cultural contexts to support their identities as they move through the postsecondary transition. 


\section{Chapter 3: Methodology}

In this chapter, I outline why critical ethnography is an ideal methodology to study how social class informs the identities and agency of West Virginian teenagers. First, I explain my personal connection to this work, a step crucial in understanding my choices. Then, I describe the methods that I used to examine identity and agency in the postsecondary transition process.

\section{Recognizing Class, Race, and Gender in Rural Appalachia-Researcher Positionality}

As ethnographies are interpretive in nature, researcher positionality is crucial in understanding the work and analysis (Berger, 2001). Interpretation "rests on the peculiar practice of representing the social reality of others through the analysis of one's own experience in the world of these others" (Berger, 2001, p. 506). My background has heavily shaped my research interests and understanding this connection will strengthen, rather than limit, my dissertation (Ellis, 1999; Holt, 2003; Smith, 2005). Wall (2008) supports recognizing positionality, “...no individual voice speaks apart from a societal framework of co-constructed meaning. There is a direct and inextricable link between the personal and the cultural" (p.155).

Prior to this dissertation I completed an autoethnography in an attempt to understand my interest in my dissertation topic and my point of view. I utilized intensive journaling, an interview, intentional conversations, letters, and family pictures and videos to explore my family and community history. Critical event narrative analysis (Webster \& Mertova, 2007) was used to analyze the data; a method that examines the entire body of data to explicate relationships between experiences that creates a synthesis of the data. Through examining my experiences and context, I have (and continue to), explore the boundaries and opportunities these experiences have provided (Webster \& Mertova, 2007). 


\section{Social Class}

I am fascinated by social class and its power, particularly its unseen and misunderstood aspects. Understanding the complexities of social class is ongoing, because of its dialectical nature. These complexities surfaced in my autoethnography as I sought to understand my own social class background.

Prior to the autoethnography, I positioned myself as growing up in a middleclass household, maybe even upper middleclass. My father had one of the highest incomes in our 900person town. He worked for over 30 years in the most stable, best paying chemical plant in the area. Though my mom had completed four years of college for a teaching program, she had not graduated, so she had the experiences of college, but not the institutional and cultural capital that came with the degree. Economically and socially, we were similar to other families in our area who worked in the local plants and coal mines. Teachers were in the middleclass because of their education, but even families with two teachers, of which there were many, had lower incomes than some of those who worked in the plants and mines. Besides the teachers and school administrators, a professional group of people did not exist; there were two attorneys and one pharmacist in our town and one physician in the county.

Annette Laureau's (2003) description of middleclass childrearing practices, concerted cultivation, fits many of my formative experiences. I took piano and dance lessons when I was younger and joined the traveling cheerleading team. I attended overnight cheer camps and took gymnastics lessons and was involved in school activities that had me busy on weekends for my entire secondary career. I took a two-week trip to Europe with a group in high school. My dad was involved in coaching when he was not working and, as a stay-at-home parent, my mom was always involved with the school (PTA, boosters, etc.). 
I also experienced parenting that was much closer to Lareau's (2003) concept of "logic of natural growth," practices drawn upon by poor and working-class families, that allows children to develop more independently and forgoes many formal, organized activities. In our home there were no discussions or negotiations between children and adults; my brother and I did what our parents told us, period. Although my mother engaged in elaborative language practices, the authority of the parent was always present. Contrasting with the school year, summers were times for natural growth when my brother and I spent summers playing with the kids in our neighborhood. Our most important social group was our large, extended family who all lived within a 20-minute drive from us.

My understanding of middleclass was jarred when I attended a small, liberal arts college. Many of my peers came from families of professionals and had grown up in metropolitan areas. On many levels, I felt uncomfortable and different from my peers. Some of these feelings related to experiential differences, to perceived family income, and many related to appearance and values. I felt intimidated by these differences, like I might not quite measure up, that I was often on the verge of doing or saying something wrong.

Having studied social class differences, I now understand why my peers intimidated me; I sensed that they were from a higher class and I felt unprepared to competently participate. The behaviors of my peers were not what I had known growing up and I had not had access to the same settings that would warrant those behaviors. I distanced myself from my college peers and I believe it was my blue-collar, rural upbringing that caused me to see myself as different.

The majority of the values I learned growing up were much closer to working-class than middleclass values. My father did not view work as fulfilling, rather as a way to provide for the family and our needs. Family members were our most important social group, not friends or 
coworkers. To a degree, we were confined by our sense of place; we vacationed only in rural areas because Dad explicitly believed cities to be dangerous places. Though my placement in the social strata at home was solidly middleclass, much of my world was blue-collar. It is these experiences that have shaped my interest in social class and its contextual nature, particularly as I understand how power dynamics played out for me in college.

\section{Gender}

Home was, and continues to be a very patriarchal place, where gender roles were traditional and often non-negotiable, at our house and in the community. Chores were split into gendered categories; I did the dishes, my brother mowed the lawn and took out the trash. My father, who assigned the chores, explicitly stated that women did housework and men did manual work. The summer job I had was gendered; I worked as a cashier at the grocery store while my male peers were stock boys who received higher pay. There was no choice in where you worked in the store; you were placed by the manager-who happened to be male. Gender expectations were similarly narrow at the high school. Female athletes who were not overtly feminine were not highly regarded and were teased for not meeting acceptable feminine standards. Gender discrimination at home was not even considered. These things were not discrimination, just the way the world worked.

\section{Race and Racism}

I grew up in an all-White landscape. During my school career, there were two students of color who had been adopted from Ecuador by a White family. In many ways, subtle and overt, I recall racism being a part of the community and my family.

There were different views on race at home. There was a small group who would have been openly discriminatory towards people of color and a small group who would not have 
considered race in any way, ignoring the concept. But most people had strong opinions on race and how it worked. These people, including my family, were against openly discriminatory acts but also against programs aimed at dismantling structural discrimination (Rowe, Bennett, \& Atkinson, 1994). Their logic was that racism only existed in overtly racist acts and laws. Programs like Affirmative Action were seen as unfairly weighing the scales in favor of people of color. My immediate and extended family fit solidly within this category.

I moved away from home with racial understandings similar to those of my family. Through coursework in my master's program I began to see structural discrimination but I did not fully understand it. I started to feel the discomfort of knowing that race was not as simple as I had believed and that probably much of what I had known was wrong and hurtful. I gained a deeper understanding of race in my doctoral studies when I took a sociology of education course. Over the past 3 years of graduate school, through explicit study and new relationships with people from diverse backgrounds, I have learned, importantly, the ways that racism is not only individual, but systemic and structural. With this knowledge I am much more comfortable with the concepts of race and White privilege and my own responsibility to help work for justice.

Growing up White and middleclass in Appalachia, I cannot recall a time when I felt people were belittling or being racist against me. This privileged position has been made clear to me in the past few years through a variety of experiences. At academic conferences across the country, at my own university, and on vacations, people have alluded to stereotypes of West Virginians when I told them where I was from. These experiences pushed me into the role of the unprivileged. The rage I have felt at these comments is intense, particularly as a student listening to academics/faculty members make the remarks. I have felt powerless to respond because of the power dynamics, giving me a tiny glimpse into what being the non-dominant group is like. 


\section{Where this Places Me}

When I think about this accumulated self-knowledge, my interest in social class makes sense. I grew up middleclass in my community but the context was closer to a blue-collar, working-class lifestyle. I say this knowing the fluidity of social class and that my experiences and values fall on different places on this continuum. I also recognize that as my partner and I have graduate degrees and work as education professionals, we are clearly in the middleclass.

My experience with social class has given me first-hand knowledge of how indistinct, yet powerful it is. This has fostered my interest in understanding the impacts that social class and Appalachian identity have on students' postsecondary trajectories. As identities are negotiated, there is a need to understand how the dialogue between self and the external are framed, particularly within positions of different power. What impact does this have, particularly when a person's group identity is often framed in a negative light (Holland et al., 1998)?

\section{Ethnography}

The continuous, fluid nature of identity construction is not definable through questionnaires or direct observations. Rather, extensive inquiry is required to elucidate the processes at work (Carspecken, 1996). The in-depth, context-seeking nature of ethnography fits this task. Ethnography cannot pin down the identity of students and the specifics that "cause" decisions to be made. However, it can explicate the processes that influence the students at the particular times and spaces in which I work with them.

It is difficult to describe something that is never static; a snapshot of the moment is the best you can hope to capture. Ethnography offers an opportunity to capture that snapshot, opening the space to account for the changing nature of students' identities. This project will be a snapshot, a picture within a series, that works to describe how something functions within the 
context of larger systems (Hammersley \& Atkinson, 1995). To understand peoples' lives is to see how lives are intertwined with the social context (Tedlock, 2005). Ethnography can capture, to the greatest extent possible, the complexities of identity processes. This happens through examination of the construction of the context of peoples' lives, including relationships and societal structures that are inseparable from the physical environment (Chambers, 2000; McCarthy-Brown, 1991; Tedlock, 2005; Wolcott, 1975, 1997a, 1997b).

The ethnographic focus on social processes (Tedlock, 2005; Wolcott, 1997b) connects with the dialogic creation of identity (Holland et al., 1998). The ascription of meaning to interactions and events is as important as the actual interactions themselves (Wolcott, 1997b). Interpretation, not simply deep description, is the end goal of ethnography (Wolcott, 1997b). This fits with understanding how students' identities are constructed and how their agency shapes their postsecondary trajectories. Ethnography fits when trying to figure out "what-thingsmean-to-those involved" (Wolcott, 1997a, p. 166).

\section{Why Critical Ethnography?}

Identity is constructed within social relationships, implying a hierarchy, or "positionality" (Holland et al., 1998). Critical ethnography examines the positional nature of social relationships and how people negotiate the inequalities that are rooted in the economic system. Carspecken (1996) describes these as “... social inequalities... [the] nature of social structure, power, culture, and human agency" (p. 3). I want to explore these inequalities so that “...the subtleties of oppression... its invisibility to those affected by it might be removed; so that oppression might become challenged, and changed" (Carspecken, 1996, p. 7). 
Critical ethnography can challenge oppression through dialogue and action. From a critical standpoint, a relativist viewpoint is inadequate because it places the oppressors' view as valid, which negates the need for change. A critical standpoint examines truth and its construction to show the role of power and how the values of the power group are embedded in "truth" (Carspecken, 1996; Kvale \& Brinkmann, 2009). Critical work is oriented toward social work. It affects how a study is organized, what is looked at, and how findings are utilized and disseminated (Carspecken, 1996; Kvale \& Brinkmann, 2009). Critical work moves towards eliminating power disparities by understanding how they are constructed.

Critical ethnography supports my long-term goals of seeking change for the people and state of West Virginia. Part of the mission of doing applied ethnography is to create knowledge that people can use to make decisions (Chambers, 2000; Tedlock, 2005; Werner \& Schoepfle, 1987). I hope that this work can be used with others' to better understand how social class is negotiated in students' postsecondary trajectories. In collaboration, we can work to better understand students from lower class backgrounds and help them to achieve their goals.

\section{Emergent Nature of the Research}

As I explored in the literature review, until 2013, West Virginia schools officially geared students toward 4-year college degrees leaving other options out of the discussion (McDonough, 1997; Carr \& Kefalas, 2009). In addition, the academic guidance that does occur falls along socio-economic lines with privileged students receiving more and better-quality information about postsecondary opportunities (Lareau, 2003; McDonough, 1997). As middleclass school officials misunderstand working-class and poor students, differences in social knowledge are perceived as differences in values and desires (Willis, 1977). One outcome of these misunderstandings is the reproduction of social class hierarchies. If Appalachian high school 
students' identities and trajectories can be better understood through a critical lens, current practices for transitioning students to life after high school no longer seem reasonable. In fact, we may imagine new and different structures for supporting young adults as they leave secondary schools.

\section{Epistemology}

The research design for this study includes a series of nested cycles that draw on Carspecken's (1996) critical ethnographic methodology and a few other tools. I will examine how power functions in the lives of students by looking at how identity and agency influence their postsecondary trajectories. A major goal for this project is uncovering the power dynamics between students, families, schools, the community and larger contexts that disempower local students and families.

I situate the work within a neo-Marxist ideology in an attempt connect the base (economy) and superstructure (culture) that inform student's identities and agency (Carspecken, 1996). The assumed freedom of a person to choose any job leads to the obfuscation of the structures that distribute economic power in America. The American Dream teaches all people to attribute their social positions to their own actions, so that personal choices and work ethic are the only valid reasons for success or failure. In America the dialogue for how social structures prevent mobility is heavily suppressed.

Given these understandings, the major research question for this study is: What are the implications of habitus and identity in the postsecondary transition? I will focus on two attendant questions: (1) How does habitus inform identity? and (2) How is identity implicated in the postsecondary transition? 
The knowledge that builds identity is not read in a book or learned at school. It is personal knowledge, gained through experience and interactions. Personal, experiential knowledge would be hard to gather through quantitative research, particularly with the understanding of knowledge as constructed; rather, it is through consensus that knowledge and truth claims are validated (Bourdieu, 1984, 2000; Holland et al., 1998; Kvale \& Brinkmann, 2009).

Power corrupts truth and knowledge and places the experiences and views of the less powerful as invalid. Critical work moves towards understanding the knowledge of the less powerful, its construction, and how that knowledge impacts their lives (Wall, 2006). This pulls from postmodernism, but rejects absolute relativism as an adequate standpoint. A stance on the failure of the structure to serve all parties must be taken if power structures are to be changed.

A focus on communication and the "exchange of understandings" (Carspecken, 1996, p. 19) will show how misunderstandings, or refusals to understand, support unequal power divisions. Interactions are influenced by positionality (race, gender, class, etc.) and when positionality is not examined it "silenc[es]...those who lack privilege and power" (Holland et al., 1998, p. 25). Just as understandings are influenced by positionality, so are discourses and language as standards are set by dominant groups and applied in universal ways. Listeners favor the powerful, though the less powerful do speak back. This back talk provides resistance and a view of what discourses and policies mean to the less powerful. This is co-development (Holland et al., 1998), interactions that build truth and knowledge particular to certain groups. Rather than upholding a universal truth as applicable to all, participation and co-development construct figured worlds and the meaning of external circumstances as they intersect with internal discourses (Holland et al., 1998). 
As a tool, critical ethnography searches for the best evidence to substantiate truth claims and by exploring this information, participants' identities and agency can be seen. Participants' descriptions of their internal states and their related "performances" are the data that show the construction of meaning and identity (Emerson, Fretz, \& Shaw, 1995) as people construct meaning to understand the way the world functions (Carspecken, 1996). These experiences can be understood by asking others about their processes and observing their actions (Hammersley \& Atkinson, 1995; McCarthy Brown, 1991; Wolcott, 1997a). It may be difficult to agree upon how truths come to exist and the makeup of their nature; however, this does not negate their existence or importance in the process of identity construction and agency (Carspecken, 1996).

In everyday life, people do not systematically investigate how they form meaning and act in purposeful ways. However, by using this methodology I hope to reconstruct the meaning of participants to understand their actions. The most important aspect of the critical epistemological standpoint is that it focuses on and privileges the views of participants (Carspecken, 1996;

Emerson et al., 1995; Wall, 2006). Although I may come to understand the structures of the participants' understanding, I will never entirely experience the world as the participants do. My understanding will come through seeing the relationships between things rather than understanding the things themselves.

\section{Study Design and Methods}

Power in the lives of the participants is an integral aspect of this project and I explore the context and process of students' lives to make the existing power structures clear. I collected data on typical events in students' lives, how and where these events occurred, the settings of these events, and how students understood these events. Carspecken (1996) describes these focus areas 
as: "social action, subjective experience, and their conditions" (p. 29). Through this process, the participants and I examined how their context contributed to their identities and postsecondary trajectories.

I used pragmatic horizon analysis (Carspecken, 1996, p. 40) to learn about events, their social construction, and what these meant to participants. The primary record was created through observation and recording as I moved between casual observer and full participant, depending on the situation. Dialogical data generation helped to "democratize...the research process" as I used conversations, interviews, and discussion groups to get participants' feedback on the data (Carspecken, 1996, p. 42; see also Kvale \& Brinkmann, 2009). Data analysis was ongoing throughout the project; however, the final data analysis looking for connections between people, events, and contexts and to explicate social structures was completed after all data was collected. Although I explain the study design in discrete stages, the process was iterative and much more fluid than can be represented in writing (Carspecken, 1996; Emerson et al., 1995; Kvale \& Brinkmann, 2009).

\section{Study Context}

In order to capture the diversity of experiences that occur in the Appalachian region and in West Virginia in particular, I studied two very different schools and communities. Multi-site studies highlight the impacts of systems structures and how this varies according to local contexts (Marcus, 1995). The two sites were purposefully sampled as information-rich sites that showed clear social distinctions (Patton, 2002). Drawing from these locales, I show the diversity of students' experiences and how students' identities are linked to their lived contexts. 
Site 1, Mill County, is inclusive of an entire county because of the small population size. There is one county high school that draws from two small communities, Millsdale and Settlement, and many rural outlying areas. Mill County is a largely White, working-class area that used to have many high paying industrial and extractive jobs, but now has only a few. The baccalaureate attainment rate for the county is half that of the state (See Table 2) and education and healthcare offer the only dependable jobs for those with baccalaureate degrees. Due to deindustrialization, Mill County has seen dramatic decreases in the local population and is identified as an "at-risk" county by the Appalachian Regional Commission (2013). At-risk is defined as "...those at risk of becoming economically distressed. They rank between the worst 10 percent and 25 percent of the nation's counties...[regarding] three-year average unemployment rate, per capita market income, and poverty rate" (Appalachian Regional Commission, 2013).

Mill County was a major player in the oil and gas industry at the turn of the $20^{\text {th }}$ century and, due to new fracking technology, there is a recent uptick in this work. Support for fracking is strong as residents are welcoming of the influx of money, but support is not ubiquitous. There is buzz about "shell-ionaires," people who have become millionaires due to fracking, and land leases that provide enough income that people no longer have to work.

Mill County has one county high school, Mill County High School (MCHS), which has a reputation in the area for being the most academically rigorous local high school. Despite having many low income students, Mill County consistently scores high on the state standardized tests and has a low dropout rate (See Table 3). MCHS had a student population of 410 during the 2012-2013 school year and half of all students were identified as low income (See Table 3). On the state standardized test, the WestTest, Mill County students scored above the state average on 
all areas except science and have a higher graduation rate than the state average. The percent of highly qualified teachers is slightly above the state average, with six AP courses available for students. MCHS offers the basics in opportunities for sports participation with 11 sports and has 11 clubs listed on the school website (See Table 3). Access to the school system at MCHS was facilitated by personal connections to school administrators and educators.

Site 2, Covington, is known as an affluent community throughout the state. The town of Covington has only 1,000 fewer residents than all of Mill County. Covington is nearly all White and their child poverty rate is a fraction of the state's (See Table 2). Covington's residents also have a different educational profile from Mill County with high school and postsecondary degrees being much higher than the state and even national average. Covington houses a new hospital with multiple positions for specialists. There are many successful local businesses and multiple regional headquarters for oil and gas (fracking) companies located in Covington. Covington is also less than an hour away from a major university, multiple hospitals, and many businesses that provide high-paying salaries.

Covington High (CHS) had 748 students for the 2012-2013 school year (see Table 3) and is one of six high schools in the county. Covington High's student population is significantly less economically disadvantaged when compared to the state average and Mill County. Students at Covington are taught almost entirely by highly qualified teachers, score above the state average on all standardized tests, and have a graduation rate higher than the state average. Covington consistently ranks amongst the highest scoring schools on the state standardized tests. Covington offers 8 AP courses, 12 sports teams, and 17 clubs and activities, as listed on the school website (See Table 3). The introduction to Covington was facilitated by a personal contact who works in the school system and agreed to introduce me to the administration. 
Table 2

Community characteristics taken from the 2010 U.S. Census.

\begin{tabular}{llll}
\hline & State & Mill County* & Covington \\
\cline { 2 - 4 } Total residents & $1.85 \mathrm{M}$ & 9,211 & 8,126 \\
Persons per square mile & 24,038 & 256 & 775 \\
Children in poverty & $23.7 \%$ & $26.2 \%$ & $.7 \%$ \\
People in poverty & $17.5 \%$ & $18.7 \%$ & $3.6 \%$ \\
White & $93.9 \%$ & $98.7 \%$ & $95.5 \%$ \\
Black & $3.5 \%$ & $.3 \%$ & $1.1 \%$ \\
Hispanic & $1.3 \%$ & $.6 \%$ & $1.7 \%$ \\
Asian & $.7 \%$ & $.1 \%$ & $1.9 \%$ \\
Native born & $98.7 \%$ & $99.6 \%$ & $98.4 \%$ \\
Residents with HS or GED & $82 \%$ & $83.8 \%$ & $94.9 \%$ \\
Bachelors or higher & $17.6 \%$ & $8.8 \%$ & $39.5 \%$ \\
Unemployment rate & $7.5 \%$ & $11 \%$ & $3.6 \%$ \\
Not in labor force & $45.1 \%$ & $50.9 \%$ & $39.4 \%$ \\
Travel time to work & 25.5 & 28.4 & 22.5 \\
(minutes) & & & \\
Median income & 39,550 & 36,563 & 72,721 \\
Mean income & 52,980 & 46,060 & 85,399 \\
$*$ Note: Only county-level data & is provided. &
\end{tabular}

Table 3

School activity, demographic, and other education information.

High schools in

$\begin{array}{lll}\text { State } & \text { Mill County } & 6 \\ & 1 & \\ 0 & 1\end{array}$

School enrollment

410

748

NCES designation

Rural Fringe. Census-defined

Town Distant. Territory inside an rural territory that is less than or equal to 5 miles from an urban cluster that is more than 10 urbanized area, as well as rural miles and less than or equal to 35 territory that is less than or equal to 2.5 miles from an urban miles from an urbanized area.

Covington

\section{6}

1

County

County technical cluster.

Low income students $52.4 \% \quad 52.93 \%$

$17.51 \%$

Students in special $15.69 \% \quad 14.9 \%$

$8.4 \%$

education

Courses taught by

$91.5 \% \quad 95.8 \%$

$97.4 \%$

highly qualified

teachers

AP courses

Calculus; Statistics; Studio Art; Biology; Chemistry; U.S. History
Calculus 1, 2; English Language; English Literature; Chemistry; Physics; U.S. History; Psychology 


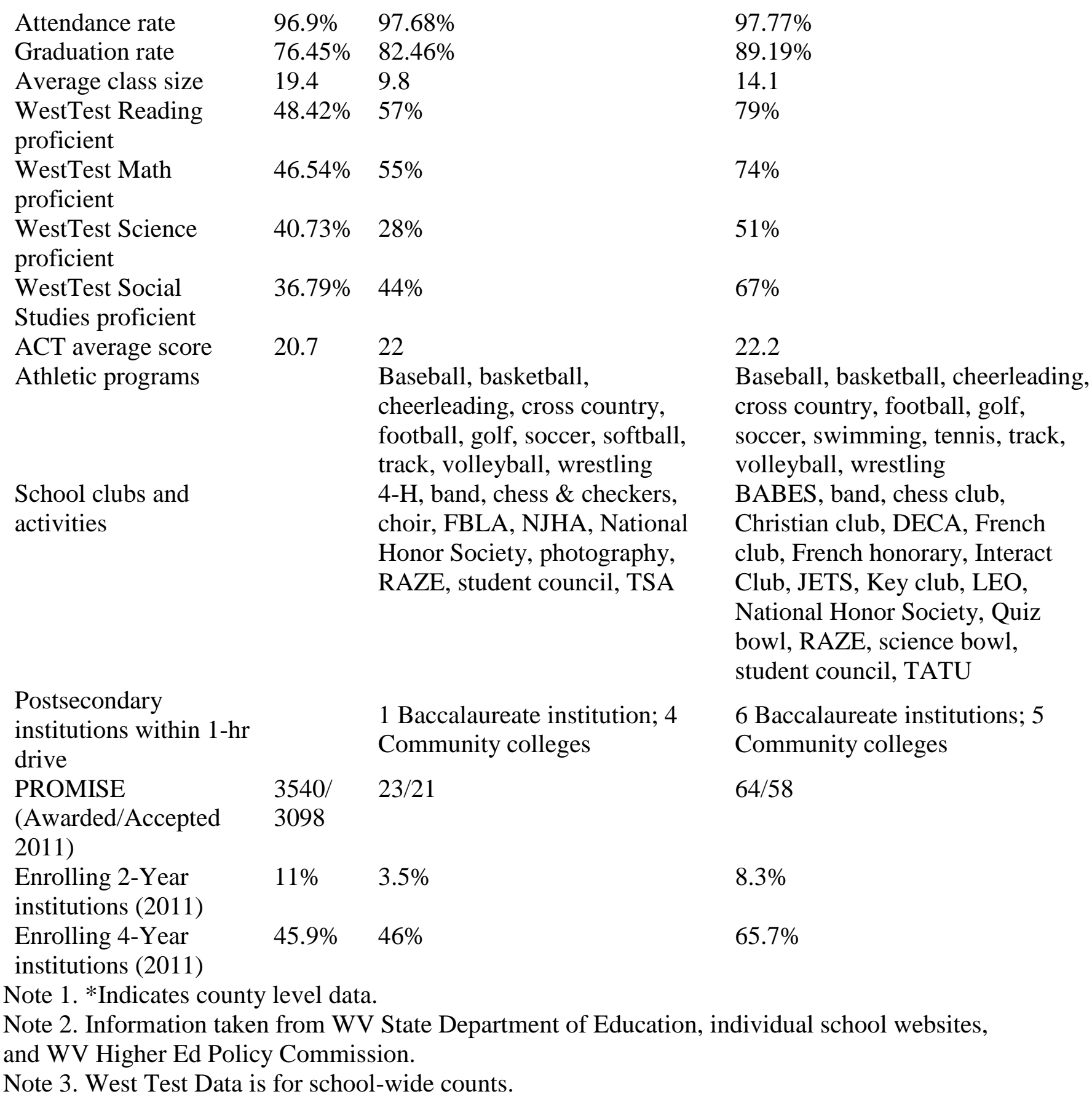

Places and events. To understand the meaning that students assigned to their experiences I needed to understand the contexts from which they spoke (Carspecken, 1996; Emerson et al., 1995; Holland et al., 1998; Kvale \& Brinkmann, 2009). I initially engaged with students through the school during the Spring (2014) of their senior year and followed them across the summer 
and into the following fall. While I had an idea of the sites I would visit, I did not make rigid plans so as to be able to attend to what was most important once I was in the field and to allow for the flexibility in how students' lives progressed (Carspecken, 1996).

While I had initially intended to visit a broader range of sites with students (i.e. religious services, afterschool or extracurricular activities, family gatherings, etc.) time, weather, students' preferences and financial limitations prevented this broad of data collection. In particular, the weather limited my access to school functions. Many events I had planned to attend were cancelled on their original dates and rescheduled during times when I was unable to attend. I visited the homes of four students to complete parent interviews and of the two students who worked, I visited one at their workplace. I attended extracurricular activities for all of the students who participated in these including athletic events, fundraising events, and a school play. I visited four students at their college campuses for follow up interviews. I also met four students at various times for coffee, lunch, to visit, to help with school work and scholarships, and to complete interviews.

I completed observations in every class (four) for each the CHS students and at MCHS I observed seven of eight classes for each of the students. I attended various school activities including the senior awards ceremony, baccalaureate, and graduation for both schools. At MCHS I attended the school play, Future Farmers of America (FFA) spirit week competition, senior project presentations, a motivational speaker assembly sponsored by a local church, and the teacher picnic. At CHS I attended a Prom Promise assembly, a senior breakfast, the senior banquet, faculty senate meeting, and teacher picnic. As I attended these different events I paid particular attention to how the settings were governed by assumptions of acceptable behavior; the "tacit understanding shared by actors that makes their interactions possible" (Carspecken, 
1996, p. 35).

I also attended to the related sites in communities that formed the mini-social systems of students' lives (Carspecken, 1996). I visited churches, stores, restaurants, and various neighborhoods around Covington and Mill County to learn about lifestyle, available opportunities, and community problems. This helped me to see the cultures of these places and I also considered these within the events at state and national levels as they impacted day-to-day lives. To aid with this, I followed the local media and newspapers of each area as well as the school websites. In Covington I collected the Covington Weekly, the weekly town newspaper, which was available as a PDF download. I also followed Connect Covington-a local media agency, the Covington News, and the Covington Farmer's market. Mill County had much less internet access to community information, particularly with independent websites so I followed Facebook sites of community organizations for information. On Facebook I followed the county newspaper, school soccer club, local farmer's market, the board of education, MCHS high school pages, the 4-H and farm community association, the senior citizens group, Mill County extension service, and the Mill County courthouse and jail.

\section{Participants}

I utilized convenience sampling (Patton, 2002) to choose three students from each school with the help of the school guidance counselors. I explained my study to the counselors and they indicated students they felt represented working-poor/poor, working-class, and middle or upper middleclass homes within their communities. At CHS I had one working-class student, one student who had a blue-collar background with a middleclass income, and one middleclass student. At MCHS I had one working-poor student, one blue-collar student with a middleclass income, and one upper-class student. 
At the outset of the study it was not my intent to have all of my students on the college track, however as counselors shared about potential students, every one they included was on the college track. When I explained that I did not need all students who were on the college track that I preferred more diversity, the CHS counselor was able to think of one student who was asked but chose not to participate. At MCHS one student had been indicated to me by a teacher who would fit the working-class profile and technical track, however he declined to participate because he was moving after graduation to work in the oil fields and would not be able to complete the summer portions of the study. Outside of this student, the MCHS counselor was not able to think of anyone outside of the college track. These experiences were indicative of the college focus of both schools and how unfamiliar counselors were with students who were not planning on attending college.

I also include the experiences of students from racially diverse backgrounds, two students, one at each school, who were Asian American. The population of the state and the participating communities are largely White, but to exclude the stories of diverse students is to exclude an important part of the story, one that has been largely ignored in Appalachia (Anglin, 2004). The intersection of social class (Bourdieu, 1984; Bourdieu \& Passeron, 1990) and race (Anglin, 2004) is incredibly important and including these voices helps to show this story.

With a group of students this size, generalization about the representative populations would be a mistake and so that is not the goal of this study. I worked to find the everyday life events that represent participants' specific stories (Carspecken, 1996) to co-create rich data rather than to survey many participants and only gather superficial data (Kvale \& Brinkmann, 2009). My aim with this work is to give a human story to the numbers that are so numbing to 
read that they become easily ignored.

\section{Data Collection}

To capture the complexity of lived worlds, I used multiple tools to build the data.

Ethnographic methods provide the breadth to create the portraits of students' lives that I hope are adequately represented through this project. I utilized participant-observation, semi-structured life world interviews, participant photography, and focus groups for data collection as well as media sources. Although the methods section is written linearly the data collection was not linear (Emerson et al., 1995); this is not a limitation, rather a reflection of the beautiful complexity of life and humans.

The project progressed through three phases over the course of one year (See Table 4). In Phase 1 I followed students as they completed the final semester of their senior year and were finalizing postsecondary plans. Phase 2 extended through the summer as students moved into the next phase of their lives. Phase 3 followed students through the remainder of the year to see how their planned postsecondary trajectories panned out. This allowed me to see not only what students planned for but also how those plans transpired.

In Phase 1 I was introduced to the students and completed all of my in school observations, this lasted through May 2014. My observational schedule for both schools was impacted by inclement weather school closings. CHS had 40 days of instruction for seniors during the Spring semester and I visited for 11 of those days; 20 instructional days were missed due to weather. While MCHS did not have specific information available for how many instructional days were missed due to weather, their school schedule was similar to that of CHS. I visited for 17 days at MCHS. 
I met with guidance counselors at both schools in January, however, because of weather cancellations, did not actually meet students and begin observations until February. Depending on what I was observing, I typically visited schools for a half-day, though did sometimes visit for a full-day. CHS was on block scheduling so the students only had four classes per day, making it much easier to observe at least once in all of the students' classes. MCHS was on a 45-minute class schedule and had 8 periods, including lunch, across the day. Initially I had planned on being at both schools once per week during the semester, but due to weather and other obligations I eventually switched to alternating weeks for each school, so that every other week I was in each school.

Phase 2 included the summer months, from June through August, when I completed parent interviews and focus groups (See Table 4). These interviews are discussed more fully below. Phase 3 closed out the study in the fall, from September through December, as I remained in contact with participants via phone, text, and Facebook. I also completed students' follow up interviews during this time (See Table 4). I visited Selene, Gregg, and Robbie at their college campuses to complete their interviews. To complete the other interviews, I visited Hedy at a local diner in Mill County, spoke with Camilla over the phone while she was in Oklahoma at college, and used Facebook Messenger to finish Fantasia's final interview. 
Table 4

Data collection activity.

\begin{tabular}{llll} 
& Activity & MCHS & CHS \\
\cline { 2 - 4 } Phase 1 & Observations & & \\
& School & 17 days & 11 days \\
Community & 15 days & 10 days \\
& Interviews & & \\
Student & 3 & 3 \\
Parent & 1 & 0 \\
Focus groups & 3 & 0 \\
Other & & Scheduled
\end{tabular}

Other

Scheduled courses with Fantasia at college

Assisted Gregg with scholarship search

Phase 2 Observations

Community 1

Interviews

$\begin{array}{cll}\text { Parent } & 1 & 1 \\ \text { Focus groups } & 0 & 2\end{array}$

Other

4

1

Assisted Fantasia with student loans

Phase 3 Observations

Community $2 \quad 1$

Interviews

Student 3

Parent 11

Participant observation. Participant observation was my main data gathering tool and my level of participation depended upon the setting and invitation of those in the setting (Emerson et al., 1995). This ranged from sitting in the back of a classroom as only an observer to full participation in activities. When I was able to fully participate, I was immersed in the world of the participants, which helped to give a closer view of what the students experienced. My shared experience of events allowed me to see the functioning of day-to-day life (Carspecken, 1996; Emerson et al., 1995).

My participation varied between the schools and a major reason for this was how I needed to navigate interactions in order to maintain students' confidentiality. Because CHS was a larger school, almost twice the size of MCHS, I was much less obvious walking through 
hallways and in classes. The participants at CHS were comfortable talking to me at school and would chat with me in their classes and around the school. At MCHS I was clearly a new person and people were curious in asking what I was doing and who I was. With this interest in me as a new person, I was careful to not engage with my participants any differently than I did with other students at the school so as not to indicate them as participants; I rarely, if ever, spoke with my participants when I was at school or other public events. This is also part of why I spent more days observing at MCHS, the decreased personal interaction gave me less insight into students' personalities and school lives so it took more work to see their school and personal identities.

As a participant-observer I was a part of the setting, so in notes and reflections I recorded my own actions, thoughts, and responses to the setting. This involvement was not problematic because while participants' initial behaviors varied slightly from the norm, mostly in introducing me to the class and learning about what I was doing, the assumptions behind their behaviors remained unchanged (Carspecken, 1996; Emerson et al., 1995). I was cognizant of how my presence might change the classroom dynamics, however I was surprised by how little impact my presence seemed to have. Also, the extended time that I spent in the field allowed me to see people and situations multiple times which lessened the impact I had on the setting (Carspecken, 1996).

At both schools the teachers seemed accustomed to having people in their classrooms and observing. When I first visited classrooms I explained to teachers that I was doing a dissertation on how seniors made the transition to work or school after college and that I was doing classroom observations to learn more about this process. Some teachers would ask more about my work, being interested in what I was doing, where I was going to school, etc. Others would show me an out of the way seat and move on with class. Most teachers did take some time to talk 
to me when there was downtime or students were doing independent work. They would share about what they thought students were like and what they were working on at the moment. The level of engagement depended on the school as teachers at MCHS were much more likely to engage with me (I discuss this difference later in the data chapters).

Sometimes teachers would introduce me to the class and other times they did not. Like the teachers, students' responses to my presence in the classroom ranged from no engagement at all to talking to me and inviting me to look at the projects they were working on. Sometimes students asked about what I was doing and I would share with them the introduction I gave to teachers. Again, this level of engagement depended upon the school, class, and class activity during the day. There was much more downtime at MCHS and I eventually became a familiar enough figure around the school that a broad range of students talked to me; this did not happen at CHS as there was almost zero downtime in any of the classes.

In my original plans I had intended to spend time with students outside of school, participating in activities with them but this rarely happened, I think for a few reasons. At MCHS students were wary to be identified with being participants in my project, so to visit with them publicly was not something I felt comfortable asking them to do. Interestingly, this seemed to change after the students graduated as I had lunch with Hedy and Robbie for their follow up interviews, and Camilla offered to meet me for lunch at a local restaurant, but our schedules did not match up so we did her follow up interview over the phone.

All of the students seemed fairly stressed out during the spring of their senior year preparing for the postsecondary transition in doing ACT/SAT testing, visiting schools, and in navigating the financial aid system. Also, all of the students at MCHS were involved in school 
activities so had many banquets, after school events, and sporting events that kept their schedules very full. While the students at CHS were not involved in school-based activities, they were still very busy with their own lives.

While I had hoped to develop more casual and friend-like relationships with the students, our age difference, I was 33 at the time and they were 17-18, created a large distance between us. Other than Gregg and sometimes Fantasia, participants saw me more as a teacher/researcher figure. Additionally, all of the students viewed the time of the study as the final times they were spending with their high school friends and families before they left for college, so were not much interested in spending spare time with me.

Though my overall relationships with the students were different than I had expected, my relationships with the students at CHS were different than with the MCHS students. While I did not particularly become friends with the students at CHS, they were much more comfortable engaging with me in conversation and interactions than the students at MCHS. The CHS students seemed more sophisticated in engaging with adults as equals. As part of the project I talked with students about their friends, who they were, etc. and all of the students at CHS had friends who were older than them. Selene's best friend and brother were both already in college and she visited them at college and would sometimes spend weekends with them. Fantasia always dated older men so was often around people who were older than her as she spent time with her partners and their friends. Gregg was best friends with his brother in law who was 4-years older than him and he also spent time with his cousins and neighbors who were both older and younger than him. In contrast, the students at MCHS were largely friends with their peers at school who 
were in their same class or only a year or two younger. The students at MCHS did not have a young adult group that they spent time with; most of the adults in their lives were more like parent or teacher figures.

Fieldnotes. Understanding the meanings participants made of their lives is at the core of this project and I used fieldnotes as a tool to record how meanings operated in participants' lives. Emerson et al. (1995) use the term textualization to describe how fieldnotes function within ethnography, where details build the contexts that frame participants' actions. In cases where aspects of participants narratives and experiences were contradictory, texutalization provided a bridge of understanding, showing the relationship between the contradictory events. Where there were no contradictions, textualization provided an in depth view of participants' contexts and lives.

As I experienced limitations on where and how I could spend time in the field, especially the schools, I began immediately with thick observation of my visitations (Carspecken, 1996). These thick observations included essentially everything that I was observing or participating in. I recorded the participants in the venue, individually when possible, by group description when necessary. I also recorded the gender and race makeup of classrooms as well as descriptions of what people were wearing. Clothes are used by adolescents as a way to express their identity and are also related to economic access so this was something that was interesting for the project. I continued to record what students and teachers were wearing until patterns of clothing styles became clear for each school. The typical functioning of classrooms and students' lives, as well as exciting and unusual events were recorded to show how participants functioned on a daily basis. These details showed how the participants constructed meaning and how those meanings 
varied.

I sketched every classroom I was in as well as the settings at community events. When I was in public spaces I took pictures of the events, spaces, and participants to create a visual aspect to support my written field notes. Pictures of the schools, inside and outside, also added a visual component to my setting descriptions and were telling of the values of the schools. Typically, I included general notes on the conversations and topics, as well as quotes that I found interesting or seemed relevant to my study based on my theoretical background and literature review. While I worked to define the settings and participants as accurately as possible, I maintained a cognizance that the overall goal of field notes is not accurate description, rather a body of work that can be used to find the meaning in accounts and observations (Carspecken, 1996; Emerson et al., 1995). I took fieldnotes through a variety of methods, depending on my level of participation and the setting. At times I took notes actively during classes. When my role was more participatory, I memorized contexts and conversations that I either immediately voice recorded or wrote down after leaving the field. I eventually transcribed all of my voice notes to be included as part of the primary record.

I continued to take fieldnotes throughout the study, using thick description for the duration, and eventually transcribed the entirety of my handwritten and voice recorded notes. While the full transcription was tedious and made data analysis a monumental task, the depth of the data provided was invaluable. This quantity of data and the nuanced descriptions I recorded helped me to not have to make value judgments about the events. The descriptions show, rather than name, the attributes of the people, interactions, and settings (Emerson et al, 1995). Moreover, the depth of the description allowed me to see connections across people, classes, and contexts that I may have otherwise missed. 
Commentary and memos. I maintained an ongoing commentary as an aside to my fieldnotes to record ideas and musings (Emerson et al., 1995). Usually I included this within my notebook as I recorded the most recent events but also occasionally typed these or used voice recordings to keep these thoughts. The commentary helped me to connect observations and experiences as I progressed through the study and was especially helpful to make connections across and highlight differences between the two sites.

While transcribing all of my notes was time consuming, the results of this process was very important. As I transcribed my notes I transferred my commentaries into comments (using Microsoft Word) so that I could see how my commentary was developing and this was also preliminary analysis as it attuned me to what I should investigate further. Rather than creating a separate section of memos, these commentaries morphed into a memoing section where I made plans for how to continue with the project (Emerson et al, 1995). As I began more directed analysis later in the project these commentaries were a crucial base for analysis.

Researcher journal. I kept a researcher journal to record my experiences through this process and this often ended up being about methodological reflections-how things were going compared to how I had expected them to go. Initially I had intended for the research journal to be a place more like what the commentary became. However, as I have mentioned in part, the process of this research project was incredibly more difficult than I had anticipated. As I progressed through the project I needed a place to process these difficulties and all that was happening and this ended up going into the researcher journal.

Interviews. The initial student interviews where we discussed home and school life were all completed during the spring of students' senior year (See Appendix 1). All of these interviews 
lasted between 50-90 minutes and were done in person and voice recorded, then transcribed verbatim. In Mill County we did all interviews in a private room at my family's home where we had access to a couch and chairs. In Covington, two interviews were completed at the public library and the other in a private room at the school. While the interview was semi-structured, I framed it as a conversation with the participants and this ended up working well. Students were very comfortable with the conversational format and it helped to build rapport as the initial interview was the first time I had one-on-one time with most of the students. My background knowledge of both communities, online research, and newspaper subscriptions were helpful in navigating the conversations with students as I had some shared knowledge of their settings (Kvale \& Brinkmann, 2009).

The follow up interviews were more informal and more varied in format and we covered what students were currently doing, how or if their plans had changed, and a look back on the postsecondary transition (See Appendix 3); these happened in November and December of 2014. I did not voice record these interviews, rather wrote notes down afterwards. Since I had been working with the participants for almost a year we had a more developed relationship so there was an established rapport. This interview was also meant to be a partial member check, however I was not far enough along in data analysis that I had developed any sort of meta-data from their stories. However, I had been informally member checking for the duration of the study; if there were things I had questions about I was able to check with students about what I was seeing and hear their feedback. These member-check conversations with the students happened at school (in Covington), over text messages, by phone, and Facebook Messenger. Despite this member checking during the study, I hope to eventually present students with their "stories," now that those have been more fully developed, and to hear their feedback. 
Originally, I had intended to visit all students at their college campuses to get a feel for how they were fitting in and I was able to do this for three students. I met Selene for our follow up interview for coffee and visited for an hour at the coffee shop near her college. Robbie had me come to campus where he was now a Resident Assistant (RA) and he gave me a small tour around campus and then we visited and finished our interview in the student center. I offered to buy him lunch but he preferred just to visit on campus. Gregg's visit was the most extended and he was the most involved in the project throughout the course of the study. I made the 3-hour trip to his college and spent almost an entire day with Gregg. He took me on a tour all around campus and gave me extended tours of the student rec center, football stadium, and locker rooms. We drove all over town where he showed me his favorite restaurants so that we could pick where we would have dinner later. Then he drove me to favorite fishing spot where he spent much of his down time. We visited his grandma's office on campus and I spent some time chatting with her and Gregg about the work he had left to finish during this last week of the semester. Then I treated Gregg to dinner at one of the restaurants he had heard about but had not had a chance to visit yet and we chatted and covered all of the follow up questions without me really asking any directly. Finally, Gregg showed me back to his grandma's house where I spent some more time chatting with Gregg and his grandmother.

Hedy was incredibly busy during the week at college so needed to do her follow up interview on a weekend. As she "hated the city" where she attended school she went home every weekend, so I visited Mill County to complete her follow up interview. We met at a local diner for a little over an hour and carried on the interview like a conversation. Interestingly, Hedy did not mind meeting out with me in public now as it seemed there was not the same sort of attention 
paid to her activities since she was out of high school. Camilla was attending college in Oklahoma and we had tried to meet over holiday break but were unable to, so we finished her follow up interview over the phone and it lasted about 30-minutes. Fantasia was very difficult to get to commit to doing something at any established time. We initially planned on meeting at a coffee shop to do her follow up interview and she cancelled this two times, then we decided to do the interview by phone to make it easier and after many attempts she still would not commit to a phone call. However, Fantasia and I often talked on Facebook Messenger so we ended up doing her follow up interview on Facebook Messenger, which worked out beautifully. Her follow up interview was more like an interview as I typed her the questions and she answered back when she had time. We ended up completing everything in three days.

As I mentioned data collection was not linear, rather I moved back and forth between methods through the process, what Kvale and Brinkmann (2009) describe as a spiral of inquiry; an iterative and generative process (Carspecken, 1996). Through the interviews I built meaning of participants' lived worlds in conjunction with them (Kvale \& Brinkmann, 2009). Kvale and Brinkmann (2009) describe this as ..."an alternation between the knowers and the known, between the constructors of knowledge and the knowledge constructed" (p. 2).

Parent interviews were conducted across the duration of the study to learn more about how the parents and schools facilitated the transition process (See Appendix 2). Similar to the students' interviews, these were semi-structured interviews that I framed as conversations and made sure that we covered all points before we ended our conversations. These interviews lasted between 45 minutes to 5 hours, while most were around 90 minutes. One important thing to note is that after the first two interviews, I stopped asking the question about social class (Question: Tell me about the different groups of people around where you live.). When I asked this question 
people became somewhat defensive claiming they did not see groups. This is consistent with the moral implications of class in the U.S. and that it is something people do not want to admit exists. However, classed issues did come out in almost all of the parent interviews as it is a construct very present in people's lives, despite the desire to not address it directly.

Accessing parents was more difficult than I had expected. It was not the access per se, rather getting parents to commit to an interview. It would have been helpful to have some form of remuneration for parents to compensate them for their time. All of the participants' parents were married and straight and I had the most interaction with mothers. This aligns with the gendered separation consistent with patriarchal norms of West Virginia. Typically students directed me that I should talk to their moms to set things up, or if I did call and a father answered he would pass me on to his wife to set things up, as the mothers seemed to be the people who ran the household schedules.

Three sets of parents were quite easy to arrange interviews with, we set up a time and I visited their homes and we completed the interviews. One family was very difficult to get to show up for the interview. For this family, I made the 2-hour drive three separate times to meet for their interview because the first two times the family failed to show up for our meeting. The third time I arrived at our meeting spot and the family again did not show up, so I called and the mother did come for the interview but the father was working. Once we were at the interview things went well, despite my trepidation, and this mother shared that she had been irritated that her daughter was participating in the study. Her daughter tended to take on too many things and Mary, her mother, had not agreed to sign her permission form to participate in the study so her daughter went to her father and he signed the form. Mary shared that she was not irritated with me personally; rather, she was concerned for her daughter taking on too much. When we 
discussed this and I let her know that I understood her concern and was not aware of those things when I asked her daughter to participate, Mary warmed up and we ended up having a very productive conversation. Two of the families in Covington were difficult hard to establish interview times with, as both families were very busy and meeting with me was not high on their priority list. I was eventually able to complete all of these interviews, visiting two families at their homes and completing the other interview on the phone with the student's mother.

Focus groups. I completed three focus groups with the students at MCHS and two with the students at CHS. I had originally intended on completing all three focus groups across the year of the study, however one of the students in Mill County served as a camp counselor and left immediately after graduation for this job. In order to facilitate all of the focus groups, we scheduled all of the MCHS focus groups during the spring semester and the CHS students actually preferred to complete their focus groups during the summer. However, once summer came, between work and travel schedules, and participants wanting to spend time with friends before college, scheduling the focus groups was very difficult. We ended up condensing the three focus groups into two for the CHS participants, which worked out well and still allowed us to cover all of the content. In the first CHS focus group we focused on Appalachian identity and how it is constructed by the media (Groenke \& Nespor, 2010) and how these identity claims have influenced students (Holland et al., 1998; Howley \& Howley, 2010; Kvale \& Brinkmann, 2009) (See Appendix 4). The second CHS focus group used photovoice to explore students' conceptions of their own identity as well as their community and Appalachia. Additionally, we added in the topics of dialect and race with this focus group (See Appendix 5).

As a tool, photovoice allows for an exploration of the context to build an understanding of how identities are constructed (Downey \& Anyaegbunam, 2010; Ewald \& Lightfoot, 2001; 
Newbury \& Hoskins, 2008; Packard, Ellison, \& Sequenzia, 2004). It can be a way to minimalize power differences between the researcher and participants as participants are in control of the photos they take and in how the photos are described (Ewald \& Lightfoot, 2001; Newbury \& Hoskins, 2008; Packard et al., 2004). Photovoice has been used with adolescents to give understanding to how they view their lives and contexts, to see "what it feels like to live in their worlds" (Ewald \& Lightfoot, 2001, p. 151). Photovoice allowed a look into participants' views and subjectivities and created a dialogue that was often different than what they shared in words (Downey \& Anyaegbunam, 2010; Newbury \& Hoskins, 2008; Packard et al., 2004). Particularly in regards to marginalized groups, photovoice opens a way to complicate stereotypical portrayals (Downey \& Anyaegbunma, 2010; Ewald \& Lightfoot, 2001; Newbury \& Hoskins, 2008).

Students used their phones, digital cameras, and in one case an instant camera, similar to a Polaroid, to capture photos that they felt represented important aspects of their lives and identities. Students were given instructions on how to use photos ethically and creatively (Ewald \& Lightfoot, 2001; Newbury \& Hoskins, 2008; Packard et al., 2004) (See Appendix 5 for these instructions and group discussion outline). Students brought their digital and hard copy photos to the focus groups where we discussed students' interpretations of the photos (Downey \& Anyaegbunam, 2010; Newbury \& Hoskins, 2008; Packard et al., 2004).

At MCHS, we completed three focus groups where we focused on dialect and race (See Appendix 6), Appalachian Identity as constructed by media (See Appendix 7), and community identity through photovoice (See Appendix 8). All focus groups looked at group norms and how these play into identity (Carspecken, 1996; Holland et al., 1998). We discussed agreed upon and contested norms and the underlying meanings and assumptions about how these influence identity. We watched clips of and about the MTV show Buck Wild and Hollow, a participatory 
documentary from West Virginia. We also discussed how media descriptions of Appalachian and West Virginian identity influence the students' identity processes (Groenke \& Nespor, 2010; Howley \& Howley, 2010).

Facebook. Facebook has shown to be an accurate representation of people's personalities and this was an interesting way to look at how students presented their identities (Back et al., 2010; Zhao et al., 2008). While all of my students had Facebook accounts, not all of them were active as they used other social media more (SnapChat, Twitter, texting, and Instagram). My interest in using Facebook was because Zhao et al. (2008) describe it as a place of "anchored relationships," meaning that there is a connection between a person's profile and their offline relationships and affiliated institutions. This anchoring provides an alignment of online identities with non-virtual identities, particularly related to groups and institutions.

Facebook also offers the space for people to explore "hoped-for possible selves." These are pieces of identities that are important but may not be expressed in face-to-face events (Zhao et al., 2008, p. 1819). While Facebook allowed me to see how students engaged with other people, institutions, and groups and gave insight into how participants negotiated and constructed identities, it was not a robust tool for all students. However, for five of my six students it did provide some contextual information. To maintain ethical online relationships students chose how they shared information with me, with all students allowing me full access to their accounts. If students were under 18 I also had parents sign a permission allowing me to be Facebook friends with their children.

Student schoolwork. I collected some writing projects from students to develop a view of how participants saw themselves as people and students. I asked students for writing 
assignments they felt were interesting or important in their lives and received a variety of works. Additionally, while I had intended to collect application letters for jobs, college applications, etc. where participants describe themselves and their aspirations, students did not seem to save these documents or were unable to find them on their computers. However, I did receive essays from Fantasia and Gregg that were helpful.

Questionnaires. I also had all participants complete general questionnaires to collect some basic information (See Appendix 9). Additionally I had all teachers whom I observed complete a demographic questionnaire (See Appendix 10). I also asked the guidance counselors I worked with to complete a demographic questionnaire (See Appendix 11) as well as a questionnaire about their department (See Appendix 12).

\section{Data Analysis}

Data analysis was completed iteratively as data were collected. The complexity of analysis mirrored the complexity of data collection. Emerson et al. (1995) indicate the explicatory nature of this process:

Rather than simply tracing out what the data tell, the fieldworker renders the data meaningful. Analysis is less a matter of something emerging from the data, of simply finding what is there; it is more fundamentally a process of creating what is there by constantly thinking about the import of previously recorded events and meanings. (p. 168)

The goal of analysis is to find meaning in the daily lives of participants (Carspecken, 1996; Emerson et al., 1995; Kvale \& Brinkmann, 2009). While it is difficult to explain how meaning is found, through careful analysis it can be done (Carspecken, 1996; Kvale \& Brinkmann, 2009). Carspecken (1996) likens finding meaning to walking; it is difficult to 
explain the mechanisms that allow walking but people walk without knowing how those mechanisms function. The following sections illustrate the analysis I used to learn about participants' meaning.

Creating the primary record. Preliminary data analysis began with data collection as my knowledge of the subject matter, participants, and local setting focused the project (Carspecken, 1996; Emerson et al., 1995; Kvale \& Brinkmann, 2009). Other preliminary analysis occurred as I chose what to include in fieldnotes and decided which lines to follow in interviews, while commentaries and memos guided this real-time analysis (Carspecken, 1996; Emerson et al., 1995; Kvale \& Brinkmann, 2009). This preliminary data analysis structured my later actions and explorations in the study (Carspecken, 1996; Emerson et al., 1995).

I used NVIVO Qualitative Software for data analysis and transcribed, verbatim, all interviews and focus groups. I collected these together with my fieldnotes to create the bulk of the primary record. Additionally I had on hand, but not in the NVIVO software (because the data amount overloaded the program), all of the newspaper and social media news I had collected as well as school documents, such as curriculum offerings and teacher handbooks.

Finding meaning. Meaning is perceived in whole, so I began this process by reading through the primary record, interviews, and focus group data to refresh the narratives in their entirety (Carspecken, 1996; Emerson et al., 1995; Kvale \& Brinkmann, 2009). Emerson et al. (1995) and Kvale and Brinkmann (2009, p. 63) suggest thinking of the data as a "series of stories" rather than an accurate rendering of events. Through reflecting on the primary record, interviews, and focus group data I was able to find connections between scenes. This overview helped me to develop the implicit meaning into explicit form (Carspecken, 1996) in order to 
support meaning reconstruction (Emerson et al., 1995; Kvale \& Brinkmann, 2009). This reconstruction helped me to understand how I interpreted the interactions and events in the data (Carspecken, 1996).

Meaning reconstruction is where participants' norms and operational paradigms became explicit (Carspecken, 1996). I analyzed the actions of participants to understand the meaning in their actions. These paradigms can be thought of as always in comparison to one another; they exist in reference to what they are or are not (Carspecken, 1996). Additionally, disparate actions and claims opened windows into assumptions and shared understandings.

Open coding. After reading through all of the data sets, I developed open codes that came from the data itself and the relevant literature (Emerson et al., 1995). Open codes were low inference words that created a picture of the events and interactions (Carspecken, 1996; Emerson et al., 1995; Kvale \& Brinkmann, 2009). In line with grounded theory, the codes came from the data and were framed by relevant theoretical knowledge (Carspecken, 1996; Emerson et al., 1995; Kvale \& Brinkmann, 2009). These initial codes were overarching, representing specific typologies and related things to one another, drawing attention to types of events, people, roles, etc. (Carspecken, 1996; Emerson et al., 1995). After I completed this first round of coding I used selective open coding that focused on unique or illustrative events and interactions (Carspecken, 1996; Emerson et al., 1995).

Theme development and focused coding. Once open coding was complete, I looked at how themes had developed and looked at connections between the themes (Emerson et al., 1995). This process again drew from the data as supported by the theoretical background (Carspecken, 1996; Emerson et al., 1995). I iteratively read codes, developed themes, and as I 
coded the themes used the NVIVO software to sort the primary record according to the themes (Emerson et al., 1995). Reading the data at different analytic stages did allow me to see new connections, expand on views, and gain new insights in consideration of themes, which helped with understanding how events were related (Emerson et al., 1995).

Unfortunately, my computer screen was not large enough to allow me to see how all of these themes were connected in a way that was visually helpful. To visualize the data I used poster board and post-it notes to create a diagram of how themes were related to one another and to my theoretical framework (See Figure 1). From this visual diagram I constructed networking diagrams in NVIVO to maintain a record that I could continue to visually explore as I progressed. From these visualizations, I began to construct my final stories.

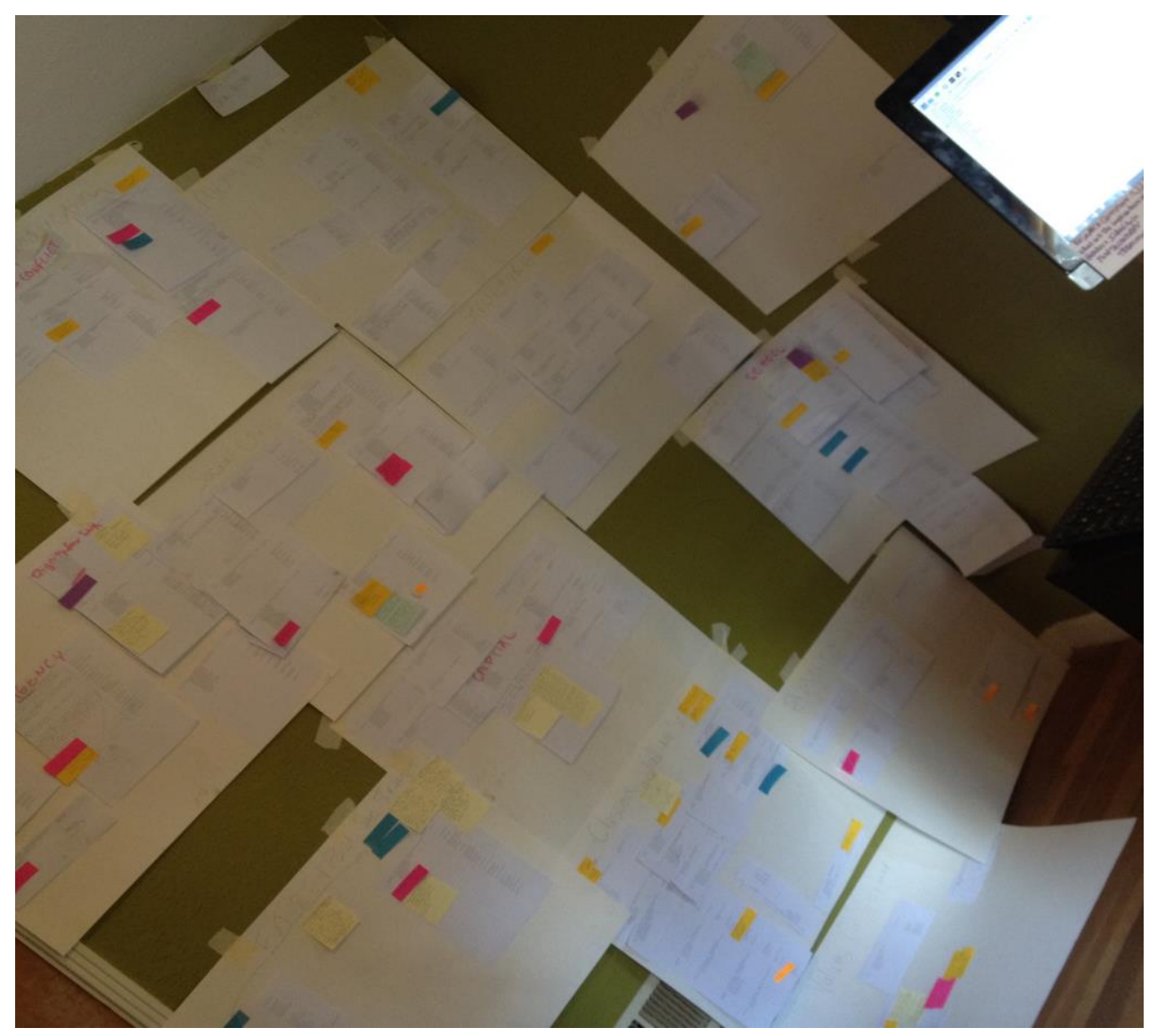

Figure 1. Coding visualization. 


\section{Ethical Considerations}

At the heart of this work, I desire to empower the participants and their families. At all times I put the participants' social, emotional, and cognitive well-being ahead of the needs of the study. These students and families, particularly those coming from poor and working-class positions, are in marginalized positions. With that foregrounding all actions, I was sensitive to the power dynamics and continuously examined my process for manipulation and coercion. As the researcher, I automatically have more power than the students and I tried to always keep this in mind.

I went through the proper channels to gain consent and access to the school system and the students. Additionally, I worked to inform parents/guardians of the purpose of the study and what was expected for their children to participate, getting permission from parents/guardians for each student. I did the same for the participants, through the formal process of assent, and at all times I made clear the policy of ongoing consent. At any time, with no reason needed, students and/or parents could disengage from the project or any aspect they were not comfortable with. Thankfully, all of my participants maintained participation for the duration of the study. 


\section{Chapter 4: Mill County Connections}

\section{What About Mill County?}

Mill County is like many other places in West Virginia. It is a very rural county with any 'major' city being at least an hour away, sometimes further depending on where you are in the county (distance is measured by time, not miles because of the two lane roads). It is also beautiful - the Western edge of the county sits along the Ohio River in the wide northern Ohio Valley while the Eastern portion of the county rolls upwards and takes on the shape of the ancient Appalachian Mountains. There are two 'main' roads (e.g. roads with the double yellow line) that run through the county. Route 14 runs along the entire Western edge of West Virginia and so along the Ohio River in Mill County, eventually connecting Mill County larger towns and to Pittsburgh with a two hour drive. Route 48 cuts through the center of the county and, once one exits Mill County, eventually connects with an interstate that leads to the shopping centers and commerce of Covington, which I discuss in the next chapter.

Millsdale and Settlement are the only incorporated towns in Mill County with many tiny communities dotted across the rest of the county. Settlement is nestled on the banks of the Ohio and a 15 minute drive East on Rt. 48 takes you to Millsdale, the county seat near the center of the county. Driving across the county makes for beautiful sightseeing (something I enjoyed on my trips) and there are many one lane and gravel roads to get lost on that lead to scenic overlooks of rolling hills and small farms. These tiny roads are lined by small creeks across the county with family farms still plentiful.

Mill County is very small; there is only one stoplight in the entire county and Settlement (population 1,396) and Millsdale (population 819) are tiny hamlets. Millsdale has one small main street peppered with local businesses (a mechanic's garage, diner, bar, gas station, funeral home, 
and florist shop) and the county courthouse and judicial offices. Settlement, being the larger of the towns, has essentially one more of each of the businesses than Millsdale, as well as a pharmacy and a public park with a pool. Each town has a small grocery store, but most people drive 20 minutes north to a larger town, North Mason, to do grocery and other shopping at Walmart and the other stores. North Mason is the economic hub of the network of local towns with a few hotels and a small hospital. North Mason also has a movie theatre, fast food, and a few local restaurants. If people take any sort of lessons, it's usually in North Mason (dance, gymnastics, art, etc.). In North Mason, there is one department store, a few discount chain, clothing stores, and multiple hardware stores.

Both Settlement and Millsdale were established as towns before West Virginia became a state. They have a long history that is drawn upon as a sense of pride. Like many places in West Virginia, both were built around resource extraction, first oil and now fracking. Though oil was rich across the county, historically and presently (See Figure 2), the majority of the wealth was maintained in Settlement (See Figure 3). One historian from Millsdale shared that the wealthy in Settlement wanted the "help" to live in Millsdale to maintain the exclusivity of their community. When I asked another lay historian in Millsdale about this dynamic she reported that there are still similar sentiments in the county with people in Settlement considering themselves to be more cosmopolitan than their "country" counterparts in Millsdale. 


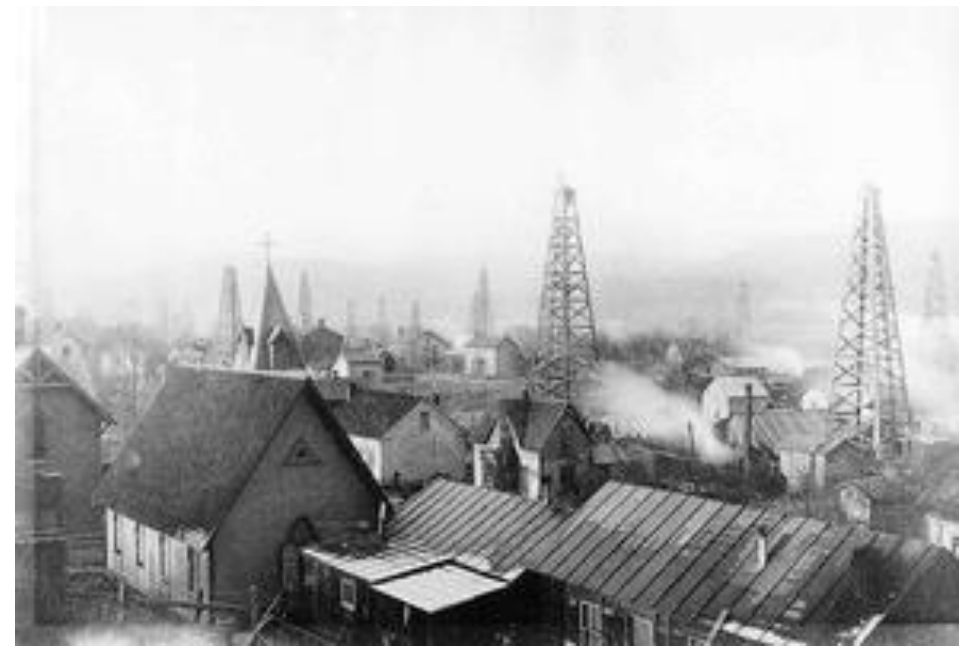

Figure 2. Settlement in the early oil days. (wvencyclopedia.org, 2015)
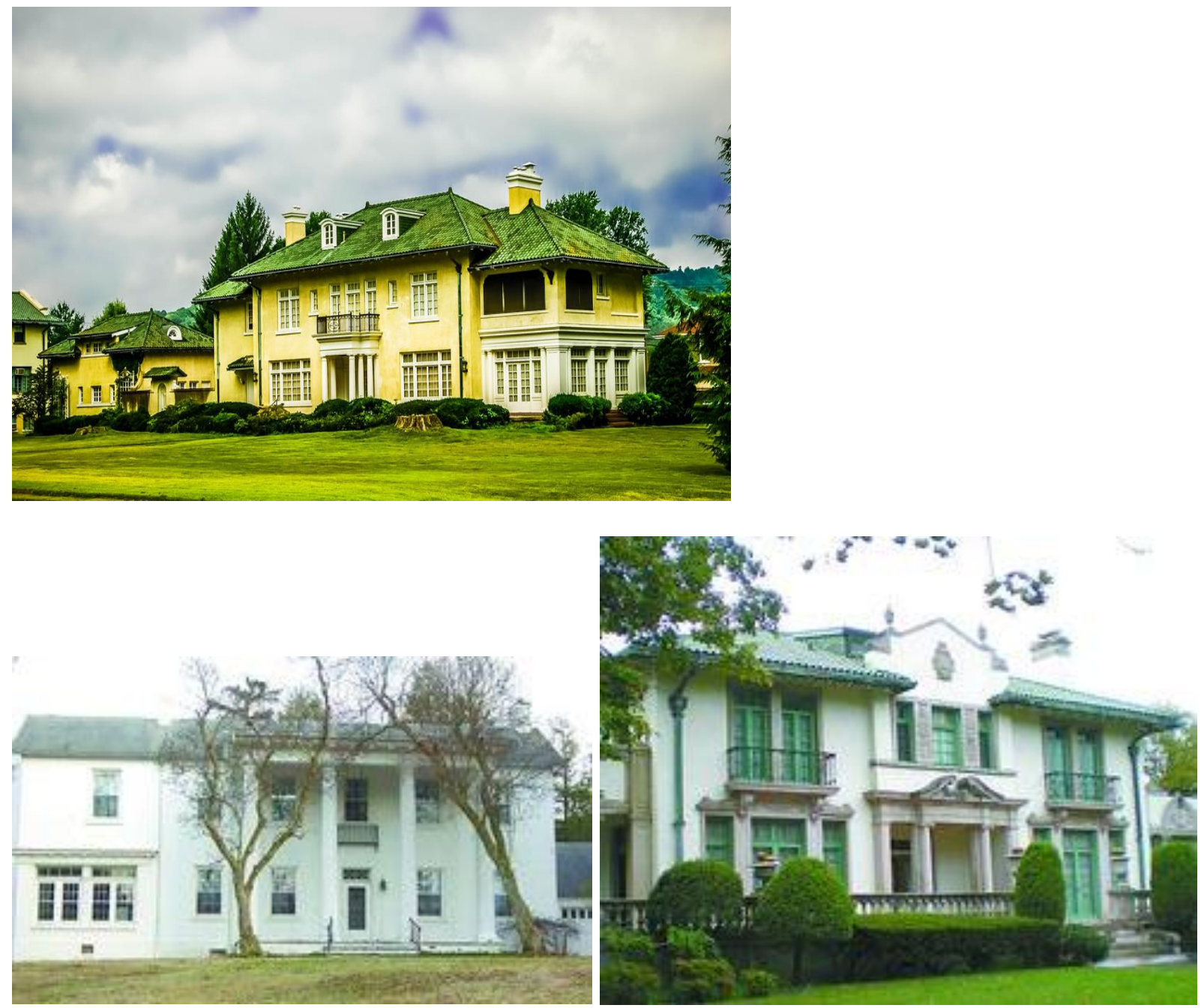

Figure 3. Mansions from the early oil boom in Settlement (Mill County News, 2013). 
Despite Settlement's wealth, Millsdale was established as the county seat and became the political center of the county because of its more central location. While a very small place, Millsdale did have some important roles in West Virginia's history. One of the first governors of the newly formed West Virginia spent his childhood and learned law in Millsdale. L.B. Hill, an important student of John Dewey and a progressive education proponent helped to establish West Virginia's first public county high school in Millsdale (See Figures 4 and 5). Millsdale was also the childhood home to a more recent governor who held office in the 2000's.

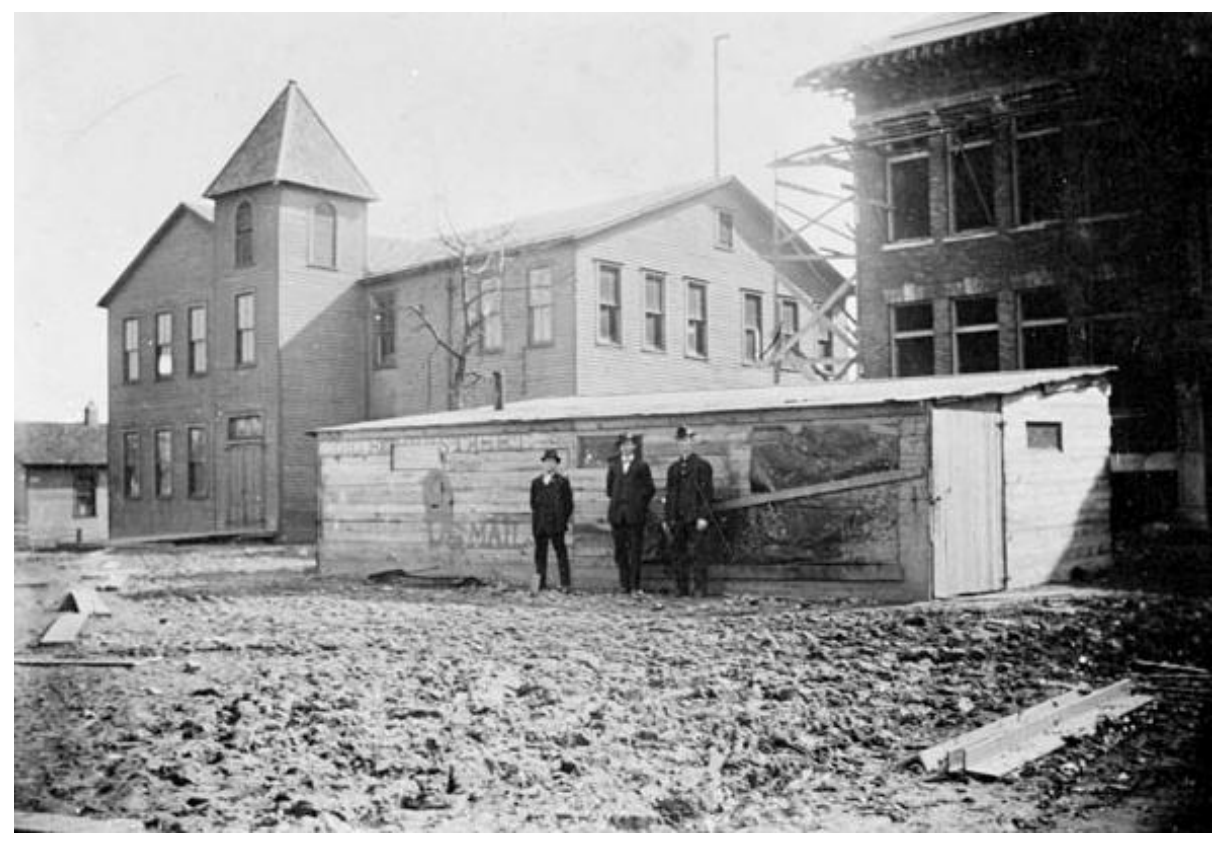

Figure 4. Building the first public county high school in Millsdale, West Virginia. (wvculture.org, 2015) 


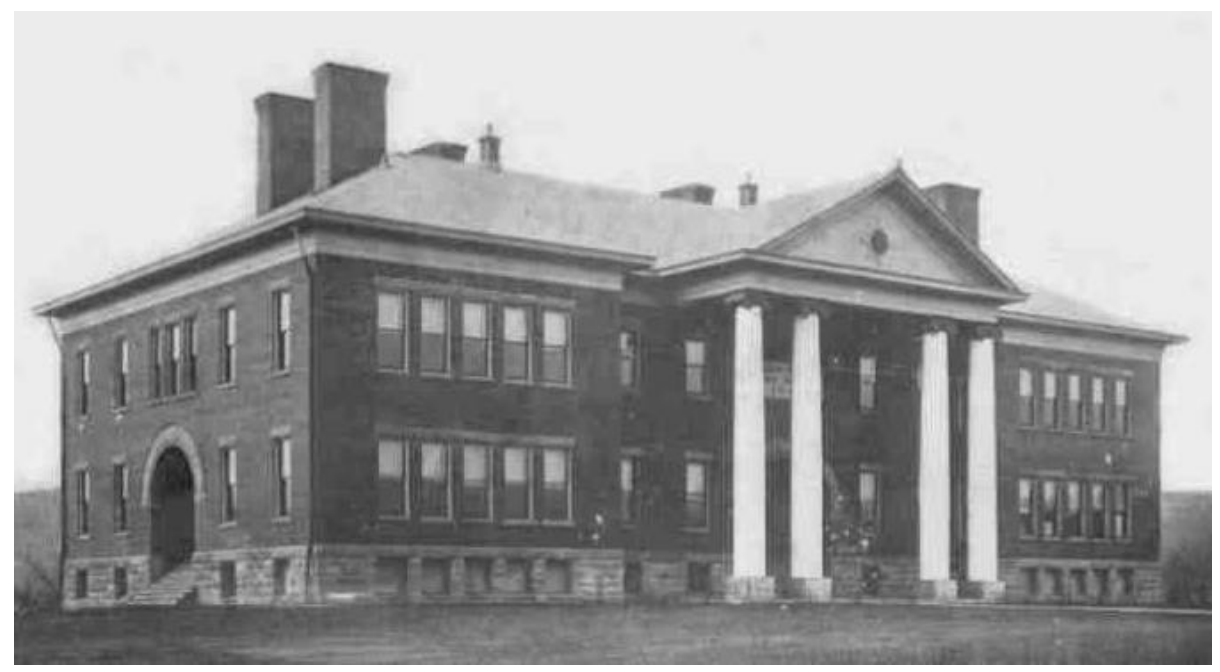

Figure 5. The finished Mill County High School. (Photo used with permission from local historian).

Like other boomtowns, when oil was discovered in Texas in the early $20^{\text {th }}$ Century, Settlement and Millsdale began to decline into the sleepy rural hamlets they are today. But remnants of the first oil boom still remain. Settlement has a few well-maintained "mansions" (as referred to locally) that speak to past wealth (See Figure 3). The recent boom in fracking has led to new economic activity in the area with a few local "shellionaires" (those who have become wealthy through the profits from shale extraction) who have built new mansions - though this time in Millsdale (See Figure 6).

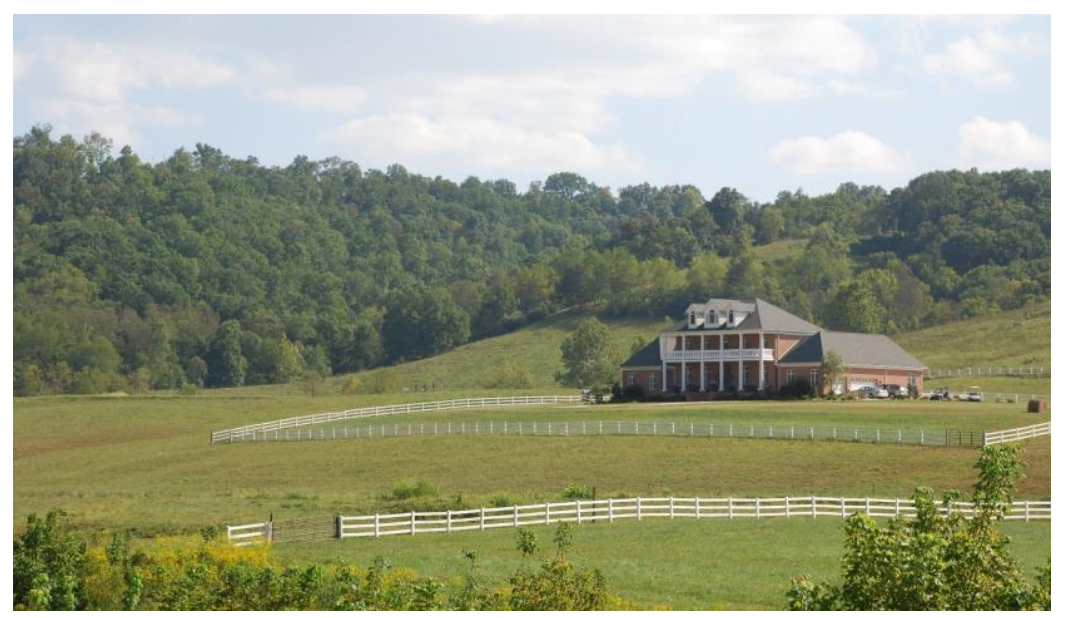

Figure 6. New "shellionaire" home in Millsdale. 
From past to present: Where blue-collar is middleclass. Outside of these

"shellionaires," some folks are seeing money from leases and royalties as many people still owned their mineral rights. However, after 4 years of actual drilling and fracking, the area has not seen the development and dramatic change promised by the companies and state government when this all began. While a few of the promised jobs are going to locals, the majority of jobs are given to out-of-state workers who are already contracted with the companies. The rhetoric from companies is that they cannot find enough workers who can pass drug tests to fill these positions, so the out-of-state workers fill that role. However, with the incredibly high unemployment rates in the area remaining, that is hard to believe. This influx of transient workers has, however, filled nearly all vacant lodgings and hotels. In the past 2 years, Mill County property prices have doubled as the oil and gas companies are buying all vacant properties to house their workers. In nearby North Mason, two new hotels have been built to house the oil workers - though once this boom is over I imagine those will end up like the hotels from the oil days before-dilapidated and falling down with no one to fill them (See Figure 7).

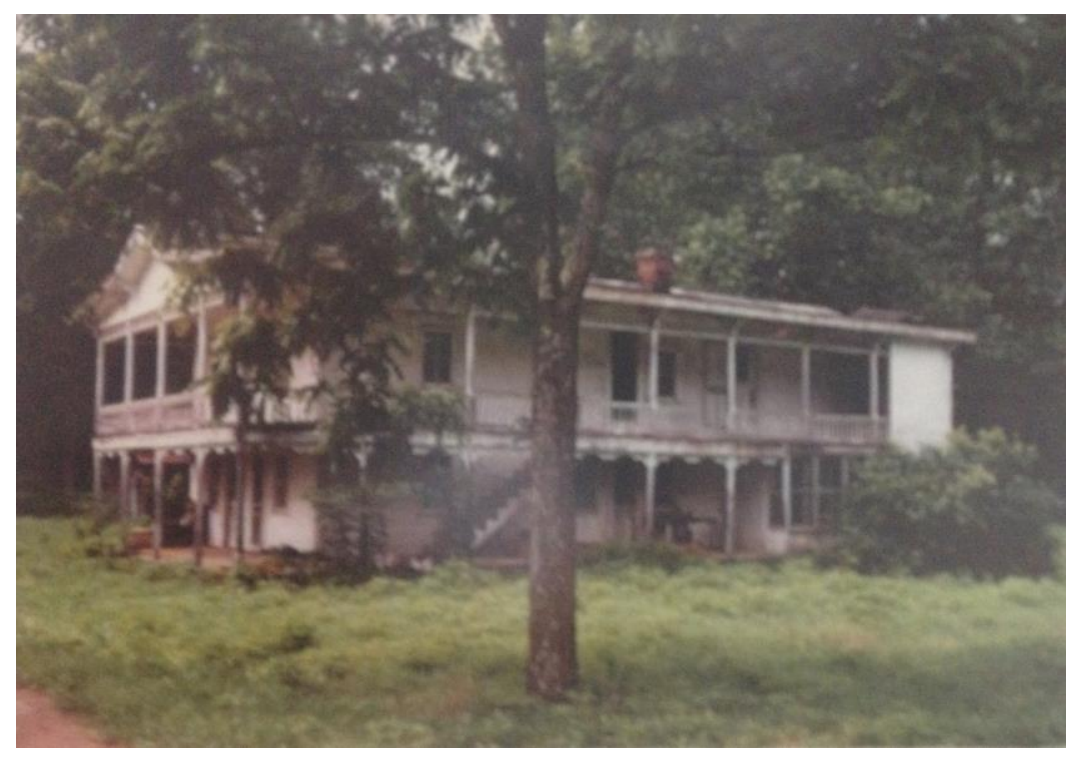

Figure 7. Former boarding house from the early oil days in Mill County. (Photo from Mill County Historical Society). 
In between oil and gas booms, people in Mill County still typically made a living in some type of industry. Located in the northern reaches of the Ohio Valley (e.g. "chemical valley"), many people made quite a good living working at the chemical and industrial corporations until the shifts in deindustrialization over the past 30 years. While Mill County itself is not rich in coal, there were many coal mines in nearby counties that provided well-paying jobs, however those too have largely cut back and closed. During the year I was at MCHS another local manufacturing factory, with 1,000 well-paying, union jobs, was closed, sending shock waves through the communities. Despite these losses, the best paying jobs in the area remain in the blue-collar industries (other than principals, the county school superintendent, and one doctor). There were very few families in the area who were not involved in some way with industry in the area and often teachers were married to someone working in industry. This gave a very bluecollar flavor to the communities, which is typical of West Virginia (Bell \& York, 2010).

Industry's heavy presence and the low education attainment levels in the area led to income being the largest determinant of social class (See Table 5). This acted as a leveler. As one student described Mill County, "Everybody is really the same here, you have the people who work out in the fields and do stuff, and you have the education. That's really it, pretty much everyone is the same." This sentiment was often repeated and one teacher described it as, "[there are] a lot more of the low, low income, mostly middle income people and few to no wealthy people." This gave an interesting dynamic to Mill County and MCHS where ocial class existed, but it was not nearly as powerful in the lives of students as it can be elsewhere (Reay, 2005; Sayer, 2005). 
Table 5

Income and education comparisons of Mill County and West Virginia. (U.S. Census, QuickFacts, 2013)

\begin{tabular}{lll}
\hline & West Virginia & Mill County \\
\hline High school degree (or higher) & $83.9 \%$ & $83.8 \%$ \\
Baccalaureate (or higher) & $18.3 \%$ & $8.8 \%$ \\
Median household income & $\$ 41,043$ & $\$ 36,563$ \\
Poverty level & $17.9 \%$ & $18.7 \%$ \\
Median home value & $\$ 98,500$ & $\$ 78,700$
\end{tabular}

One person with an industrial job could make as much money as the combined income of two teachers with baccalaureate degrees. While income was a stronger determinant of social class than job prestige or education level, these markers were not entirely absent and could be used within certain groups to distinguish status. I spent a fair amount of time with one teacher, Linda Hamilton, as she needed judges for the senior research project presentations. I agreed to help and spent three days with her and another school administrator on this activity. Linda described a time when she had difficulty with one class and was called in by an administrator and demeaned for the problem rather than supported. Linda felt that "because I only have a bachelor's" some administrators did not fully respect her classroom competency. In self-defense, Linda drew on her own experience in the work world saying, "I've been out in the real world, doing the hiring and the firing, and I know what it takes." Linda was in her early 50's and had only been teaching for 8 years, coming to the profession after time in the military and years as an administrative assistant. Linda had worked hard to move from a lower to higher status career and did not capitulate to the classism of those who valued credentials. Linda's pride in her work experience was something that came up frequently in my Mill County interactions where people highly valued "hard work" with no credentialing attached. 


\section{Processing deindustrialization: Adapting (long standing) identities to changing}

circumstances. Despite this valuing of hard work, opportunities to earn a living this way were becoming rarer as the symptoms of deindustrialization were ever present and often on the minds of community members. Families worried about the lack of jobs in the area, jobs of all sorts, blue-collar, service, industry and professional. Multiple parents and school officials lamented that their children would be unlikely to stay in the area because of this problem. The exodus of jobs has also brought with it increased poverty. One teacher, who had worked in the county for over 20 years, shared that there were many more "low-low [income]" students than there had been in the past. With poverty had also come drug abuse, beginning with methamphetamine a decade ago, then prescription pills, and most recently heroin. As I followed the newspaper across the year, there were multiple arrests for possession and even trafficking of narcotics and prescription pills. One community member described that their close proximity to Pittsburgh had made heroin easy to come by and there were multiple drug related deaths described by people and during my time at MCHS—often recent graduates and young adults.

Mill County has been one of the few historically Republican counties in West Virginia, however the changes that have come with globalization and deindustrialization have led people to move even further right on the political spectrum. There is a strong, influential Tea Party movement in the area, and other residents found the Tea Party's narrative resonant. As jobs have been lost, sentiments against unionization and the EPA have become common. Despite the remaining industry still being unionized, there is a constant battle (and fear) against what unionization has allowed to happen; that is, a milieu of "lazy" workers and pay so high that the companies "can't make it." This perspective seems counterintuitive, but industry has used propaganda over the past thirty years to maintain power and position within the community 
while removing their economic input from dependent areas (Bell \& York, 2010). This far right rhetoric extended to other issues as well. In a place with a very strong hunting and gun culture (girls and boys alike hunted in Mill County), fear mongering that the government would take away Second Amendment rights abounded. These changes, and loss of power, because of impending economic and personal insecurity, led to hunkering down into defensive and fearful stances.

This Far Right influence, and loss of power by working-class White men, also raised prickles of racism in the area. Like many other places in West Virginia, Mill County was nearly all White, even Whiter than the rest of the state. At MCHS you could count on one hand the families from minority groups and several of these families were White families who had adopted children of color. As with White privilege and systemic racism in other places in America, folks in Mill County eschewed and spoke strongly against individual acts of racism, yet were ignorant to the ways that systemic racism and "diet racism" were prevalent through the area. For instance, during lunch with a group of staff members, one woman shared her sister's current dilemma: she had moved to a community in North Carolina for the "good" school system and the district had recently implemented a busing program to diversify the school district. Because there would now be "urban," troubled kids at the formerly "good" school, the lady's sister transferred her kids to private school. Another staff member shared about her experience growing up in Cleveland and how when the schools integrated her parents did not want her to be exposed to the violence at the school, so they put her in Catholic school. A generation later, when her children were in school in Cleveland and busing programs began to diversify districts, she and her husband chose to move back to Mill County to have their kids in "a better school

\footnotetext{
${ }^{1}$ http://www.collegehumor.com/video/6987157/kinda-racist-try-diet-racism
} 
system." While none of these women would likely ever have been openly racist to a person of color they were completely unaware of the racism flowing through their conversations and life choices. This ignorance highlights the insidiousness of systemic racism and the ways that racism functions in America today as an embedded part of society.

\section{This Appalachian Identity}

Despite the header on this section, I do not want to reify a non-existent Appalachian identity. Appalachia is a place created from a socially constructed consciousness with various intents across many constructors. To divvy out a list of Appalachian traits would likely send me either into a defense of stereotypes or a romanticization of the place and people. However, being Appalachian, and West Virginian in particular, does create a specific framework from which people are considered (Towers, 2005). This means that even though most people in Appalachia do not identify as being Appalachian, how the region and people have been constructed for centuries (Batteau, 1990) has led to them being treated in particular ways by national media and in a general national perspective. When people treat you a certain way, whether their actions are based in reality or a fictional construction, there are consequences from that treatment. This means that even though there is not "an" Appalachian identity, coming from this place does have meaning based on a shared history of struggles (Bryson, 2015) and being othered (Keefe, 1998). These meanings are important to consider when thinking about outcomes and how people engage with these narratives. This is particularly true for West Virginia, and West Virginians, who tend to be the butt of jokes and derision, even within Appalachia (Towers, 2005).

In the attempt to describe, but not reify, this section builds a space to describe things that are typically considered as constructing culture—-language, geography, social groups. After this section, throughout the rest of the writing, I point out the spaces where people expressed specific 
cultural identities, which sometimes did and sometimes did not align with Appalachian-ness (Obermiller \& Maloney, 2011). Since culture is woven within every aspect of our lives, I choose to incorporate cultural tendencies and aspects within the context of where they were taking place rather than artificially extracting them into a "culture" section.

Mill County sits just north of the Central Appalachian divide, near Pennsylvania and Ohio. As such, a blend of dialects and heritage are evident. There are country and town accents, including the Pittsburghese ${ }^{2}$ of workers moving up and down the Ohio Valley. These accents are not hard and fast. They blur along lines of class, age, and education level—crossing boundaries often, speaking to other forms of diversity in the area despite a lack of racial diversity. Even in such a small place, country and town (or classed) distinctions also created other divisions in practices. Hunting was a focal part of the local culture, the county based the school Thanksgiving break around the first day of deer rifle season. Nearly all men participated in hunting, while women who lived in the country hunted more often than the women who lived in town. For example, one student who lived in Settlement did not participate in many of the activities the students named as "Appalachian" (hunting, ATV riding) while the other Mill County participants did.

In the newspaper's social section, 51 churches were listed as serving the 9,000 person count. The majority of these were small independent churches with only a few mainline denominations, with one Catholic and one Episcopal Church in the county. Most of the mainline churches were in town in Millsdale and Settlement, in imposing brick and stone structures, speaking to the wealth that was once in the county. For example, the Presbyterian Church in Settlement had stained glass windows from Tiffany's. The many independent churches were

\footnotetext{
${ }^{2}$ http://www.pittsburghese.com/
} 
often in small buildings, but sometimes larger ones in the more rural areas. The churches' sizes and geographic locations reflected the historically classed nature of religious denominations, particularly in Appalachia. Mainline denominations tended to have more money, a full time pastor/leader, and required their leaders to have a certain level of education. Rural communities preferred to have a local person in the pastorate who was not supported solely by the church body because this was not economically feasible. This economic situation led to many independent churches across rural Appalachia, something still present in Mill County. I also met many people across the county who, despite not attending church services, shared stories of Christian spirituality and faith, which was reflective of the religiosity often attributed to Appalachia. Similar to stories of Appalachia historically, some community members mentioned disliking being told what to do by church people and shared that you do not have to go to church to have a spiritual relationship with God. Each of my participants at MCHS mirrored these sentiments. Two students had home churches that their families attended on special occasions but did not attend regularly. The other participant was not fond of organized religion but did find a general spirituality with the outdoors, though she did describe her mother as a "devout Methodist."

Religious and spiritual values tended to be conservative in Mill County and this spread to how people viewed most things related to the LGBTQ community. There was only one openly queer (adult) couple I heard of while in Mill County. Similar to how people dealt with racism, they did not condone open hostility, however their views and actions across the board were heteronormative and rigid when it came to sexuality. For example, one MCHS mother, who was relatively liberal for the area, mentioned her disapproval that the school allowed public displays of affection between queer couples at school, despite straight couples having this privilege. Her 
daughter had told her about multiple lesbian couples at school and she viewed this as a fad that the girls were using to get attention. In fact, another community member shared that her pastors had pulled their children from school to homeschool them because of the school allowing queer students to show affection, a last straw for their disapproval of the school.

Interestingly, the only openly queer couples or people (adult and youth) who I encountered were women - speaking to the very traditional role of masculinity in the area. Women had more fluidity in their roles and self-presentation than men, where men were more closely policed for their presentation of sexuality and masculinity. The traditional masculinity ascribed to Appalachia was very much at play, particularly with the rural nature of the area and most work being blue-collar. This hyper-masculinity oozed in relationships where, despite women often working, men were still seen as the primary providers in the family and as the heads of households (sometimes even when the women made similar incomes). This hyper-masculinity spread over into women's views and presentations, particularly at the intersection of class where the middleclass women were more traditionally feminine (in their clothing, accessories, etc.) than were the country and lower class women.

Neither of the young women who participated in the study viewed themselves as girlygirls, nor did they want to be classified in this category. One student's farm and country girl persona placed her firmly against frivolous femininity (i.e. an over concern with hair, makeup, clothes, or men). The other student, despite being more upper-class and having a mother and sister who were quite traditionally beautiful and feminine, had been rejected by the popular, girly-girls early in school largely due to her competitive nature. It seemed that her achievement orientation caused her to also view femininity and girly-girl-ness as undesirable and even perhaps barriers to achievement. Something conspicuously absent, across the community and at 
the school, were the trappings of overt femininity (for the most part). Many women in the area dressed similarly to men in tee shirts and jeans with a practical, comfortable shoe. The girls at MCHS wore camouflage and work boots nearly as often as the boys and fashion (hair, makeup, accessories, clothes) was not something that seemed particularly important to students. In fact, the few students who had more trendy clothes stood out from the rest of the student body.

This eschewing of femininity seemed tied to the economics of the area in multiple ways, where often more than one income was necessary to make ends meet. Even if a woman did not have a traditional job with a steady paycheck, they often worked at odd jobs or bartered services for goods or other services. To do this a woman has to be capable, a traditionally masculine trait; to those ends, women and adolescents pushed off femininity as frivolous and not something particularly attractive. This is similar to the history of other areas in Appalachia, where women have been in the workforce, whether formally or informally, far before the women's liberation movement. It is important to note that while this is a tradition and history associated with Appalachia, this story is not confined solely to Appalachia. Rather women of color and lower class women have been in the workforce long before middleclass White women "earned the right" to move into the workforce. This highlights the intersectionality of class, place, and race, showing overlap amongst the stories of people in othered spheres.

Providing for the family, economically and otherwise, was a family affair. One of the things I was most interested in when beginning this project was the connection participants may have to their families and how this might influence their choices for what to do after high school - particularly as this is a trait ascribed to Appalachian culture. In line with other work on tie to place and family, family was one of the most important groups for people generally and also for my participants. This crossed class lines, as often professionals talked fondly of family 
and its importance. In fact, the guidance counselor at MCHS, Tami, one of the most traditionally middleclass people I met in Mill County, shared that her daughter was going to transfer to Fairmont State from Marshall University because she did not like being so far from her family. Tami's other daughter attended Fairmont State so her youngest transferred there to be with her sister and closer to family in general as Huntington is a 3.5 hour drive from Mill County while Fairmont is only 1.5 hours. Tami's daughter was similar to other people who placed their family as the primary social group, followed by neighborhood and work friends. Family as the main source of support and socialization is common in Appalachia and also other rural and low income communities. Family as the primary social group differs from the majority middleclass spaces where social and work relationships are the main social groups.

This sort of family atmosphere was shared amongst members of the community despite some problems (poverty, drugs, and the related petty crime). The Mill County News (the weekly newspaper publication) often advertised dinners and fundraisers to help out local families who were in financial distress and there were letters to the editor thanking people for their participation in these events. The newspaper reported on local goings on around the county, many related to sports, and focusing on activities or achievements of local people, whether in Mill County or elsewhere. For example, one article shared the story of a Korean War veteran who had left high school to fight in the war and at the MCHS graduation ceremony was honored as a graduate and awarded a high school diploma, an incredibly moving story. This culture of community and connection is highlighted in a letter to the editor, addressed to the students of MCHS:

[Residents show] our love and support throughout the community, Mill County High students, we applaud your efforts to pursue education, athletics, and school 
activities. We the community have put up signs throughout town to show solidarity to the students, parents, teachers and to let you know we appreciate you all for your efforts. (Mill County News, 2013, p. 4)

\section{The Challenges of Education: An Appalachian Community within a Neoliberal Context}

Mill County High School, as the name suggests, is the only high school in the county, which is similar to surrounding counties. As you come around a turn, from either way, you see the combined high school-middle school campus that was built in the early 1990's. To enter the school site you cross a bridge over a creek and enter a small valley surrounded by woods. Though the two-story building is very industrial, grey cinder blocks, the setting is beautiful. As you walk into the closed campus, a secretary buzzes you in to the front offices where all guests sign in with paper and pen and get a guest lanyard. From here you can head to the middle or high school "sides" of the building, as they are kept separate (each have their own gymnasium and cafeteria). In addition to one elementary school in each town (Millsdale and Settlement), these are the only other schools in the county.

One MCHS faculty member shared her concern over recent state legislation that allows for charter schools because she feared it may compromise the finances of the county school system and endanger her job. She talked about tales of a local church, the one whose pastors removed their kids from school, starting a private school and also drawing kids out of the system — something the church is working towards. She mentioned that multiple families from this church had begun homeschooling their children recently, an option exercised occasionally in the county, most often for religious reasons. The faculty's concern was not only for her job but that the people behind these movements, charter schools and the religious private school (both 
very conservative), did not understand what really happened in education and how complicated the process of teaching and learning actually is.

Other faculty were concerned about a local conservative group that was advocating for the county to reject the Common Core Standards, which the group viewed as an overreach of federal government purview. This group was quite active, holding community forums, and attending and presenting at board of education (BOE) meetings about the dangers of the Common Core. One member of this group, Betty Hovat, was very active in the group West Virginia against the Common Core, writing blog posts, presenting at the state legislature and organizing community forums in Mill County around the issue. Betty represented the group in presenting their concerns to the BOE where, supported by other parents in attendance, she shared stories of her children being behind in school because of the new pedagogies and "fuzzy" curriculum, particularly in math. She was also concerned about protecting the privacy of data and test scores from government officials and researchers, but she mostly focused on curriculum. Especially troubling, was Hovat's suggestion that Toni Morrison's The Bluest Eye, a Common Core reading requirement, was child pornography. However, the excerpts Betty presented from the book, which were sexually explicit, were from a conservative blog (Politichicks.com) and were a decontextualized excerpt of a scene of sexual assault—not consensual sex and child pornography as conservative groups have suggested (Jones, 2013). Opposition to The Bluest Eye is a specific tactic conservative groups have been implementing to gain support against the Common Core (Rosenberg, 2013). The use of this book, by the local group and more widely, is an example of the racist and nationalist elements within the Far Right and Tea Party movement despite these groups' vehement denial of such motivations (Lowndes, 2012). 
In her opening statements Betty emphasized that she was not giving a political presentation, however she wrapped up her presentation with worries about the "indoctrination" of children with unacceptable (i.e. liberal, social justice oriented) values and stated passionately that a back to basics approach would "promote knowledge, independent thought, and truth instead of political views, morals/ethics, questionable teaching methods" (Betty Hovat, Board of Education Presentation, 2013). Within Far Right movements, mothers have been placed as the cultural bearers and reproducers whose duty it is to assure that their children are educated in the "right" way (Reimer, 2014). Betty and the other mothers (mostly moms involved in this group) have taken on this mantle in the fight against Common Core locally.

Betty's and other concerned parents' involvement in education is important. Parents should have a say in how their children are educated, but teachers and the children themselves should also have a voice as part of deliberative, democratic education (Gutmann, 1987). Betty's information, whose sources include the Far Right think tanks like Concerned Women of America was inaccurate, particularly the lack of understanding of how curriculum and pedagogy are (not) mandated through the Common Core Standards. Moreover, this group of parents, and other Rightist movements, fail to or refuse to recognize the politics of their positions that continue to support inequitable social structures, for example by blocking multicultural and social justice teaching. Perhaps more problematic are the groups' insistence on taking power rather than creating dialogue and compromise.

Similar to the rise of the Far Right across the country and the Tea Party locally, this group seemed to be responding to the economic strains of the Great Recession (Rosenthal \& Trost, 2012). Parents in the community were clearly feeling the pushdown from the neoliberal context of the emphasis on every person (and child) as a cog in the economic machine. Parents 
were rightly worried about how their children would fare in a place where for the first time in generations, children are achieving less desirable life outcomes than their parents. These discourses are powerful in the deindustrializing context of Mill County where there have been dramatic job losses and economic strain, which makes a well-functioning education system imperative for a good life. The industry rhetoric and identity work (Bell \& York, 2010) that has coincided with deindustrialization that blames government for these ills has been powerful in the area and tightly aligns with the Far Right movement and rhetoric that surfaced in regards to education (Reimer, 2014). This connection across legitimate concerns, tied to the local and larger economic contexts, has given a power to conservative narratives that call for a push against the government, which is no longer serving (some) (White) people well (Apple \& Oliver, 1996; Disch, 2012).

Educators were also concerned about how the context of mandates and standardization was influencing the students; one teacher shared that kids were not learning to learn, rather they were learning to follow directions and take tests. He was concerned about what this meant for students who would someday need to participate in life without direct instruction and what this meant for them as human beings and citizens. This faculty member was openly opposed to the culture of standardized testing and the high stakes that accompanied these regulations. In fact, he had applied multiple times for principal positions within the county and felt like he was not awarded jobs because of his opposition to testing.

Others educators felt confined and/or restricted by state level demands. For instance, the state promotes College and Career Readiness Week (CEA) in October each year and strongly encourages every high school to participate. While the counselors at MCHS felt this was a good idea in theory, pulling it off was much less successful. October was a terrible time for them as 
the high school was participating in required standardized testing. Oddly, the state required that every high school have this event during the same week as the testing. Because of these other responsibilities, CEA ended up being mostly superficial and likely not having a large impact on students' postsecondary trajectories. The main activities included snacks decorated and passed out in local college colors, college sweatshirt day where teachers wore their alma mater's colors, and bulletin boards that had pictures of local college mascots. When I prodded to see if there was anything more substantial that teachers did, the counselors shared that it was difficult to get teachers involved with "extras" like this. Teachers felt so strapped for time to cover content standards that they were, understandably, resistant to doing more.

In another event that highlighted counselor and teacher difficulties, the guidance counselors worked with community members to put on a 2-hour life skills event for students, an event that had been very popular with students a few years before. There were about 20 guest speakers who presented on a variety of topics, including: opening a checking account and balancing a budget, writing a resume and applying for jobs, and healthy dating relationships. When I chatted with one teacher about this event, she lamented that she wished she had known what topics were going to be covered because she could have counted those towards content standards in her lesson plans and been able to cover other required content instead. It seemed that people felt like they could not do the valuable work they hoped because of the demands placed on them. The counselors surmised that it was like the policy makers at the state level had "forgotten what it was like to be a counselor" because they had been "detached from the day-to-day things for so long." 
The standardization from the neoliberal push for education to serve the needs of state, national, and global economies was especially problematic for MCHS because it was a small school. At one point the state passed a guidance policy requiring that all technical education classes be in 90 minute blocks, which would have forced these classes to be eliminated at MCHS. A seasoned administrator who was contest the policy at a state meeting stated, "It's some young punk who isn't even certified in making changes doing this, thinking it's a good idea." The highly regarded Agriculture teacher made similar comments about the change after it was rescinded, “I don't know what they were thinking.” In another problematic push towards standardization, the state was implementing a new mandate that all schools offer 16 (instead of the current 6) career clusters. In response, the guidance counselor shared her frustration with not being able to meet unreasonable requirements:

[That's] unrealistic for a small school with the staff and resources we have to be able to provide this. What do I tell kids if they want to be a tattoo artist or an architect? 'Pick something, there's only so many classes we have.' (Guidance Counselor, 2014)

These types of policy problems, which seemed to be fairly continuous, indicate, perhaps, a need for more school autonomy as small schools like Mill County work to meet the particular needs of their communities with the resources they have. It is ironic that as trained professionals with advanced degrees and continuing education, policy is enacted that places little faith in professionals to competently perform their work. When talking about changes from the state and local BOE, one teacher suggested:

I'm sorry to say it's your politicians, and once you get your politicians, right behind there is your parents. Well, all the parents don't understand all the new stuff's 
comin' up, we got some new board members comin' on, it's gonna be difficult, I'm afraid we're up for some battles. Because things are going to have to prove to them what we do and how we do it. I wish the board of education would go back through, you know the board members go back to the rooms, go back through the schools, make a visit, I think they should go back through the schools make a visit, I really do, but they quit doin' that years ago. (Karen, Parent Interview, 2014)

This faculty member's concern about for the newly elected BOE members, including Betty Hovat, who was elected as president during the study, echoed what I heard from other faculty. Multiple faculty shared concern about Betty's zeal and lack of accurate information and how that may affect the schools with her position. While Betty's power concerning the day-today functioning of the schools may not be great, her position was viewed as something that could make things difficult for people. Betty's election to the school board highlights the traditional views of many regular, everyday people who make up the town's majority. Like other places, the BOE is made up of people who have various experiences with education, a former principal and teacher, and community members of various ranks and professions, a former barber who now sells insurance and the owner of a small logging company. Like much of the county, the former educators were the only members of the school board who held baccalaureate degrees. Unlike other, larger places, the BOE members were not local elite or political climbers looking to establish a foothold in a first elected position, rather they were average community members, interested in how the school system was functioning. For example, the logging company owner, also a newly elected member, ran on a platform of providing stronger and more technical education to meet the needs of what students wanted. 


\section{Finding Success within Stringent Barriers}

Families, students, and the school staff and faculty praised the strong connections they shared across class and career lines within this largely blue-collar community. A variety of people talked about these connections as strengths and praised the ways in which people worked for the good of the kids and community. While the school is a formal institution, this connection with the community, as part of a larger network of connections, speaks to a history in rural Appalachia of communities and families building networks of support outside of formal institutions (Keefe, 2005). At times, these networks were built in opposition to institutions that brought different values such as a focus on "expert" knowledge and practices and relationships that were based on hierarchical and formal rules rather than egalitarian and communal standards (Keefe, 2005). Sometimes formal support institutions were not available because of the rural nature of places and low population, so that even if people wanted access it was unavailable. I imagine that in Mill County, there was a combination of these factors at play, but certainly the rural nature and dwindling population were powerful influences in a lack of formal services. Many amenities that used to be available in the communities have left with recent population losses, for instance there was limited access to healthcare with only one pharmacy in the county and only the most basic healthcare services available in Settlement.

To make up for the lack of formal services, residents drew on each other as resources. For instance, the teacher of the Family and Consumer Sciences class shared her experience of giving her daughter's crib to one of her students who was pregnant, who later passed the crib on to another girl, and the teacher imagined that the crib was still, 17 years later, being shared amongst young mothers in need. According to the local newspaper, Milltown had one of the highest teen pregnancy rates in the state. In order to help the young mothers, the school was plugged into 
local churches that donated baby clothes and crocheted baby blankets. The school also helped to register young mothers for the Women, Infants, and Children (WIC) program so that they could receive free and subsidized formula and other infant supplies. Another parent praised these strong community-school connections telling of a local restaurant that held a 5-K race to raise funds in order to buy timing equipment for the school cross country team. These were common stories of ties between the community, government, and school, the sorts of things that participants praised.

These types of stories and the connections they highlight are what many attributed the success of MCHS and its students to. Despite the economy of the area and a large low income population, MCHS consistently performs well on standardized tests when compared to the state and also has higher overall graduation rates than the state. MCHS was known as the most academically rigorous of the local high schools and was particularly good at serving students with learning disabilities. One teacher mentioned that MCHS often has transfer students from neighboring counties because parents prefer their special education services where they "try to integrate kids as much as possible."

Most community members and even the students had very positive things to say about the school and I often heard the school referred to as "good." People did not gloss over struggles but did find positives, despite these hurdles. One young teacher who had grown up in the area and returned with her husband after college shared that she had never expected that she would be happy at "home," but that the school was like a community. She shared that the school was also connected to the community so that parents knew what was going on with the school and their children, something she was thankful for with young children in elementary school. Another teacher (and parent) shared that many of the teachers were local and so were committed to the 
area and the students, something she felt was a strength that cushioned the struggles of the local communities and families (drug abuse, poverty, lack of jobs). Students shared similar comments noting the school as a "central point" of the community where people were "super connected," while another participant described her school activity group as a family. This strength of connections across and within the communities and schools came up again and again and seems a pivotal point in how a school that seemed to lack so much capital continued to perform strongly on markers success.

\section{Mill County High: An Appalachian High School}

The high school principal, Kevin, was a local man who raised his family in the area (his wife is a teacher) and was a coach and special education teacher before moving into his position. Kevin was an imposing man who at 6'8, sauntered around the school, not in a hurry, keeping watch over the domicile. He walked as if on a Sunday stroll, stepping in to chat with teachers in their rooms or with groups in the hallway. He seemed to know what needs to be done, let it happen on its own and only intervened when absolutely necessary. One faculty member described that he "just lets us do our job" and only took action when something was really amiss. Kevin was funny with a dry sense of humor, a no frills kind of man. At the senior awards ceremony, after the seniors marched out to Pomp and Circumstance, there is a tradition of the juniors moving into the senior seating section of the auditorium. Kevin showed his sense of ceremony when he directed the juniors to take their new places, "Juniors, you know what to do" (MCHS Observation, 2014). The assistant principal was a pretty perfect partner to Kevin. Affectionately known by his high school nickname, Willy was a former athletic star from one of the "old" high schools, before there was a consolidated county school. He was the athletic director and also on the football coaching staff and his wife was a county administrator. 
Together, Kevin and Willy created an atmosphere of casualness and getting the job done, a school culture analogous to the blue-collar influence of the area. While I did not get a chance to chat with Willy (he was usually in his office doing administrative things), I would talk with Kevin when I would see him in the halls, where he told me, "Just let me know if you need anything."

\section{Providing Postsecondary Planning}

The guidance office extended this openness. It was a welcoming space in its own bay off of the administrative offices. You walked into a sort of setting room, with a couch and chairs and a table where the staff shared lunch. There were dried flower arrangements above each of the counselors' doors (there were four offices off of the main setting room) and a few had wreaths on their doors. An oversized quilt square hung over the copy machine in the setting room. There were two counselors for the high school who split the student load, each responsible for around 200 students. I worked most closely with Tami who had the senior class, though the other counselor, Patty, was helpful if there was anything I needed.

Tami first worked as a counselor in higher education and later became certified to work as a high school counselor. She had been at MCHS for 13 years and had two children in school there during the study and another who had recently graduated. Despite Tami's vast workload she never seemed rushed or frazzled, she always had time to sit down and answer my questions and chat for a few minutes.

Mirroring the literature on the practice of school guidance, Tami and Patty wore many hats as counselors - testing, psychological counseling, postsecondary advising and planning, scheduling and guidance, along with whatever else was on the plate at the moment (McDonough, 
1997, 2005). All of these duties left little time for postsecondary advising and planning, as the counselors described:

The end of the year is overwhelming...we could use two people just for the senior class duties in addition to an in-house social worker to work with seniors who haven't developed coping mechanisms for high school, let alone college, hindering their transition. (Paraphrase, Guidance Counselors, 2014)

As the counselors shared, they were not able to provide an ideal level of postsecondary advising. They did the best they could with their resources, however the guidance for the postsecondary transition was barebones. Together the counselors distressed that if a student came down to the office they could help them, but "kids fell in the cracks" if they did not come down on their own. Unfortunately, despite the guidance offices being a welcoming and warm space, they were isolated from all of the classrooms and public spaces where students might be, so there were few chances for casual visits between students and counselors.

Table 6 shows the official structures the counselors listed for facilitating the postsecondary transition. Many of these tools are standardized tests, which, in the larger picture, are only the very basics a student needs to move to education or work after high school. Additionally, these postsecondary supports were almost all geared towards college. When I learned that this was the only official guidance, I pushed to see if there was anything I was missing. There was so much on the counselors' plates that they were almost ambivalent towards changing or adding activities as, without more help, additional work was beyond their capacity. 
Table 6

Postsecondary advising activities at MCHS.

Freshman

CEA week (College Exploration and Application), Freshman Academy

Sophomore

PLAN (Pre-ACT exam), CEA week, sophomore interview

Junior

College night, CEA seek, PSAT, ACT

Senior

College day, College night, CEA week, ACT, Financial aid/FAFSA Workshops, senior seminar class

Other

College visits at lunch, military recruitment, scholarship announcements

College rule and limited options. Congruent with the literature (DeYoung, 2007;

Locklear, 2011; Wright, 2012) and despite the rhetoric of the state (CFWV, 2013a; Edvantia, 2011) the culture of formal postsecondary advising at MCHS was entirely focused on students attending college, largely baccalaureate institutions. When I asked Tami what they do to support students who have other goals like technical schools or work training, she openly shared that they did not do much and she wished they could do more. Both counselors wanted to build connections with these types of institutions and felt the administration supported that, but felt they did not have the time nor resources to make those connections. The counselors and school recognized local preferences and verbally and emotionally supported students who would move into technical schools or work after graduation. However, they were bound by the structures of standardization and accountability requirements that did not allow this support to develop. When not all pathways are equally supported, the school and state are reproducing an inequitable society (Bourdieu \& Passeron, 1990). This inequity is hidden by rhetoric that purports to offer equal opportunity to all by supporting all pathways, i.e. college and career pathways from West Virginia's Teach 21 Standards, but only structures support for some outcomes, i.e. college.

As I mentioned, CEA was superficial, with minimal impact at best. Regarding other postsecondary support activities, parents and students accessed some of those listed in Table 6, particularly financial aid and FAFSA nights, however these were only a few nights across the 
school year. Only one night was set aside for a college fair and with many people working shift work and the county being so rural, I am sure there were students and families who missed this opportunity. In following up on this limited access, I suggested that if the counselors wanted I could help out and contact some schools to visit during lunches. Tami and Patty shared that, in addition to frequent military visits, "most of the state schools" visited; when I asked specifically about the schools they named around six schools that were all under a 2 hour drive away. I offered to contact more schools but they did not think it was necessary as most of the students went to the schools that visited and would not have interest in schools further away. The counselors were right too, as nearly every student who went on to college stayed in state or at nearby Ohio schools; amongst these schools, almost all were within a 1.5 hour drive. These counselors and multiple teachers mentioned that most kids wanted to stay close to home so their school choices were very limited, even within the state. Around $50 \%$ of the senior class went on to baccalaureate institutions after graduation and, of this group, nearly $80 \%$ were registered for the same state school.

MCHS was connected to the Tri-County Technical School (TCTS); however, the increased GPA and standardized test score requirements had greatly limited the number of students who could attend the school. Tami described TCTS as more like a postsecondary school and less like a place that provided general learning opportunities for students, especially as students had to commit to a specific program and could no longer take general courses at the center. She said that many students at MCHS went into welding, attending a nationally known welding program, and these students shared schooling information within their group, similar to the way more privileged groups also share this type of information. However, outside of personal 
social networks there were no systemic structures to support postsecondary options outside of college.

One participant, who seemed to navigate the college transition process entirely independently and seamlessly told me:

Going through the process was like a secret experience, everyone does it, but does it on their own and no one talks about it. It would have been nice to talk about the process and be able to share those things. (Camilla, Interview 2, 2014)

This statement came a student who had applied to over nine schools with National Merit Scholar application waivers and figured out how to look at the strength of universities, programs, and even faculty. When I asked how she had learned about this process, she replied that she had muddled through the process on her own and learned it bit by bit, which her mother confirmed, sharing that she had barely been involved. When I dug deeper to see if any faculty had helped the student she shared that one teacher had talked with her because her son was in a similar major; however, this conversation was mostly around what sort of classes to take and what the major was like. Another participant had learned about her college major from her Future Farmers of America (FFA) advisor, who was also the agriculture teacher. But unless students had personal experiences like these, they received little help outside of the limited guidance opportunities and what their families or social networks could provide.

\section{Teaching Community}

As students mentioned and I often observed, teachers offered personal support and relationships to students, something they welcomingly offered to me as well. Teachers extended the casual, friendly culture of the school in their classrooms where we shared conversations during every visit. On multiple occasions teachers offered to allow me to sit and observe at their 
desks while they were teaching. Most of the staff had grown up in Mill County and still lived there while a few teachers lived in neighboring counties. There was a network of connections amongst the faculty as people knew one another's families or were friends. Many of the younger teachers had graduated from MCHS so had been students of the more seasoned faculty and these connections created a strong teaching community. I attended the teacher picnic at the end of the year where there was a celebration for two teachers were retiring. There was a heartfelt presentation and bittersweet tears as one teacher shared stories of the retiring faculty and their commitment to the school and students over their near 30 year careers. The faculty had pooled together to get each retiree a beautiful rocking chair and a gift card.

Teaching community: The struggle to sustain. These retirees were just a few of the many baby boomers to recently retire. Since 2007, the county had seen four superintendents due to retirements. This turnover led to the teaching staff at MCHS being fairly young, around half of the faculty had been teaching for fewer than 10 years. One veteran faculty noted the benefits of the younger teachers "coming home" as they cared deeply for the school and students, even if they only stayed for a few years to get experience. While the newer faculty brought an appreciation for and support of the local place, they were not as credentialed as the faculty retiring, though $95.8 \%$ of the faculty were considered "highly qualified" which is higher than the state average of $91.5 \%$ (WVDE, 2013). Problems maintaining qualified teachers were particularly visible in the advanced courses where it had been difficult to fill multiple positions for AP and dual credit.

In addition to these administrative issues, some students, parents, and teachers had concerns about teacher quality. One parent mentioned that both of her daughters struggled in math and that during middle school her younger daughter had an unqualified, permanent sub for 
an entire year and felt that so had lost that entire year of learning. This parent, who was also a teacher, shared that a majority of students from the senior class, including her daughter who was an honors student, had qualified to take remedial math courses in college. This stood out as a glaring problem for her and speaks to some of the systemic problems facing rural schools, particularly West Virginia, in attracting and keeping highly qualified teachers.

One student, who took all honors courses, lamented that one teacher, while qualified to teach AP, was not a "good" teacher. The student had actually contacted the recently retired AP instructor to see if he would tutor her and another student. This same student shared that she was glad she was in honors classes because a friend of hers, in one regular class, was "basically teaching himself and his group" during group work. These experiences illustrate the systemic disadvantages students face; on paper (transcripts) students may appear qualified but in preparation they are not.

These stories and experiences present a complicated picture, as the overall view of the school was "good" within the community. In testing, MCHS scored above the state level on everything but science; however West Virginia's scores are some of the lowest in the nation (See Table 7). These inequities are indicative of the transferability of success, while students were more successful than the state average, only around half of the students scored at the proficiency level. However, the testing is problematic too as standardized tests disproportionately implicate low income students as failing (Brantlinger, 2003; Delpit, 2006; Rist, 2000). At MCHS over half of the student population (52.8\%) was identified as low income (WVDE, 2013). 
Table 7

Achievement test scores at MCHS in comparison to West Virginia.

\begin{tabular}{lll}
\hline & State & Millsdale \\
\hline WestTest Reading proficient & $48.42 \%$ & $57 \%$ \\
WestTest Math proficient & $46.54 \%$ & $55 \%$ \\
WestTest Science proficient & $40.73 \%$ & $28 \%$ \\
WestTest Social Studies & $36.79 \%$ & $44 \%$ \\
proficient & & \\
ACT average score & $20.7 \%$ & $22 \%$
\end{tabular}

Teaching community: Victories. While the negative stories of unqualified teachers strike a note, I also observed and talked to teachers who were going very far to provide strong academic and experiential learning for their students. There were teachers in advanced courses doing great things, as is typical (Hallinan \& Oakes, 2011), but more noticeable was the work of the faculty who were not teaching in core subjects. The agriculture teacher, Lenny, was amazing. Many teachers praised him, particularly his work with students who other teachers found trying, i.e. lower class boys. One colleague said, "I don't know what he does, but he gets them to work for him" (MCHS, 2014). As two of my participants were involved with agriculture activities, I spent a fair amount of time in Lenny's room and observed there often.

On an early visit, when students were preparing for the ham and bacon sale, Lenny took me on a tour of the meat processing facilities, proudly showing them off. This tour also took us out of the classroom for about 30 minutes, with the students unsupervised; however, Lenny mentioned multiple times that the students were "good" kids and that once they were taught what to do they did so on their own while working together. I stayed after school that afternoon to watch the students prepare the bacons and Lenny's comments about their work were on target. Around 25 students, which Lenny said was a low number because of sports and work, enthusiastically collaborated on the bacon preparation process: getting the sides of meat out of the curer, seasoning them, and moving them to the pressing room. There were a few parents who 
had come to hang out for the event as it was the culmination of much hard work raising the hogs. There were also former students who came in to help, one who was a local butcher, and the unassuming owner of a local fracking company who supported the agriculture program both personally and financially. I spent about two hours hanging out and chatting and the event was still not over.

During this visit Lenny shared that, to his great surprise, a former principal had told him that the ham and bacon sale was the most important night of the year for the county school system because it brought in so much money. The ham and bacon sale raised over $\$ 60,000$ in one night a few weeks later! Lenny beamed as he told me what the principal had said, as the work his students, who sometimes went unrecognized and could be seen by others as problematic, had accomplished was commended. This feeling went both ways, the students loved Lenny. One of my participants shared how important he had been in her choosing to become an animal behaviorist. One administrator mentioned that she wished more of the students would take advantage of TCTS but they would not go because they would miss Lenny's agriculture classes and not be able to participate in FFA.

\section{A Day in the Life: Constructing School at MCHS}

MCHS ran on an eight period day with students arriving at 8 a.m. and classes starting at 8:10, the school day was over at 3:20. The year was separated into six weeks grading periods but other than some rotating classes (gym/health) and electives, students had the same schedule for the entire school year. This schedule, in face of increasing demands from the state that students have more and more credits to graduate, was becoming problematic. If students failed a course, it was difficult to make it up without missing other graduation requirements. Tami described that it was like things were being pressed so much that students could not breathe. This tightness of 
schedule was problematic for students attending TCTS, which was a 30-minute bus-ride away. If TCTS students failed a course, the tight schedule and long driving times often meant that they could no longer attend TCTS, which was a major disadvantage as many of these students planned on technical careers and work.

To put it mildly, the weather was insane in the spring of 2014. MCHS missed almost 30 instructional days due to weather. There was near constant snow during January and February and because of the many creeks in the county there were multiple days missed due to spring flooding. On a typical day the eight periods seemed rushed, classes were around 40 minutes, but there was also social time at the beginning of class where everyone would say hello and catch up. The greeting time was genuine with folks catching up on what had happened in between visitsnot students trying to avoid work. When there was a 2-hour delay the schedule was impractical with all classes shortened to around 25 minutes. On these days little was accomplished and occasionally teachers were so frustrated that they let the students have a free period. Often, classes consisted of reviewing for or taking tests so that students could have at least some grade. In some classes, students were failing because they only had one grade for the grading period and even students were complaining about not having enough school.

MCHS's course offerings met the state standards for the career and professional pathways. They had the basic advanced classes, a very strong agricultural program (animal and plant sciences), strong visual and musical art programs, and were connected to TCTS. In addition to the state's tracked pathways (college/career ready and professional paths), MCHS's courses were tracked based on accelerated and honors designations. This system offered some flexibility; for instance, one of my participants was in regular math, AP Psychology and dual credit English. However, the nature of the accelerated courses, which began in middle school, was limiting, 
particularly when combined with the full-year course schedule. In order to take AP Calculus, a student would have needed to be in honors courses since middle school. Since courses were based on a full year schedule, students could only take one math per year, this "fifth year" class was only available to those who had started on advanced math in $8^{\text {th }}$ grade (Algebra, Geometry, Algebra II, Honors Trig/Pre-Calculus, AP Calculus). One of my participants, who was very good at and enjoyed math, proudly stated he was in Honors Trig/Pre-Calculus. When I observed this class, my participant was the only senior in a class of juniors who had all started this progression in middle school. While this participant was getting a strong math education, he was not receiving the same benefit as these juniors who would have access to the AP course as seniors, along with the college credits, prestige, and academic transcript. Even though this student was in an honors course, because of his "late" entry to the progression he did not receive the same capital from this participation that other students did.

As I mentioned, the agricultural and technical programs at MCHS were very strong. When the county invested in the school they paid particular attention to the technical facilities. MCHS had a greenhouse and animal processing facility, wood shop, agriculture mechanic shop and welding facilities, all on site. Lenny, the agriculture teacher, bragged on the facilities as they could do all of the students' meat processing for the ham and bacon sale from beginning through end on site, less the slaughtering that was done at a federal facility. In fact, a few surrounding counties shared the smoking and curing facilities at MCHS. This investment speaks to how the school and county valued and supported local agricultural ways.

MCHS offered the basics in when it came to sports, clubs, and activities (See Table 8) and provided support so that as many students as possible could participate. MCHS had applied for a federal program and was able to provide dinner after school, free of charge for anyone who 
came. Nearly everyone who stayed after school took advantage of this program, including teachers and coaches who raved about the homemade sweet tea the cooks prepared every day. This participation made the feeding program a fun event and students who needed the program for dinner were not stigmatized by partaking. The county also ran an activity bus each evening so that students without vehicles or who did not have a ride home could participate in afterschool activities. Because there were so few students at MCHS, most of the sports were open to anyone who wanted to participate. The athletic boosters provided supplies for most of the sports and made up the difference for students who wanted to participate but had trouble getting supplies. Some of the clubs (4-H, FFA) were so active that kids were busy multiple nights a week after school. MCHS also had a club day every six weeks where classes were cancelled for half of the day so that all students could participate in at least one club. This provision of participation was an important aspect of the school that contributed to the overall culture of supporting students as whole people. In fact, all of my participants from MCHS spoke multiple times about the importance of leadership that they had learned from their activities - despite not appearing as "leaders" on paper or even participating in leadership.

\section{Table 8}

Extracurricular activities at MCHS.

Athletic programs Baseball, basketball, cheerleading, cross country, football, golf, soccer, softball, track, volleyball, wrestling

School clubs $\quad$ 4-H, band, chess \& checkers, choir, FBLA, FCCLA, FFA, Hi-Y, and activities National Art Honor Society, National Honor Society, photography, Project Pediatrics, quiz bowl, RAZE, school spirit club, school pageant, Spanish Club, student council, TSA, yearbook 


\section{Constructing Connections: School, Community, and Spare Time}

For many people in the county, the school provided a central base for community activities. Parents were typically at the school when extracurricular and special events were going on. They filled auditoriums when there was a play or awards ceremony. At the ham and bacon sale parents had put out a beautiful spread of home cooked food as a gift to everyone who attended the event — desserts, drinks, and specially prepared soup beans and corn bread that had been slow roasted all day as a specialty of a particular community member. It was a veritable feast! There were many parents and community members involved with the 4-H program, many of whom overlapped with the agriculture students and FFA. Parents also participated in the athletic boosters, running the concession stand at sporting events and at the county fair to raise money for student athletes; there was a band boosters as well. Parents were also involved in their children's schooling and extracurricular activities by supporting them financially, providing transportation (often and far in such a rural county), and generally supporting and encouraging them in their goals. If a person only looked at parent participation as volunteering during the school day, they would have seen minimal participation. However, when it came to showing up and providing for kids, parents were incredibly present. These dynamics speak to the ways that traditional notions of parent involvement are lacking, particularly when only a narrow space is given for parent involvement (Epstein, 2007).

For many students at MCHS, school sponsored or affiliated activities took up much of their time. All of my participants were quite busy with extracurricular activities. Many of these extracurricular activities also served as family time as families were often involved, particularly in agriculture. Sometimes entire families were involved in building housing for animals, taking care of animals and crops, harvesting, preparing and preserving crops, and showing the animals 
and crops from the local to national levels. The school also had a Farm to School program where kids sold their farm products to the school for school lunches. With the rural nature of the place, people often had property that needed caring for and along with house care and repair this was an intergenerational family activity that sometimes included help from friends. While technically this is "work," these were often activities that were shared so they were also social events where teens visited with their families and friends, learned life skills, and also earned money.

Outside of agriculture, many of the male students were very interested in car mechanics and racing as there was a popular dirt race track in the county. The senior class president even mentioned the race track and all of the memories associated with it during her address at graduation. While girls and guys attended the races, many of the young men were interested in car mechanics and spent time working on vehicles with multiple generations of their (typically male) relatives, even if this was not geared towards racing.

Agriculture, racing and many of the other activities kids and the community participated in were outdoors. Fishing was popular in the many creeks and on the Ohio River. People hunted nearly all year round, depending on the season: deer, squirrel, 'coon and turkey hunting; bird hunting with dogs was rarer. Camping and ATV riding were popular as was "mudding," driving vehicles, typically 4-wheel drives, through the mud and rough terrain to show and practice handling a vehicle with skill and speed—all while making a huge, entertaining mess. My participants mentioned multiple times their appreciation for the outdoors and being able to be outside to do anything. In contrast to more suburban and urban places where incomes may be higher and more shopping and dining options available, informal time was not spent consuming through purchases. Of course there are costs associated with the activities mentioned, particularly ATVs, racing, and hunting, but the actual process of purchasing and showing was not the end 
goals of these activities. Rather the focus was on the experience and sharing those with other people, as these were nearly all group activities. Also, the materials for many of these activities could be shared, bartered for, and did not have to be new.

Some students did work in formal work, though there were not a large number of opportunities. Some earned money or bartered their work in agriculture and mechanics and it seemed like these informal jobs were the most prevalent. Students also worked at fast food restaurants in the neighboring county and at a local pizza place. A few teachers mentioned that some kids worked too much and their schooling suffered, though one of these teachers also acknowledged that these students were often contributing to family income.

\section{Cracks in the Community: Social (In)Justice}

In thinking about social justice and equity, MCHS was incredible at providing for the needs of students in poverty, which is, perhaps, why there was such positivity around the school. Support for students in poverty also seemed linked to why students performed well relative to other schools with a similar income profile. People affiliated with the school were savvy at garnering grant funding to supplement needs in the county. In addition to the free after school feeding program, there was also a summer feeding program open to anyone who could travel to the school for deeply discounted prices (think \$1\& \$2 per meal). When some teachers noticed that not all students who qualified were taking advantage of the free lunch program as lunch bills were passed out in class, they began mailing lunch bills home so that students on free lunch were not identified and participation in the program increased. Time and again there were instances where teachers and administrators talked openly to kids of being able to provide required materials if kids needed them. Teacher's announcements were not in a way that singled these students out, rather as a general announcement to classes and/or assemblies that kids could speak 
privately to educators whenever they needed. The school also provided clothes for kids who could not afford them. The middle school had a dressing program where kids could come every morning and pick clothes out for the school day. In addition to this they also provided coats, winter clothes, and Christmas gifts to students who may not otherwise get them.

Tami shared the story of a student whose mother needed to move but allowed him to stay in Mill County to finish his senior year; however, without a place to say he essentially became homeless. To address this issue, multiple staff members opened their homes to the student until he found a place where he wanted to stay. Teachers seemed very cognizant of students who had responsibilities to home that took away from their school focus-jobs, caring for siblings or themselves, etc. While teachers had high expectations for these students, they understood when these expectations were not met.

While there was this support for students, materially and emotionally, this goodwill was not necessarily extended to students' parents. As with other social network policies in America, and as viewed writ large in society, children were seen as victims of poverty while adults were seen as the causes of their poverty. One parent, who was also a teacher, was more understanding of families' economic situations and recognized the lack of work in the area and the low pay for what was often available. One student, whose family was working-poor, both parents worked at Walmart, participated in discourses blaming other families in poverty for their situation while placing his own family as an anomaly. The power of these narratives is strong and shows a desperate need for reframing to focus on the structural causes of poverty and the ways that these can be ameliorated. However, reframing narratives controlled by the powerful and that challenge the powerful, particularly as they are such a part of American identity and culture (individualism, meritocracy, a land of opportunity) is difficult. 
I also saw the school and individual teachers supporting queer students or students who may be queer, despite there not being much support within the larger community. Some parents expressed dismay that the school did not discriminate when it came to their "PDA" policy (public display of affection) where any students, queer or straight, were allowed to show a modicum of affection (handholding, quick kisses). The art teacher shared that he felt his room and the arts offered students who were "different," (an ineloquent, but well-meaning description) a space to express themselves and be accepted. "When I was in school they just would've gotten beaten up," he shared. Another teacher shared her support of a student who came out to the class as queer in a presentation. She commended the girl for sharing something so important and for being brave enough to do it in class. The faculty member also checked with the guidance counselor to make sure that her response was supportive enough and to see what else she could do to support the student.

Perhaps because there was so much poverty in the county taking care of and providing for some of those needs was just part of the way things were done. However, when it came to other issues of diversity the school was not quite as accommodating. Some teachers commended a strong special education program and there were parents from neighboring counties who transferred their students to MCHS for this programming. However, full understanding of ability and academic performance was not ubiquitous. I heard multiple teachers talking about "gifted" and "low" kids in ways that were problematic. As these students were labeled, teachers expressed expectations for students in line with these labels.

Perspectives on race were problematic, to say the least. In addition to the racial elements disguised as curriculum concerns by Common Core opponents, stereotyping and "diet" racism were fairly common. For the senior class "who's who" each of the elected students acted out a 
parody skit that was recorded and then shown during the senior awards ceremony. These were clever and quite funny in general but the "most musically inclined" skit was blatantly racist. Two students dressed up as elderly Amish people with rap music playing in the background—in mock elderly voices the "couple" miscommunicated about the "cripples" and who performs rap music. After the old woman yells "cripples" multiple times while making "gang signs," the couple concludes, "the cripples make signs like these...it's like the Aborigines" (Senior Awards Video, 2014). The video garnered a similarly appreciative response as the other videos and no one raised any objections. The lack of objection to this video, and that it was allowed to be made at all, is a powerful picture of the enduring presence of racism. In this case, the video represents institutionalized racism, as it was approved by school officials and shown at this school sanctioned awards ceremony where parents and community members attended.

This particular instance speaks to the falsity of being in a post-racial society and the denial by White Americans of the persistence of racism. One student told me, "Yea, ok, some will use the word $\mathrm{n}^{* * * * *}$ or something like that...but nobody here's ever meant it like mean or derogatory in anyway." While silencing the voices and experiences of those who have been harmed by this word, the students, and many other people, also displaced racism as existing "somewhere else." For instance, one student surmised that there were not problems with racism in Mill County and that it did not exist there:

I think when there are pockets, or if there were more black people they would probably kind of stick together and then [would] in turn exclude themselves, and that would become like, if we had more [black people] there might be a problem. But I, because we don't, I don't think it is [a problem]. Like in the cities where there are pointedly black and White neighborhoods and when they go to school together, 
they stay to themselves and that causes tension and then leads to the racism. And because we don't live in a city where a lot of the crime is black crime and there isn't that kind of "Ooooo, you're a criminal” feeling...so I think that's probably why we don't have it [racism] here. (Camilla, MCHS Focus Group 1, 2014)

Not only did this student fail to see the racism at home, she placed "Black people" as the cause of racism elsewhere. Unfortunately, these are maneuvers of White people that exclude them from having to address issues of inequity that they do not see as harming themselves. Conversations around race also revealed the hierarchical nature of this categorization as the student quoted above was Asian-American — though mostly identified as White. The need to not be identified as a racial other was strong for this student as she shrugged off jokes her friends made to her, such as in this quote: "So I mean my friends sometimes make Asian jokes, but I'm only half Asian so it doesn't really bother me, and the jokes themselves don't bother me at all because they're not actually derogatory" (Camilla, Interview 1, 2014). The layers of racism in American society can be seen here; as an Asian-American this student could be made the butt of jokes and experience racism, however as "not Black" she was able to participate in racist discourses that still oppressed others. Experiences like this students offer a space to understand that all forms of oppression, and racism, are related. Had this student had the education and experiences to understand how her miseducation around black life also contributed to her lack of power as her friends joked about her heritage — perhaps she could have taken a stance that she was building for herself and other racial others, rather than grasping at the Whiteness available to her and highlighting others" "lack" of Whiteness to support her position. 


\section{Student Stories and Major Themes}

Table 9 provides background information for each of my participants to help develop a picture of their lives and social class backgrounds. When looking at social class, I include how the guidance counselor described the students, which she did easily and quickly. However, as I learned more about the context of Mill County I saw the students somewhat differently than how

they were described by the counselor, so I include that as well. Also, I describe how the students may have been "classed" had their backgrounds been evaluated by more typical standards that focused on high levels of education, income, and job prestige. I think this is an important aspect of this work as the class structures in Mill County were different than in places where higher education and professional careers are more highly valued. Here, blue-collar was middleclass. As I work through the major themes that came from Mill County I utilize portions of students' stories to show exemplars of the processes taking place. The first vignette profiles Hedy, a young woman with strong connections to her community. After this I compare the stories of the two other participants who, while participating in similar activities, drew capital from them differently and were thus recognized differently. I end with the stories of participants' parents and how they agentively disrupted dominant discourses that hide structural inequalities. 
Table 9

Background information for students and families in Mill County.

\begin{tabular}{|c|c|c|c|}
\hline & Robbie & Hedy & Camilla \\
\hline \multicolumn{4}{|l|}{ Social Class } \\
\hline Counselor & Poor & Working-class & Upper-class \\
\hline Mill County & Working-class & Blue-collar, middleclass & Upper-class \\
\hline Broadly & Working-poor & Lower middleclass & Middle/upper middleclass \\
\hline Family & $\begin{array}{l}\text { Parents married, } \\
\text { younger sister. Adult, } \\
\text { paternal } 1 / 2 \text { siblings. }\end{array}$ & $\begin{array}{l}\text { Parents married, younger } \\
\text { sister. Adult, paternal } 1 / 2 \\
\text { siblings. }\end{array}$ & $\begin{array}{l}\text { Parents married, younger } \\
\text { sister. Adult, maternal } 1 / 2 \\
\text { siblings. }\end{array}$ \\
\hline Race \& & Mom, White & Mom, White & Mom, White \\
\hline ethnicity & Dad, White & Dad, White & $\begin{array}{l}\text { Dad, Filipino } \\
\text { Sister, Indian, adopted }\end{array}$ \\
\hline $\begin{array}{l}\text { Parents' } \\
\text { education }\end{array}$ & $\begin{array}{l}\text { Mom, some college, } \\
\text { nursing } \\
\text { Dad, high school } \\
\text { degree, technical } \\
\text { certificate }\end{array}$ & $\begin{array}{l}\text { Mom, AA, BA Education } \\
\text { Dad, GED, technical } \\
\text { certificate }\end{array}$ & $\begin{array}{l}\text { Mom, AA, medical } \\
\text { technician } \\
\text { Dad, MD }\end{array}$ \\
\hline Parent's jobs & $\begin{array}{l}\text { Both worked part-time } \\
\text { (not by choice) at } \\
\text { Walmart. Raised show } \\
\text { rabbits (self-sustaining } \\
\text { family hobby). }\end{array}$ & $\begin{array}{l}\text { Mom, teacher, family } \\
\text { and consumer sciences } \\
\text { Dad, school bus driver, } \\
\text { small engine repair } \\
\text { business. (Both helped } \\
\text { with FFA \& 4-H as extra } \\
\text { income) }\end{array}$ & $\begin{array}{l}\text { Mom, dog breeding } \\
\text { business } \\
\text { Dad, general medical } \\
\text { practitioner }\end{array}$ \\
\hline $\begin{array}{l}\text { Parent(s)' } \\
\text { school \& } \\
\text { community } \\
\text { involvement }\end{array}$ & $\begin{array}{l}\text { Lions club (mom } \\
\text { officer), athletic } \\
\text { boosters, } 4-\mathrm{H} \text { leader, } \\
\text { foster parents }\end{array}$ & $\begin{array}{l}\text { 4-H leader, FFA (both } \\
\text { helped with these } \\
\text { organizations, year } \\
\text { round) }\end{array}$ & \\
\hline Career goal & FBI agent or cop & Animal behaviorist & Bio-medical engineer \\
\hline College major & Criminal justice & Animal sciences & Biology, engineering \\
\hline School type & $\begin{array}{l}\text { 4-year small public } \\
\text { university, WV }\end{array}$ & $\begin{array}{l}\text { 4-year large public } \\
\text { university, WV }\end{array}$ & $\begin{array}{l}\text { 4-year large public } \\
\text { university, OK }\end{array}$ \\
\hline PROMISE & $\begin{array}{l}\text { Did not meet reading } \\
\text { subscore }\end{array}$ & Yes, took ACT 4 times & Yes \\
\hline $\begin{array}{l}\text { How they paid } \\
\text { for school }\end{array}$ & $\begin{array}{l}\text { Loans, grants, stipend } \\
\text { (AmeriCorps), tuition } \\
\text { reimbursement \& } \\
\text { stipend (from RA } \\
\text { position) }\end{array}$ & $\begin{array}{l}\text { Loans, PROMISE } \\
\text { Scholarship, other } \\
\text { scholarships }\end{array}$ & $\begin{array}{l}\text { National Merit Scholar, } \\
\text { full tuition scholarship for } \\
5 \text { years, plus stipend }\end{array}$ \\
\hline Overall GPA & 3.4 & 3.85 & 4.43 \\
\hline
\end{tabular}




\begin{tabular}{|c|c|c|c|}
\hline $\begin{array}{l}\text { High school } \\
\text { activities }\end{array}$ & $\begin{array}{l}\text { Technology student } \\
\text { club, soccer, cross } \\
\text { country, basketball }\end{array}$ & $\begin{array}{l}\text { FFA (officer), National } \\
\text { Honor Society, powder } \\
\text { puff football }\end{array}$ & $\begin{array}{l}\text { Technology student club, } \\
\text { National Honor Society, } \\
\text { student government } \\
\text { (officer), school spirit } \\
\text { club (officer), band, track } \\
\text { science bowl, quiz bowl } \\
\text { team, Hi-Y, powder puff } \\
\text { football, ultimate Frisbee } \\
\text { club }\end{array}$ \\
\hline $\begin{array}{l}\text { Outside } \\
\text { activities } \\
\text { (organized) }\end{array}$ & $\begin{array}{l}\text { 4-H, youth leadership } \\
\text { academy (summers), } \\
\text { raising rabbits } \\
\text { competitively }\end{array}$ & $\begin{array}{l}\text { 4-H, raising animals } \\
\text { competitively }\end{array}$ & $\begin{array}{l}\text { 4-H, dance lessons, piano } \\
\text { lessons, horseback riding } \\
\text { \& competition (boarded } \\
\text { horse at local stable) }\end{array}$ \\
\hline $\begin{array}{l}\text { Other } \\
\text { activities }\end{array}$ & $\begin{array}{l}\text { Video games \& online } \\
\text { communities, hunting, } \\
\text { 4-wheeling } \\
\text { **mainly with family }\end{array}$ & $\begin{array}{l}\text { Hunting, 4-wheeling, } \\
\text { camping } \\
* * \text { friends and family }\end{array}$ & $\begin{array}{l}\text { Photography, camping } \\
* * \text { mainly with friends }\end{array}$ \\
\hline $\begin{array}{l}\text { Work or } \\
\text { volunteer }\end{array}$ & $\begin{array}{l}\text { Camp counselor } \\
\text { (summer after } \\
\text { graduation with } \\
\text { AmeriCorps), } \\
\text { community service }\end{array}$ & $\begin{array}{l}\text { Earns money from } \\
\text { animals raised, animal } \\
\text { shelter volunteer, } \\
\text { community service, NHS }\end{array}$ & Community service, NHS \\
\hline
\end{tabular}

\section{Networks of Support: The Kids Know if they Need Somethin' I'll be Right there}

The quote in this header comes from a teacher and is illustrative of the connections across people and organizations in Mill County, some that I have shared about in previous sections. These connections functioned as networks of support for those in the community and are made visible through the stories of the students in the study. Family was a cornerstone in each of the students' lives and these connections extended to other community institutions. Not only were the participants tied in to multiple institutions within Mill County, but this appeared to be common across many families, the school, and other community organizations. 
Hedy's story exemplifies the connection among family, community, and organizations. Hedy was not simply connected to these organizations because they were what her parents had chosen, rather the pathways were reciprocal. Her parents had become involved in some of the activities because of Hedy and her sister's interest; her sister, who was one year younger, was also involved in FFA and 4-H. Through the connections with her family and corresponding organizations, Hedy co-constructed a space for herself as a person of value with a purpose that was also valuable, as well as enjoyable. As a person of value, Hedy pursued this identity and also offered it as a space for others.

Hedy became interested in agriculture when she was a little girl playing with animals on her grandparents' cattle farm. She vividly recalled the first time her dad put her on a horse and just "knowing" that she wanted to be around animals. As her family worked together in the agriculture industry, she had grown to love this life and come to pursue it as her own. She found value in the production side of agriculture, viewing animals and produce as things "that people need," something she and friends pointed out as a contrast to fracking and what it was doing to the land. In elementary school she had become involved in 4-H and this had developed into a family activity where here mom was a leader and her dad helped with maintenance at the camp. Her dad had worked with the county commission to secure funding for a new tractor and other equipment to help maintain the camp. Hedy described the annual 4-H camp as one of the best weeks of her year when she connected with friends and learned leadership.

Along with learning leadership at 4-H, Hedy had developed a strong sense of community and appreciation of the need for involvement. When sharing what she appreciated about Mill County, one thing she mentioned was the care people in the community had for one another. She shared about 4-H and FFA: 
When we have dinners or anything like volunteer stuff at the 4-H camp, everybody pitches in - they're like, "What can we do to help, what can we do to help?" And I'm just like, "OK this is really good." I went to other places and it's just the kids who are doing it, the parents aren't involved, the community's not involved...Well I'm glad where we live people actually want to get involved. You know you've got a select few that don't want to, but the majority they want to help out, they want to see the kids succeed. Like the ham and bacon sale, these people pay $\$ 10,000$ for a carton of eggs, I'm like "Yes, you definitely want to see this kid succeed in life"... And then at 4-H camp, we go up there for "Make it Shine" where we help clean up the entire camp a few weeks before we actually have 4-H camp and you've got adults out there that aren't even in 4-H that want to help. It's one of the great things that I like. It's a lot more fun when you have other people that aren't even involved that want to help out. (Hedy, Interview 1, 2014)

Hedy had picked up the narrative of leadership and involvement, particularly as community businesses very visibly supported students financially at the ham and bacon sale. The ham and bacon sale was the biggest night of the year for the FFA, as it was a culmination of nearly an entire year's worth of students' work raising and tending animals and then harvesting their work. While the ham and bacon sale was a place for businesses to show off and make a very visible community contribution, Hedy viewed the event more as the earned fruits of labor, rather than as businesses using the evening for publicity.

Hedy drew on these internally persuasive discourses to mediate her action as an involved leader. She shared the story of a "corrupt" extension agent who had falsely accused her mother of "cheating" for her by choosing Hedy to receive an important 4-H award because she was her 
daughter and not because she earned the award. Despite the extension agent being an adult and a person in a position of power, Hedy decided that she would take action to stand with her mother. She shared this story of how she and her friends showed support for her mom at the meeting where her mom's future with 4-H was being decided because of the cheating accusations: I personally got mad because it was not her fault, [Mom] was supposed to be cheating about me [according to the 4-H agent], and I personally took that as offense because I'm like, "Nobody cheats for me, I do my own work." But a bunch of us kids, I'm like you know what, we're gonna show them that we're not messin' around anymore, so probably about anywhere from about 50-100 of us kids, they had a meeting at the 4-H camp and we all sat out there 'til the meeting was over. They told us that we weren't allowed to sit in there 'n listen at the meeting, I'm like “OK, fine we're gonna go sit out here." So we waited the entire time, we were not leavin', we ordered pizza, we had water, we were sittin' there the entire time. But that's one of the nice things is that...cause my parents are so involved in this community that we're like, you know...we're not gonna let her stand alone in this...If we don't stand up now_-if we wouldn't've stood up then for that, I swear we probably would've not got this great agent that we got now. (Hedy, Interview $1,2014)$

Hedy's identity as a leader allowed her the space to act according to that discourse. She organized her peers to stand up for her mother, which she felt ultimately resulted in the replacement of the finger-pointing extension agent. As Hedy found success within this identity, she was able to move in ways to support that identity and to draw upon in challenging situations. 
Through 4-H, Hedy became involved in FFA, another cornerstone of her life. She loved it and also found her friend group here as well as satisfaction in what the group provided. She had particularly picked up on the narrative of hard work as valuable and how the work, and not necessarily the profits or rewards of that work, was most important. She had been an officer in the FFA since she was a sophomore and had raised a variety of animals: lambs, hogs, and steer. Her senior year she raised a steer and won the showmanship award at the county fair. She described her pride in winning this award - even more so than Grand Champion (the more prestigious award) because:

Showmanship is skill, I mean Grand Champion, yea that's really nice, that means you have a really, really good animal, but also Showmanship means you've worked with your animal the most, means you know how to handle your animal. If you don't get Grand you want Showmanship, it means you know how to handle that animal in any situation you could put it in. It means you've worked with that animal, no matter what you could do with it, you've worked with that animal to its maximum limit. (Hedy, MCHS Focus Group 3, 2014)

The FFA instructor, Lenny, provided narratives about the value of hard work in his classroom and in FFA. These discourses seemed influential for Hedy. Lenny valued animal husbandry with his words and actions. He had set up independent study courses for his students who worked outside of school in order for them to receive academic credit. Lenny's actions set these students up as contributing members of their families and communities and provided institutionalized capital in the forms of course credits and grades for efforts that would have otherwise gone unrecognized. 
FFA and 4-H were not the only places where Hedy learned how to value herself and others, these teachings came from her parents as well. Hedy's father, Harry, had grown up poor; after leaving high school to work in the service industry, he joined the military and was sent to Vietnam. When he returned to the Ohio Valley he worked at multiple jobs until he had the opportunity to complete his GED. Once this was completed he was able to apply with the Board of Education for a position as a bus-driver, which he worked at for over 20 years and retired from during the year of this study. Over this time he and Karen, Hedy's mom, had decided to build a house and when they had saved enough money they went to the bank and were denied a loan. Harry recalled his disgust at the experience, though they were viable loan candidates, they were not seen by the bank as "good enough." The credit union, however, offered them a loan and after almost 20 years of wise-spending and frugality, at the time of the interview, they were one house payment away from paying off the home they had built on 3 acres.

I tell this story because it connects to how Harry and Karen built value in their girls. As parents, Harry and Karen maintained a space of open and explicit communication and stressed the value of hard work. They had frequent family meetings where everyone shared, including sharing with the girls about finances and when money may be short. Viewing herself as a full family participant, when Hedy began to earn extra money from raising animals she came to her parents to offer to contribute financially to the household. In addition to occasionally helping out with bills, Hedy and her sister also bought an ATV with their FFA profits so that they could more easily feed and care for the animals on their property. Hedy also bought herself a laptop to take to college. Because Hedy had been treated as a full participant in her family, she took up this dialogue and acted as a contributor and supporter of her family — a position of value, of which her parents were quite proud. 
This network of many people and organizations - parents, extended family, community, school and club advisors, and the FFA and 4-H—shaped a space for Hedy to learn about valuing people for how they support one another. Hedy picked up these discourses and authored her own space, creating pathways for herself to be a valued and also to value others. While this story is particular to Hedy, I saw this happening across students at MCHS and within the broader community. For instance, although Robbie did not have a paying job, he helped his family out with many chores that provided skilled work that otherwise would needed to have been hired out. One picture Robbie shared in the photovoice focus group was of their house where he described all of the improvements he had helped his dad do. He explained that it was important to him because it showed what hard work could get you and also it represented time spent with his family. Robbie also shared about how he and his family cared for a farm for another family who lived out of town and in exchange they could use the property however they wanted. So as Robbie spent summers brush-hogging the property and generally caring for it, he was also helping to acquire a space where his family could hunt at leisure and spend time on ATVs. In the figured world of Mill County, value could be gained through cooperative participation and support and not only through competitive endeavors. Through this process, Hedy and other students were able to gain value as participants that helped them to move through the world. They authored spaces for themselves as people of value and not only as participants in a contest with winners and losers with correspondingly assigned values.

While these connections and support were built across different entities such as the school, community organizations, and individuals, I did not find any evidence to show that this was an intentional explicit effort between these groups to say, "Hey, let's work on building value in people outside of traditional markers of success." Rather, it may have been a local practice 
where people recognized value in others and appreciated what could be done to support people, building a network of community social capital and also cultural wealth with this interconnectedness. I think this is particularly important when thinking about how typical markers of value, such as financial wealth and prestigious jobs, were not common in the area and thus were not given as much clout. This is not to say that at times these things were not viewed as valuable, as I will share later; however, they were not the usual ways of how a person came to be seen as valuable.

\section{Being Present: Relationships and Experience}

Closely tied to the idea of building value within a person as inherently valuable, was the focus at MCHS, and more broadly in Mill County, on being present. I title this section in reference to the way that life was often interpreted and authored. People were firmly anchored in the present with an understanding of how to appreciate and/or take in the experiences happening in the moment. More often than not, there was not a distracting focus on how the present may be instrumentally used for gain in the future. As a reminder, instrumentalism is when activities are used as a tool to a further outcome and the actions and activities are not the end goals themselves. This is in contrast to neoliberal instrumentalism where every person is a rational actor who bases, or should base, their actions and decisions on how they may be profitable. Often, experiences that produced this being in the present were shared in relationship with others. Relationships were also characterized by a lack of motive for gain, which is why I also include relationships within the title. Moreover, this section highlights how positionality within fields, in this instance, the field of education, was influential in shaping how agency was enacted. 
Robbie's story is an example of this way of being, of valuing the experience over where the experience may get you. While this theme continued to pop up during the study, one of the most pronounced instances was in how Robbie participated in the Technology Student Club (TSC). A teacher who was very popular with the students and also a coach for multiple sports sponsored the TSC. While the TSC was a club open to any student, there were also associated classes: TSC class, drafting, computer programming, engineering, etc. Every year the TSC went to a state competition and a few winners went on to the annual national competition. Interestingly, the TSC was one of the few organized activities I encountered in Mill County where competition was a central focus. During the photovoice focus group Hedy described the camaraderie she experienced at the FFA national conference:

If you go up to somebody nobody disses you. The officers you meet, every national officer up there. Every single one of them will come over to you and meet you, no matter who you are. No matter what state you're from or anywhere. They meet each individual county from each individual state, from some point during the week. (Hedy, MCHS Focus Group 3, 2014)

In response, Camilla shared about how the TSC conventions were different, "I know at TSC conventions it's not probably, not as close friends, you kind of stick with your chapter 'cause it is a competition still” (Camilla, MCHS Focus Group 3, 2014). The TSC was more closely aligned with neoliberal narratives of competition and different from many of the dominant discourses of the figured world of Mill County. As I will discuss shortly, Camilla took up these discourses in her participation with the TSC as well as in other areas of her life, making her stand out from the other students at MCHS. 
Since Robbie enjoyed the TSC teacher, he was in the club and taking the TSC class at the time of the study. I had learned that the state and national competitions were a pretty big deal from Camilla so I asked Robbie about his participation in these events. Even though Robbie had previously taken drafting, a course associated with the TSC, he had just joined the club his senior year and had not participated in the club competitions before. He was unsure about details of the competition and shared, "I really don't know much about conferences. But I'll be goin' to the state level I think" (Robbie, Interview 1, 2014). Robbie was more interested in participating in the projects for class rather than being able to use them at the competition.

When I asked what he was working on for the state competition, he talked about building a model house for an architecture competition. He shared, "I'm building, I'm doing that architectural. Right now I'm on AutoCad building and designing and dimensioning the house. My friend is working on getting ready to build the house" (Robbie, Interview 1, 2014). He was working with two friends on the project using AutoCad software to create a design that was then transferred to a laser engraver to be cut out and then assembled into a house for the state TSC competition. While Robbie had talked about this activity in a blasé way, what he was doing was actually quite impressive. The AutoCad software the students used is technical software used in architecture and engineering and Robbie had taught his peer, who was a star academic and athlete, to use the software since he had already had the drafting course. Despite the possibility for this activity to be a gain of multiple types of capital, Robbie did not approach the event in a way in which he instrumentally "pulled" capital from the interactions. For example, even though Robbie had mastered the AutoCad software to a degree to where he could teach it to others, in his explanation he had just helped a peer to learn the program. As I mentioned, this peer was an academic and athletic standout but Robbie did not focus on his position of power in teaching this 
more socially powerful peer, rather it was just sharing with another classmate. In the quote above, when Robbie first told me about the AutoCad software and that it was used in architecture, he did not know how to pronounce the word architecture, he had pronounced it ARCH instead of ARK-itecture. While Robbie had the technical knowledge of this tool, a form of embodied capital, he did not possess the cultural capital you would expect to come with that knowledge, i.e. exposure to the world of architecture or people who talked about and/or knew about architecture. Even though he had mastered this technical tool that could have functioned as a powerful bargaining chip, say on a college application, that indicated valued institutionalized capital, he did not activate these forms of capital to function in an instrumental way. Robbie tended to not participate in activities for where they could get him, rather he participated in them because he enjoyed them or enjoyed with whom he was hanging out when he did them. Through Robbie's participation, he was authoring spaces where other people were valued for their time and company and shared experiences, which, in turn, allowed him to participate as a reciprocally valued person. Robbie seemed to have found these local discourses as internally persuasive and as such was reproducing a space that reinforced these discourses within the figured world of Mill County.

There were similar types of narratives within Robbie's parents' experiences as well. It seemed that Robbie had learned from his parents how to value experiences presently rather than instrumentally. For instance, Robbie shared that he "always knew" that he would go to college because his parents had formed this in him from a young age. His father, Ben, had been in the military and as Robbie described, "He didn't want me to have to go through what he had went through," (Robbie, Interview 2, 2014) so had always pushed for Robbie to go to college. Ben's reasoning for Robbie to go to college was not for social-climbing or entrepreneurial reasons, 
rather for a concern for his general well-being and of wanting him to be able to avoid some of his own struggles. During the parent interview Ben shared about how he had fostered discourses valuing education that he felt Robbie had adopted and thus helped him to succeed:

Ben: [Robbie's] been thriving in his head, education first, sports, women leave him alone (laughter), until he gets his schooling done. That's something I've been pushing for a long time and I think that's why it usually falls into play.

Brandi: What has made you push that for him?

Ben: Because I didn't get to go [to college] myself, just like anything else in this valley you have to strive for what you get and if you don't have that [education] you have to go to work, you live the opposite side of the coin you have to struggle. (Ben, Parent Interview, 2014)

This discourse was not one of material, or immaterial cultural, acquisition, rather what helps to make a good life - the absence of struggle.

When I spoke with Robbie's mom, Carrie, about how they were going to pay for his schooling, she was unsure about how they would cover the costs. At the time, Robbie was considering two state universities. To help out a bit, I put together an information packet on the local community college that had a $2+2$ program for Robbie's major, criminal justice, and laid out all the different costs in comparison to the schools Robbie was considering. When his mom and I talked about the different options she already knew that the community college, which she had attended when she was Robbie's age, was a much less expensive option. But she also knew that Robbie had his heart set on attending a school where he could have that "college experience." Carrie shared about Robbie's excitement when they went to the college open house and he saw the student recreation center, "When I go to pick him up I know where he's going to 
be...between eating and his exercise and the sports, he'll be there...that's where he'll be" (Carrie, Parent Interview, 2014). Carrie recalled living at home when she had attended college and she wanted Robbie to have the full, away from home experience that she had missed. She shared, "He wants that away from home, in the dorm experience and I want him to have that because I did not, so I think it's a good thing for him" (Carrie, Parent Interview, 2014). Despite knowing that a $2+2$ program would be a more feasible way for Robbie to complete a baccalaureate degree, Carrie shared that even if Robbie only went for 2 years to the 4-year college and then came home and worked for the police that he would "still be ahead" of those who had only attended the police academy. Her brother-in-law worked for the local sheriff's office and had helped Robbie in choosing criminal justice, so perhaps he had shared some insider knowledge of the inner workings of the institution. For Carrie, Robbie having the experience that he hoped for as a college student was more important than the actual completion of a degree. While Carrie was willing to forgo the institutionalized capital of a baccalaureate degree, she did see that completing some college would still confer some institutionalized capital as Robbie would be ahead at the local police office, and perhaps even some cultural capital that came with the "college experience" she referenced.

Robbie was generally spoken of as a "good" kid when people mentioned him, which was typically in passing. His parents were never recognized or mentioned by others I engaged with. However, when Camilla was mentioned, her name was often attached to a listing of the achievements she had completed or about how she excelled at many things. Additionally, her family's place in the community was well-known. On at least two separate occasions when 
teachers referred to her, I asked of whom they were speaking in an attempt to maintain confidentiality and the teachers looked at me like I had three eyes. One teacher replied, "She's Camilla Bainbridge," as if that were enough for me to know why I should be impressed.

Unlike Hedy and Robbie, Camilla often spoke of activities in relationship to their expected or hoped for outcomes, and focused less on being present within the actual exposition of activities. Given these experiences and with an understanding of how Camilla was positioned by other actors within the figured world of MCHS, it is not surprising that Camilla's interpretations of the TSC were different than Robbie's. When Camilla talked about the TSC she recalled the contests she had participated in, who had been on her teams, how she had ranked, and how she had performed at nationals after winning multiple contests at the state level. When Camilla first described the TSC, she shared:

It's Technology Student Club it's the biggest club [at MCHS]...I think we take 5060 kids down to [the state conference] every year. We've won first place overall with the points the past 2 years in a row, I've gone to nationals both years, got fifth place last year in promotional graphics [at nationals]. We had a lot of people place last year. (Camilla, Interview 1, 2014)

When Camilla described her participation in multiple contests, she did share some about her teammates and of the being aspect of the experience; however, these were limited and embedded within a much stronger focus on the talents and abilities of her peers and in how they placed in competitions. For example:

We had a lot of people place last year...Corey Lands and Chris Washington. Chris Washington is computer genius. Like he's, if he wanted to hack into anything he could. Like he's not even going to college cause he's already got a job with some 
big computer association.... and I think they won $\mathrm{Cy}-\mathrm{Viz} \ldots$... and I think he either got first or second; first, second, or third—it was really big.

I don't know if you know Brian Cash. He and his brothers have done [videography] every year, but since [they] graduated he's now the director and I'm the tech person. I do the editing with after-effects and I'm just Adobe stuff, so I'm doing the technical aspects... And music is kind of harder, a lot harder, because we have to come up with complete scratch, you can't just film something, you have to build every piece. It's the first year I've done it and same with Justin...I don't know if you know Brian Conrad...but he's kind of he's really good at the drums, he's going to State University right now for music education, he's just very, very talented and he helped last year. And it's just a lot of work and a lot of fun though. (Camilla, Interview 1, 2014)

In addition to this substantial participation in TSC, Camilla completed all of her projects outside of class time as she did not take any club classes since her schedule was packed with, literally, every AP course the school offered and the required senior civics course.

While Camilla did participate in local community discourses, as I will detail shortly, she was often focused on how she could use experiences in other ways and not necessarily on the experiences themselves; thinking about how they may relate to other endeavors, while avidly pursuing success. Camilla had what her mother described as an "inner pressure" to succeed, something she was concerned would push Camilla too far. Mary, Camilla's mom, was not originally from Mill County and described that with her older children, who were now adults with children, she had been "one of those mothers who pushed and pushed" for her children to succeed and be involved. However, with Camilla and her youngest daughter, she was much more 
mellow and focused on letting the "kids be kids," a change she attributed to wisdom that had come with age. Some of her other views had also changed as Mary had lived in the community longer. She described how her views of the area and people had changed:

When I first moved here it was like this huge black cloud hung over this area and I was so depressed because I lived in city environments and to come to this rural environment and I used to think [that] the deeper I went into West Virginia I felt like I was in the bowels of some hideous beast that I'd never get out, and now I just am completely the opposite, you know all of the hideous things are happening out away from us.

So [people] might be the redneck types, but they're the wonderful type. So I don't know that I'd change anything. I used to be really up-tight about people using bad language, I have a lot of pet peeves about that and I just cringed, but now I don't, cause that it isn't what makes a person. (Mary, Parent Interview, 2014)

Despite not being instrumental in pushing Camilla to success, Mary had still cultivated a home environment that was filled with dominant class culture that was available to Camilla. Because Camilla had grown up in a home with access to dominant capital, her habitus reflected this, making her a paragon of middleclass success and a good match with the education system. For example, Camilla's younger sister was named after a character from Mary's favorite opera, international travel was valued, and Mary bred popular designer dogs that sold for around $\$ 1.5 \mathrm{~K}$ per pup. Mary’s deportment was that of a cultivated, upper-class lady; she was soft-spoken, with a very feminine voice and impeccable posture. These classed and cultured positions became a part of Camilla's habitus and identity through her mother, placing her in a position of power when it came to engaging with others. Additionally, Camilla was close with her older siblings 
who may have influenced her focus on success. Her siblings' father had been a chemistry professor in the DC area and later moved to work as an industry chemist at one of the chemical factories near Mill County, which would have provided a very high salary and thus economic capital. While I did not learn a great deal about Camilla's siblings, the glimpses I did get showed lifestyles filled with dominant class capital. Her brother was in the banking industry and boarded his daughter's horse at the same stable where Camilla had her lessons and her sister's daughter had recently started violin lessons.

Unlike many others I encountered MCHS, Camilla was quite competitive and often won or was at the top in much of she did, which made her stand out. However, there may have been model minority stereotypes flowing around Camilla's identity that were persuasive in how she was positioned within the figured world of MCHS and also in how she authored herself. Camilla's father, who was the only physician living in Mill County, was Filipino and she identified as "half Asian." To my knowledge, other than her sister who had been adopted from India and an exchange student from China, Camilla was the only other student of Asian descent at MCHS. Camilla shared that her father's family was heavily involved in the medical profession, "[Dad] was a physician, so most of his family became either some kind of medical profession. One aunt's an OB-GYN and the rest are nurses and he's the doctor" (Camilla, Interview 1, 2014). Camilla's father had high expectations that she would enter the medical profession as she shared when she told me about her career choice to be a bio-medical engineer:

[Dad's] glad that I'm doin' something medical profession because at one point I kinda wanted to be a surgeon or some kind of doctor...but he's still glad that I'm doing some kind of medical something, even if it's through engineering. (Camilla, Interview 1, 2014) 
These weighty family expectations may have built some of Camilla's desire, and put pressure on her, to achieve. Her achievement, which was very visible, may also have led the MCHS faculty to treat Camilla in ways consistent with the perception of her as a model minority student. As I mentioned earlier, there were definite racist undercurrents within the figured world of MCHS to which the majority group was oblivious. However, one conversation with a teacher who taught all advanced science courses is relevant when considering how the model minority discourses may have influenced Camilla and been influential in how people viewed her. In a classroom observation this teacher was telling about a trip the quiz bowl team, which Camilla was on, had taken to the state university and shared about one team they competed against:

Phew! You should've seen [the team] [shaking his head in disbelief], there were so many Asians, and our kids just didn't know. And some of my [students] go to WVU or somewhere in some of those classes and they see that it's all Asians and they just walk out. (Teacher, MCHS Observation, 2014)

Despite this teacher applying what I am guessing he understood to be a "good" stereotype, the racism inherent in the statement limits the potential identities of students from Asian backgrounds, students like Camilla. Statements like this also potentially serve as relationship barriers as non-Asian students may view Asian heritage students as competitors taking limited resources rather than potential friends or allies. This teacher, who was very focused on high ability students, had also pointed Camilla out to me during my first observation as a student who was particularly impressive.

Despite digressing from some of the local cultural norms through her competitiveness and instrumentalism, Camilla had incorporated some of the local ways of being that valued people and helping others without thought of profit. Each student at MCHS was required to do a 
senior project meant to help prepare them for the postsecondary transition. To fulfill these requirements, Camilla came up with a business plan for how she could use her photo editing skills to start her own small business once she went to college to earn spending money. She had talked about this plan in our initial interview sharing:

My mom has always been self-employed, she had a grooming business with dogs and it's really nice to be your own boss, so with what I'm going into I can't be my own boss... and I'm really good at photography and Photoshop and all the different Adobe programs for editing film and video and I was just thinking about it...I was like why don't I do this and really display my abilities in that and really present it as an idea for my own business through college for another way of making money... so it's nice to have the ability to take the initiative and have your own business. (Camilla, Interview 1, 2014)

In Camilla's thought processes and actions, she maneuvered in ways that would translate her skills for future gain. For her final senior project presentation, Camilla shared her business plan that was very robust and contained the terminology of neoliberal free markets. She focused particularly on "clients, quality products, knowing your market, knowing your audience, etc." (Camilla, Presentation Observation, 2014). As Camilla constructed these spaces of business they were within the framework of a rational economic actor placing a value on market based ideologies.

Despite these enactments being different than dominant local discourses, how Camilla had developed an interest in photo-editing that inspired her business plan did incorporate local values. Camilla had learned how to use the editing software that she planned to use for her business because she had decided that she did not want her family to pay the high costs of senior 
photos. Instead of having her photos professionally done, she let her mom take her photos and then did the editing herself. After she did this project she realized that she was "good" at photo editing and had then taken friends' senior photos and done the editing to help save them money. With these actions Camilla seemed to have found local discourses of helping people and providing for others persuasive. Additionally, Camilla described that she had been "inspired" (Camilla, Senior Project Observation, 2014) to create a business because she had watched her mother run the dog breeding business, which she had also helped with. In this way, Camilla was incorporating valuable knowledge from her family and of helping family into her more entrepreneurial goals. Camilla's incorporation of what would seem like competing discourses, helping out and pursuing for-profit businesses, represents the complexity of the heteroglossic discourses that are drawn upon in identity and refigured within the space of authoring. Camilla was drawing from the various discourses that she found internally persuasive and authoring a place for herself across these competing narratives.

Having found success in learning the editing software, Camilla had shared this knowledge locally and within the school, participating as cultural producer of local narratives of helping out. As a favor to a teacher, Camilla put together the senior video for the class that incorporated students' photos and short video clips into a digital montage set to music. She also helped the art teacher to learn some of the editing software as well as the TSC advisor whom she mentored so that he could teach other students. The TSC advisor was impressed not only with Camilla's skill in the program but also in her teaching him, an observation that he passed on to the principal. In sharing her skill, Camilla had converted a technical skill, embodied capital, into more powerful symbolic capital in the forms of teacher and principal recognition and even cultural capital as a person who was recognized with high academic and intellectual ability. 
There was no evidence that in the case of helping the teachers that Camilla was acting instrumentally in a way that she expected would accrue recognizable capital; however, this was the result. Recall that Robbie had also shared similar technical knowledge of the AutoCad software with a peer in a TSC class where the advisor would have had ample opportunity to see this happen. Despite this similar event, Robbie was not recognized in the same way by the TSC advisor. It seemed that because of Camilla's positionality as a person who was already recognized as having high capital, i.e. high achievement and ability, that the faculty paid close attention to her and so recognized her strengths as capital more often. In contrast, Robbie was not positioned as powerfully within the school and so faculty were not attuned to his accomplishments in the same way that they were to Camilla's. Within Bourdieu's work, this is an instance of where people who start out in a field positioned with greater capital are more likely to gain capital. In this case, Camilla was positioned with more capital within the field of education, which allowed her to be more easily recognized by those in powerful positions, the principal and teachers. This recognition conferred even more recognizable capital to Camilla within the field of education and the figured world of MCHS. In contrast, Robbie's less powerful position did not give him the same visibility to the faculty, so that his similar work went unrecognized and he was not afforded the same access to capital.

I tell Robbie and Camilla's stories together here, to show the complexity in how local discourses were negotiated and the classed differences between how they were recognized within the figured world of MCHS. As I mentioned, multiple faculty spoke at length about how impressive Camilla's academic and extracurricular achievements were; the principal even made special time to come and watch Camilla's senior project presentation and went on for almost five minutes afterwards about her. He described her as “one of the most impressive students who's 
ever come through this school" (Principal, Senior Project Observation, 2014). While the teachers were very impressed with Camilla's ability, it was not necessarily something that I saw them pushing as important for other students. A few of Camilla's AP teachers, who taught mostly honors courses, spoke in a way that was more instrumental, in valuing success in the forms of dominant institutionalized and cultural capital over the idea of appreciating the present for the experience and relationships it offered. However, Camilla's AP Art teacher, who was very impressed by her achievements did not necessarily find instrumental narratives persuasive. His goals were not for students to complete AP Art portfolios and go on to be recognized. Rather, when I asked what he hoped he could offer the students through his classes, he described that he wanted them to find a life-long hobby, something they could enjoy doing and find satisfaction in for as long as they wanted.

The ways that experiences and relationships are performed, intended, and interpreted shape the ways that students can accumulate and activate capital. As institutions, schools are focused on accumulating and conferring various types of capital to deserving actors, often based on the recognition of matching capital (Bourdieu \& Passeron, 1990). Because some of Camilla's practices were similar to the ways that the school treated capital, she was recognized for this congruence with the system and thus awarded more capital. When Camilla approached activities by connecting them to one another or focusing on more than the relationship or activity's inherent value, she was navigating the figured world of MCHS in a way that aligned with the dominant system and discourses and thus was recognized as high achieving. 
As Camilla participated in events, she was able to identify potentially profitable ways to accumulate capital that she was later able to activate for her benefit. For instance, Camilla critiqued a new AP faculty and their teaching ability feeling that she was not learning the things she needed to be prepared for college in the way that she wanted:

Mr. Smith, he's first year teacher, really miss Mr. Andrews, reeeeeallllly miss Mr. Andrews! He knew what he was talking about really well and [what] Mr. Smith is doing right now is he goes through the book and picks out stuff and we have to copy stuff...and it's just like, you know, I really don't get this, there isn't a lot of examples, and while you're writing he's talking about something not that you're writing and it's really hard to concentrate... But since it's his first year, he's still not super comfortable teaching. Even though Mr. Andrews was kind of slow sometimes, he'd always make sure you knew what you were doing. And last year I just flew through everything, aced everything, and this year it's kind of like I really have to think about it and apply myself to understand because of the teaching, the way of teaching. (Camilla, Interview 1, 2014)

As she had been a successful student previously, Camilla had developed a positive relationship with the now retired Mr. Andrews and actually contacted him in his retirement to be her tutor. In this experience, Camilla's success as a student gave her academic capital that was related to social capital in her relationship with the teacher, which placed her in a position to feel powerful enough to activate these forms of capital for her benefit when she asked for tutoring. Camilla was the only participant at MCHS to act in this entitled manner, that what she was getting was 
not good enough and that she was entitled to more. Based on her positionality within the figured worlds of MCHS and Mill County as a person of power, Camilla was positioned within the field of education to navigate relationships and activities in accordance with this position.

Again, I contrast this with Robbie who despite technically having some capital, did not view it in the same way nor use it as instrumentally. Robbie had attended a youth leadership camp every summer during high school, a place he enjoyed being with other students and where "you can just be yourself." His mom elaborated on the other campers, " [they're] down to earth, they're not trying to be the snotty, they're just regular kids that he gets along with just like he is, it's not trying to impress anybody, they're just them, they're themselves" (Carrie, Parent Interview, 2014). At the encouragement of some of the camp leaders Robbie applied and was selected for a position as camp counselor the summer after his senior year. When Robbie talked about this AmeriCorps Vista job he was most excited because he would be able to see his friends, “I got friends from last year which will be goin' back, since I can’t be a camper anymore [so] I get to see them" (Robbie, Interview 1, 2014). He would also be "helping" the younger children who came from low income backgrounds. That Robbie would receive a stipend to help pay for college from this position was an ancillary detail he mentioned in passing.

At Robbie's follow up interview at college in the fall he shared that he had gotten a job as a resident assistant (RA) at the university, which he loved because he had his own dorm room. When I asked how, as a first semester freshman, he had gotten this position, he said that a friend from camp was also an RA and had suggested that he would, "be perfect since he had done leadership and camp counselor stuff all summer at camp and stayed on campus most weekends" (Robbie, Interview 2, 2014). At the friend's suggestion Robbie applied for and was awarded the RA position. He described, "I went down that night and applied for the position, had an 
interview at 10 the next morning, and then four hours later they told me I had the position" (Robbie, Interview 2, 2014). This also meant that Robbie got a room and board reimbursement and a living stipend, which were very helpful given the uncertainty of his family's financial position. Robbie had accumulated a range of capital, both institutional and cultural, as a leadership camp participant and later counselor. Additionally, the experience of working with multiple children and teens also would have given him an embodied capital of the experience of being responsible for other people. However, he did not activate this capital in an instrumental way that propelled him forward in preparation for something else. In fact, Robbie's habitus disposition of where he and others belonged in life and what they were entitled to, did not position him in such a way that he felt entitled, nor perhaps knew how, to draw upon his available capital to place himself at advantage over others. It was only at the camp leaders' encouragement that Robbie applied for the position as a camp counselor and only at his friends' suggestion that he applied for the RA position. As others recognized the capital he had gained from his life experiences, and also recognized his ability to care for others, they encouraged him to activate that capital and draw on his new experiences. As Robbie was encouraged in his experiences he activated capital that had previously been inactive. These stories of Robbie and Camilla are exemplary examples of how a person's place in life and their experiences shape how they engage with the world around them.

\section{Disrupting Dominant Discourses}

In the past two sections I focused on the student participants and now I am shifting to the voices of the parents to give a more robust view of the figured world of Mill County. It seemed that, due to their life experiences, the parents that I focus on in this section were able to name discourses related to structural barriers and inequalities and push against them by authoring 
spaces where their experiences outweighed national and state level discourses that blamed West Virginians for social and economic hardships. In particular, people saw how the social class hierarchy and neoliberal power systems limited life opportunities for some. While these insights could be sharp and incisive, there were often not systems in place that would allow people to move forward in ways to produce beneficial change. This is the power of the system of social reproduction. Even if people see inequity and are able to name it, the power they hold in naming those things is often not strong enough to disrupt the more powerful discourses that perpetuate inequity, particularly in fairly isolated, rural areas like Mill County. Holland et al. describe that this is why positionality matters. Willis (1976) found similar events in his work with the British lads, where the students were able to name actions of the educators and school systems that reproduced inequality. However, because of their social position that afforded them less power, their insights were disregarded.

I saw these insights most clearly from Harry, Hedy's father, and Ben, Robbie's father. Harry and Ben shared similar backgrounds as both had grown up poor in Mill County, in the country. While Harry had achieved more financial security later in life, Ben and Carrie continued to struggle to provide a financially stable home. Ben and Harry's stories are particularly powerful when thinking about their age and the economic context of their work histories. Both came of working age during the late 1960's and early 1970's when work was abundant in the Ohio Valley with many coal mines, chemical plants, and other industrial jobs available. Even though both had worked at multiple of these jobs, neither was able to get into one of the more stable mines or plants that did not have frequent strikes and layoffs. Jobs at these more stable 
places were often gained through family connections, a form of social capital. When fathers or uncles worked at a site they were able to access positions for their younger relatives; however, neither Ben nor Harry had access to this social capital, which impacted their life outcomes.

Ben and Harry both shared about how difficult things had been for them growing up and in school—not having the right kind of clothes, having to work on the family farm, and Ben even described how the other kids had "tortured" him. These struggles at the bottom of the social rung had opened a space for them to see that not everyone had the same access to opportunity. Ben described:

Overall picture in state is, the structure for the people is, you have the high class and the low class, low and high income, you don't have a middle income, so if you're not born in the high income, you're gonna live the low income, that's it. The opposite side of the coin, you're born, you live, you work you die, that's West Virginia.” (Ben, Parent Interview, 2014)

Ben, who was a self-taught history buff, had quite a bit to say about power in West Virginia. When sharing about how hard you have to work and that it often does not pay off in the ways that people claim it should, he referenced the state flag (See Figure 8). He pointed out the figures on the flag are a farmer and a coal miner. "The bottom line, that's West Virginia started with coal mines, that's how this state was formed, look at the state flag. That basically tells you the whole system, looking at the pictorial on it, I'm here to work, that's it" (Ben, Parent Interview, 2014).

Rather than having a pride for the "hard work" that "actually produces something" like many people in West Virginia present, Ben critiqued this system as being inequitable with clear winners, those who make money from the system, and losers, those who work to make money 
for others. Perhaps because Ben had been excluded from the steady jobs of the coal mines and other local industry, he had not bought into the "community economic identity" that supported industry, often to the detriment of local areas (Bell \& York, 2010).

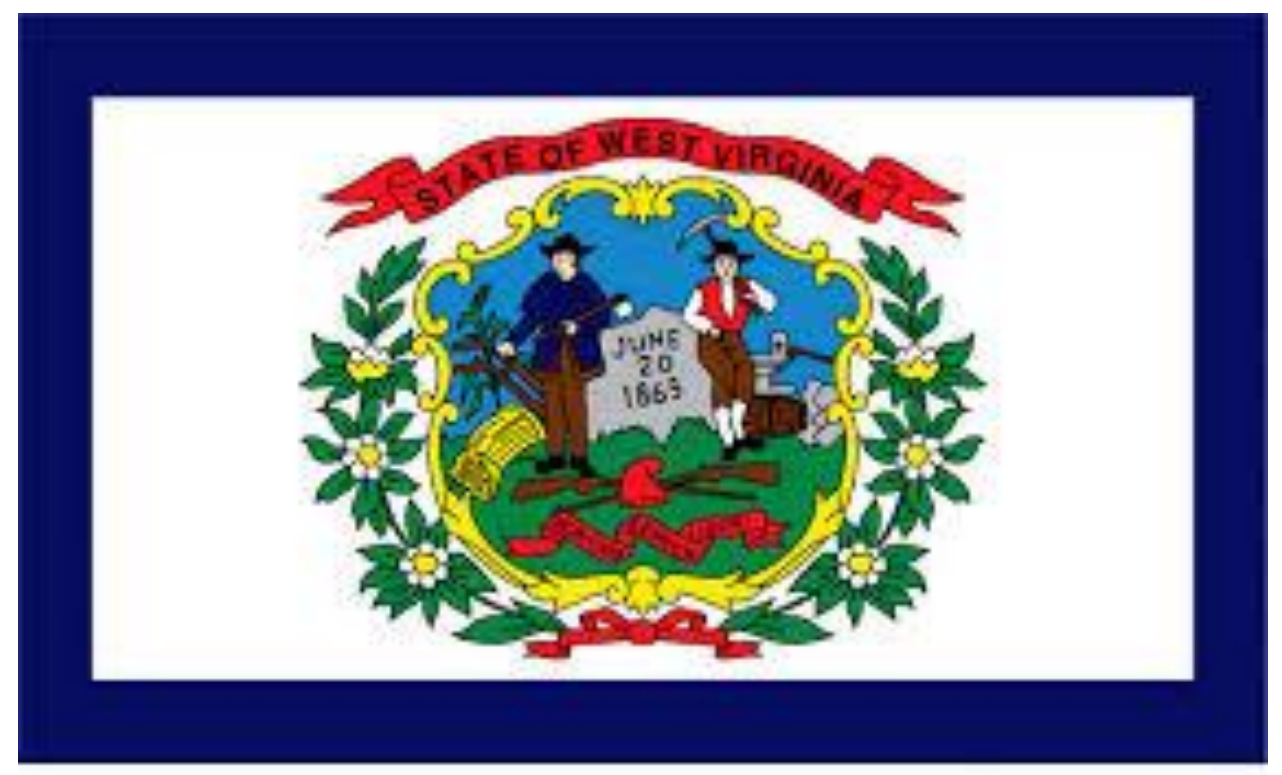

Figure 8. West Virginia state flag featuring a farmer and coal miner and the phrase "Mountaineers are Always Free" in Latin.

Having worked at Walmart for years at less than full-time but more than part time status (a typical neoliberal industry practice to avoid providing workers with full-time benefits), Ben had recently had his hours upped to full-time status. Both he and Carrie were very excited about this, as it also meant he was eligible for employer provided healthcare that they hoped may be extended to Carrie. When sharing about this promotion Ben and Carrie praised the new store manager who was going to improve working conditions at the store with "no more skeleton crews," a critique of another industry practice, typical of Walmart, of operating with only a minimal crew which made things stressful for the staff as there were too few people to complete required work. 
Despite being able to name these exploitative industry practices, Ben had picked up on some of the available neoliberal discourses that I heard from others in the area. When Ben was describing some of the economic difficulties of the area he named globalization, without actually calling it that, as damaging and noted how manufacturing had shifted from production in America to production in Asia:

Prime example, Walmart first started and established itself and used to have all made in USA, now it's all made in Asia-Philippines, China. What happened to made in USA? They're now overseas, why, because they couldn't pay what government wanted them to pay or it was cheaper labor...Compare Chinese labor wages with American pay, five cents on the hour compared to $\$ 18$ an hour. But we built that ourselves too, greed, unions. Unions didn't help much because every time a contract came up, 'Well we'll shut you down if you don't work for me-so now we want another $\$ 5$ on the hour. So now it's outrageous - always asking for more money. (Ben, Parent Interview, 2014)

While Ben could name the troubling symptoms of globalization, rather than placing the cause of economic trouble on industry practices that prefer profit over providing jobs and a living wage for American workers, Ben named the government and unions' overstep in wanting too high of wages as to why industry had to "move overseas" to maintain profitability. Despite unions having negotiated much of the best work in the Ohio Valley over the past 30 years, the industry's powerful propaganda has infiltrated narratives and views in the area (Bell \& York, 2010). This is not to say that union members do not have valid critiques of the union itself, where the union has become an institution unto itself that puts institutional interests above the needs of members (Schwartzman, 2015). However, that others, outside of the union, like Ben, have also picked up 
on these narratives illustrates the power of the neoliberal machine where particular discourses are repeated while others are silenced, negating them as alternatives to the pro-neoliberal discourses (Cassell \& Nelson, 2013).

For some, the neoliberal discourses of potential wealth, coupled with the false promise of “energy independence" that fracking could provide were very persuasive. However, this sentiment was not ubiquitous in the area and particularly not for people who were not involved with businesses that fracking supported or who did not profit from land and mineral rights. Harry was not convinced that fracking would provide the economic boom that had been promised and that some people were still hoping for, despite being five years in and not having seen positive economic growth.

During Harry and Karen's interview we sat on their front porch, which is near one of the local highways, and as we were chatting fracking trucks were frequently driving past. Harry pointed out the trucks and commented on how much money the drivers made, upwards of $\$ 60,000$ with only a high school degree, but then also pointed out:

Your oil industry is coming in here, the big demand is for drivers, that's your big demand anywhere....it'll be here five to seven years, what's there after that? You have to [have] a little college to go after that, because you're going to have to learn to operate some of the other equipment they install. (Harry, Parent Interview, 2014) Harry knew that the fracking boom was not permanent and that the temporary jobs provided, no matter how good they paid, were not a solution to the economic issues in the area. He was keen in understanding that the oil workers would likely need some education to fall back on so that when the fracking boom was over they would still be able to make a decent living. As Harry moved through this train of thought, he shared that he did not think that schools, the high school 
nor colleges, were serving students, nor people in general, well by not offering technical training that could have served people locally. At this point Karen chimed in and reiterated the lack of technical training available for high school kids that could be helpful. Recall that offerings from TCTS, the technical school had become increasingly limited for students because of structural barriers that included transportation, scheduling, and increased admission requirements for students to participate. Tami, the guidance counselor, had shared that this precluded many students who could have benefited from technical education from participating and that this contributed to many students "falling through the cracks" when it came to the postsecondary transition.

Harry continued on (he did tend to "preach" a bit—our interview lasted for 5 hours) to critique the college system and how he saw it as a business model that exploited students. He named colleges as a business, sharing about what he viewed as the outrageous costs of tuition and fees despite colleges not being able to guarantee a job for students when they graduated. He also critiqued faculty salaries, questioning if some really earned the $\$ 80-90 \mathrm{~K}$ salaries they were given if they were not able to help students secure careers after college. Harry also critiqued what he saw, but did not explicitly name, as predatory business practices, citing the high cost of textbooks that would only be used for one semester and also credit card companies pursuing college students. After Hedy had registered for college she had begun to get credit card offers in the mail specifically geared towards her as a student with interest rates often above $20 \%$. Harry rightly identified these practices as predatory and recognized how difficult it could be to maintain or, for a young adult with student debt, attain financial solvency when there were so many systems putting (potential) barriers in that path. 
Separately, Ben also named the illusion of security that was promised by a college degree pointing to the falsity of this powerful discourse. He accurately pointed out that in West Virginia, and particularly in Mill County, there were few jobs that required people to have college degrees (U.S. Department of Labor, 2013). Ben saw through this neoliberal discourse, that more education always meant more economic success, and pointed out that while having a college degree may be a route to a more stable life elsewhere, that "in West Virginia, a college degree is like a piece of toilet paper" (Ben, Parent Interview, 2014). However, Ben recognized the Catch 22 of this situation knowing that if you did not have a college degree that there was even less chance of a stable economic future. Recall that he had encouraged Robbie from a very young age that college was his best option and was still actively supporting Robbie in striving towards this goal. Ben shared his concern that Robbie would likely have to move away to be able to use his college degree and earn a decent living. He was shrewd in his recognition that a college degree may even put Robbie at a disadvantage locally. Ben described his concern that if Robbie completed a 4-year criminal justice degree and came home and applied to the local police department that they would likely choose someone who had completed only the police academy over Robbie because they would be able to pay that person less - a serious reality in a community with limited funds and even more limited police positions. Ben's experience, and perhaps interest in history, had allowed him to name the alternative discourses, often made invisible by neoliberal rhetoric, that helped to explain the dire economic context of people and places. Despite naming these alternative discourses that were more accurate than the powerful discourses of neoliberalism, Ben lacked the power to make any sort of systemic change within these structures and could only hope that Robbie would be more fortunate than him in being able to move through this system. 
Moreover, Ben was keen in seeing how larger national narratives were not true for the local area and that the opportunities available to people in larger locales were not available in rural Mill County or even West Virginia. Ben's response is reflective of multiple Bakhtinian concepts utilized by Holland et al. (1998). As Ben was addressed by discourses that portrayed him, and West Virginians, as having more opportunities and resources than they did, he answered the social by rejecting this positioning. He indicated that a college degree did not function in Mill County, nor West Virginia, in the same way that they may in other places. Additionally, Ben named the local inaccessibility of essential services as a reason for diminished opportunities. In particular, he pointed out how expensive the options for insurance (car/home/health) were locally and so when he saw a commercial guaranteeing lower insurance rates on television he called to investigate. It turned out that even though that ad had been televised on their local station, the advertised carrier was not allowed to operate in West Virginia. Ben went on to name politicians, specifically Joe Manchin, the sitting West Virginia Senator at the time, in colluding with corporations to profit from these structures. As particularly egregious, he pointed out Joe Manchin signing a bill that dissolved the state run, workers' compensation system and replaced it with a privatized provider that had a legal monopoly in the state for six years; the move was critiqued by workers while praised in the business community. This illustrates the dialogic nature of spaces of authoring where all communication is a response that in turn is intended to evoke a response from the addressee, even if, in Ben's case the addressees are a hypothetical political and economic system. These are structural barriers that Ben exposed as he named that despite the appearance of opportunity, not everyone has the same access to amenities or even necessary services. This is one of the great foils of the neoliberal system, particularly in America, where the national rhetoric of equality and land of opportunity 
disguise the inequity in access of our society, which also allows those who do not achieve success to be blamed as responsible for their positions. As a person who had been on the lowerrungs of American society for his whole life, Ben astutely named these things that did not place him as the bearer of responsibility for this struggle; rather he named the structural inequalities that created these hierarchies, as well as the powerful people who work to maintain and profit from these inequities.

Ben and Harry's experiences are powerful examples of understanding the falseness of neoliberal narratives. Insights into dominant narratives that are used as tools to maintain power and prevent others from gaining power, present an opportunity for change. As Ben and Harry recognized inequities and a lack of opportunities, these are spaces where community coalitions can be built to address issues of inequity. Neither of these men were profiting from these dominant narratives nor the structures the narratives supported, which perhaps gave them the insight to disrupt them. I did not see these sorts of insights from those who were profiting from some of the neoliberal profiteering coming from industry whether in fracking, coal, or otherwise. 


\section{Chapter 5: Covington-A Story of Success}

\section{Community History: Present-Not Past}

Covington is one of two cities in Harman County, with slightly more than 8,000 residents and sits in one of the few West Virginia areas experiencing economic growth. I begin the story of Covington by also describing the neighboring city, Cairnwell, because that is how my participants describe Covington, in contrast to Cairnwell. This comparison is necessary because social class is constructed comparatively, by what one is or is not (Bourdieu, 1984; Mendez, 2008). Covington was very much depicted in comparison to Cairnwell, by its residents and people who were not residents but engaged with Covington. Cairnwell was the county seat and older of the two towns but had seen better days, as it had been hit hard by deindustrialization. Though nearly twice as large as Covington with around 16,000 people, there was a fairly bitter rivalry between the two towns and between their respective high schools. Folks in Cairnwell painted Covington as rich and snobby while those in Covington did not necessarily deny these depictions. In response, one Covington High School (CHS) alumnus said, "Covington kids think they're better than Cairnwell kids, who are "ghetto, " [our] town is nicer and we're richer" (Personal Conversation, 2014). A drive past each of these cities revealed different pictures as well. A four-lane highway, Route 20, ran around the edge of Cairnwell where you could look down into valleys and see shuttered factories, and once-beautiful municipal office buildings leading to rows of highway-dirt stained houses. After passing through Cairnwell, Route 20 soon ran into Interstate 55 and Covington began at this crossroads. Interstate 55 stretched along the length of Covington's north/south trajectory and revealed the growing commerce of Covington with strip malls filled with retail shops and chain restaurants, car dealerships, and new construction of hospital and medical facilities, stretching nearly the entire length of the town. 
The drive through these towns marked an economic disjuncture from industry, to decline in Cairnwell and to the current knowledge and service sector economy in Covington. This difference was a point of pride for Covington's residents and distinguished them in the rivalry with Cairnwell.

While Covington was incorporated as a city in the late $19^{\text {th }}$ century, the focus of residents was not on the past, when Cairnwell was more prominent, but rather on the newness, economic growth, and success that was at hand. As I spent time in Covington, people often talked about the new businesses going in at Elmhurst, a 400 plus acre business area being developed by a local engineering firm, which boasted on its website that over $\$ 1 \mathrm{~B}$ had been spent on development in the past 5 years. As the expansion of Elmhurst and Covington moved northward along the interstate, the growth was literally visible daily as bulldozers and earth movers carved out sides of hills and fields to make room for development. Elmhurst boasted new hotels and chain stores and housed regional corporate headquarters for national fracking companies. The Covington Connect, a town news site I followed on social media, frequently had announcements such as, “Over $\$ 1$ million being spent on the addition of a favorite local eatery...SweetFrog to open site in Elmhurst." While an occasional local business went into these new builds, most were chains. In addition to this economic growth, Covington experienced their population increasing by over 10\% between 2000-2010 (U.S. Census, 2013).

A state of the art hospital complex had recently been completed in Covington. The hospital had relocated from its older facility in Cairnwell, creating another point of contention between the towns. Covington was also home to federal facilities involved in biotechnology, forensic sciences, and biometrics. In addition to these economic opportunities, Covington was less than an hour's drive away from two other major West Virginia hospitals, the largest state 
university, and multiple small state and private colleges. It was also within a 2-hour interstate drive from Pittsburgh. Additionally, the growth of ancillary retail and food services indicated Covington as a hub of local economic activity and these businesses offered multiple managerial positions, adding to the robust professional class.

With all of these available positions there was a greater demand for higher education in the area than there is elsewhere in West Virginia, where most jobs do not require a baccalaureate degree. Importantly, a majority of those who have higher educational and corresponding income profiles had chosen to live in Covington rather than in some of the surrounding areas (See Table 10). Like the rest of West Virginia, Covington was largely White, however it did have a larger Asian population $(1.9 \%)$ than the state average $(.7 \%)$, as there were immigrant families who moved to the area to work in the medical and technology fields.

Table 10

Income and education comparisons of Covington to other local areas. (U.S. Census, QuickFacts, 2013)

\begin{tabular}{llll}
\hline & West Virginia & Covington & Cairnwell \\
\hline High school degree (or higher) & $83.9 \%$ & $95.5 \%$ & $85.2 \%$ \\
Baccalaureate (or higher) & $18.3 \%$ & $43.4 \%$ & $20.7 \%$ \\
Median household income & $\$ 41,043$ & $\$ 79,398$ & $\$ 35,201$ \\
Poverty level & $17.9 \%$ & $4.9 \%$ & $21.9 \%$ \\
Median home value & $\$ 98,500$ & $\$ 194,600$ & $\$ 79,000$
\end{tabular}

Along with the jobs that called for a highly educated workforce, Covington also offered opportunities for families with less education to make a decent living. In addition to fracking's corporate headquarters, many of the regional parts supply companies for the industry were located in Harman County and provided opportunities for sales and delivery positions. The federal facilities I mentioned earlier also employed many people without higher education in living wage jobs. Covington was home to the county's airport which had an internationally known aircraft engine production and repair facility based at the airport that employed people in 
blue-collar work, many who drove in from surrounding counties. Another regional contracting company based in Covington specialized in concrete production and was a major provider for much of the new construction in the region. While the most prestigious and visible jobs in Covington were those in engineering, business and medicine, there were still many opportunities for blue-collar workers to make a good living, despite those opportunities decreasing in most other places in West Virginia (Boettner, 2013a).

In the next portion of this chapter the social makeup of Covington and its social class dynamics are described. This is followed by background on how the community practices in Covington fit within the discourse of Appalachian culture. The chapter concludes with the main themes that came from the Covington data.

\section{Covington: A Separate Class}

While there were a range of jobs that were steady and paid well in and near Covington, the layout of the area reflected the hierarchy of residents, their jobs, and their corresponding incomes. The most highly educated and wealthier residents lived within the city limits of Covington, while those who worked in the blue-collar sector lived in the small, often unincorporated towns on Covington's periphery; these tended to be older areas that were in the "country" and "where the poor kids live." As described by some Covington students and alumni,

there were two of these "poor" areas. Stone Eagle Drive was on the North end of Covington and more rural, "where the farm kids live." At Stone Eagle Drive there were a few trailer courts and family farms, though the Elmhurst development was fast encroaching upon this area. The other “poor" area, Antwerp, was more industrial and still had a working chemical factory with rows of small houses that had been built in the early $20^{\text {th }}$ century by the chemical corporation for workers (Cairnwell News, 2000). 
Like nearly all of the small cities and towns in West Virginia, Covington was surrounded by rural space. While the Stone Eagle Drive area and Antwerp were negatively described as "the country," many of the newer, wealthy developments sat in similar surroundings. However these new spaces were a "cultivated country." This reveals classed differences in how "country" could be valued. The newer neighborhoods sat on the outskirts of Covington, while the older homes sat closer to the city center. Even within this proximity to the city center, Covington still had a very suburban feel, the homes were almost all large with large lots that were landscaped with mature trees. Partly because Covington was not the county seat, but as one long-time Cairnwell resident described, it had always been a "bedroom community," it lacked a downtown space. While there was technically a main street through Covington that had a few local businesses: insurance, tax office, florist, children's consignment store, and the city pool. There was no historic downtown space, but rather a few historic homes dotting the suburbs.

The zoning map of Covington reflected the recent growth of the area and how that growth was encroaching on other areas. On the map there were multiple areas connected by a shoestring to the city limits and these were newer developments that reflected the growing wealth of Covington. These were neighborhoods with names like OakRidge and Cliffmont Estates that welcomed residents through large stone gates and were filled not only with "McMansions," but even some estate homes and properties. Homes in these neighborhoods sat on large, manicured lots and were listed from $\$ 250 \mathrm{~K}-\$ 400 \mathrm{~K}$. There was also the occasional estate for sale that pushed the multi-million dollar mark (See Figure 9). When describing the neighborhoods, one Covington High alumnus said, "Then you have the middleclass neighborhoods, like where I grew up" (Personal Conversation, 2014). Her neighborhood was also a new development situated around a lake with very large suburban homes that typically 
sold for upwards of $\$ 200 \mathrm{~K}$. In West Virginia terms, this was a lot of money, even though these neighborhoods were not comprised of the "rich kids" McMansions. Covington's most prominent and popular families tended to draw from both middleclass and McMansion neighborhoods. In Covington, neighborhoods were important indicators of social class, and thus they marked families' community standing and belongingness.

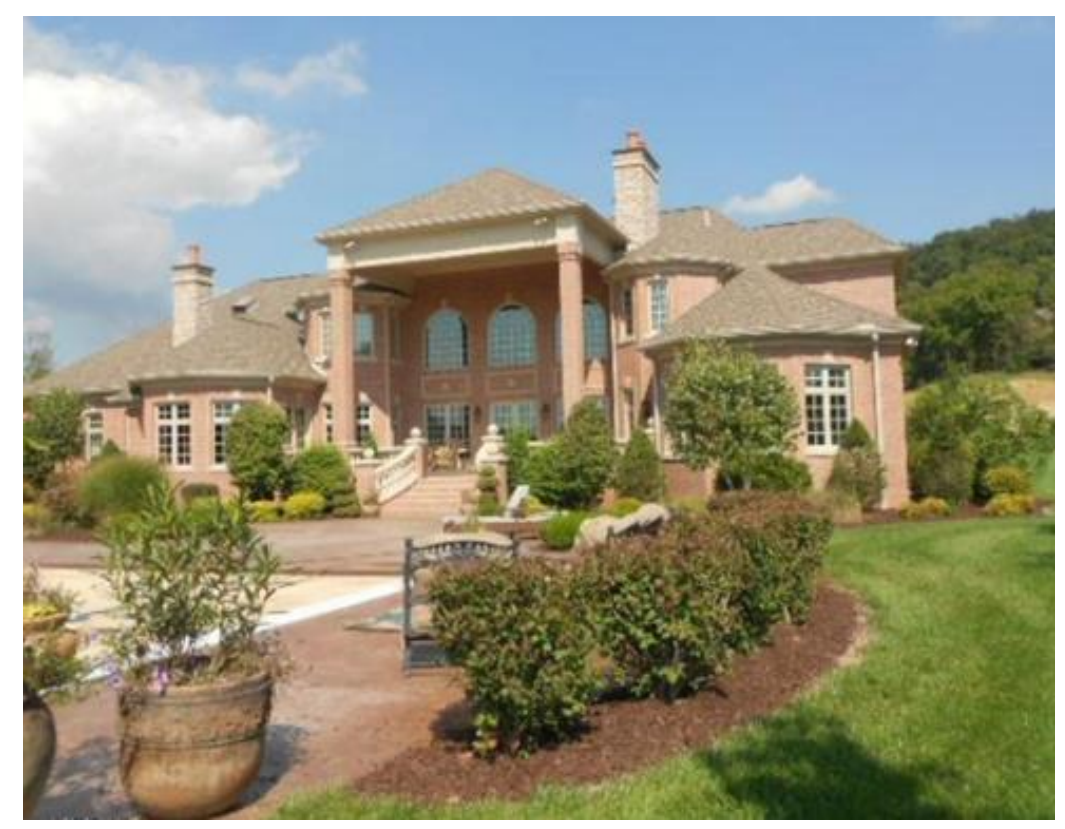

Figure 9. Home for sale in wealthy Covington neighborhood. List price: $\$ 2.1 M$.

\section{Belonging in Covington: The Right Class}

The American majority tends to shy away from the notions of social class divisions because of its moral implications and also because class divisions disrupt essential American notions of equality and opportunity. In America, everyone is supposed to be equal and talking about social class quickly leads to a picture that shows this is not true. However, this did not seem to be the case in Covington. Perhaps because Covington was so different from the immediate surrounding areas, these divisions were often at the forefront of people's descriptions and thoughts. Many Covington residents also seemed to participate in the construction of a community identity that was more elite than surrounding areas. This identity flowed across 
community and school. In fact, the CHS website "About Us" page described the community: "The community is upper middleclass socioeconomic status, with a high number of educated parents working in various professional fields." While this was written by a student, it did appear on the official school website on a page that I would expect to be frequently visited and that is used to give an overall impression. That this student, who was very popular and from Covington's upper middleclass, would find it important to include this as part of the description, and that it was approved by the school, supports the description of Covington as a place concerned with class status.

At its base, social class is about relative access to money and economic power and while the economic roots of class can be obfuscated, it always returns to this base (Bourdieu, 1984). Since there was so much money in Covington, people could be sorted in a powerful way by those who had and those who did not. There were many explicit indicators of economic capital in Covington that indicated social class and class power. Living in one of the more prestigious neighborhoods was a sign of economic capital as there had to be enough income to afford one of these homes. Covington also had a toney golf club, designed by a prestigious course designer with club dues at upwards of $\$ 8 \mathrm{~K}$ for membership. There was also a less pricey country club. As inheritors of their families' incomes, the students at CHS displayed their economic assets in visible ways. When one student described why Covington "has the reputation we do," he shared, "just drive around our [student] parking lot and look at the cars."

Mirroring neoliberal discourses of economic success as a sign of virtue, success in the business world was a powerful and visible narrative in Covington. As is true with some of America's upper middleclass, the focus on business success was an integral part of the community and school identities (Lamont, 1992). For example, the CHS yearbook featured 35 
pages of "community" photos that all focused on local businesses; the spots were almost advertisements but fashioned so that students were simply visiting their families' businesses. There were many doctors, restaurants, and car dealerships, amongst others, highlighted; a typical ad featured a photo of the student and family member and a small blurb like: "Deals for wheels. While looking for a new car, Jane Doe stops in to see her dad, Mr. John Doe at John Doe Buick, GM, Covington Hill Rd., Covington.” When one teacher described what she would like to improve at CHS, she shared, "There are many paths to being successful. Money is not the measure always for success" (Teacher Questionnaire, 2014).

While business success and income were important in determining social class, these did not guarantee a person high social standing within the community. Job prestige and education level were also central components to social class standing in Covington and it seemed that people needed to have at least two of these three markers to be "in." For instance, while one student's father had an upper middleclass income, his high school diploma and blue-collar position as a coal mine foreman did not hold clout with the Covington power group.

Location as a Covington "insider" was a very important component of social standing. When I asked Judy, one of the CHS guidance counselors, to describe Covington, one of the things she mentioned was that it could be difficult to find acceptance within the community if you were not born and raised there. For this reason, she intentionally did not live in Covington, despite having worked at the school for over 15 years. One student, whose family was not originally from Covington, described an experience her mother had: "So it's just like that aspect, a lot of people are just discriminating for like stupid reasons, like 'Oh, well she's not from here, she's not friends with all the other popular parents"' (Selene, Interview 1, 2014). It was interesting that multiple people in the community mentioned the "popular parents" as the term 
"popular" is usually applied in adolescence. However, there was a group of powerful people in Covington and they and their children were in this "popular" group. These were people who had grown up in Covington, were involved in athletics, and often their families had been there for generations and also often owned successful businesses. Another student, Gregg, commented on the exclusivity of Covington. He believed that family name conferred social status, "Like Otterman...Abignail, Benoni, like they're like the biggest names of Covington" (Gregg, Interview 1, 2014).

\section{The Covington Ideal: Pursuing Privilege}

For those who were not granted insider status in Covington it was easy to see that "fitting in" was for a particular group of people. However, the leaders of Covington, often composed of the popular families mentioned earlier, lauded the hospitality and family atmosphere of Covington, as did their children. These were the people who were most visible in public spaces, for example the students giving speeches at assemblies and graduation and the students, business and civic leaders lauded in local news publications. However, within these discourses of "openness" and "hospitality" were clear qualifiers of who was welcome. For example, a town leader interviewed by a popular West Virginia lifestyle magazine described Covington in this way, "Our residents are the biggest asset we have. We are competitive and fair. If you are willing to work hard, be a good neighbor, and raise responsible young people, then Covington is your kind of town" (Magazine, n.p., 2013). Belonging and success could supposedly be earned within this "meritocracy," although data presented in this chapter troubles this assumption. In Covington, success was reflected in having a prestigious, high paying job, particularly in business, though medicine and technology were also considered high prestige jobs. Having a college degree and living in the right neighborhood also marked people as successful. While 
being a Covington native did not always equal success, it did seem to be a factor that played into being accepted to the "in" group in Covington. Moreover, there were racial undertones to stories of success as nearly all of the people in leadership in the community, school, as well as in the success stories that were published in local media were nearly all White, despite the community having some racial diversity.

Success as an identity marker stretched from the town to the high school—Covington and CHS seemed inseparable. When people talked about Covington they also frequently talked about CHS and vice versa. In Covington, CHS sports and particularly football were king. The football team had won their second straight state championship during the study and were on their way to win a third the following year. Despite the championship win taking place in December, businesses in Covington maintained scrolling electronic billboards and signs touting the win the following May during graduation season. The town's involvement in school sports was described in the lifestyle magazine article such that, "People in Covington live for school sports...CHS alumni pack the stands on game days even years after graduating, cheering for the next generation" (Magazine, n.p., 2013). In addition to sports success, CHS was known for its consistently high test scores on the state standardized tests, something talked about frequently in Covington and also displayed on billboards around town. As the school and students experienced these successes, they connected with the community identity. These successes were attributed to the involvement, support, and hard work of parents in the community_ideals of American meritocracy. In the lifestyle magazine mentioned earlier, the interviewee shared, "Our schools are strong because the overwhelming majority of parents support the schools at all levels" (Magazine, n.p., 2013). 
As these involved parents and community members influenced young people to be successful, their influence also extended outside of Covington into West Virginia's political arena. One community member was a senior-level state representative and owned a prominent personal injury law firm in Cairnwell, though he resided in Covington. The owner of the engineering firm developing the Elmhurst Business Park was appointed by the governor to the state university's board of governor's during the study. In another instance, someone from a politically powerful West Virginia family was unexpectedly and controversially hired as the school superintendent, which I will share more on later. As Covington's residents stretched their political influence, their children also played a role. Each year, West Virginia holds the West Virginia Forest Festival, the oldest state festival inaugurated in the early $20^{\text {th }}$ century to build bridges between industrialists and the politically powerful (Rice, 2011). The week-long festival brings in thousands of people to a tiny West Virginia town, notable dignitaries as well as sitting presidents have attended the festival. The crowning event is the Coronation of the Forest Festival Queen, selected from a court of 40 young women, often daughters of the state's politically powerful, who have all been selected to the court by "state dignitaries" (Connect Covington, 2014). Four CHS alumni were selected for this honor during the study and spent the festival week as guests in local homes, visiting with festival goers as members of the royal court. These young ladies' biographies showed their early political involvement, particularly with democrat organizations, reflecting the political makeup of Covington as a historically Democratic city within a Democratic county. Despite this political affiliation, Covington was conservative on many matters, similar to the political affiliation and orientation of the state at large (Schwartzman, 2015). West Virginia is a historically Democratic state but this is largely due to the influence of labor unions and not because of liberal social values. Socially, West 
Virginia is conservative and has been moving further that way over the past decade (Schwartzman, 2015). Covington seemed to mirror this shift. However, the influence of prominent businesses may also have influenced this conservatism. Social conservatism permeated events in Covington, often painted in the colors of Christian values and highlighted in connection with CHS. For instance, the school was asked by an outside group for their football coach to "cease and desist" leading prayer at football games and asking the other team to join. Though prayer by school officials has been banned for some time, this was still happening at CHS. The school board sent a memo to all schools in the county that had Covington's parents and community leaders up in arms. Parents and community members had misunderstood the ruling to mean that there could be no prayer at all at school events, rather than that school officials were restricted from leading prayer. A past president of the Covington Country Club, who was running for city council at the time, commented on the issue:

I hope our confident, Christian kids take to a knee whenever they feel the need... and do so in confidence without fear of reprisal. And I believe they will—which makes me proud of our kids and our community. It is frustrating, though, that freedom of religion (or in some people's case, freedom to not have religion), a right of all people, now takes on so many different caveats! (Connect Covington, 2014)

This event was indicative of the conservative Protestantism circulating as a powerful discourse within the figured world of Covington. As this powerful community member, who was pursuing further privilege and power in an elected position, very publicly valued the integration of school and conservative Protestantism, it seemed that he would not have been making these statements and taking this stance if he did not think it would sit well with voters. This vignette is reflective 
of the tenor of Covington, where conservative values were powerful discourses as well as the public display of religiosity as put forward not only by the community but also community leaders.

In the following section I discuss how Covington was situated within the context of Appalachia. As discussed in the literature review, Appalachia is more a construction of consciousness rather than a "real thing." However, because the discourses of Otherness that circulate around Appalachia are so powerful and have an impact on people, it is important to consider Covington within this regional and cultural context.

\section{Appalachian Identity: Covington Style}

This section first discusses how Covington does not fit the profile of being othered as much of Central Appalachia is. I then discuss dialect and country-ness and how these were negotiated in Covington. Following this, I discuss family ties and how these presented differently across groups. Then I finish by discussing the larger constructs of patriarchy, religiosity, and heteronormativity that worked in support of one another.

Important aspects of the participants' stories come out in this section, as they were often othered in Covington based on traits and practices that are discussed in this section, so I include the table below that introduces the students' backgrounds (See Table 11). As I did in the Mill County chapter, I included a section on social class for how the guidance counselor described students. Her descriptions were fairly inaccurate, particularly regarding Fantasia. While the guidance counselor did know some about students outside the school, some of her descriptions did not match with the realities I found in my research. Her placement of students into social strata was more closely aligned to the students' physical appearances at school rather than their families' backgrounds. 
Table 11

Background information for students and families in Covington.

\begin{tabular}{|c|c|c|c|}
\hline & Fantasia & Gregg & Selene \\
\hline \multicolumn{4}{|l|}{ Social class } \\
\hline Counselor & Poor & Blue-collar, middleclass & Upper-class \\
\hline Covington & Lower middleclass & Working-class & Middleclass \\
\hline Broadly & Lower middleclass & Working-class & $\begin{array}{l}\text { Middle/upper } \\
\text { middleclass }\end{array}$ \\
\hline Family & $\begin{array}{l}\text { Mom and stepdad, } \\
\text { younger } 1 / 2 \text { brother. } \\
\text { Older, paternal } 1 / 2 \text { sister. } \\
\text { Rarely saw biological } \\
\text { father. }\end{array}$ & $\begin{array}{l}\text { Parents married, younger } \\
\text { brother. Older sister } \\
\text { recently married and } \\
\text { moved out. }\end{array}$ & $\begin{array}{l}\text { Parents married, older } \\
\text { brother at college. } \\
\text { Adult, paternal } 1 / 2 \\
\text { siblings. }\end{array}$ \\
\hline $\begin{array}{l}\text { Race \& } \\
\text { ethnicity }\end{array}$ & $\begin{array}{l}\text { Mom, White } \\
\text { Dad, White }\end{array}$ & $\begin{array}{l}\text { Mom, White } \\
\text { Dad, White }\end{array}$ & $\begin{array}{l}\text { Mom, Chinese } \\
\text { immigrant } \\
\text { Dad, Filipino-American, } \\
\text { identified as White }\end{array}$ \\
\hline $\begin{array}{l}\text { Parents' } \\
\text { education }\end{array}$ & $\begin{array}{l}\text { Mom, some college } \\
\text { Stepdad, AA }\end{array}$ & $\begin{array}{l}\text { Mom, less than high } \\
\text { school degree } \\
\text { Dad, high school degree }\end{array}$ & $\begin{array}{l}\text { Mom, high school } \\
\text { degree } \\
\text { Dad, high school degree, } \\
\text { trade certificates }\end{array}$ \\
\hline Parent's jobs & $\begin{array}{l}\text { Mom, managed rental } \\
\text { properties, took care of } \\
\text { ailing father } \\
\text { Stepdad, fracking well } \\
\text { planner }\end{array}$ & $\begin{array}{l}\text { Mom, various service } \\
\text { jobs, "when she got } \\
\text { bored" } \\
\text { Dad, diesel mechanic }\end{array}$ & $\begin{array}{l}\text { Mom, stay-at-home, } \\
\text { worked at a Chinese } \\
\text { restaurant, owned a } \\
\text { seasonal store at mall } \\
\text { Dad, coal mine foreman }\end{array}$ \\
\hline $\begin{array}{l}\text { Parent(s)' } \\
\text { school \& } \\
\text { community } \\
\text { involvement }\end{array}$ & N/A & N/A & $\begin{array}{l}\text { Hosted French Club } \\
\text { picnic }\end{array}$ \\
\hline Career goal & FBI Agent & Pediatrician & Fashion Management \\
\hline College major & Criminal Justice & Pre-medicine & $\begin{array}{l}\text { Business, Minor in } \\
\text { Japanese }\end{array}$ \\
\hline School type & $\begin{array}{l}2+2 \text { program, WV } \\
\text { community college }\end{array}$ & $\begin{array}{l}\text { WV small state liberal } \\
\text { arts baccalaureate }\end{array}$ & $\begin{array}{l}\text { WV state university } \\
\text { baccalaureate }\end{array}$ \\
\hline PROMISE & $\begin{array}{l}\text { Did not meet core } \\
\text { subject GPA } \\
\text { requirements }\end{array}$ & $\begin{array}{l}\text { Did not meet core GPA } \\
\text { requirements }\end{array}$ & Yes \\
\hline $\begin{array}{l}\text { How they paid } \\
\text { for school }\end{array}$ & $\begin{array}{l}\text { Loans, community } \\
\text { scholarship }\end{array}$ & Scholarships, grant & Parents, scholarships \\
\hline Overall GPA & 2.645 & 3.045 & 3.828 \\
\hline $\begin{array}{l}\text { High school } \\
\text { activities }\end{array}$ & N/A & N/A & $\begin{array}{l}\text { National Honor Society, } \\
\text { key club, French club, } \\
\text { school talent show, } \\
\text { school play }\end{array}$ \\
\hline
\end{tabular}




\begin{tabular}{|c|c|c|c|}
\hline $\begin{array}{l}\text { Outside } \\
\text { activities } \\
\text { (organized) }\end{array}$ & & $\begin{array}{l}\text { Dirt bike racing, } \\
\text { mountain bike racing, } \\
\text { church, youth group }\end{array}$ & \\
\hline $\begin{array}{l}\text { Other } \\
\text { activities }\end{array}$ & $\begin{array}{l}\text { Video games, } \\
\text { photography, hanging } \\
\text { out with friends, being } \\
\text { with significant other, } \\
\text { watching brother, } \\
\text { helping with Grandpa }\end{array}$ & $\begin{array}{l}\text { Video games, fly fishing, } \\
\text { hunting, 4-wheeling, } \\
\text { backpacking (to fish), } \\
\text { going to the gym, } \\
\text { hanging out with friends } \\
\text { and family }\end{array}$ & $\begin{array}{l}\text { Video games, painting, } \\
\text { drawing, photography, } \\
\text { piano, designing clothes, } \\
\text { shopping } \\
* * \text { mainly with family }\end{array}$ \\
\hline $\begin{array}{l}\text { Work or } \\
\text { volunteer }\end{array}$ & $\begin{array}{l}\text { Olan Mills } \\
\text { Photography, } \\
\text { independent portrait } \\
\text { business, telemarketer, } \\
\text { restaurant server } \\
\text { *Worked only one job } \\
\text { at a time, less her } \\
\text { portrait business }\end{array}$ & $\begin{array}{l}\text { Pizza place, restaurant } \\
\text { server } \\
* * \text { Often worked more } \\
\text { than } 20 \text { hours a week }\end{array}$ & $\begin{array}{l}\text { Community service, } \\
\text { NHS }\end{array}$ \\
\hline
\end{tabular}

Appalachia has been discussed in much literature as "a place apart," due to multiple variables: its rural nature, poverty, and "hillbilly" culture that includes maligned dialects, illiteracy, ignorance, and also as a place frozen in the past (Batteau, 1990; Norman, et al., 1999). The construction of these stereotypes and the ways that people respond to them have served to limit opportunities for the region and its people (Bryson, 2015). Despite its location in oftothered West Virginia, Covington does not easily fit within the construct of an othered space and people. Covington's majority group, who had high prestige and paying jobs, were community leaders, and White, were the most visible group and fit closely with mainstream America. This othering did not necessarily seem to apply to them, like they were in an exempt bubble. Covington's social scene was suburban: It was a largely White place, populated with people who were highly educated and valued mainstream American culture. Also, because of the economic capital and wealth in Covington, people had access to dominant cultural capital that could level the playing field for them when engaging with the larger national cultural discourses. For example, while CHS offered multiple international trips for students each year, families who 
took international family vacations were also common. However, outside of the city limits of Covington, people were much more likely to fit within vulnerable Appalachian groupings. So, as I describe some of the particularities of culture, I will talk about the core group of Covington residents and the differences and some similarities between them and the other families who attended CHS. This is particularly important as two of my participants, Gregg and Fantasia, lived within these districts that were othered in the sense of not fully belonging to Covington.

Dialect. Dialect is a common signifier of where a person comes from and dialect has been used to place Appalachians and West Virginians as aberrant. When West Virginians are not being criticized for having a hillbilly dialect, the dialect is often incorrectly romanticized as Elizabethan in origin (Hazen, Butcher, \& King, 2010). In fact, when we discussed dialect in a focus group one of my students shared, "Apparently our accent came from a type of way of speaking from like King's or something in a certain area" (Selene, CHS Focus Group 1). Like reality often is, the dialect in West Virginia draws from many of the groups who settled here and also varies across region, age, social class and education level (Hazen et al., 2010).

What was most notable about an Appalachian dialect in Covington was its absence. Research has shown that vernacular dialect is less likely to be used by people who have attended college and who are in the middle and upper-classes (Hazen et al., 2010), which is likely why there was not a particularly noticeable dialect. My participants, Covington outsiders who had all experienced othering related to their own or their families' dialects commented on the "vanillaness" ${ }^{3}$ of Covington's speech. Fantasia described that, "It seems like here you have an accent, but you turn it on and off... Here... [the only time people] have an accent is when they get mad" (Fantasia, CHS Focus Group 1, 2014). Selene hypothesized that perhaps this was because of

\footnotetext{
${ }^{3} \mathrm{http} / / /$ www.urbandictionary.com/define.php?term=vanilla\&utm_source=search-action
} 
large number of people who had moved to Covington from other areas and influenced speech patterns to be less culturally specific, with a "more casual accent, that's more easily understood by everybody" (Selene, CHS Focus Group 1, 2014). Selene's comment that the "accent is more easily understood" places the un-vernacular accent as "more normal" and less marked than more vernacular dialects or thicker accents.

As some Covington residents held the dominant cultural capital of a "vanilla-accent," they were able to use this as a power marker distinguishing them from those who had accents that carried less cultural capital within the Covington area. For instance, Selene and Fantasia shared stories of their parents who were from areas of West Virginia with more distinct accents. They were made fun of in Covington, by both teens and adults; Fantasia's mom was called "country" in a condescending way and Selene's dad was told that no one could understand what he was saying. These students, who had both moved to Covington during elementary school, each recalled being put in speech class when they moved there. They each recalled that they had been put in a pull-out speech class because of their dialect and grammar, rather than because of actual speech impediments. Gregg, whose family had been in Covington for generations, though in the country section of Stone Eagle Drive, had a more distinct accent that was different from the mainstream group at Covington. He shared about feeling pride for his accent:

I just think it's part of you, your accent makes you, it's part of building your character, cause it's how you were raised and it's just like—if you, I think if you [move away] from you're accent it's just like takin' part of home away from you. (Gregg, CHS Focus Group 1, 2014) 
Country-ness. Just as accents in Covington varied and were evaluated based on location, location was also used as a status evaluation tool. Appalachia is stereotypically portrayed as a rural place, isolated from the rest of the nation, both historically and presently (Lewis, 1999). Lewis, a historian, details in his work how Appalachia was constructed as a place of "isolation and homogeneity" to serve the interests of those who would like to profit from the region. So, like many of the discourses circulating about Appalachia, that it is a pastoral place, isolated from the culture and world outside is a myth. While much of Appalachia is rural, there are urban centers like Pittsburgh and Knoxville, among others, as well as suburban spaces within the region.

Covington was reflective of the more diverse reality of Appalachia and had both country and suburban spaces and, as mentioned previously, was within a 2-hour drive to Pittsburgh and only 4-hours from the DC Metro area. Gregg, who spoke earlier on accent said:

A lot of people tell me I don't belong at Covington, because I'm really not that preppy. I race [dirt bikes] and I play in the dirt and...I'm a farmer boy, like I belong at Lester or Summer Valley [other country high schools in the county]. (CHS Focus Group 1, 2014)

While this narrative of country other-ness was used by those with the more powerful suburban cultural capital to distinguish themselves from the "country folk," it did not necessarily dissuade individuals from embracing this country identity. Gregg told about how his family reacted to othering: "Like [Dad] refuses to like conform to like Covington, cause we're kinda, Covington's kinda outcast... and he refuses to be any bit sophisticated" (Gregg, CHS Focus Group 1, 2014). As Gregg and his family embraced their identities as country people, they were agentively disrupting dominant discourses that positioned country as other. Moreover, Gregg's family were 
providing an alternative discourse for Gregg to draw upon when he faced othering from his more suburban and higher class peers. As Gregg's parents provided alternative discourses that allowed Gregg to negotiate around being placed as other within the figured world of Covington, they served as an important cultural touchstone and support.

Family ties. A strong connection to family is often cited as common value for many people within Appalachia (Bryan \& Simmons, 2009; Howley, 2006; Stewart, Scott, \& Thompson, 2006). Within Appalachia this has stemmed from the historical construction of communities, when European settlers came to Appalachia, they settled in family groupings that were often separated by great distances (Keefe, 2005). As settlements were so distant, the kinship network became the social group. These vestiges remain today in many places in Appalachia, where family ties are strong and families serve as the primary social group.

Within the figured world of Covington family was a common and powerful discourse for the students from Covington's majority groups; however, their discursive construction of family was less from kinship ties and more from social and community ties. Though these students were not participants, these were the students speaking at public assemblies and writing school paper articles and having features done on them in the town paper, which is where I gleaned this information. At many of the graduation-related ceremonies, these students spoke passionately about the CHS community as a "family" and of the town as a "supportive family." This construction of family from social rather than kinship relationships was more closely aligned with the practices of middle and upper middleclass groups (Annette Lareau, 2003). The only time I saw family constructed as kinship for these students was in the community pages yearbook spread, which was mentioned earlier. In these pages, the students were "seen" around 
town visiting their families' businesses, connecting kinship to business ties. These yearbook pages highlight the valuable social capital of families and of how family networks could be draw upon instrumentally to connect to successful businesses.

Covington also had a large Italian-American community where kinship ties were important. The Italian-American community had been around the Covington for generations, originally immigrating to the area, largely to Cairnwell, to work in the coal mines (Goldenseal, 2013). However, they had since moved into powerful positions in Covington and owned some of the most successful businesses, which had been operating for generations. Within this group there was a marriage of a strong sense of kinship familialism as well as a connection of family to business, as younger family members moved on to continue family businesses.

Contrasting with the discursive construction of the majority group and the ItalianAmerican community, all of my participants constructed family as kin, a practice more traditionally associated with Appalachia. The participants expressed strong connections to their families and for Gregg and Selene, their families were still their primary social group. They both spent the majority of their free time with their family rather than with people from school or work, as did their parents and extended family with them. Fantasia and Selene, whose families had relocated to Covington from Southern and South Eastern West Virginia, spoke of the importance of maintaining connections with their "homes" in the places where their grandparents and extended family lived. They often took summer vacations to visit family and maintained strong ties to these places.

Patriarchy. Covington was a very traditional place, with participants' commentaries and actions showing a clear gender hierarchy and separation between male and female specific activities and roles. For example, a pervasive masculinity was expressed through sports and a 
competitive spirit. The performance of gender was very classed at Covington, where men expressed masculinity through success in the business world and through prodigious financial provision for their families. Wives were the public faces of their husbands' success, particularly as they cared for and cultivated homes, children, and themselves. In keeping with the overlap between school and community, some of the most obvious examples of gender segregated activities related to the publicity of school sporting events and celebrations. Every year the "senior football moms" made up a dance routine that they performed to a popular song along with their sons at a football pep rally. At this event the mothers sported shapely physiques and salon-styled hair. The moms dressed in denim capris, many with designer-embellished pockets, and wore their sons' jerseys, solidifying the connection between caring mothers and strong, successful sons. As a family, they were extensions of the success of the fathers whose incomes allowed these mothers the time to not only cultivate themselves and their children but to also participate in silly-fun school functions with their flexible schedules. In another example, the town paper detailed the special send-off ceremony the football players give for the cheerleaders the evening before their regional competition. At this banquet, the football boys dressed in suits and bow ties while the girls donned their competition warm-ups. For the coup de grace of the evening, the players serenaded the cheerleaders with a rendition of "My Girl" as they performed a corny dance routine, crooning, My girl (my girl, my girl), Talkin' 'bout my girl (my girl), for “their biggest fans" (Covington Weekly, n.p. 2013). Parents could be seen and heard in the background chuckling and "ahhhing" at the presentations. These actions drew upon gendered identities and used the power of the group to reinforce the role of men as providers for their deserving women who should be spoiled for the support they provided to men. Also, that masculine humiliation, when performed for the weaker sex, was a sacrificial act that showed 
"care" by providing emotional provision to women. This story highlights the notion of women as supporters of men, while men played the central role in relationships.

While the classed role of robust economic provider was available for men in Covington, the town did participate in masculine narratives that have more broadly been applied to workingclass West Virginia (Bell \& York, 2010). This could be seen in the intense focus on sports within the community. While football was a huge deal in Covington, competitive success in all sports was a powerful narrative. A walk through the CHS cafeteria took you past hundreds of feet of trophy cases filled to overflowing with state championship trophies, photos of notable sports alumni and donors, and other sports memorabilia, artifacts constructing the figured world of Covington as a place of success. One day I ran into the softball coach who was running off flyers for a golf scramble fundraiser where the prize for a hole-in-one was $\$ 10 \mathrm{~K}$ and the putting prize was $\$ 2.5 \mathrm{~K}$. The coach shared that not only was there an athletic boosters club for the school, there was also a boosters organization for every sport that were largely supported by alumni. While Covington tended to dominate local and even state sports, technically they received the same amount of funding from their state and district as other schools; however, because the community viewed sports as so important and also had great wealth, they were able to channel that wealth into hidden supports for the sports teams, giving them a distinct advantage over their competitors. These practices exemplify the neoliberal discourses that focus only on outcomes while assuming equality of access and process, while the advantages that come with economic and social capital are concealed (Cassell \& Nelson, 2013). The major focus on sports in combination with great financial support, also shows the intersection of classed understandings of sports participation. In keeping with the theme of patriarchy, religious practices in Covington often supported patriarchal narratives, so in the next section I address religiosity. 
Religiosity. Appalachian religiosity is described as manifesting as a personal religion and spirituality that is not always paired with church attendance, but is typified by reading the Bible and an overall spiritual view of life matters (Whisnant, 1983). This version of spirituality stems from historical practices when communities were more (but not entirely) rural and isolated, so rather than travelling to church, people had church at home independently. While religiosity is typically a trait applied to Appalachia, the manifestation of this in Covington seemed mediated by social class and tended toward conservative Christianity. Within the city of Covington there were 20 churches; most were independent evangelical churches, eight were mainline Protestant churches, and there was one Catholic Church. In Covington, there was religiosity in the sense that it was common practice for people to speak openly about their religious beliefs and spirituality, any public meals I attended in Covington and at CHS were always preceded by a blessing, and within the last five years both Jesus Christ Superstar and Godspell had been put on as the senior plays, the highlight of the schools' yearly theatrical productions. However, this integration of religion and spiritual beliefs into the public sphere was coupled with religious practices more typical of mainstream American middle and upper-classes. For example, volunteerism and community outreach were strong components of the religious and general community of Covington (Lamont, 1992). One feature article in the weekly paper presented local churches working together to create a food pantry for the community. The article was more focused on the achievement of the churches in creating this ministry rather than on the focus of need in the community. The article went on to mention that the families who were provided for at the shelter were monitored so that they were not "taking advantage" of the community's 
generosity (Covington Weekly, p. 15, 2014). The narrative embedded within this story was that Covington was meeting its Christian duties by providing for those less fortunate. Additionally, this provision came with the classed notion of the right and need to monitor those who receive services.

Heteronormativity. An extension of the very public, Christian morality of Covington was the heteronormativity pervasive in the area. The narratives supporting traditional gender roles were strengthened by heteronormative performances. For instance at graduation, every CHS female carried a rose and was escorted onto and off of the stage to accept their diploma by a male attendant; there was not a parallel ritual for men. In another instance, Rent was chosen for the senior play but later replaced because of its "risqué" queer content. Selene and Gregg spoke of the queer community in homophobic ways, which came out during one of the focus groups. As Gregg shared about a college campus visit where his tour leader was a transwoman:

Gregg: I don't like hate gay people, but up at [college] there's transvestites and they really bother me. I don't know if that's just me...

Brandi: What is it that bothers you?

Gregg: Because I don't see how someone can do that, like someone's like, this is probably the wrong way of thinking, but if someone's really that messed up, to where they want to change, it just really bothers me, like what went wrong that you thought that? (CHS Focus Group 2, 2014). 
Selene also expressed her "discomfort" with the queer community during this conversation:

That's why during gay pride week at like a college it's so awkward, my brother was talking to me about it. People are always yelling on the streets about gay pride and I'm like [takes deep breath] I have nothing against them it's just really awkward to be in that situation and just like severe anger [from the gay community] just towards one general thing. (CHS Focus Group 2, 2014)

Fantasia was more progressive in her views as her best friend was gay and she positioned herself as an ally of the queer community. Within my time at CHS, queer students were notably invisible, except for two young men who were openly gay, one of which was Fantasia's friend. Interestingly, there was some acceptance for one of these young men as he was voted "best dressed" and considered something of a style icon. It seemed that his privileged class status as someone who appreciated and could afford fashionable clothes mediated some of his queer other-ness.

\section{Covington High: Succeeding at the Competition}

CHS was one of six public high schools within Harman County that shared governance with a county board of education, which was made up of six members drawn from across the county. At the time of the study it was made up of prominent local business owners, two former educators, and an investigator from the prosecuting attorney's office. During the study there was a fair amount of politicking that went on surrounding the board of education. The president of the board was from Covington and was a prominent community businessman, whose son, considered a local prodigy, had begun a successful sports consulting firm during middle school and had received national recognition for his work. He even won the chamber of commerce's Covington Youth Entrepreneur Award. The board president left his position early in order to run 
for state legislature, but not before he participated in a controversial transition between school superintendents. Sarah Craddock, the Harman County superintendent and 30-year employee of the county school system, had recently been awarded the state superintendent of the year award. However, her contract was up for renewal and to the surprise of many, it was not renewed. Mike Blankenship, a man from a politically powerful, and at times controversial family, was named in Ms. Craddock's stead within a week. Parents and educators spoke at the board meeting to voice their support for Craddock and to voice concern for how quickly she had been replaced.

However, because everything did follow within legal order, there was nothing that could be done about the changeover. While the majority of the board did vote in favor of this replacement, one board member spoke out against what he saw as the political motivations behind this change, particularly as it came from the former board president who resigned his position at the meeting where the new superintendent was announced. While many of the board members engaged thoughtfully with educators and families on school issues, within Harman County, the board of education could be used as a stepping stone for people looking to move into more powerful positions.

CHS drew students from four elementary schools and one middle school. There were two high schools that served the Cairnwell area. One drew from within the city limits and was larger and another drew from the rural suburbs and was smaller. In addition there were two, smaller rural high schools that served the northern and southern portions of the county. In addition, the county had a combined technical center and alternative learning school. These secondary schools drew from four middle and eleven elementary feeder schools. There was a very small K-12 Catholic high school in Cairnwell, and a small, conservative Christian K-12 school in Covington. West Virginia has a long and violent history of struggle around curriculum, specifically literature 
and textbook censorship (Mason, 2009). In response to the Kanawha textbook wars of the 1970's, several Christian schools cropped up in the vicinity of Charleston for the purpose of protecting young hearts and minds from secular texts (Kay, 2011). But because the city schools in Covington were so successful and were governed by overtly Christian citizens with considerable influence, there did not seem to be major threats of privatization to the local area. This is somewhat surprising, for example homeschooling is especially popular nationally in areas that do not have a strong Christian school presence (Isenberg, 2007). However, the relatively small private school influence is reinforced by the fact that West Virginia is quite unique amongst states as it is one of eight that does not allow charter schools (AFT, 2015). As the community identity was constructed in Covington, privatization would have seemed a counterproductive position for community members because the public high school was a site of identity construction and education that allowed the community to maintain its dominance. As one alumnus shared, CHS and the community of Covington were very connected, as even those without children in school still attended sporting events and community functions for the school. Because of this school-community spirit, it is possible that threats to the school system via privatization may also have been construed as threats to the community as a whole.

In the figured world of Covington, CHS was viewed as the best school within Harman County. However, being the "best" meant different and sometimes complicated things to different people. One father, who had graduated from CHS and worked in a blue-collar job in a nearby town said: 
Dad: Sometimes well you get, once you get out and get into the world, ha, you come from Covington High School...I work at John Deere, there's guys I work with they went to school in Farthing, they wen' to school in Peasant County, this ' $n$ ' that, they find out you went to school at Covington, you're kinda, put in a class...

Gregg: A little bit of higher standard.

Dad: ...well you're, but they also think, well, heck, you was a snob. (Parent Interview, 2014)

Privileged parents from surrounding areas often negotiated advantages for their children within the county school system in order to get their children into CHS, citing the school's academic superiority. It was common community knowledge that CHS consistently had high scores on the statewide standardized tests. Parents from many backgrounds cited sports success and high achievement test scores as evidence that CHS was an excellent school.

Achievement test scores were a point of pride that CHS, the community, and administrators drew on often and CHS had scored well again during the year of the study (See Table 12). Next to sports achievement, academic achievement seemed the most important point of pride for CHS and the community. As I mentioned, when state-testing results came out, the electronic billboard at CHS and at other businesses around town "shouted" the local schools" dominance. The wealth and privilege of the community, paired with these consistently high test scores, mirrored the literature which finds SES associated with achievement test scores (Brantlinger, 2003). 
Table 12

Achievement test scores at CHS in comparison to West Virginia.

\begin{tabular}{lll}
\hline Test Scores & State & Covington \\
\hline Reading proficient & $48.42 \%$ & $79 \%$ \\
Math proficient & $46.54 \%$ & $74 \%$ \\
Science proficient & $40.73 \%$ & $51 \%$ \\
Social Studies proficient & $36.79 \%$ & $67 \%$
\end{tabular}

Because CHS was so successful, neither teachers nor school officials seemed to feel pressure to improve achievement; rather, it seemed that what they were doing was working. Despite the nearly 3-week disruption for testing in the spring, the teachers did not seem to view this as anything other than a slight schedule disruption. However, the block scheduling helped in limiting the number of classes that were missed. This is not to say that the testing was taken lightly. Indeed, testing was very serious at CHS. At the beginning of each day during testing, the CHS principal would announce over the intercom that there should be no talking in any classes and no students should be out of the classrooms at any time, for any reason. I happened to be in an art class during one of these announcements and both the teacher and students mocked the principal's announcement. As the teacher and students mocked the principal they were challenging the dominant discourses of the school. These were also students, in a subject, that were not highly valued within the figured world of CHS as they were not achievement ambassadors for the school.

Other students and some educators also critiqued the culture at CHS that focused so much on the appearance of success and winning. Judy, one of CHS's guidance counselors and a few other educators, discussed the community's focus on success and shared that there was intense parent pressure for the school to perform well. These same educators elaborated that a vocal group of parents and their children seemed to care more about the appearance of success, for example high test scores and grades, than they did about student learning. The intense focus on 
the success of test scores and of CHS as the best in testing even though there were other academic achievements that were more impressive was notable. For example, CHS had multiple national merit scholars; however, the only time these students were recognized or talked about was in passing at the senior awards assembly and at halftime during a basketball game (though there were framed photos of each of the winners tucked up above a tall window, about 15-feet high). There were also multiple students who had received prestigious scholarships at a variety of universities, including Northwestern University and WestPoint; however these honors were also mentioned only in passing at the senior awards assembly. To a broader national audience these achievements may have been more impressive. However, in the figured world of CHS most immediate indicators of success relative to others in West Virginia was what was focused on the most. It was a bit like a big fish in a little pond, CHS's high achievement scores consistently placed them as dominant amongst their West Virginia counterparts. While the other academic achievements I mentioned were impressive, comparatively speaking, there would be many schools across America who would surpass these achievements. The focus on very particular aspects of success, those that were more visible, dovetailed with the community identity of winners and success.

While the focus on test scores did place CHS and Covington as winners statewide, the focus on test scores also seemed to be instrumentally drawn upon by the community to entice potential businesses and future employees to the town. Covington was nominated as one of West Virginia's "Cutest Communities" by a West Virginia lifestyle magazine and the write up read like an advertisement for the community where the high achievement of CHS was featured: 
Covington is in a perfect position to continue its upward growth....Consistently scoring high on national standardized tests, CHS, like many Covington schools, boasts great educators and passionate administrators in an ideal, small town setting, and several other local schools have won awards for excellence. Ralph says an emphasis on keeping community members involved in preparing the next generation is key. "Our schools are strong because the overwhelming majority of parents support the schools at all levels." Coupled with growth in the Elmhurst business park and the new hospital center, the city is adding new opportunities for residents to succeed at every turn. "All these areas have thrived. Really, it has helped make Covington a destination for business, recreation, and health care," says Ralph Sunder, director of community development for the city. (Magazine, p. 2-3, 2013)

Community members utilized CHS's high test scores, which are a transformation of cultural capital into institutionalized capital, in order to develop potential economic and social capital by drawing in new businesses. Not only did the standardized test scores represent a "good" school, but also a school that was universally achieving, as the whole group of students were represented by the test scores. In this feature article this universal up-lift was linked discursively to the strong community and caring parents as valuable capital for potential newcomer and businesses.

\section{Covington High: An In-Depth Portrait}

CHS sat close to the center of Covington, in the middle of a residential section of town. Off the interstate, a visitor would travel through a half-mile of various gas stations, commercial businesses, and medical offices, turning at a two-lane, winding road that broadens into four lanes to accommodate school traffic. The Covington school campus opened up into a small valley that 
ran along a creek. The school campus graced one side of the road, looking onto large residential homes shaded by mature trees across the street. After driving past the baseball and football fields, the three schools sat in a row: first Covington Elementary, then CHS, then Covington Middle School. A scrolling electronic sign with school announcements welcomed you onto the CHS grounds where the two story school building sat.

One of two administrative assistants buzzed guests into the building where a large central hallway opened up to the school. The walls have been painted cream but were yellowed with age as the older part of the building was constructed in the 1960's. There were two additions to the school in the 1990's to accommodate the increasing student population and to update technology spaces. The entryway was adorned with large murals of Native Americans, as the school mascot was the Chief and similar murals were found throughout the school. Once you entered the office, all school visitors had to present a photo ID which was scanned and made into a printed visitor tag. In a crowded office space, two administrative assistants sat behind separated cinderblock dividers and a long cinderblock wall fronted a counter-space with various office equipment. The two male principal's offices opened up behind this wall and counter space, while the female principal's office was in another space. The female principal was the newest administrative hire, however her separation from the other principals was reflective of their broader positions where she played an ancillary role to their center stage. The tone of the office space quickly initiated a visitor into the figured world of CHS, people were separated from one another and divided by position and duty. The office was strictly business, there was little chit-chat or welcome but a constant flurry of activity as the administrative assistants kept things rolling. 
There were three full-time principals. Mike Danza, a short, bustling man with White hair and a large, salt and pepper mustache was the head principal. He had been a local athletic star in his earlier days, a role he was able to draw on to identify within the local figured worlds, but was nearing retirement and there was talk every year of whether it would be his last. As a powerful actor within the figured world of CHS Mike constructed dominant discourses valuing achievement that strongly connected the figured worlds of school and community. His actions supported these discourses of forwarding the school towards success as he seemed to stay constantly busy with administrative tasks. On occasion I would see him walking around the halls as he checked up on teachers and students to make sure things were happening as they should be. Mike ran a very tight ship and as multiple students and faculty described continuously pushed to increase achievement.

Mack DeAngelis was one of two assistant principals and served as the athletic director and handled all the school discipline. Mack fit within the figured world of Covington, he was a handsome, athletically built man in his early 40's who typically wore CHS polos and khaki pants- he looked the part of an athletic director. Mack seemed to be generally liked by the faculty, more so than the other administrators. As the athletic director, Mack also seemed to have a special place in the community as head of the very successful athletic programs at CHS. His relationship to the important artifact of the sports programs positioned Mack as a person of value and also one with cultural and institutional capital. During the follow up of the study, Mack was heading up the PR campaign to raise funds to replace the turf football field at CHS. Theresa Marie was the other assistant principal and served as the school's curriculum coordinator. She had waist length hair that was dyed black, often dressed in a bohemian style with long flowy skirts, boots, and loose blouses; she often seemed frazzled. Theresea Marie's appearance made her stand 
out at CHS and, just as her office was in an ancillary space, she also was positioned as not within the center of administrative power within her principal role. During the in-school hours she and Mike were the most visible around the school.

Similar to the community, there was also a gendered nature to the roles of the administrators. Mike and Mack were the most public faces of the school, Mack for athletics and Mike for everything else school related; these roles were highlighted during graduation activities. For example, at the senior awards assembly, which was attended by the whole school and open to the community, Mack and Mike were dressed to the nines in suits and ties and were the speakers for the assembly. Theresa Marie was dressed in much more casual clothes and generally "took care" of the students, she ushered them in to the auditorium, showed them to their seats, and fixed their clothes before they went on stage. Similarly, at graduation Mike and Mack handed out diplomas and made speeches while Theresa Marie stood at the edge of the stage and made sure that students' timing was right as they were directed to walk across the stage for the ceremony. In these instances, Theresea Marie was literally positioned to the side of her male colleagues in very public spaces; these actions served to construct her role and positionality as secondary.

Mike and Theresa Marie spent the most time with the teachers, so they had more direct engagement with them than Mack did as the athletic director; as such, the teachers had quite a bit to say about them. Multiple teachers displeasingly described "being yelled at" by the administrators. In one of these teacher's literature class, students had created videos where they had to demonstrate the concept of irony. The classroom teacher had talked so much about her dissatisfaction with the principals' management in class that the students chose their teacher's frustrations as the topic for their video. The video was set to the song "I Had a Bad Day," and ran 
for a little over 15-minutes. It parodied a faculty continuing education day and how rude the administrators were to faculty. As the teacher introduced the video to the class she described, “Apparently, I suck at education... because all they [administration] do is yell at us" (CHS Observation, 2014). I had the opportunity to sit in on a faculty senate meeting and saw these dynamics at play. As Mike and Theresa Marie ran the meeting, there was a din of teacher talk as most people were not paying attention; multiple times Mike asked, "Be quiet, please" (CHS Observation, 2014). Some faculty were having individual conversations while others were playing on their phones. Mike addressed an issue of concern that some teachers were leaving the building five minutes prior to their release time and chastised, "You guys are supposed to be professionals. I don't want to have to watch you” (CHS Observation, 2014). His reference to watching the teachers was followed by a warning of his ability to do just that with the new cameras that had been put in for school security. These types of sarcastic approaches were not welcomed by faculty and did not foster a strong community of educators within the school. Moreover, the principals' actions did not position teachers as people who deserved full respect. While they may not have had optimal relationships with faculty, the principals repeatedly drew on discourses of achievement and continuing success to develop the culture at CHS. These practices that supported the figured world of CHS as a place of success were commented upon by faculty and students, sometimes critically. In the photovoice focus group, Selene brought in a photo montage of objects related to learning and education that she described as representative of her community (See Figure 10). 


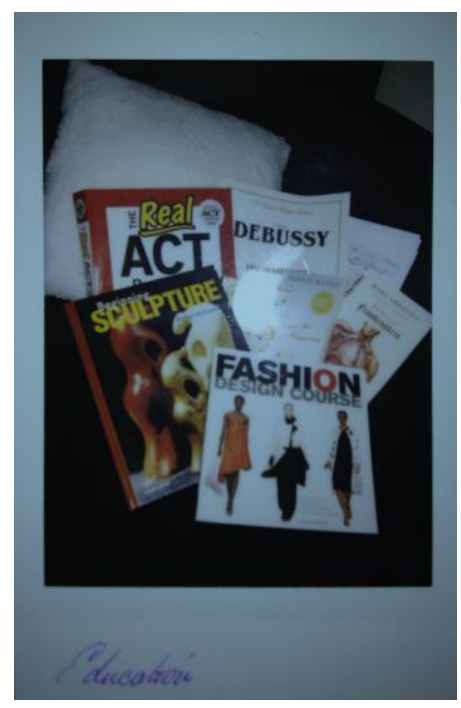

Figure 10. Selene's depiction of her community's focus.

Selene shared:

This represents education...basically my whole entire community has focused around education. I mean it's like in your face at Covington, do good, do good, do good, make sure you get a good grade on the ACT, what were your scores this year, they were terrible, do better. So [my] whole entire life up til now, I'm not sure about college yet, it'll definitely be focused around education, I'm just not sure if it'll be that much press. But for right now most of my community focuses around education. (CHS Focus Group 2, 2014)

When I asked the other participants if they felt the same way they described:

Gregg: That's all Covington focuses on....

Fantasia: That's totally true, that's all it is, that and athletics

Gregg: Not education, but high test scores...

Selene \& Fantasia: Yea....

Gregg: They want it, as long as it looks good they don't care what happens...

Selene: WestTest, man...(CHS Focus Group 2, 2014) 
This culture of success, whether things were actually successful or not, was omnipresent at CHS. Despite the discourse of success being very powerful at CHS, there were other discourses being circulated that disrupted this narrative. These heteroglossic discourses opened the space for people to call into question the "truth" of this narrative. While not every person bought into the narrative of success, as evidenced by the student exchange above, it was a strong cultural script.

\section{Teacher Business: Maintaining Status with Concerns}

In keeping with the push to achieve, the school was strictly business at all times, a cultural schema that affected teachers and students. There were no frills or non-academic activities happening during in-class time. From the moment students were in their seats to the end of each 90-minute class, the students were to be fully engaged. Teachers and students did not chat or catch up before class began, there was either a bell ringer, the teacher took roll, or class started immediately. These practices positioned teachers and students as co-producers of the success at CHS. While the teachers were not rude, overall there was no time taken to welcome me to the classrooms to observe or chat; rather, teachers directed me to where I could sit in the classroom. Once teachers had students engaged in independent work then they would take time to talk to me and answer any questions. When I asked one of the faculty about this strict operation he shared:

[The administration] had been after us for years to have no down time [and to be] constantly engaged. Having a bell ringer always. The administration is very ruledriven and oriented. When there are any spaces for downtime those are to be used towards academics. (Personal Conversation, 2014) 
This culture of "strictly business" was quite different from what is typical of Appalachian relationships, which is based on a style of familiarity and personal relationships (Keefe, 2005). Interestingly, this also made it difficult for me to have conversations with teachers as they were so often engaged.

While the ethos of the school was an overall focus on success and the appearance of success, this did not come without challenge. I asked each of the teachers I observed to complete a short survey and on the survey one of the questions posed was, "What would you do to improve your school?" Heteroglossic discourses were present as teachers' answers spanned a range. Some were very aligned to the culture of success, such as, "A greater degree of autonomy from the county. Policies for this school should not be dictated based on needs of other area schools" (Teacher Questionnaire, 2014). Others pushed against this focus of competition, to dig a little deeper into the education that a broader section of students were receiving. For example the one AP teacher responded:

There seems to be a large gap of rigor between the highest achieving students and the "average students." The "upper level" students are expected to complete "college level" work while some "regular" students face expectations that are too low for their ability. (Teacher Questionnaire, 2014)

While the discourses of achievement and success were very powerful within the figured world of CHS, some teachers were agentively moving around these by putting forward competing discourses that provided space for more students.

As these responses suggest, there was a mix of teachers and not all supported the community identity of achievement and success. Many of the teachers at CHS had grown up in Covington and formed a sort of insider's club. One teacher commented on the exclusive nature 
of the community, calling it a "bubble." This discourse seemed to extend to the teaching community as Judy, the guidance counselor, described that it was like some of these teachers had never left Covington except to go to college. The AP teacher who pushed against low expectations described how this cultural bubble extended to the students in ways that made them unmindful of those around them. She shared that in teaching about Appalachian Literature, students were not receptive to the works. Specifically, she spoke about teaching Denise Giardina's 1988 novel Storming Heaven. The students were put off by the dialect because it did not reflect how they spoke, as if it was something out of time and embarrassing. She elaborated that the students had no clue that they were Appalachian. Despite being surrounded by coal mines in the area, they were oblivious to the history of mining in West Virginia because it was so far from their privileged, suburban existences.

There was concern among teachers about this "bubble" atmosphere not serving all students equitably and several teachers mentioned this in individual conversations. The Family \& Consumer Sciences teacher revealed that she did not feel that the school took technical education very seriously because it did not fit with their high achieving reputation. She worried about students who got lost in the mix. She was a seasoned teacher who had been a principal but had come back to teaching because she felt that was where she could make the most impact. She described her teaching philosophy as focusing on, "quality of life for individuals and strong families" (Teacher Questionnaire, 2014), which is quite different than the focus on success that was more common across the school. Through her words and actions, this teacher engaged with the dominant discourses of CHS to construct spaces that attended to the needs of students other than the highly successful. Other teachers, particularly those who were not teaching the advanced track courses, voiced that they felt the administration and school myopically focused on the most 
successful students. When speaking to a veteran special education teacher, who had grown up playing sports with the head principal, he described, "I've been telling them for years they need to pay more attention to these kids [in Special Education]" (Personal Conversation, 2014).

It seemed there was a dual-push on the teachers at CHS to foster achievement with the school and students. The focus was very much on standardized testing achievement but it was more to outshine the local and state competitors and attract newcomers than to escape punishment for not meeting state benchmarks. The principals had fostered this culture of achievement in the school as they seemed to serve as a mouthpiece for the community within the school. One teacher who had been at the school for 15 years shared about this culture as it was passed on from the community via the administration:

Some [teachers]...do care about the learning but because testing and scores are so pushed by the administration that it's just the prevailing ethos of the school. A lot of what admin and teachers do is to keep the parents happy. And for a lot of parents grades are the most important things and getting scholarships, the community is very performance based (Personal Conversation, 2014).

As these teachers were concerned about how the push to succeed from the administration and community affected students, the guidance counselor also spoke of her concern about these practices. In the following section I first share about the guidance counselors and the overall practices in the counseling department. Then I specifically detail how the counselors worked at the school to facilitate the postsecondary transition. 


\section{Counseling Under Pressure}

Similar to the teachers, the guidance counselors felt a pressure to produce. Surprisingly, for a college preparatory high school, there were only two guidance counselors for all $727 \mathrm{CHS}$ students and they were constantly busy. They were so busy that guidance counselor Judy Robin graciously spoke with me over a weekend to help me set up the study and meet students because she had no break during the school week. Judy was responsible for the junior and senior classes as well as alumni needs. The other counselor, Catie Romine, and Judy seemed to have a perfunctory relationship; other than talking about official activities there was little personal relationship between the two. I never met Catie nor spoke with her.

The guidance offices were set back off of the school's main, central hallway that led to the cafeteria. A door opened up into a small, foyer-like room that led to two offices and a storage room. The foyer had high ceilings and the same yellowed paint as the main hallways. Two hard chairs sat against one wall for students to wait for the counselors, while multiple filing cabinets and shelves filled with informational material crammed the space and left little room for the student office aide to sit at a small desk. It was a bit like a sterile health clinic.

Judy's office was to the left of the foyer and was a long thin room packed to the gills.

Tall bookcases, lining two walls, stretched to the ceiling and were overflowing with books. Two desks took up the other two walls and were covered with papers and office supplies. Judy's family photos and inspirational signs dotted the space. Her office reflected the controlled chaos that was her world in counseling at CHS. As any downtime with Judy was extremely limited, I mostly learned about what she did through the questionnaire she completed. Similar to the literature, Judy had responsibilities that ranged from administrative to counseling to postsecondary advising. On the questionnaire she described her duties as: 
Endless!! Career counseling, college advising, financial aid and scholarships (FASFA), PROMISE Scholarship, graduation requirements/transcript cleanup, transcripts (current [students] and alumni), enrollment of students, withdrawal of students, grade maintenance, HTAC [tech and alternative learning centers], personal counseling, testing ACT/WestTest, PSAT, class ranking, group counseling, referrals, attendance maintenance, parent advising, National Merit, 504s, credit recovery, schedule changing, common applications, send applications, senior awards ceremony, graduation, and the list goes on... (Counselor Questionnaire, 2014)

Postsecondary planning. Despite Judy and Catie's massive responsibilities, they had crafted a robust on-site structure to facilitate the postsecondary transition (See Table 13). One of the strongest assets available for postsecondary advising and planning was the daily 30 -minute homeroom period. For homeroom, students remained with the same teacher for the duration of their high school career, with the intention that this time would be used to develop postsecondary planning. The homeroom teachers were responsible for collecting students' pertinent documents for the postsecondary transition into a student portfolio and were expected to advise students in the postsecondary planning process. Unfortunately, this seemed to be something that happened more at the students' request if they had questions rather than something the teachers systematically worked on. However, this time was still put to good use in other ways for the postsecondary transition process. Between the two counselors, they visited every junior and senior homeroom, multiple times each year to work on postsecondary advising. Sometimes these 
homeroom sessions would be held in the computer labs so students could explore the College

Foundation of West Virginia website and other scholarship sites. Students also applied for the

PROMISE Scholarship during these times, and there were specific makeup dates for students

who were absent on these days.

Table 13

Postsecondary advising activities at CHS.

\begin{tabular}{ll}
\hline Freshman & Orientation, school calendar, community test prep, visiting schools across the \\
& year, postsecondary pamphlets and information in hallways, College \\
Application \& Exploration (CEA) Week
\end{tabular}

There were also visual and physical presences of postsecondary planning available across the school year. The school's IT specialist maintained a calendar on the school's public website that listed everything of interest happening at the school or in the community that day. This included nearly everything related to the postsecondary transition, including the days and times of: visiting postsecondary institutions; guest speakers to specific classes or the school; visitation 
and open house days for institutions; start and closing dates for local, national, and institution specific scholarships; counselors' homeroom visit schedule with topics; and deadlines for test and application due dates. In addition to the listings, many of the links were live so that more information could be found by clicking on the link.

In addition to this calendar, access to information about the postsecondary transition process was easily available to all students. For example, the guidance office was in the main hallway near the cafeteria so every student passed the office multiple times a day. Within the guidance office, the counselors had set up a file folder with hard copies of every scholarship application available so that students could drop by, look through the applications, and take any that they were interested in. In the main hallways outside of the guidance office were three large magazine racks that contained information on the postsecondary transition. Two of these shelves contained pamphlets for technical and community college programs, while the other contained information geared toward 4-year institutions. While students' art was absent from the school hallways, commercially produced information on postsecondary institutions, scholarships, pertinent deadlines, and enrichment opportunity information abounded, such that students were visually exposed to this information daily.

In addition to this visual information, a variety of institutions sent recruiters to visit CHS. While CHS only had one formal college fair during the year, institutions frequently visited during the students' lunch hour. In fact, during the fall semester, the military and/or colleges visited at lunch nearly every day. The counselors had set up a seamless system so that representatives checked in at the front office, stopped in to the counselors to say "I'm here," and then set up their information at a designated table in the cafeteria. While CHS only had around $1 \%$ of their graduates enter the military, several branches recruited aggressively during these 
visits. Other institutions ranged from technical institutions, to state schools, to the ivies (See

Table 14). There was clearly a focus at CHS on the postsecondary transition and while

baccalaureate institutions had the most presence, technical and trade schools were also present.

Table 14

Postsecondary institutions visiting CHS during lunch.

Military Army/Army National Guard (14), Airforce, Marines (3), Navy

technical and 2-year WV Junior College (4), Harman Electrical Youth, Mollohan

institutions $\quad$ Foundation (4), Robert C. Byrd Institute, Wyoming Tech Vehicle

Maintenance School

In-state baccalaureate Wheeling Jesuit University (2), West Liberty University (2), Davis \&

Elkins College, Alderson Broaddus College, Fairmont State

University, West Virginia University Institute of Technology, West

Virginia University College of Pharmacy, West Virginia University, Glenville State College, West Virginia University Engineering, Marshall University

Out-of-state Harvard, Princeton, University of Virginia, Washington University in

baccalaureate St. Louis, Columbus College of Art \& Design, University of

Richmond, Savannah College of Art \& Design

Open house \& $\quad$ University of Pittsburgh, Fairmont State University (2), New York

visitation days listed City Campus of the American Academy of Dramatic Arts, West

Virginia Wesleyan, Columbus College of Art and Design, West

Virginia University Technical Institute, West Virginia University, University of Akron, Prospective Jewish Student Weekend at College

of Charleston (SC), Pierpont Technical College, Wheeling Jesuit

University, West Virginia University, West Virginia University

School of Engineering, Alderson Broaddus, Shepherd University,

West Virginia Junior College, National Aerospace Education Center,

Harman Technical and Alternative Center, Institute for Advanced

Flexible Manufacturing

Note 1. Numbers indicate how many times the institution visited in the 2013-2104 school year).

Note 2. Institutions are listed in order of visits.

Students did take advantage of these opportunities. All of my participants knew about

these activities and had accessed them as well. Despite the high counselor to student ratio, both

the counselors and students commented that one strength of the counseling department was the counselors' availability. After they graduated, I asked the student participants what they wished 
CHS could have done differently in the postsecondary transition process. One student replied, “Actually they did a great job with us! I really miss their hands on help. There's times when I want to go to the high school counselor and tell her to help me now!" (Fantasia, Interview 2, 2014).

While postsecondary information was available for students, unless parents approached the school there was little outreach to help parents facilitate this process. My participants were all first-generation college students and each of their parents shared that they wished that they could have helped their children more in this process. Parents did everything they could to help their children through this process; however, when it came to some of the more nuanced aspects of applying to school like helping their children build strong applications, they were entirely dependent upon what the school provided. While students were reached and seemed satisfied with the services provided, there were missed opportunities to work with parents.

\section{The CHS Life}

CHS ran on a 90-minute, alternating block schedule so that students could carry up to six courses if they had alternating courses. The school year was divided into semesters, which were further split into 6-week grading periods with classes changing at the end of the fall semester. Since classes were completed within a one semester time-frame there was time available for students to make up failed courses and graduate on-time and also still take electives.

The school day began at 7:30 a.m. and ran until 3:00 with four, 90-minute class blocks, one morning break, and two 30-minute lunches. After first period was a "grab-n-go" breakfast break where students could get a packed breakfast from the cafeteria to take to second block and eat while they watched the 15-minute school announcements. This was an especially important program for low income students who were not able to get to school early enough to eat 
breakfast before 7:30. The grab-n-go "snack" amounted to a full breakfast, even though it was typically sugary, processed food. It was billed according to free and reduced lunch schedules but it seemed like almost every student, regardless of income, took advantage of this meal.

After second block, students either went to a 30-minute homeroom or lunch period. The daily homeroom was an asset for students, academically speaking. As I mentioned earlier, this was a time when guidance counselors met with students to work on the postsecondary transition and when teachers were supposed to provide guidance. Students took advantage of this time to complete homework and work on school projects. One of my participants described that he never had to take homework home because he was able to complete it during homeroom. Additionally, because most teachers were on duty during this time, students could go to individual teachers if they had questions for study or homework. Structured tutoring was also provided by teachers during this time so that if students were struggling with a particular subject or class they could go to the relevant tutoring room. Finally, this was also used as a re-test time called "lunch-to-learn." If any student at CHS failed a test, it was mandatory that they re-take the test during lunch-tolearn after they had, hopefully, studied more. While part of the benefit was increased learning, students were able to somewhat improve their grades. However, the highest grade students could receive after a test re-take was a 65 , the lowest $\mathrm{D}$, so that they technically passed the exam, but did not use the time to simply make up for not studying when they should have been.

CHS offered many courses and had the broadest course selection in the county, particularly when it came to AP courses and electives. Students from high schools across the county were able to opt in to courses at CHS, either by travelling to CHS in person or through courses set up via distance learning. CHS offered AP courses as well as dual-credit college 
courses that had minimal tuition fees, for example $\$ 100$ for 3-credit hours through a local state university. Some courses were equivalent to 6-credit hours. As seniors, students could opt to attend college courses at the small state school in a neighboring town.

CHS had a few, basic, technical courses on site. It was also attached to the county technical center, Harman Technical and Alternative Center (HTAC), which offered a broad array of courses. HTAC was only a 10-15 minute bus ride from CHS and multiple buses ran across the day giving students flexibility in taking courses off site. Additionally, students could enroll in single courses at HTAC and did not have to be in a full-program to attend. All CHS students were required to go on a tour of HTAC at the end of eighth grade where all students were bussed to the site so they could learn about its opportunities. Students could enroll in dual-credit courses free of cost at HTAC, and complete programming that met partial and full-requirements for certificate programs so that some students would graduate from high school with a certificate inhand, prepared to begin work. While the main thrust of CHS was toward students who were focused on prestigious advanced courses, they were quietly providing a strong path for students who had a different profile.

Troubling tracking. Courses were highly tracked at CHS and this tracking also denoted social class and students' standing within the school. The "really smart kids" took the most advanced courses while the "not cool kids" took the regular and applied courses (Personal Conversation, 2014). My participants commented on how distinctly students were grouped according to tracking, though they were not aware that this was what they were commenting on. One participant, who was in almost all AP courses her final semester shared that when she would take "easy classes" there were often people she "didn't know" and "hadn't seen since middle school." She shared: 
Sometimes I would try to take a free class and like this is terrible, but in my free classes, there were people I didn't even know... So weird, it's like really weird. How do I say this? How the same people get the same kind of grades and the same ... it's like a different set up, I don't know how to explain it... most likely I would see the same people over and over again. (Selene, CHS Focus Group 2, 2014).

The alumnus I spoke with also shared that, "Smarter kids had parents who cared, were wealthier or middleclass [and] their parents are involved. AP takes a lot of work and is expensive too because you have to pay for the test" (Personal Conversation, 2014). Along with these classed and value laden descriptions of more privileged students came similarly classed descriptions of the HTAC students. As one of my participants was describing the different groups at school, he shared, "There's the trailer park White trash people clique, like you can see them comin' in off the tech bus" (Gregg, Interview 1, 2014). Not only were courses tracked at CHS, but the sorting of students was also happening in noticeably classed ways.

Courses at CHS ranged from "applied" and "conceptual" courses; through regular courses, which included most electives; to advanced, college credit, and AP Courses. Students were placed in courses according to standardized test scores, grades in prior courses, and teacher recommendation. However, parents could advocate for their students if they did not agree with their tracked placement; which did sometimes happen. In math all freshman students were tracked into either the general math course, which offered the potential to move into the advanced pathway, or the applied courses through assessment on their $8^{\text {th }}$ grade math grade, a county wide standardized test, and teacher recommendations (CHS Course Offerings, 2014). 
English 9 was even more stratified, with an applied, regular, and honors version. Placement in the applied courses was based on state standardized test scores, while entry into the honors section was restricted to students who met eighth grade standardized test scores and had writing samples that were approved by the honors course teachers.

While some electives were open to general students, others had limiting prerequisites Some had grade or testing requirements, including many English electives such as journalism, photography, and the film/video courses. Others required commitments outside of school that could limit participation for students from low income backgrounds. Similar to how students were ranked according to the tracked level of their required courses, electives at CHS were also hierarchically ranked. In line with the school and community focus on visible achievement and success, CHS was very proud of its performing arts programs and these were some of the most exclusive electives to gain entry into. For example, in order for students to participate in band as freshmen, the official school curriculum listed that required prerequisites were having participated in middle-school band or private lessons, while "private instruction is highly encouraged" (CHS Course Offerings, 2014). Other performing arts that were highly valued at the school and competitively successful around the state included the dance ensemble and show choir. Each of these groups required not only an audition but also required those elected to participate in classes, workshops, and conferences, which would have been highly limiting for students who lacked the economic capital to pay for these extras. Students who participated in these electives were lauded by the school. At the senior awards assembly there were multiple individual performing arts presentations which Mike, the head principal introduced with, "That's because we always seem to have so much talent that we want them all to be able to show off 
their talents" (CHS Observation, 2014). As students in these electives were displayed by CHS, they were offered access to dominant cultural capital through their training, as well as social capital through their relationships with teachers, administrators, and networking at performance events.

Similar to research (Hallinan \& Oakes, 2011), my students in general track courses had less consistently strong teachers than those in the advanced courses. In the majority of the classes I observed teachers were engaged with students, often scaffolded learning, and made connections between the material and students' lives. I did observe these practices in applied, general, and advanced courses, so there were teachers across the spectrum supporting students' learning in a variety of ways. However, the only classes I did observe clearly problematic practices in were general track courses, both social science courses, one that was required and the other an elective. The elective course, sociology, was problematic. The course was made up mostly of students from the general track courses, which was also a distance learning course for two other county high schools. The teacher, who was a certified, permanent faculty, had poor classroom management skills, relied on sexist and racist stereotypes to justify information, which I will expand upon later, and occasionally gave information that was entirely inaccurate. The teacher relied almost entirely on videos, mostly from YouTube, which he had not prepared prior to class, so that there was always in-class time spent with the teacher searching for relevant videos. Once the teacher found a relevant video, he played it while the in-class students chatted, slept, or worked on other school-work. Students in the distance learning classes often had their heads on their desks, appearing to sleep. They were called upon perhaps 1-3 times per 90-minute block to participate. Sometimes students in the distance learning classes would attempt to engage with the teacher, however the teacher failed to notice them. In each class many of the students asked to be 
excused for the bathroom, etc. with students occasionally being gone for up to 15 minutes. When discussing the topic of the world's population, the teacher shared the following misinformation:

Let's go back to Neanderthals—well, they ate their children, but let's go back... How many know what the Inuit Indians are called?-otherwise known as Eskimos. They live above the Arctic Circle and are hunters of things like seals. The Inuit Indians, especially the ones who live above the Arctic Circle, used to do something called female infanticide...It's the practice by the Inuit Indians, up until the 1800 's, because once it was found out it was frowned upon by White men and especially the [U.S.] government. (CHS Observation, 2014)

This passage from class was problematic in many ways, at a very basic level the information was wrong and the teacher's terminology inaccurate. The teacher's description was also racist, likening the Inuit people to a sub-human species and then positioning them as murderous savages who were saved by White men from the United States. Not only were students in this course missing out on opportunities to learn about important sociological issues, but they were also being exposed to mis-information that was layered in racism, sexism, and other problematic discourses.

Reigning athletes. Just as courses positioned the participants as particular types of students, school-based activities served as artifacts that positioned students within the figured world of CHS. The athletes at school were constructed as winners, as they won championships they were awarded literal and figurative identities, which positioned them as powerful actors at CHS with great cultural capital. One alumni described: 
The rich kids are jocks who play sports, it's expensive to play sports because everyone buys the same shoes, warmups, t-shirts, and travels a bunch. The moms cook dinner the night before [games], parents have to work concession stands so many times, [it takes] money to play sports and parental support to play sports. That's why a majority of kids who play sports are popular, because they have money and parents who are involved. (Personal Conversation, 2014)

The students who seemed to benefit the most from being in the recognized role of popular athlete were young men. While the varsity cheerleaders were positioned as popular, they seemed to be the only female athletes who were in this group. The junior varsity cheerleaders were described as, "Not cool, they would just take whoever [for the squad]." While some of the other girls who played sports were cool, some were described as "really awkward, so they are good at sports." The discourses of acceptable masculinity and femininity limited the potential for some young women to have valued roles when their performances did not fit within the limited boundaries of these discourses. Within this figured world, there were shared understandings of what it meant to be an athlete, as well as how different types of athletes were distributed across the world with varying levels of power.

The "power" students were very visible across the school, as not only were they athletes, often in multiple sports, but they were also visibly involved in the most popular activities at CHS. One of these activities was the "shop for tots" Christmas program where popular students from CHS, many of whom were athletes, were paired with a young "child in need." The language of the shop for tots programs discursively placed CHS students as benevolent and also as economically successful in relationship to the "children in need" whom they were able to help. Students spent the day taking kids shopping for toys and clothes and then had a party for the kids 
CHS where Santa Claus visited. This event served as an artifact that constructed the student participants as "good" and also positioned them as contributing to their community. Students and kids were out and about in the community, a newspaper article detailed the event, and a multipage yearbook spread documented this event. The positioning of the event as very public supported the identities of students as contributing to a good community that cares about its residents, while also supporting discourses making the community more marketable to potential businesses.

The success of the athletes was a prominent feature of the local figured worlds as it was commented on and highlighted often at the school and within the community. For example, at the senior awards ceremony, multiple students from a variety of sports were recognized for receiving athletic scholarships to attend college. These students were also recognized across the spring in signing ceremonies where students would be photographed sitting at a table signing on with their respective colleges, surrounded by their parents, high school coaches, and often the college coaches. These events were published on the town's news site, "Connect Covington.” In these instances the transactions of capital were connected; as students were supported by parent and community economic capital to develop competitive sports programs, students were awarded economic and institutionalized capital in the form of scholarships, which was then translated to further cultural capital in the recognition ceremonies.

Graduation time presented another opportunity for athletes to be recognized, reinforcing their positions as valuable and prominent actors in the figured world of CHS. At the senior awards assembly, the economic capital that was invested in CHS was on high display. The awards were split up into academic, sports, and performing arts awards and the sports awards were opened by the head principal. He began: 
The athletic boosters give $\$ 400$ each to 11 students to give back to the students since they raise thousands of dollars. BHS alumni are giving $\$ 30 \mathrm{~K}$ this year to students, 6 years ago that was around $\$ 3 \mathrm{~K}$ and we hope to have it up to $\$ 50-60 \mathrm{~K}$ in the next few years. (Mike Danza, CHS Observation, 2014)

Students' identities as athletes positioned them as deserving of money and recognition as they were contributing to the coproduction of the community identity of success. As the athletic awards continued with each donor presenting their own award, one CHS alumnus, recalled the state championship he had won as a CHS student. He shared, "Like many of you [state champions] are now, you'll remember that out of all your academic and athletic achievements" (CHS Observation, 2014). These words highlight the capital activation associated with being on a winning CHS sports team. The capital was re-activated through memory generated at yearly ceremonies such as this one. In this way, the symbolic meanings of this capital were resurrected and strengthened in a community bond among generations. After the awards ceremony, scholarship winners were invited to a private reception in the school library where they could meet the donors who had funded their awards. Students also drew upon these narratives as evidenced at graduation. One popular athlete, the son of a teacher and prominent community business member, had been nominated by teachers as "Mr. CHS" and spoke at graduation. He related the importance of his sports experiences in his life and success. He recalled the varsity football seniors' role in capturing the state championship football game: "My last memory of CHS...On that snowy night in Wheeling, no one gave us a chance, but us 16 seniors wanted it... No matter how tall the mountain, it can never block out the sun. An ancient Chinese proverb" (CHS Graduation, 2014). Mr. CHS drew on his identity and experiences as an athlete to reinforce the importance and value of this position not only for himself but also for his community. 
Together the students and community created and reinforced the narrative of winning and success as an ideal of the community and its people that became a collective identity. In addition to the community providing financial support to students through the various boosters organizations and scholarships, they negotiated other ways for the CHS sports teams to have advantages over other teams. One major incident revolved around the AstroTurf football field at CHS. Ten years prior to the study the community of Covington had raised private funds to pay for a turf field for the football team. This had become a point of pride within the community and, as with other issues, a point of contention with neighboring areas. After CHS had their turf field installed other schools in the county petitioned the board of education for turf fields. However, because Covington had raised their funds privately, they were opposed to others in the county receiving help from the board and persuaded the board to not fund fields for other schools. As one person described, "Covington got mad because they did not want their tax money going to turf for others because they raised their money on their own" (Personal Conversation, 2014). As a community, Covington was comfortable spending their own money to advantage their own, as well as to block others who did not have the same private funds from receiving public help.

While some of the most dominant narratives of CHS and Covington were focused around the success of sports teams, there were those who did not see these as such great assets. For instance, in the irony videos mentioned earlier that poked fun at the administration, students also mocked the intensive focus of CHS on sports. At one point in the video, students mocked the football team, saying "You know there is other stuff that goes on here," while the end of the video concluded with, "We'll be first in WestTest as well as our football team-Gooooo Chiefs!" (CHS Class Observation, 2014). These students were creating alternative discourses to push against discourses of winning that led to the erasure of other school groups and individuals. 
Other activities. Outside of reigning athletes, there were other, quite visible, performing arts programs. Fitting with the focus on presentation and success, the activities that could travel and compete with other schools were the most prestigious in this figured world. Students who participated in the performing arts activities were positioned by administration and the community as another "power" group in the school. The same students popped up across these clubs and activities and were especially visible during graduation activities when the school was on full display for the community.

The CHS show-choir was touted throughout the state as being pre-eminent, along with the dance-line and dance ensemble. Two school plays highlighted the theatrical talents of CHS students and a few years ago Connect Covington wrote an article about "New York choreographers" who had worked on a Tony Award winning production developing the choreography for the play, showing the reach of social capital at CHS. The Shop for Tots event described earlier was a conglomeration of all of these star students; a culmination of the good community. At Shop for Tots, all of the school's performers, from athletes through dance stars, could contribute to valued community discourses.

Parent involvement. School-sanctioned, middleclass ways of relating between homes and schools were often visible at CHS as parents were present at the school helping out and also engaging with faculty and administration when they were not satisfied with their children's progress. White, well-heeled, mothers were visible at special occasion events like the senior breakfast. At the senior breakfast the mothers prepared breakfast for the students and faculty, acted as servers at the meal, and joked about things like spiking the breakfast milk for the adults. 
Moreover, CHS parents were consistently praised by the school administrators and the community as being "involved" in their children's education, something that was viewed as impetus for the success of the school, academically and athletically.

All of the participants' parents were quite engaged in their children's education, however this looked different from the ways the middleclass mothers engaged. Parents all spoke of supporting their children through emphasizing the importance of education and through encouraging them to attend college. Each of the participants had parents accompany them to college visitation days and to schedule their college courses. Selene's parents, mostly her mother as her father did shift work, participated in school in traditional ways, such as attending oncampus school events and hosting the picnic for the CHS French Club at their home. However, this was an exception to the rule and these parents were not involved in high-profile activities like boosters and other popular parent organizations.

Students' time. There were many opportunities for students to participate in school based activities in Covington. However, these seemed to be filled with the same students participating in multiple activities rather than a broad group of students participating in a few activities. Selene was my only participant to engage with school-based functions and also the only one not to work. Gregg's and Fantasia's both found plenty to keep them busy outside of school, particularly with their jobs as a server and photography assistant/telemarketer/server, respectively.

With the booming local economy there were many service sector positions available for students, often ones that paid more than minimum wage. Often, students could choose areas that were interesting to them. For instance, Fantasia was interested in photography and so worked at 
Olan Mills as a photography assistant. After her hours were cut, she moved on to a telemarketing position where she made around $\$ 10$ an hour. These jobs were close enough to home that her family could drive her as she did not have a driver's license.

There were students at CHS who did have to work to help support their families (Faculty, Personal Conversation, 2014). However my participants, and I would guess many other CHS students, were able to use their earnings for play money. This was interesting, as Gregg and Fantasia had both taken up narratives of consumerism present in Covington. With the commerce and shopping in Covington there were many ways to visually indicate disposable income.

Fantasia and Gregg were able to use their jobs as pivots that allowed them to participate in these practices and discourses. For example, Fantasia loved to get her nails done and often used this as bonding time with girlfriends. Despite not dressing up for school, Fantasia was very interested in clothes, makeup and hair, so she also spent money on these things. Fantasia's fashion consumption was mediated by her classed and more 'country' standing. She constructed an identity as a "red-neck, tough girl" and used her fashion choices as identity tools to support this position. One of her favorite nail designs included camouflage and she often wore clothing or accessories that were punctuated with country girl, pink camouflage splashes.

Gregg's participation in these discourses of consumption was shaped by his classed position as well. For instance, he used his money to buy clothes so that he would fit in more with the "preppy" Covington look. However, he used his extra money to buy fishing and hunting supplies and also to pay for his dirt bike racing. Gregg's consumption was modified by his parents' rules as his dad felt it was important for him to earn his way and not have too much handed to him. Rather than buying him a vehicle, Gregg's dad set up a sale with a friend and found a good deal but made Gregg pay for his vehicle and his own insurance. 
The context of social justice. The identity of CHS was not constructed around much other than its own success and promoting its most successful students; however, it was quietly meeting the needs of some less privileged students. Low income students at CHS were barely noticeable as a group, making me wonder if there was programming to help support them. I had not heard about any programs for these students, so asked around and one faculty shared that despite the invisibility of these student and help for them, there was programming that helped provide materially for these students. My lack of knowledge of these events may have been more a product of the "strictly business" nature of CHS which led to a few conversations with designated faculty rather than a democratic design for these programs by faculty, students, parents, and community agencies to protect students.

For example, lunch bills were sent home so that students who received free lunch were not identified. There was also the grab-n-go snack that most students participated in that allowed students who could not get to school early enough for breakfast to have some food before lunch. Another program sent dinners home each day of the week and over the weekends, though I am not sure how accessed this program was, as I had not heard about it until I spoke with the faculty. The school had a yearly clothing drive amongst teachers to gather winter clothing and coats for students in need. Each year the school also did a Christmas drive to provide gifts for students who otherwise may not receive them.

Bullying, but not. When I asked my students about the different cliques at school and how people got along with each other, they explained individually that the school was a good place where, though groups were different, people were generally nice to one another. When the participants were together for a focus group they concurred: 
Gregg: I think like Covington, I'm not just sayin' this because I'm from Covington. Maybe it was just that...I never let anything get to me, sometimes I do, but like, I don't see a lot of bullying at Covington, like Covington High School, I know there's a lot of stuff that goes on that I don't see. Like our athletics are awesome, our academics are awesome, but when people talk about bullying at school, I don't really see that in Covington High School, I mean the popular kids get along with the nerdy kids and the nerdy kids were able to be popular and like I know, it's like Covington is a whole different breed of school.

Selene: Yea we really did not like ...

Fantasia: If it happened it was because you pissed someone off, they'll use that against you, like if you're big they'll use that against you...

Gregg: Yea...

Fantasia: But that's with really anybody. Honestly Covington really was....

Gregg: It's like a utopia.

Fantasia: It was a great school.

(CHS Focus Group 2, 2014).

However, outside of these direct questions each of the participants shared stories of being othered or made fun of by more powerful groups at the school. The participants seemed to have taken up dominant discourses of CHS as a good place as an internally persuasive discourse, despite their personal experiences. As participants discarded their own experiences of being othered they erased aspects of the figured world of CHS that did not align with the school identity. 
For instance, body shaming was prevalent at CHS, multiple times thinness was discussed as an issue for girls and Fantasia noticeably did not fit this profile, even describing herself as a BBB (big beautiful woman) on Facebook. Body monitoring was so prevalent that Gregg described one school clique as the "bigger" kids (Gregg, Interview 1, 2014) and Fantasia shared that if kids at school were angry "like if you're big, they'll use that against you..." (CHS Focus Group 2, 2014). In response to being othered, Fantasia shared why she dressed up fashionably outside of school but typically wore baggy jeans and oversize t-shirts and hoodies to school. Early in her school career she had dressed up, doing her hair and makeup but kids made fun of her efforts. In speaking back to that and to push against these limiting norms, Fantasia refused to conform at school and simply removed herself from the appearance game; if she did not try, kids could not demean her efforts (Personal Conversation, 2014). She shared this photo on her Facebook page which I found to be quite funny because it very accurately portrays how differently she presented herself between school and home (See Figure 11).

\section{How I dress during the week vs.}

\section{On the weekend}

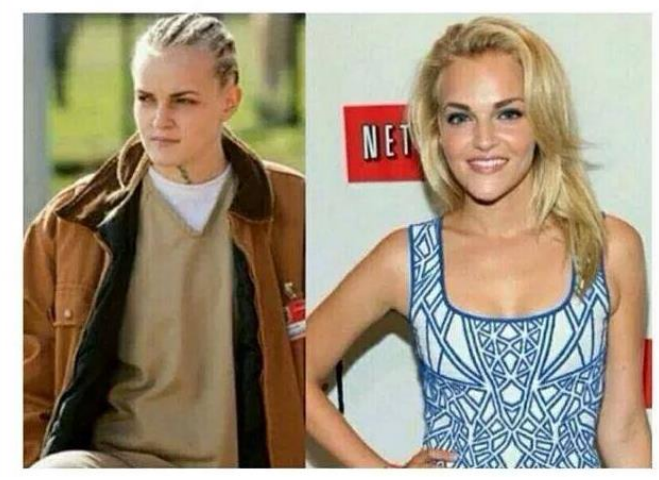

Figure 11. Fantasia's presentation of how differently she dresses between home and school. 
Racism. There was racism across CHS and Covington, a racism that seemed to be a part of the everyday atmosphere. Everyday racism surfaced at the annual senior breakfast put on by parents. Students brought photos from elementary, middle, and high school that were displayed on tri-fold boards for everyone to see as the students passed through the food line. One of the photos on the middle-school board was a young White woman, dressed up in blackface, ostensibly as an "African orphan" holding a cardboard sign that said, "I'm hungry." The photo being included on the board was indicative of White complicity and perpetuation of racism and fit with the casual racism at CHS. However, I was surprised blackface representation was worthy to be selected years after the fact to be re-displayed and publicized to a larger, more mature audience at an important public celebration. There were multiple times at CHS where a cloak of humor was used to make racist comments and experience.

As symbolized in the artwork adorning the school walls and the visibility of the mascot, The Chief, at sporting events, a visual tapestry of chiefdom was woven deeply into the community itself, as well as school spaces beyond the office and hallways. For example, in community parades people would dress up in Native American headdresses and costumes to represent the school. The art room was entirely done in an "Indian theme" because the art teacher wanted the room to match the school. I noticed large, drawings of Native Americans that had been sketched on the blinds in the art room. Thinking that perhaps they had done a project that researched the Native Americans that were known to have been in the area, I asked how the subjects had been chosen and the art teacher replied, "I just picked pictures that I liked.” The 
teacher's actions were appropriating the lives and stories of Native Americans for her aesthetic pleasure and to add to the "Indian theme" of the room. However, art is a practice that has the potential power to disrupt dominant discourses and reshape proscriptive practices, though that was not realized in this instant.

As a bi-racial student, Selene had many experiences herself with the racism in the school, as well as in what her friends had experienced. One instance that I observed occurred with the art teacher. Selene was running an errand during the "no one in the halls" standardized testing time, and a peer joked to her to not get caught in the hall to which the teacher replied, "just pretend like you're an exchange student and can't speak English" (CHS Observation, 2014). The teacher was drawing on Selene's Asian features to work around the principal's edicts. While the teacher was finding ways to move around limiting practices, her use of Selene's ethnicity to do this was problematic. Selene rolled her eyes and exited the room without otherwise responding. She shared about another incident when the school forced her to choose a racial category that did not accurately describe her identity so that it could capitalize on her presence:

They called me down to the office to change my race once...I used to just flip a coin in my head and pick one because my dad's White and my mom's Chinese, like, "Mmm, just gonna pick one.” And it turns out my race...I was White on my data, so...they called me down to the office to change it [to Asian]. That was probably the most, it was kind of offending, understandable at the same time, but it was mostly offending 'cause I know that the school gets more funding for having a more diverse school, so that was partially [why it happened]. (Selene, Interview 1, 2014) 
Selene shared other stories of where her race became the subject of conversation, and she was stereotyped and objectified, "When I used to sit at my other table, that happened all the time, always with the Asian jokes" (Selene, Interview 1, 2014). Her peers were able to slide in racist jabs under the guise of humor that could be used to manipulate intent. In other instances, her friends from Asian backgrounds had also experienced racism. Selene described that, "There used to be a girl who made fun of Jasmine because she's Indian, and I think she thought she was probably Middle-Eastern...like, "She's gonna drop a bomb on us" (Selene, Interview 1, 2014). While Selene was able to name racism that was directed at her and her Asian friends, at times Selene participated in racism towards other groups. Selene did share, very openly, that her father, was racist, particularly towards African Americans. However, she failed to see that while her racism was more subtle than her father's, it was nonetheless present. The Covington students who participated in the focus group on race were steeped in White privilege and the everyday racism that comes from this position, though they were vocally opposed to more overt forms of racism. For example, Gregg shared a video of a White woman on a plane asking to be moved so she would not have to sit next to a person of color. In response to the request, the airline attendant replies that she can take care of that problem and proceeds to move the person of color to first class so they do not have to sit next to the racist White person. All of the participants readily agreed that what had been done was wrong.

Unfortunately, when I selected the videos for the focus groups to prompt our discussion on race, locally and in Appalachia, I chose only work from the Affrilachian Poets who are African American and Appalachian, and not from a more diverse group of poets such as Chinese-Appalachians and Middle Eastern immigrant poets living in Appalachia. The students seemed to have a hard time accepting the words of the Affrilachian artists because of their racial 
background. For instance, when I asked what students thought of the first video, Selene did not seem pleased that the group was focusing mainly on the experiences of Black Appalachia. She shared, "No offense, but African American people are complaining about things that are not necessarily because of their race" (Selene, CHS Focus Group 2, 2014). When I asked if she could give an example, she noted the importance of specifically positioning Whites as vulnerable in media stories. Selene's example is from an accident that included both White and Black teens: [It] wasn't considered racial just because he was White [even though]...it was a racial thing, that's the thing because he was White, but they didn't point it out like that because it would anger the black community. And I think that's something to point out every once in a while. That's why with the poetry group I'm not sure if it's just really pointing out that black people—-this and that—or if it's just equal. (Selene, CHS Focus Group 2, 2014)

Fantasia and Gregg both used similar tools to proclaim White innocence; for example, "I am not like my family who does this" or "I like all people equally." Interestingly, the CHS students seemed aware of more sophisticated norms of what was okay to say and not, for instance, when mentioning others who used racial epitaphs, they said "the ' $N$ ' word" rather than saying the word itself. For these students, race was largely set up as a Black/White binary, although Selene did identify that there was the "Asian stereotype" at their school, where people assumed that all of the Asian kids were smart. In general though, the students were oblivious to their own racism. In fact, Gregg shared that racism "was a big thing" but had since faded (CHS Focus Group 2, 2014). This lack of recognition and misrecognition of racism highlights the importance of reframing conversations around racism to focus on its systemic nature and not only individual acts of racism. 


\section{Student Stories and Major Themes}

The following section draws together the context that has been described to illustrate a vignette of each of the students' stories as they relate to community and school practices in the local figured worlds. Selene and her family's story comes first, to illustrate how belonging was performed by those in Covington at community and school levels. Gregg's story follows, as I describe how social class and country-ness were salient to his identity as he positioned himself in Covington, with his family, and in his future. Finally, Fantasia's story of how she moved through the postsecondary transition is described, paying close attention to what her identity as a first generation college student positioned her in this process.

\section{Success at Othering: Community and School Practices}

Success has been a constant that has run through the stories of Covington and CHS. Success as growing a business, success as having a large income, success as landing a prestigious job, success as having a home in a certain neighborhood, success as a winning sports team, success in achieving high standardized test scores, and success in having a competitive spirit and working hard, the traits that allow success to blossom in this figured world. This narrative was dominant across community and school. Because success was so narrowly defined, there were many opportunities for people to not fit into this mold. This section is the story of how narratives of success and competition served people differently within the local figured worlds.

How these narratives served to other students and families is important to consider when thinking about how agency is shaped by positionality. When a person is put into a position of less power they are denied access to dignity as a person of value, such as at CHS and in Covington where a person was not valued as highly if they were not bringing the school or 
community recognition. This limited accessibility to dignity and value through the community and school shaped how the participants engaged with these figured worlds (Carspecken, 1996). Despite none of the participants being positioned in roles of high value within the figured worlds of the local community and school, the students all showed great strength and were able to build identities as valuable people via relationships and activities outside of these spaces.

For instance, Selene who, as I will detail, would typically be considered "in" or successful because of her social class standing, but she had many experiences within the school and community that were excluding. This othering happened across race and class, each seeming to work against her. Selene's experiences show that in Covington not only was a certain level of capital required, but also the right types of capital were required in order for it to be recognized. For example, Selene was very stylish, looking as if she stepped out of a magazine every day. Her mothers' parents lived in New York City and they visited frequently so Selene did much of her shopping in Manhattan. She had a variety of looks that ranged from sophisticated to edgy and stood out from the other stylishly dressed CHS girls. Selene was interested in fashion and her dream was to work in the fashion industry. When she entered high school she had sought out similarly interested "friends," who happened to be popular and somewhat mean. Selene shared how the lunch table she sat at and eventually fell apart because of the mean Queen Bee, Lisbeth:

I used to sit at a table with a bunch of people that were more popular than the group I was in...We all sat at that table and slowly one by one they started leaving the table because what happened is...I ended up not being myself, you know how that happens, high school, that type of stuff... basically every time they would see someone who's overweight walk by and I think her pants are amazing because they're just like really cool...they would say something directed towards how she 
shouldn't be wearing that...there'd always be a couple people that are like, "I don't know, I kinda like it..." and they would kind of shut up because [of] a bigger group, conformity. So that's how it went at the table and slowly one by one people left. I left because I just couldn't deal with it anymore, I didn’t get along with Lisbeth, she's the person I didn't get along with, she always made fun of me at the table, the fact that I'm Chinese, which I make fun of, I make jokes, but it was different, it was offending and make fun of my height, compare my legs to hers, stuff like that, girl stuff, oh you're legs are too short mine are so long. Just petty stuff. (Selene, Interview 1, 2014)

In the experience Selene described, humor was used by her peer to draw upon racism in "acceptable" ways and to assert symbolic racial power. Also, this discursive positioning intersected with gendered expectations for beauty as Selene's "short-legs" were used to position her as not meeting beauty standards. This "falling out" happened Selene's junior year and by her senior year she had entirely switched friend groups and dropped out of clubs because of Lisbeth's animosity. As Selene needed to respond to her peer's racism and bullying to protect herself, her peer's actions limited her access to the potential capital gained from participating in clubs that would have been helpful on college applications. Lisbeth's access to the symbolic power allowed her to control others' access to capital as well, showing that while official school practices do control access to capital, students positioned in places of power can also control access. 
After this, Selene continued to experience othering at school as people spread rumors that she dressed to draw attention to herself and found her snobby. Selene shared that this was exacerbated by her quietness and the fact that she did not party with the popular kids, which they seemed to interpret as rejection. She shared:

Maybe it's like a "look at me thing, 'cause when people dress up, typically it's like "look at me, look at me," and I guess I do want to do that but it's not "look at me," it's "look at my clothes, this is fashionable." And it's also because I have a really bad habit, I'm not sociable, I'm really quiet, when people talk to me I get stone faced and completely like...no expression and it makes me look very stuck up. And I know that for a fact, but I try to help it, but it doesn't really work. So I guess I can understand it. It's also the fact that when you don't do anything sometimes and you talk about how you don't do it, you don't go out to drink...you're not supposed to be like that, I know that now, because some people do it and they're perfectly fine, but people look at you like you're self-righteous (Selene, CHS Focus Group 2, 2014)

Selene's experiences show some of the nuances of life and belonging in Covington and at CHS. While Selene initially seemed to fit with the popular, stylish group, her lack of conforming to their judgmental ways made it difficult to fit in. Not only was belonging important to this group, but it was also to explicitly position those who did not, which Selene was not comfortable with. The exclusion was driven by racism, classism, and rigid gender norms, which were employed as artifacts to construct a hierarchy of power, with White, middleclass, and traditionally feminine identities and performances as the most powerful. Finally, that Selene chose not to engage in drinking worked against her as well, as students claimed she thought she was better than them 
because she did not socialize with them outside of school. Selene highly valued her close relationship with her parents and largely did not drink because her family was against it; she was not interested in the potential disruption her drinking may cause. When Selene's family had been involved with church they had attended a Baptist church in their previously rural town. While this religious conservatism may have played a role in her parents' decisions to not drink, Selene seemed to be drawing more on a high value of respect for her parents that they had actively fostered by drawing on her mom's Chinese heritage to frame the parent-child relationships. While in appearance, Selene embodied the "right" type of capital, stylish clothes, she was excluded from one of the power groups at CHS because she was not willing to participate fully in the way that they asserted their power.

Like Selene, her family provides critical insight into (not) belonging in Covington, particularly as they had the most markers of any of the families that would place them closest to the power group. Just as Selene had experienced the intersection of racism and sexism at CHS, her mother had similar experiences that shaped her view on belonging in Covington. In the following section I describe how racial identity and gender differently shaped experiences for Selene's parents, Tindy and Andrew, within the community.

As a Chinese immigrant who had moved to America a little over 20 years ago, Tindy had a thick accent that immediately spotlighted her immigrant identity. While Andrew was Filipino American, he had lived in West Virginia most of his life, and had a more "American" accent, though it was still mocked in Covington as too country. Moreover, as he was bi-racial his features were less pronouncedly Asian than Tindy's and he further erased his ethnicity as he identified as White. 
Speaking to the gendered differences within the community, Andrew more clearly fit into the masculine profile of economic provider that was available. Tindy had not fit as easily into the Covington mother profile. Selene shared about her mom:

Cause I felt bad for my mom when we first moved here...she was dressed in the past...and when she came here, totally out of place, her fashion immediately changed, I think something happened but she won't talk to us about it. I think parents were probably mean to her or stuff like that. There's always that one, like my mom used to go to Chuck's and some people wouldn't talk to her. (Selene, Interview 1, 2014)

Selene's assessment touches on the classed and xenophobic nature of Covington, where despite getting fashionable clothes, they were still not good enough because Tindy got them at Chuck's, a local discount store that carried overstock items. Even though Tindy changed her looks to fit the Covington mother profile, this was not enough to give her belonging with mothers in Covington.

While Selene's parents' ethnic identities positioned them as different in the figured world of Covington, in other ways they more closely fit classed norms. Selene and her family were the only participants to live in Covington proper. Her parents had intentionally chosen to live in Covington rather than the town where her father worked, an hour away, because of the good school system. They had built their home in Edgewood Estates, a community fashioned after the more elite neighborhoods but without the same obvious show of wealth. For example, the entrance sign to the neighborhood is two wooden planks with Edgewood Estates woodburned into them, nailed askew to posts. This was in contrast to the gated entrances of more elite Covington communities. Selene's family home sat on a cul-de-sac and would fit in one of the 
prestigious communities as a large 3-story with a stone turret that housed the winding inner staircase. However, while there were other large, new builds in their neighborhood there were also a range of older, smaller homes that would not fit into the more prestigious neighborhoods. Selene's father, Andrew, was very proud of their home. He and his brothers had built it, and he was particularly proud of the interior which Tindy had decorated. The décor was classical in design; tall Grecian columns separated the high ceilinged living and dining rooms. The fireplace was painted white, with classical figures carved into the façade. Sumptuous oversized furniture, loaded with oversized pillows with velvet and tassels, filled the formal living room. Andrew was proud of his status in the community of Covington. He had worked his way through multiple blue-collar jobs to his current position that allowed his family to live in a place like Covington and have a nice home. Andrew had grown up very poor in rural West Virginia and his success in being able to provide for his family was something he was very proud of. He felt like Covington offered a space where you could have opportunity, belong, and people did not bother you or judge you. Tindy did not agree with Andrew's assessment and their conversation that followed shows some nuance in what belonging meant:

Andrew: A lot of people immigrated in [Covington]. But...they don't try to control you here, I've been in places and schools and stuff and counties that people try to control people, you know that. They're in their own groups, you know what I mean, this group hangs with this group and this group is more well off or just a little bit and they, they like to dominate. Here it's a little more different...people just come and people work and I guess because of different areas too, you don't have that as much, at least what I've seen now. ...well here, I say that the majority of people keeps to theirself. They're off to theirself in some ways but they're not partial. 
Tindy: I see it [division between groups]... you see people, more wealthy, you could tell they're in one group, you could tell people like the color you were, where you're from, how you look like, they do have [a] group. I see it. Some people don't want to talk to you... there just be a group that is set in one group, that just talk to certain, their group people, they don't talk to [you], they say "hi”" maybe, or if your kids play with a good friend in that group then they may try to talk to you, but still it's not. I feel like not part of anything, I'm not, no group, not any group...He [Andrew] feels different way. Andrew: Well you might see it different than me.

Tindy: They be nice to you, but you not in the group. (Parent Interview, 2014) Tindy's comment that "they be nice to you, but you not in the group" reflects her more extensive experiences with those in the power groups, particularly the sports mothers as Selene's older brother had played soccer. While Andrew did engage with the community and school, his work kept him from attending and being as involved as Tindy. Additionally, Tindy's more obvious immigrant identity may have been cause for exclusion among the largely White group of sports mothers; whereas Andrew was able to use his Whiteness as symbolic capital that absolved him from racial othering. Tindy could see that people speaking to you and being polite was not a true embrace and welcome into their community, rather a superficial nicety.

With these experiences of othering, both Selene and her family had made changes to try to fit in with Covington: Selene in "not being herself" at the fashion table and her mom changing her style and, as I will share shortly, how their home décor changed. These were agentive moves on their behalves as they attempted to negotiate spaces for themselves as people of value within the community and school. However, as they continued to 
experience othering, they again chose to withdraw from these spaces in order to protect themselves. These actions were symbolic of the changes happening in Selene's family; in their previous home in rural, working-class Edinburgh, they had not been in the upperclasses and seemed to fit in more with the tenor of that community. However, when her father was promoted to his current position and they "moved up" in the world to Covington, they moved up in class status. However, because the community profile of Covington was so different from Edinburgh, their increased cultural capital did not translate into some of the benefits I imagine they had hoped.

Covington as not home. One major point of interest for my study was to better understand students' attachment to their families and places, traits cited as important in Appalachian places, which are characterized as in danger of losing their "best" youth to cosmopolitan cities and suburbs. When we discussed the concept of home in the focus group, Selene elaborated on more experiences of othering that her family had that made Covington seem not like home:

My mom had so much trouble trying to make friends in Covington...in Edinburgh she was perfectly fine, she knew all the moms, she was active in my school life and all this stuff... when we came to Covington, not quite the same... my mom completely changed the way she dressed...she still didn't fit in and so she just stopped hanging out with people here... a lot of competition with moms, a lot of it...I used to have this friend...her mom came over to our house [and] refused to sit in our house because she was mad because it was a little bit bigger than her house. And it's just like stupid stuff, it's all stupid superficial crap that doesn't matter in the end of it. It's, once you die, you're not gonna bring that with you. 
Why do you have to be jealous about it, like to care about that stuff? And that's where we had [the] main problem when we came to Covington, the family had to change based on that, based on that fact, and you know those politics and all that stuff that kind of get in the way of you doing stuff... Not genuine people, you have all these people in a bigger area, turns out to be that way. (Selene, CHS Focus Group 2, 2014)

Selene and her family's experiences highlight the classed, raced, and gendered nature of belonging in Covington. Even though they had a large house, it was offensive to a neighbor for being too big. Perhaps in Edinburgh, the small town Selene and her family had lived in before her dad was promoted, such a large house would have been viewed as "making it;" however in Covington which was more cosmopolitan, social class was more refined and the showy house in a more modest neighborhood indicated the family's new arrival to their privileged economic status. In Covington, it was the everyday presentation of achievement and wealth that was valued rather than gauche displays.

Despite Selene's family changing in an attempt to belong in their new community, they were still not welcomed and were denied the symbolic capital of belonging. Relationally, they were not positioned as belonging nor offered the internal value that can come with being welcomed from a community. While Covington presented itself as a welcoming community for newcomers, recall the "cutest communities" article, there seemed to be racialized and nationalistic undertones that tempered who was actually welcomed. In the face of this lack of welcome, Selene and her family still found value and dignity within themselves, particularly as they supported one another as a close knit family, showing resilience in the face of the community exclusion. 
As Selene's family navigated being positioned as periphery actors in the figured world of Covington, they attempted to draw on economic and middleclass cultural capital to mediate this positionality. Selene articulated a loss of Appalachian cultural identity by noting the visual changes in their home as her family utilized middleclass artifacts to offset their cultural otherness. She shared that when her family moved to Covington they drastically changed the way their home was styled:

We had to change a lot when we moved to Covington, we used to have like a huge country home, like the typical, like sentimental West Virginia stuff, then we moved to Covington... And then when we moved here, it's like filled with Pier 1, you got your fancy looking sofa. And you have [a] nice fireplace and it was just, it's still home because it's, but it's a lot different, different feel to it. (Selene, CHS Focus Group 2, 2014)

For Selene, this switch to middleclass, suburban norms gave her a sense of loss of identity and sense of home. Gregg commented on an interesting aspect of fitting in at Covington related to physical location. Responding to Selene's family's need to change based on living inside of Covington proper, he indicated that living outside of Covington offered more flexibility when it came to avoiding othering:

It's [living in Covington]...causes a lot of people conform, like sometimes they have to, like in [Selene's] case she lives here so she had to conform to the community. Like get to know everybody and like that. But since I live kind of on the outskirts, I live like in between Covington and Fairchance, I live on this big farm and my dad has big red beard and you look at him and you just say redneck, I call him redneck all the time....and like my 
mom...she's like a country girl too and when we come into Covington, well my dad doesn't have very many friends from Covington ...like he refuses to like conform. (Gregg, CHS Focus Group 2, 2014)

To Gregg the actual physical distance from Covington provided a buffer for the need to conform to the middleclass, suburban expectations.

Throughout the Covington story there was much more of a sense that each of the focal students and their families experienced othering at school and within the community. This othering has happened around place (i.e., home location), dialect, country-ness, race, and class. While none of the students explicitly identified as Appalachian, I see the Covington participants' experiences as fitting with some common applications of Appalachian identity. Students experienced, in a variety of forms, othering for being too country, which is related to social class and place. Appalachians are framed in the literature as different because they do not fit the suburban/urban, middleclass norms (Obermiller \& Maloney, 2007). The students at Covington had this experience within West Virginia, a state typically thought of as rural and working-class. This shows the breadth of experiences within Appalachia and pushes against the stereotypes of a homogenous place. It also shows how choices that are not mainstream enough for the pulse of the community may come to be degraded within a globalizing Appalachia.

A tie to place despite othering. Despite this othering, the Covington students still expressed a tie to place however they constructed that place as not Covington. Constructing their home as not Covington was an agentive move that allowed them to maintain their valued local connections while not striving to fit in to a place where they were not valued. Variously, the students all expressed how important their families were to them and constructed their place as where their families were presently and, for Selene and Fantasia, also where their families had 
come from historically. When I asked Fantasia which local places she considered her community, she replied, “To be honest I don't really fit into any of them. I mean Antwerp is the area I know the best but, my community would definitely be Boone, WV because that's where I grew up" (Fantasia, Interview 2, 2014). Since Gregg's family had been in the area for generations they did feel like they belonged, however when I asked his parents where they considered their community it was not Covington, rather their immediate neighborhood. His parents shared:

Mom: The property [is our community]. It's like all the friends came here, they went up in the woods, they're in the back yard, dirt bikes, 4-wheelers, this is where they hung out. Fireplace, this is where they were all the time. What do you think it'd just be here wouldn't it?

Gregg: Well there's the trailer park over there that's part of this community, and Ben, and up the street you have my friend, Rob Smith, lives there.

Dad: It always seemed like every time you turned around, it'd be like who's coming up tonight. Our driveway...

Mom: The entire yard...

Dad: Well even when they was little, it seemed like the kids across the hill ' $\mathrm{d}$ be here, the kids from down there, up the road would be here.

Mom: But junior, senior year when everybody started drivin' my yard would be full and across the road would have cars.

Gregg: Yea we'd load it up and have fires here and stuff. (Parent Interview, 2014) Gregg's family was very attached to the area, with ties to the local people and their family property which served as an artifact of belonging. 
While Fantasia and Gregg both indicated that they would like to return to Covington after they completed college, it was because of their families and the place their families created for them. Because they owned property that had been in their family for generations, Gregg's family did have a more literal tie to the physical space, though Fantasia's attachment was more related to people. Selene believed that with pursuing fashion she would probably not be able to live in Covington, but also that it would be very different if she returned because of all of the development. These experiences speak to the understanding that place may be more related to a sense of belonging to a community and less of a literal physical location. It also speaks to the notion that people need to be valued and that home and community are places where this is found. However, for the students and families who did not fit the Covington profile, there was little support for identities as people value of coming from the school or community.

\section{A Late Negotiated Habitus}

As the previous section details, fitting in was not open to everyone in Covington, in fact it was open to a very specific set of people, often based on classed aspects. This made meeting the classed expectations of Covington a delicate dance. Students worked to protect themselves from the classism that was prevalent in Covington, though in doing that, at times, they had to displace their family worlds. This is misrecognition of the arbitrary tastes and values of class. However it illustrates power that these arbitrary markers have in deciding who is powerful or not within a space (Bourdieu, 1984). Gregg's story was particularly interesting as he was very aware of the classed aspects of life, though not necessarily that they were aspects of something termed "social class." He carefully constructed a space at Covington and in his hoped for future that was very centered around the presentation of who he was as a classed person, which was different from his family's background and current life. 
When Gregg was at CHS he was very much influenced by the classed presentation of the town, school and people. This seemed to come from his conscious understanding of how his family was different from Covington and how he was different from the CHS power group. Gregg shared multiple experiences of when his family was excluded from Covington's mainstream. Additionally, he lived on Stone Eagle Drive, the place described by community members as "poor, farm kids" so he would have had an internalized understanding of how people viewed his home area. In another instance he shared an experience of having his family degradingly positioned when he worked as a restaurant server:

One of the managers made fun of my mom, because she...come to eat and then like there [was a] bread tie in her potatoes and she ate it and like cut her mouth and she complained and I guess the manager was back there callin' her trash and stuff so I quit there. (Gregg, Interview 1, 2014)

As I mentioned earlier in the chapter, Gregg self-described his family as "Covington's outcasts" (CHS Focus Group 1, 2014). Gregg had felt the sting of being indicated as lower class and in response was conscious of how he was perceived. He shared multiple times that he wanted to be respected. For example, he said, "I like to have a good appearance, when people see me they respect me, I like respect, that's a big issue in my life, people who respect me, I respect them" (Gregg, Interview 1, 2014). As I mentioned earlier, Gregg knew the "big" names in Covington and shared that in the Stone Eagle Drive area his family name was similarly respected. He shared, My last name Renner is really respected around this area... where I'm from, like the farm country, Renner is [a] very respected name, like your last name's Renner people look at you differently. And I just want to carry that name. (Gregg, Interview 1, 2014) 
As the oldest son, his father had promised that he would pass on the bulk of his family property to Gregg so that Gregg could return to the area in a place already prepared for him to start his own "respectable" life as a pediatrician. However, once in Covington, Gregg and his family name were not as worthy of respect as the more powerful names in Covington.

Gregg's future plans were to go to school to become a pediatrician, a path that would give him the respectability he desired and that he could use to shield his family from abuse. Gregg shared that, in addition to wanting to be respected, one of the most important reasons he wanted to be a pediatrician was so that he could provide financially for his family, both his future family and also his parents. At a very basic level Gregg wanted to move out of any sort of financial struggle, he shared, "I wanna be able to make enough money to be able to do whatever I wanna do when I grow up...I don't want to have to struggle with my finances when I grow up" (Gregg, Interview 1, 2014). Additionally, the income that would come with being a pediatrician would provide the economic and cultural capital that could help shield his family from being positioned as "trash."

As Gregg mentioned earlier, he was also concerned with his appearance, as that was something that he felt earned respect. Gregg had very much molded himself to the CHS "look." He had a popular Justin Bieber style haircut, wore name brand athletic clothes and sneakers like many of the students at CHS, and typically wore either jeans or cargo pants. However, Gregg positioned his style differently, as "Duck Dynasty," a popular TV show where the men always wore camouflage and had burly beards, and indicated that when he got to college he wanted to change his appearance to look more professional so that people would respect him more. It is interesting that Gregg perceived himself as dressing like "Duck Dynasty," as I would never have 
described this style. However, perhaps in comparison to his wealthier, more suburban peers at CHS this is how he felt he dressed. He actually described what he thought the response at school would be if he started dressing more "professionally:"

I've thought about tryin' to pull that [professional] look off, but I think I'd have to start new, cause if I go from dressin' like Duck Dynasty camouflage, Nike, to like U.S. Polo and khaki's and Sperry's, people would be like, "Ummmm are you gay?!” So I just like, I should probably just wait 'til college and try that. (Gregg, Interview 1, 2014)

Clearly, Gregg was picking up on judgments that came with particular appearances and that drew on discourses of class and sexuality. He understood that a professional, "higher class," look was judged to be more respectable than a country, "lower class," which included camouflage and the less expensive brand that he wore. In his assessments of how various looks were judged, Gregg did not necessarily assess his look as "lower class," but rather he understood that people gauged appearances differently and that was something that could be modified. This understanding gave Gregg the opportunity that he saw in college where he could change his appearance to fit more closely with the "respectable" discourses that went beyond Covington's figured world of success.

Gregg's negotiation of his "look" seemed to come from the tenuous ground he tread as a student at CHS where country was not a powerful position. While Gregg seemed aware that his appearance was not really reflective of his intrinsic value, he contributed to the reproduction of inequitable hierarchies (Bourdieu, 1977a) because while he modified his country-ness, he was chastised for that at home as moving too far away from his roots. Ultimately Gregg saw what he needed to do at school to fit in, which was something he desired. As Gregg consciously 
negotiated the discourses around country and class, he was negotiating discourses of identity as well. He was consciously modifying dispositions of habitus that often are considered unconscious, that is the very basic understandings and appreciations gained from the home-life.

While Gregg toyed with identity markers and performances that placed him as less country and more professional looking, there were consequences for this in other parts of his life where his family teased him for being "Covington" and not country enough. The rest of his family was very country and proud of that fact. During our interview his mom shared:

[Gregg], he fits the Covington profile. Cammy and Bobbie don't. Cammy is my cowgirl and whatever. Bobbie's my rebel child, everybody'll even tell you to this day they don't even see how he [Gregg] fits in this family. You fit the Covington profile from head to toe. (Parent Interview, 2014)

In response to being teased by his family Gregg replied by degrading his brother's country-ness and placed himself as a "better" country:

You wanna know the difference between me and my brother...they think my brother's a little redneck kid...that's why he doesn't fit in the Covington profile. I'm a country boy. (Gregg, Parent Interview, 2014)

Gregg's dad then took up for him and shared about how he had similarly changed his appearance to fit in as a student at CHS:

See, I was picky, my hair had to be so, so, and I had to wear certain clothes...but that's the way I was when I went to school. And actually, I started workin' on the dairy farm when I was 12 years old, and I went and bought... my own Nike tennis shoes and stuff. I bought my stuff, so it made me feel better...Covington School, it always seemed like there was your 
low class, the middleclass, and your upper-class. I wasn't low class, I was middle to upper-class, but I wasn’t upper-class. I had to, I bought my own nice clothes and stuff, kept my hair parted certain way, this ' $n$ ' that. But I didn't interact with other people...And it's a Covington thing, yea there's different classes of people that go there. (Steve, Parent Interview, 2014)

It seemed that generationally, Gregg's dad had some of the same experiences Gregg was having now. As Gregg negotiated the classed identities and positions at CHS he was similarly negotiating the social space within his family.

As Gregg negotiated classed experiences at CHS, he protected himself from judgement regarding other matters of home as well. Gregg lived in an older, nicely kept trailer and across the street was a trailer court that he and his family lovingly described as "their neighborhood" (Gregg, Parent Interview, 2014). However, in a focus group Gregg shared that he had once been embarrassed by his house because it was a "little country house" and his dad refused to buy a bigger place, though as he matured he learned to appreciate his home and his dad's view. Despite this change, he was still hesitant to share with the group that he actually lived in a trailer. These discursive tactics were helpful for Gregg in protecting him and his family from narratives that positioned them as "less than." This was a skillful move as when Gregg described the groups at CHS, he identified the "trailer park, White trash" clique (Gregg, Interview 1, 2014). Gregg drew upon the heteroglossic discourses available, at times taking up narratives that demeaned his family's life, while at other times pushing against these as he and his family shared their fondness for home. In these moves Gregg was maneuvering around symbolic violence. While Gregg occasionally demeaned his home space, these seemed to be improvisational actions that he used as tools to protect himself, rather than adopting these as internally persuasive discourses. 
College changes. I visited Gregg at Stanley College at the end of his first semester. Despite Gregg's projection that he would change his look to professional once he got to school, these changes had not happened. When I arrived on campus Gregg was wearing a camoflauge fleece and baseball cap. He took me on a tour of the college campus and around town, showing me where he liked to hang out and eat and then he excitedly took me to his favorite fishing spot. He offered to show me his favorite fishing spot outside of town, chattering away about a girl he who had gone fishing with him. He told me a story about this young lady and that she had not noticed he was "country" and was surprised to learn that he raced dirt bikes as he then proudly told her about how country he was and about his success in racing. Gregg seemed pleased that his friend had not immediately pegged him as country, and this space became a choice for him in how to engage with that identity. Gregg had become more nimble at framing his country identity. With his new friend at Stanley College, Gregg was able to "opt into" his country identity and use it as a source of pride, unlike at CHS where this was an identity assigned to him because of where he lived and his hobbies that identified him as a lower class country. At Stanley, country could be an identifier for him that was not tainted with a lower class status. There were particular reasons for why this was so.

Stanley College was located in a Washington, D.C. bedroom community. As Gregg started his first semester of college, he had not made a transition to middleclass, suburban life. Instead, he had actually become more comfortable in his country skin. He was uncomfortable in this new setting, describing the other students as "weird," even though he was offered access to the moneyed life that had seemed so appealing to him during high school. In this way he was perhaps becoming a more confident, and thus competent, actor in his own figured world of home and country. Gregg expected that college would provide the opportunity to become more 
professional in a way that supported his country-ness. That is, he saw a value in becoming a country doctor that he believed would be seen as meritorious by his pre-med professors and classmates. In that way, being authentically country was no longer a negative as it had been in Covington. Instead, he was seen as one with insider knowledge and one best suited to heal the rural people most in need of good medical care. Because of the heightened emphasis on social class in Covington, being country and becoming professional were prominent markers for Gregg. At Stanley, Gregg had experiences that allowed him to re-negotiate the misrecognition of country as "less than" that had been so influential in Covington. Now, rather than participating in the symbolic violence, Gregg was able to disrupt dominant discourses by proudly drawing on his country heritage.

Gregg had found the space to experience becoming middleclass at Stanley College. Here he was allowed to explore class more freely without a constant audience of peers that he believed were judging him for becoming less country. Because his peers at Stanley did not know Gregg's history, he had a fresh slate from which to negotiate his identities without feeling bound by what people already knew of him. As Gregg was able to try out the artifacts of Stanley's middleclass culture without perceived judgment, he had more space to negotiate what he felt matched with his life and what he wanted to reject based on his experiences. In this sense, Gregg was becoming more confident in his country-ness because he had been able to reject some middleclass values that did not jibe with his country heritage. This rejection of the more powerful classed identity gave Gregg power that he did not have when that identity was denied to him in Covington based on his and his family's assigned country and working-class status. Gregg was now more country because he had made the choice, not because others had assigned him that position. Some of this process may also have been facilitated by Gregg's new access to 
cultural and social capital as a pre-med student. The change in Gregg's positionality gave him more space to play with his identities, moving the power to his person.

As Gregg became more comfortable identifying with his family background he decided that after medical school he would like to build a house on the family property to maintain family connections rather than living in a more prestigious Covington neighborhood. He attributed this change to "maturity." Gregg was still moving towards the spaces of comfort, financial stability, and respect that he had so desired in high school and continued to build the pathways to become a pediatrician. Once he gained this position he would have the access to the financial stability and respect of this profession. The cultural, financial, and institutionalized capital Gregg would have as a pediatrician would allow him even more space to embrace his valued country lifestyle. This capital would give him the power to ignore and speak back to those who may question his desire for a country lifestyle and presentation.

\section{First Generation Barriers}

All of the students at CHS were first generation college students and despite the support that CHS did offer, they and their families' experiences show the limitations of what seemed like a robust postsecondary transition support system. This was especially apparent when it came to parents being able to help their students through this process. The students at CHS were able to take advantage of what the school did offer such as looking for scholarships on FastWeb, applying for the PROMISE Scholarship, and exploring colleges online. However, much of the rest of the process ended up happening outside of school where parents all expressed being at a loss as to how to help their children. 
All of the parents in the study were strongly supportive in wanting their children to attend college. Education, and college in particular, were incredibly important to them. Like Bryan and Simmons' (2009) work with first generation college students from Appalachia, participants pushed back against the research that positions parents who have not attended college as less likely to support their children in this process (Ali \& Saunders, 2006). This research positions parents as ignorant and as not recognizing the value of college because they did not recognize its benefits (Cabrera \& LaNasa, 2001). However, the experiences of the participants' parents pushed strongly against this knowledge, where it was precisely because they had struggled through work to provide for their families without a college degree that they understood how valuable it was. For instance, Selene's father shared:

[I] didn't have a higher education...but I know it's important to have a college education, 'cause you really gotta work hard to climb the ladder, you know. You really do...We always explained to our kids to go that route [of college], and we didn't have any trouble 'cause they wanted to do that. (Andrew, Parent Interview, 2014)

While parents supported their children's college ambitions, they also expressed that they felt unprepared to help them in this process because of their lack of experience. When I asked Fantasia's mother, Marcy, how they had helped Fantasia in this process, she revealed:

We haven't done anything, it has been Fantasia doing research and finding things out on her own or asking people, Google. We are the parents who we are. There's a lot that she missed out on because we couldn't help her, where she was behind everyone else because we didn't know what to do. (Marcy, Parent interview, 2014) 
Marcy's statement that "we are the parents who we are" reflected her frustration that they wanted to help Fantasia but because of their lack of experience with higher education, they were at a loss for what to do. Marcy's critique was not necessarily directed at CHS, rather at the process more generally. However, it points to a gap, that despite students being able to take advantage of CHS's assistance, there was more that needed done. It was these soft skill and knowledge that were not explicitly discussed or taught at school that are typically made up for in middle and upper middleclass homes by the cultural capital of family or friends who have attended college. Because of these students' first generation status, much of this capital, in the form of information, was denied to them.

This gap in knowledge was highlighted further by parents' understanding that the school was doing everything they needed to be doing. The parents included in this study had faith in the school system that whatever needed to happen for their kids to move on to college was happening and that when there were difficulties it was either their own or the student's fault. For example, Selene's first choice for a career and college major were to go to design school to become a fashion designer. As this is a postsecondary path that takes even more long-term planning than perhaps others, with the need to develop a cutting-edge portfolio, she and her family's lack of experience painfully show how the gap in postsecondary advising works against first generation college students. When I asked what Selene's parents felt were barriers for them helping her through the postsecondary transition process, her father, Andrew, replied:

Well, now, if [the school] would've, if she'da [Selene] been open and maybe told the teachers what she wanted to do and how the teachers would've told her maybe how to achieve that, what she needed to do to put in for college to achieve the college she needed to, and tell her how to put it all together, cause we just don't 
even understand it. With [her brother] it was little different, he knew what he was going to go into, chemistry and the teachers basically you know, told him, when he studied, what he needed to do, but in art, we're you know a little lost in that. Now...we searched it [but]....let it go too long, (Andrew, Parent Interview, 2014) There are a few important things in Andrew's statement that show how the nebulosity of postsecondary advising works against first generation students. First, he blamed the inability to get Selene into a design program on their family's lack of action in the process. While neither Selene nor her parents were able to create a portfolio they felt was adequate, they had worked on this process. Second, Selene's older brother went into a pre-med program and had been guided successfully through this process by his AP teachers. In Selene's case, there was no AP Art option and her art teacher did not provide help in the postsecondary transition process, nor was the guidance counselor involved enough to be able to provide this help. While the gap of Selene's parents' lack of knowledge in the postsecondary transition had been bridged for her brother by his teachers' involvement, she did not have a teacher who was involved or knowledgeable, and so the informal structure that bridged an advising gap was unavailable.

Selene ran into difficulty accessing her desired program and major because the school system did not take responsibility for tailoring secondary preparation to meet the needs of all students. Selene's parents' lack of knowledge about this process did not help her to compete with the middle and upper middleclass youth whose parents could provide art school visits around the coasts and the years of expensive private art lessons typically required to produce competitive portfolios. As Bryan and Simmons (2009) emphasize, this had nothing to do with the parents' lack of care or value for education and Selene's goals, rather their lack of experience with the postsecondary transition process. 


\section{Social reproduction and the hidden knowledge of grades and tracking. While CHS}

did offer many opportunities for facilitating the postsecondary transition, tracked courses and students' and parents' lack of knowledge about how to progress through these courses presented further barriers to the postsecondary transition. This was less explicit knowledge not offered by the school and so it depended on students' and families' knowledge of the postsecondary transition process. For example, Fantasia had a cumulative $2.6 \mathrm{GPA}$ at the end the fall semester and had hoped to bring it up by April to a 3.0 overall GPA to qualify for the PROMISE Scholarship, not understanding the credit points she would need to reach that goal. Her final semester she took an "office aide" class which was technically limited to students who had a cumulative 3.0 GPA since it was a non-credit course (CHS Course Offerings, 2014). However, Fantasia had been permitted to take it and so was only receiving credit for three, rather than four, courses her final semester, potentially making her final GPA even lower than if she took a fourth class that she could earn an " $\mathrm{A}$ " in. She described her frustration with the lack of guidance from the school; however, like Selene's parents, rather than faulting the school for this lack of information, she faulted herself. She shared:

I've worked really hard all the years that I've been in school, and it may've not seemed like it, especially my freshman and sophomore year because I kinda dropped the ball on things and you can clearly tell from my grades...I did not think that it was gonna affect me... Now that I'm looking at my grades and I have a 2.6 instead of a 3.0 like I should've. And I also wasn't assertive enough to get the information I should've whenever I was getting my grades. (Fantasia, Interview 1, 2014) 
For Fantasia, the PROMISE Scholarship would have meant that her family would have had to take out many fewer loans as that would be the primary way the family would be paying for college. This was social reproduction in action. By all accounts, Fantasia assumed she was progressing successfully towards her goal of attending college, as she had not heard otherwise from the school. However, because there were gaps in the information that the school shared and she was a first generation college student, she missed some of the most important information that would have made the postsecondary transition much more feasible; such as the need for grades to be high across high school rather than just during the senior year to be competitive for scholarships.

Gregg was similarly hindered by the gaps between his and his family's knowledge and what the school provided, particularly regarding grades and curriculum. His parents were very proud of what he had achieved academically, his dad shared, "He'd show me his report card, 'n I'd just be like WOW!!!!” (Steve, Parent Interview, 2014). In contrast, Gregg felt that his parents had not pushed him enough, despite having an overall 3.0 GPA at graduation. He shared: Like I never really_I had my dad and I had my mom to push me, but they never really like, like one day I had to sit down with my mom and dad 'cause I was makin' C's and I was like Mom, I want you to like ground me if I get a C and stuff, cause they never pushed me. (Gregg, Interview 1, 2014)

While his parents felt like they were supporting him by being proud of his passing grades, Gregg understood that it would take more than just passing grades to achieve a career that would give him the respect that he wanted so badly. It seemed that Gregg had picked up on this knowledge of needing a competitive GPA through the culture at CHS and his academically achieving peers. 
Not only was GPA an issue for Gregg, but as a hopeful pediatrician, not taking the right courses presented a potential barrier to this dream. When I asked Gregg's parents what they thought the school could do to improve the postsecondary transition process they shared that they thought the school did a good job and specifically mentioned that the school had guided Gregg in the courses he needed to take to meet his career goals:

[Gregg] pretty much had a game plan, he was goin' to college. And of course I wanted my daughter to go, she went. I wanted Gregg to go, he's goin'. But they used their heads and went ahead and took the classes they needed to in high school. I didn't know what to tell them to take because I was never taught. [Gregg]'s talkin' with other people, 'n' he's figured things out, 'n' basically he's taught me more things about the classes you need in school to go to college. (Steve, Parent Interview, 2014)

While technically Gregg did have the requirements necessary to get into a baccalaureate program, with no honors nor AP courses he would likely have not been accepted to a pre-med program without his grandmother's help, which I describe in the next section. While Gregg had not decided on this career path until his junior or senior year (he could not recall quite when), even after that he had not taken any courses that would make him better prepared for this path. However, neither Gregg nor his parents understood that he was likely academically underprepared to enter a pre-med program. Again, this is the sort of soft-knowledge that people more experienced with the college transition process would be likely to know. 
During high school I asked Gregg what the school did to help prepare him to go to college and he shared:

They always push AP classes, they help ya as much as they can, but they really just try to push credits and high scores. You almost have to push yourself to be ready for college...'cause I've heard it enough, like they tell you over and over and over again, college is a completely different story. 'Cause when we take notes they'll wait on us...In college they're not gonna do that...You're gonna have to learn all the stuff, they don't actually do that. I was like we need to do college, college prep class, where it's like you go and it's just like a college class...I think that they can do better, but they're trying, they're doin' ok I guess. (Gregg, Interview 1, 2014)

Gregg seemed to understand that he would need to be doing more in college than he was in high school, in fact people had told him that. While he recognized that the AP courses were pushed by the school as a way to prepare for college, there was a gap for him between the school saying this but not telling him how it would prepare him. Gregg and his family’s lack of experience with baccalaureate programs and honors curriculum left them unaware that a large part of AP courses is preparing students for college level work. As one AP teacher at CHS shared with me, the last three weeks of her course were spent "help[ing] students to transition to college where they have to learn to assess their own learning and study for larger test chunks, not just chapter tests" (CHS Observation, 2014). During Gregg's follow up interview I asked what CHS could have done to prepare him better for college and he described that:

They need to prepare you to cover material more quickly. At CHS they'd take 3 weeks to do a chapter and then be tested on only that chapter and now [we] do a chapter a day and then have a test every 2 weeks. (Gregg, Interview 1, 2014) 
Gregg's recommendation for what the school should do to better prepare students was, literally, exactly what the AP teacher felt the courses provided for the students. Technically, CHS was offering what Gregg was saying he needed, academics that would prepare him for college. However, because of the way that CHS offered these experiences and information, it was limited to students who already knew about this knowledge and not the students who perhaps could have benefited the most from these experiences. This was a clear picture of social reproduction, where Gregg wanted to move beyond his family's class status and technically the school provided those opportunities. However, because of the way that the opportunities were presented, Gregg did not recognize them as opportunities that could help him to achieve his goals.

Specific transitions. I have shared a bit about each of the CHS participants' postsecondary transition stories and that despite everyone being a first generation college student, each of them ended up enrolling in and attending college. In this section I will share a little more about how each of the students and their families made this happen, but spend the most time discussing Fantasia's transition, as she had the most difficult time.

On paper Gregg did not appear to be a strong candidate for a pre-med program, his overall GPA was average at a 3.0 and he had not taken any honors courses, nor was he involved in any school affiliated extra-curricular or volunteer activities. However, he was accepted into a pre-med program. At the very beginning of the study Judy, the CHS guidance counselor, told me about Gregg, and shared that he was sure that his grandmother, who worked in administration at Stanley University, was going to get him into the pre-med program, though Judy doubted this would happen. However, Gregg's grandmother, who was the co-director of the Financial Aid Department at Stanley made this happen. Not only did Gregg get into the pre-med program, but he also received enough scholarships through Stanley, in addition to his need-based grants, that 
all of his costs were covered. His grandmother had even gotten him a work-study job with the university football team. While Gregg may have otherwise struggled greatly to achieve his goals of getting into a pre-med program, through his grandmother's maneuvering this was made possible.

While Selene did not have this same sort of insider-access, she was able to make the transition to college successfully. Two things seemed to influence her ease in making this happen. Her older brother had recently entered college and was helping her to prepare for this process. He encouraged her to take AP courses and was also helping with the actual transition process. Additionally, being able to pay for school was not in question for Selene as she had received the PROMISE Scholarship and her family was more than able to make up any difference. While Selene did not get into any of the fashion design schools she had applied to, she was able to negotiate a space at the state university that she hoped would lead to a career in fashion. Selene registered for the business program and decided that she would go into fashion management.

In both Gregg and Selene's cases, they each knew that because of their social capital that they would definitely be attending college in the fall. Gregg was certain of his position as a college student because of his grandmother and fully identified as a pre-med student, he was confident in his path and sure that it would happen. Likewise, because of her academic background and family's assets, and her brother's experience, Selene knew that she would definitely be attending college despite being unsure of her major. Fantasia on the other hand was the least well-positioned to make a successful transition and while she was pushing head-forward to make these things happen and identified as a college student, she was met with barriers and doubted her identity as college-successful the entire way. 
Fantasia's story. Fantasia had the least sure postsecondary path of any of the CHS participants. While her stepfather had completed an associate's degree, it had been many years ago and he "had done it through the military," so was not knowledgeable about the college transition process. Fantasia was also the least academically prepared to transition to college with a 2.6 GPA and some applied courses. She worried if classes at college would be difficult, sharing:

People told me they don't wait on you and you have to do the learning by yourself. I mean I'm scared. But some people told me they help you and some people told me they don't. My classes at HTAC were college [dual credit] and they helped you...so they might help [in college]. (Fantasia, Personal Conversation, 2014)

Fantasia was drawing on her knowledge of the dual credit courses at HTAC, however she was unsure that this is what the classes at the college would actually be like. As Holland et al. (1998) describe, the more closely a person fits with a figured world the more likely they are to succeed in that space. As Fantasia moved through the postsecondary process she was finding in many places that despite her enthusiasm, neither her experiences and knowledge nor those of her family fit well with the transition to college. These things made it difficult for Fantasia to identify a "natural" college student who could walk through this process with confidence and assuredness.

Some of the most frustrating incidences occurred as Fantasia and her family tried to navigate the bureaucracy of the postsecondary transition. Anytime she encountered these barriers, which seemed quite often, she became unsettled as neither she nor her family could maneuver around these barriers. They were not positioned by nor did they position themselves as authorities when dealing with these institutions and were at a loss for where to go when 
information was inadequate. Moreover, because of her lack of experience in this process, Fantasia wisely listened to all information from institutional representatives; however, this information was often inaccurate or conflicting with other information that she had received. All of this made the process very confusing and frustrating for Fantasia.

In multiple instances Fantasia shared experiences that she viewed as major barriers that would have presented as minor road bumps to people more experienced with the higher education process and the tedium of bureaucracy. At one point Preston Point Community College (PPC) called to say they had not received her transcript, which she had sent in, informing her that her application would be delayed. She was terribly frustrated, saying "I didn't know what I was going to do." PPC later called back and had found her transcripts. In another instance, her mom filled the FASFA out incorrectly, which delayed her registration and knowledge of whether she qualified for any grants. Her parents did take her on-campus to speak with a financial aid counselor to find out what was happening with the FASFA. In another instance, PPC claimed that her math placement scores had not arrived, which they should have, again delaying her course registration because she was not sure whether she would need to take a remedial math course. Eventually, the principal at CHS was able to get that information forwarded back to PPC so she could register for her courses. In describing this process Fantasia shared, "It's crazy, it's just so busy and there's so much I have to do" (Fantasia, Personal Conversation, 2014).

The bungling of information from institutional officials when coupled with Fantasia's own, often inaccurate, knowledge was troubling. For instance, Fantasia had somehow confused information about in and out of state residency requirements to mean that to attend an institution you had to live in that particular town. She shared with me that she would no longer be attending 
PPC but a different school, the Underwood Center in Cairnwell, closer to where she lived with her parents in Antwerp. She shared about changing her decision on where she would attend school:

I was going to originally go to the Preston Point [Community College] that was right next to the actual Fairchance State University, but I have still not gotten my [driver's] license and I decided that, I don't really want to spend seven grand on living there...so I would rather live at home for my first year and be closer to my job and my family and keep my job for a year to build up credit and then be able to move. (Fantasia, Interview 1, 2014)

Fantasia had decided to switch institutions because, as she understood it you had to live in the town where you attended classes. Being further confused, Fantasia referred to the Underwood Center as if it was an independent institution, however the Underwood Center was actually a branch site for PPC. When I tried to explain to Fantasia that the Underwood Center was still a part of PPC, she did not understand how PPC could have multiple branches. She elaborated that because she was living at home in Antwerp that she would be "out of bounds" to attend PPC. In this case, at a very basic level, Fantasia was not even sure of the name of the institution she was attending.

When Judy, the CHS counselor, introduced Fantasia's story to me she shared that she wanted to go to college but was not sure if her family could afford the cost. While Fantasia's stepdad had too high of an income for her to qualify for Pell Grants or the West Virginia Higher Education Grant, she did not meet the requirements for the PROMISE Scholarship and so they would have to cover nearly all costs out of pocket. In attempting to apply for loans, Fantasia's mom, Marcy, shared with me the difficulty they had experienced. She had initially completed the 
FASFA incorrectly so they were delayed in learning about what loans Fantasia could access. Marcy and her husband had also applied for loans through Sallie Mae and been denied. She shared her frustration:

We don't really know that much about the school transition anyway and we tried to do what we do know. Even with the loans for Fantasia, we don't have bad credit, but we don't have good credit either, because we have stuff, and Sallie Mae denied us loans because of bad credit. (Marcy, Parent Interview, 2014)

As Fantasia struggled to negotiate the financial aid process and do her part by applying for scholarships, she shared, “I don't feel like I'm getting the help I need for college, no one is telling me anything" (Fantasia, Personal Conversation, 2014). Fantasia shared that despite applying for multiple scholarships she had still not heard anything back. Though Judy had helped her apply for these scholarship, her options were limited because she did not meet the 3.0 GPA requirement for many.

A major aspect of why I am doing this project is to help disrupt inequitable social reproduction and critical ethnography is meant to further the means of social justice, not just uncover what is happening (Carspecken, 1996). To those ends, I offered to help Fantasia in this process. Fantasia was rightly confused about how to register for classes. Despite a plan to attend on the Cairnwell campus of PPC she had to register in-person on the campus in Fairchance, a neighboring community. We arranged an appointment and Fantasia's mom brought her to campus and I went with her to help her register for classes. When we walked in to the building, Fantasia did not see the name of the person she was supposed to visit on the directory and worriedly questioned if we were in the right place. She thought that maybe we should leave, despite not knowing where else we might go. She did not know that we could just go to the 
general offices and ask for directions. This was a moment of clarity for me in understanding how the mismatch of figured worlds can be such a major obstacle. Fantasia, who was normally confident and assertive, particularly in her tough girl persona with her family and friends, virtually melted into the floor when she entered this institution of higher education that was so intimidating for her. Her position as a first generation college student and the lack of knowledge that entailed, positioned her as a less powerful figure in the figured world of higher education. This placement of less powerful made her question her capability despite her dogged determination to succeed in this space.

Fantasia and I eventually found the academic advisor and she was able to successfully register for classes. We also went and spoke with a financial aid officer while we were on campus so Fantasia could have that information as she continued to walk through the financial aid process. Later in the summer, I also helped Fantasia with accepting her government loans as she had to walk through more red-tape to have that happen; her email account for the university had been disabled and so she was not able to access her account to accept her loans. It did seem that at nearly every turn Fantasia was running in to bureaucratic mishaps that made this process much more difficult than it should be.

Fantasia's story especially highlights the inequitable and reproductive nature of the postsecondary transition and of the tenacity and courage she exhibited in successfully navigating this process. As a first-generation college student who had no familial or social resources who were more knowledgeable in this process, Fantasia was entirely dependent upon the (mis)information of school officials. Having no other resources, Fantasia and her family took people at their word and this was often counter-productive in helping to navigate the postsecondary transition. Because of their lack of experience in this process, they were not aware 
when they were given poor information, in turn meaning that they could not get better information elsewhere. As this was a first time process for all of them, they were entirely dependent upon the official institutional structures and representatives to walk them through this process. Fantasia's mom later shared her frustration with this whole process and how difficult it had been:

We've been to campus four times since you were there with us, we don't go for phone calls anymore, we clearly know that you have to go up there and stay until it is done...I wonder how many people get pushed out of the system because of things like this and just don't go back?! (Marcy, Personal Conversation, 2014)

Marcy's comments reach to the heart of this study, when students and families are presented with near constant barriers to this process it limits access to pathways that are integral for students to reach their futures. While Marcy and Fantasia were not well versed in the system of higher education, their tenacity allowed them to eventually facilitate Fantasia's goal of enrolling in college. However, it is unethical to expect every student to show this sort of tenacity in a system that claims to work with students rather than against them. In the coming chapter, I discuss the overall meaning that I have drawn from this work and how I hope that it can be used to support students and families in the postsecondary transition. 


\section{Chapter 6: Discussion and Implications}

In this chapter I first review my major findings related to social class, habitus, and identity and agency and discuss the relevance of these findings as they relate to current knowledge and practices. The early portion of the chapter largely focuses on students and families as they go through the postsecondary process. Following this section, I move to a more systemic view and discuss structural and policy practices that limit agency. After this, as I move through the final discussion and implications for this work and take the opportunity to return to my own story that I shared in the methods section. Moving through this project my position and identity as a critical ethnographer has grown and been shaped as I interacted with the participants and communities. To highlight this co-development, I connect my research story to the data, FWT and activism as I reflect on where I stand related to identities that were salient for me during the study. I then incorporate my overall suggestions for how institutions, educators, faculty/staff, and policymakers can shape policies that better serve vulnerable students within the framework of my own and the participants' stories.

\section{The Research Story}

The stories that follow are the partial stories of my participants, whose lives have changed mine as my own work and identity have developed in response to their stories during the postsecondary transition and their willingness to share their lives during this important season. In this section I share what was learned from their stories of preparing for and moving through the postsecondary transition regarding, identity, agency, and the postsecondary transition and what these meant for students, as set within the contexts of West Virginia and globalization. As the students and their families negotiated their ways through the postsecondary transition process they were voicing who they wanted to be through their choices in schooling and hoped 
for careers. The students and families engaged in the figured world of the postsecondary transition while negotiating their positionality in response to the school systems that are positioned as institutions of power in American society. As the students and their families were answerable to these contexts and the positionality embedded within them, they authored their own spaces within these figured worlds.

In some instances students and families were able to negotiate within stratified figured worlds and occasionally they could make changes to inequitable structures. As I have pointed out in Chapters 4 and 5, the heteroglossic discourses produced within two different West Virginian communities provided both challenges and resources for changing communities' language to support students' postsecondary trajectories. At times, participants were supported in this work by the cultural scripts of their schools and communities. They worked at improvising within these discursive boundaries along with teachers, counselors, parents, community people and other students who did sometimes make a difference. Sometimes there were policies and programs that did help all students navigate the postsecondary transition, for example schools providing in-class time for students to explore postsecondary institutions online and to apply to these schools. However, students and families were not always positioned in ways that supported productive dialogues and action; issues of power related to class, race, gender/sexuality, and language/dialect added complexity to the fields in which the communities navigated. In many instances structures presented barriers to this work.

\section{The Relativeness of Social Class and Social Class Experiences}

Social class was constructed differently between the figured worlds of Mill County and Covington. Each place had a range from lower to higher class, but what meant middleclass in Mill County was different from what meant middleclass in Covington. For example, because 
Camilla's father was a doctor, her family was one of the most upper-class families in Mill County when considering their income, her father's institutionalized capital, and the family's cultural capital. However, if Camilla had been in Covington, her positionality would have been similar to that of the other middle and upper middleclass students and she would not have been positioned as powerfully. Additionally, because of the tenors of racism in Covington, her father's Filipino background may have counted against the family being fully upper-class. In Mill County, the capital of being the only medical doctor living in the county seemed to trump the racial otherness of Camilla's father. These differences between contexts are examples of how the discourses that constructed social class varied between the figured worlds of Mill County and Covington.

Differences between the schools and communities regarding the dominant discourses that constructed social class mediated the ways that class influenced students' lives. Because of the relative lack of stratification in Mill County, students who would be considered working-class or poor, based on their families' income, jobs, and educational backgrounds, were positioned more powerfully in regards to social class because these cultural artifacts and storylines within the figured world supported more well distributed flows of power. For these students and families there were not the same punitive consequences for expressions of identity and agency that varied from mainstream middleclass because the mainstream middleclass was different.

Similar to the agrarian community described by Howley and Howley (2010) some of the important values in Mill County ran counter to dominant middleclass discourses. For example, as members of the communities valued one another, they built a network of support where community resources could be drawn on collectively to share benefits. Additionally, the practice of being present in activities and relationships seemed to work symbiotically with the value 
afforded to others to strengthen the networks of support. Also similar to the community described by Howley and Howley (2010), there was less social stratification in the Mill County communities related to the (relative) lack of economic stratification, which supported community cohesiveness. Not only did these practices provide literal supports, the subjective experiences that came from understanding that people supported one another were profound.

Unlike in Mill County, because there was so much wealth in Covington, economic differences were much more visible. These differences allowed class to be a stronger marker of position and social standing in Covington and for social class to be a prominent marker of community identity. In the figured world of Covington, social class status was a much more salient discourse and positioned people in a more stratified way than in the figured world of Mill County.

This complexity of social class, even if it is well defined, demands that when it is examined it needs to be contextualized. It forces us to consider what it means that in the figured world of Mill County where middleclass was more blue-collar that these students had similar advantages to middleclass students in places like Covington. For instance, blue-collar students at MCHS were counted as good students, teachers recognized them as having "ability" and so paid attention to them, and fostered learning for them. As "ability" is often conflated with social class status, practice, and mannerisms (Brantlinger, 2003; Delpit, 2006; Rist, 2000) the blue-collar students at MCHS were counted amongst the able. Additionally, while research shows that more privileged students are typically those steered towards baccalaureate programs (Engberg \& Wolniak, 2010; Stephan, et al., 2009), because of the lack of classed stratification in Mill 
County, many of the blue-collar students were actually geared towards baccalaureate programs. These experiences seemed to build pathways, or at least supported students in making the postsecondary transition, opening up multiple ways to become educated in Appalachia.

\section{Social Class and Habitus}

An understanding of the context of social class also helps to understand the nuances of habitus as the base of identity and to consider how habitus and social class are implicated in the figured world of the postsecondary transition. Habitus is the dispositions that result from life experiences that are bounded and shaped by social class, which in turn shape identity and agency (Bourdieu, 2000). The habitus sets general boundaries for the knowledge students have of how to engage with classed systems. Certain limited experiences come with each social class, and so in belonging, relatively speaking, to a classed group, every person's knowledge and dispositions are also limited.

Within classed spaces people are also exposed to limited discourses, framing what students can expect as realistic options for themselves - in this case in relation to the postsecondary transition. All discourses are constructed and negotiated in dialogue, which necessarily requires a speaker and addressee. As speakers and addressees converse they simultaneously place themselves, while also placing the other and this positioning is reflective of social background. As Bakhtin (as quoted in Holland et al., 1998) describes, "Voice...positions persons as it provides them with the tools to recreate their positions" (p. 45). This voice, as agency, gives people the power to discursively change their positionality.

However, voice for the participants was not purely constructed by individuals; culture was also at play. Habitus shaped identities, which shaped the ways that students engaged with the figured worlds of the schools and postsecondary transition process. Sometimes students' 
habitus worked to their benefit when they were more privileged by class, such as when Camilla called her former AP teacher to tutor her when she felt she was not getting what she needed from her novice teacher. At other times, habitus worked against students, such as when Fantasia was afraid to ask questions when she went to schedule her classes for college.

Another important instance of how habitus shaped engagement with the world came in how the participants decided on going to college. All participants, across social classes, described that they always knew that they would go to college; something the literature typically describes as being a trait of the middle and upper-classes. This was a trait of my participants across classes, a college-going mindset, if you will. However, there was nuance within the students' contexts and processes that they used to achieve their college going goals. The collegegoing disposition was founded from their complex classed positions within their local figured worlds. While the results of the disposition were similar, that students attended college, the disposition was shaped differently in each community and by individual backgrounds. This college going disposition prompted students to make plans for college and to follow through with the necessary steps to make those plans happen. The participants and their families' plans speak back strongly to research that suggests that lower-income families and those with less education have lower educational expectations and also that these families do not as strongly support education (Ali \& Saunders, 2009; Baldwin, 2000; Brown, et al., 2009; Cabrera \& LaNasa, 2001; Klasik, 2012).

For the students from the lower class backgrounds, their parents had helped them to "know" that they would attend college, drawing on discourses of building lives that would avoid economic and classed hardships. Through the knowledge and support of their parents, students internalized their parents' discourses as their own internally persuasive discourses, expressing 
the desire to want to prevent economic struggle. While Selene did come from a more economically privileged background, her parents had not grown up with this same privilege. Because they had to struggle early in their careers due to a lack of education, Selene's parents also modeled the discourse of needing education to provide a decent life. Parents clearly understood the benefits of a college degree, even though some, like Robbie's father, were skeptical of a degree's applicability in West Virginia. This again pushes back against condescending notions that families do not understand the benefits of a college degree (Cabrera \& LaNasa, 2001).

A similar process was true for Camilla despite her class privilege. While she had always "known" she would go to college, the essence of her knowing was different than the knowing of the students from the lower class backgrounds. Her figured world was different than that of other students because she constructed her identity as one entitled to participate in the future figured worlds that included college. For example, Camilla did not just hope that she could go on to college, she expected that she should be able to go and to have her choice of good programs. Also, she positioned herself in such a way that she was deserving of institutions and their staff supporting these goals. In contrast, students from less powerful classed positions hoped to attend college but were satisfied with simply being accepted and attending a program that would lead to their future goals. The lower class students did not position themselves, based, in part, on how they had been positioned by others, to expect colleges to personalize and scaffold their postsecondary experience, academically or socially. In comparison to her less privileged peers, Camilla's agency was different; while she applied to schools and for scholarships, her identity as a college student was secure from the moment she first thought of it. Even if she had not gotten any scholarships or awards, her family would have been able to finance school for her, which 
was not the case for four of the other students in the study. With this identity of becoming a future college success story firmly in place, Camilla confidently acted within the figured world of the postsecondary transition.

Students' translation of habitus and identity to action was not formulaic, however, and it is important to highlight these complexities. Students did have dispositions or experiences that did not fit neatly within their classed backgrounds. For example, Gregg's family was opposed to giving him too much too quickly, like when his parents arranged for him to buy a used car with his own money rather than them paying for a new car. However, Gregg's parents were not opposed to his grandmother, an admissions secretary at a state university, pulling strings to get him into the pre-med program with a full tuition scholarship. Despite the participants in the communities studied were largely isolated by social class, people sometimes had connections to other classes through a family member or group association. This social capital offered the opportunity to access unfamiliar worlds with the cost of needing to learn quickly how to perform within them. Gregg's willingness to negotiate his own iteration of unearned advantage put him in a challenging position, but one that he had tools to deal with, in part, because of tools acquired from his more privileged peers within the figured world of CHS. Gregg's fluidity along classed practices is an aspect of an important theoretical contribution of this work, which pushes on the understanding of how habitus is formed. I discuss this in the following section.

\section{Pushing Habitus Development}

Bourdieu's work, particularly habitus, has been critiqued for being deterministic as habitus is conceptualized as very slow to change and anachronistic in its catch-up to circumstances when it does change (DiMaggio, 1979; Reay, 2004). However, researchers who continue to use Bourdieu's work have found room within his writing that allows habitus to be 
amenable to development across the life-span (Reay, 2004; Maton, 2012), rather than only during early childhood. This work continues these lines of inquiry to extend the work of Bourdieu's concept of habitus.

The "primary habitus" (Bourdieu \& Passeron, 1990) is imparted most strongly in early childhood by the family (Bourdieu, 1977a; Di Maggio, 1979; Reay, 2004; Swartz, 2002). Schooling during this time also influences the construction of habitus, what Bourdieu terms a move towards a "secondary" habitus (Bourdieu \& Passeron, 1990). The success of the work of the school in shaping this secondary habitus depends on the match between a student's' primary habitus from early childhood with the family, and that which the school is trying to shape, their secondary habitus. For Bourdieu, the shaping of the primary habitus and the secondary work done by the schools are largely completed at the end of early childhood (Reay, 2004). While the habitus is open to change after that, change is typically minimal or only happens because of a cleft, or "hysteresis," when the primary habitus encounters circumstances to which it is not well suited (Maton, 2012). However, this process appeared to be happening differently in my work with the habitus still being malleable well into adolescence.

Bourdieu (1984), and other researchers (Maton, 2012; Reay, 2004), describe that habitus should always be considered in conjunction with the concepts of field and capital as these show the active and relational nature of the concept. Considering the habitus along with field and capital was useful in identifying where habitus was constructed differently from Bourdieu's work. Within my work, habitus was still being shaped during the postsecondary transition in fluid ways. For example, as students from lower class backgrounds navigated the postsecondary transition and went to college, they encountered fields where their habitus and capital placed them as less powerful. However, I often saw these students engaging in agentive and more 
powerful ways than their backgrounds would suggest. When this happened, the students did not experience a delayed transition or cleft within their habitus, rather, as they encountered new situations they were able to engage fluidly and differently than one would expect.

This was most clear in Gregg's story as he seemed to have vicariously accessed capital from his higher class peers at CHS. Gregg seemed to have learned to engage with the world in more entitled ways from his experiences at CHS with peers who had more class privilege. For instance, at CHS and in Covington, social networking to access capital was often visible with people name-dropping and drawing upon weak social ties. In his time at CHS, Gregg had learned about how these types of social relations worked and had taken up these practices as internally persuasive discourses (Bakhtin, 1982). He easily drew on social capital, via his CHS connections, to tap into capital in ways similar to others in Covington and at CHS. For example, Gregg loved fly-fishing and had the chance to visit at school with a famous CHS alumnus, Kent Firstwell, who had his own fly-fishing show on cable television. Kent moved back to Covington the summer after Gregg graduated and suggested that Gregg visit their family and meet Kent's daughter. Gregg took up this invitation and spent some time dating Kent's daughter over the summer. Then, drawing further upon these connections, when Gregg went to college in the fall, he asked Kent to speak to the owner of a fly-fishing shop in his college town to recommend him for a job, which Kent did. In this vignette, because Gregg lived within a community where it was common practice for the privileged to draw upon weak social relations to access capital, he had learned to do so similarly, despite not having the same privileged place as a member of the suburban, upper-class. As soon as Gregg had the opportunity he drew upon social capital with a much more powerful community member and was not hesitant to engage with Kent, nor later draw upon him as a resource. 
As Gregg had learned this practice from his peers and community, despite not being from an upper-class background, his habitus was shaped by these experiences. In turn, these experiences influenced the ways that he engaged with others in ways that would not be typical from a person from a working-class background. As Gregg had these experiences, they transpired without a crisis in his habitus, rather it was a fluid and timely change coming from his placement in a field with those who were often more powerful.

This work, then, continues the work of current scholars who utilize Bourdieu's habitus and shows that it is a construct that continues to be shaped later in life than Bourdieu posited. As habitus continued to be shaped well into adolescence, it shows the ways that people are able to move outside of limiting class boundaries when they have access to different capital and fields. Finally, this aids in furthering the use of habitus as a construct that can be used to understand relationships and power dynamics and how those function for individuals as well as for groups. In the next section, I describe how students continued these novel ways of acting and living as I describe how identity is drawn upon to provide agency in the postsecondary transition.

\section{Identity and Agency in the Postsecondary Transition}

The dialogue between a person and figured worlds shapes a person's identity, as their identity becomes more or less reinforced by their experiences in this dialogic engagement. Available discourses shape who a person sees themselves to be and also shapes the possibilities

for what their identities are and are not allowed to be (Holland et al., 1998). As my participants engaged with possible identities such as "college student" and "successful student," their engagement shaped how they experienced and engaged with the postsecondary transition process. 
As students made decisions about what to do after high school, the dialogue with their figured worlds impacted their futures. In particular, classed experiences influenced how confident and competent students were as actors in the figured world of the postsecondary transition. As the identity of a competent actor in the figured worlds of high school and the postsecondary transition was shaped by various discourses and practices, students' actions, thoughts, and emotions were mediated by these events as they constructed their identities.

For example, as Robbie found support at MCHS and success as a participant, and later counselor, in a leadership camp for low income students, he came to identify more strongly as a leader. Then, when a friend who, was an RA, suggested that Robbie apply for an RA position because of his camp experience, his identity as a leader was supported, reinforcing his agency as he applied for the position. Moreover, Robbie's social capital through this friendship positioned him with more power when he gained status as an RA. Robbie's RA position solidified his ability to finance college, shaping profoundly his trajectory in the figured world of the postsecondary transition. Robbie's potential as a successful student became imminently less tenuous and he could also, now, participate as a leader in college. The competence and confidence that came from this new position supported Robbie's identification with the figured world of college and college student. These chains of experience allowed him to internalize and use less familiar discourses in crafting and enacting his own story. With this brief snippet of Robbie's story, the process of the relational, positional, and agentive aspects of identity and figured worlds are made visible. As I move through the following portions of this chapter I attempt to show how the figured world of the postsecondary transition was navigated agentively by the participants, often within structures that were not set up to support this process equitably for all students. 


\section{Agency Beyond Bound Spaces: Figured Worlds Theory}

As Holland et al. (1998) describe, the more closely a person fit within and identified with a figured world, the more adept they became at moving within and accessing that figured world. The students who were more/less confident of their places as college students were accordingly adept at accessing the structures they needed to set them on the path as successful college students. Once they started college, how well they fit within that world was influenced by this identification.

As the participants in the study were immersed within very different figured worlds between their communities, they were differentially prepared for the figured world of college. At MCHS, the culture of warmth contributed to an identity as a valuable person for the students. In this way, the social was in dialogue with the internal, shaping identity, which then shaped the social. As students from MCHS enacted identities as people who had been valued, they acted agentively as competent and confident actors within the postsecondary transition process, supporting their roles as college students within the new figured world of college. The processes of FWT are made evident here, as the social influenced the personal, which re-addressed the social in improvisational ways that constructed new spaces for agency.

The processes of FWT are similarly visible within the figured world of CHS. The dominant discourses of achievement at CHS positioned a limited number of students as valuable and each of the participants at CHS talked about this culture and critiqued it. Despite not being a superstars or highly valued at school, the participants drew from heteroglossic discourses circulating in other spaces in their lives to re-position themselves as valuable people. Students negotiated around the discourses that did not place them as valuable people, authoring desirable 
spaces for themselves as dignified humans and as deserving of success in the postsecondary transition process. In this way they drew on the personal, their identity, to shape the social. All of the participants had constructed a fairly clear picture of their imagined futures. As students negotiated their identities and pathways through the postsecondary transition, this space of authoring was not determined by limiting discourses, rather they drew selectively from the heteroglossia to support their goals. Through these spaces of authoring, students exercised agency, placing them more firmly in control of their outcomes. This extension beyond tight social class determinism of trajectories offers a view of students as not "victims" of their circumstances or areas. Students and families want to be, and can be, partners in their postsecondary trajectories if they are given the space to do so.

Parental agency: Disrupting dominant discourses. Within figured worlds actors are able to draw from the circulating heteroglossic discourses to shape their own spaces. As Holland and her colleagues (1998) state, "the author...creates by orchestration, by arranging overheard elements...not by some...ineffable and central source...the author works within, or at least against, a set of constraints that are also a set of possibilities for utterance" (p. 171). Heteroglossic discourses can be constraining, such as in the ways that first generation and lower class families are often described. However, these discourses can also be "possibilities" as authors reconstruct discourses to position themselves outside of limitations, creating new internally persuasive discourses that push against limitations. Similar to other critical educational research (Auerbach, 2007; Doucet \& Vukovic, 2011; Graue et al., 2001; Graue \& Sherfinski, 2011), paying attention to the ways that families constructed new narratives is an important step towards including them more fully within their children's educational processes. 
Within FWT, even though people are positioned as less powerful, such as working-class and working-poor or rural families, this does not prevent them from seeing the inequities in these places. This act of naming oppressive systems is an act of agency that creates counter-discourses with the potential to disrupt inequitable systems. This space of change is political in nature as it disrupts discourses that maintain inequality, particularly discourses that purport American education to be a place of meritocracy that offers every person an equal opportunity for success.

The stories from this project push against some of the limitations that Bourdieu would have expected based on participants' social class positions. Though some of the participants had less power in the field of education and the postsecondary transition because of their social class and lack of knowledge of the postsecondary transition, at times they saw through the cloaks of misrecognition that hid inequitable processes. The parent participants disrupted the doxa of this system, which would position them as less successful just as the immigrant parents in Doucet's (2011) work pushed back against school doxa that disparaged them. The parents saw that the discourses being offered, i.e. a college degree is the way to have success, did not fit everyone's lives or their figured worlds.

For example, several parents in my study, particularly those who were positioned as working-class and working-poor (Hedy and Robbie's fathers, Gregg's parents and Fantasia's mother) were able to name practices, policies, and situations that stood as barriers in the postsecondary transition. They named these as immediate barriers in the postsecondary transition and also for the future when considering whether their children would be likely to achieve their hoped for outcomes. Moreover, parents were able to name that the dominant cultural narrative of success was a myth, recognizing that "hard work" did not equate to similar outcomes for 
everyone. Parents also recognized that place impacted outcomes, particularly the parents in Mill County, where there were so few jobs and especially jobs that required a college education.

Parents of first generation students, from Mill County and Covington, also disrupted dominant narratives that families with lower educational attainment are less likely to support their children's education (Epstein, 2007). For the parents who had not attended college, that their children succeed in this pathway was immensely important; they felt that education would be the best way for their children to make good lives for themselves. Similar to the parents of first generation students in Bryan and Simmons' study (2009), while parents had high educational hopes for their children, they voiced that they were often at a loss for how to help them through this process. Parents expressed that their level of support did not match their level of capability in supporting their children through the postsecondary transition. Parents saw that they and their children needed more help in this process than they were given, however the schools and institutes of higher education failed to provide this scaffolding. As parents named this lack of help, they were narrating a counter-discourse to those that placed them as in need of remediation. Parents did not need remediation in being taught that education was important for their children; rather, parents needed scaffolding to be able to help their children achieve these mutual educational goals.

As parents recognized these barriers, they showed agency in speaking back to the discourses that blame parents while fail to identify the structures and institutions that have created and perpetuate these inequalities. As rural people from the working and lower classes with lower levels of education, these are the parents who are often othered in the educational literature (e.g., Epstein, 2007; Howley \& Howley, 2010; Theobald \& Wood, 2010). As parents negotiate the postsecondary pathway, it is imperative to understand how the narratives of 
dominant literature and middleclass educational institutions place them as in need of repair and not as agentive, capable supporters of their children. Parents speaking out against these societal discourses helps to change the ways that they are represented by those with more power. As parents were able to push against limiting discourses, they were able to provide assets of support for their children. In the following section, I will discuss how students and communities have systems of support, in the form of othered capital, that often go unrecognized.

\section{Disrupting Social Reproduction: Othered Capital as Unrecognized capital}

In this section I share about othered capital; capital that exists in lower class and rural communities that provides support but goes unrecognized as capital. I discuss how othered capital was constructed and offered in Mill County and of how this translated into benefits for students, then end with the importance of why this capital should be recognized.

In the figured world of MCHS, discourses that supported a culture of warmth positioned many students as valuable actors. As students at MCHS had more opportunities to participate in sports, clubs, and general life, there were many opportunities to engage in relationships where they were positioned as valued. Within these relationships, the discourses of competitiveness (like at CHS) were less relevant than the discourses that placed value on the experiences a person had while participating. Warmth occurred at the community level as well, giving continuity to the experiences of being valued. Participants at MCHS had an understanding that what they did mattered and that was something that was important to them. This local discourse had become an internally persuasive discourse; that is, a discourse drawn from the external and modified to have new meaning, a way of making things your own (Bakhtin, as cited in Holland, et al. 1998). This discourse of valuing of people, outside of their success or competitive spirit, pushed against neoliberal discourses that value only a select group, those who are economically and publicly 
successful and possessive of the corresponding economic and cultural capital. This disruption of dominant narratives served as a form of othered capital for the Mill County students.

Othered capital was important for students; particularly with the empirical evidence of this study, which shows how this othered capital was activated and used within the figured world of the postsecondary transition. Though othered capital was not dominant capital, it still brought benefits. Through self-authoring, students demonstrated that they were using the capital developed through language and experience in order to change cultural scripts typically considered as fixed because of class habitus and associated doxic effects.

As an example, while Hedy did have to take a remedial math course in college, she was finding success there as a student and very much liked her agriculture courses. However, socially, she was not fitting in as easily, "Pretty much since everyone parties, I don't hang out with a lot of people" (Hedy, Interview 2, 2014). Though initially excited about living with a new roommate who was from a different high school, Hedy and her roommate did not get along. Hedy had essentially kicked her roommate out of the dorm for partying and smoking pot in the room. She shared that she was not willing to risk herself getting in trouble or kicked out of school as she had worked so hard to get there, "And then where would I go?!" Hedy nearly exclusively hung out with other people from Mill County with whom she had more in common.

Hedy also described that she "hated the big city," actually a town of 50,000 where she was attending school, so much so that she was hoping to take summer classes so she could graduate in three years. As early as possible every Friday, she and her best friend returned home to Mill County to spend the weekend. For Hedy, her identity as a rural person did not match the more urban/suburban setting in her college town. However, because this identity was so strong for Hedy and being rural was such a powerful internally persuasive discourse, Hedy was not 
upset that she did not feel like she fit into her new figured world. Within her new figured world of college, Hedy was not willing to place herself as a meaningful actor in a context where she felt she did not fit, so she rejected some of the social spaces of this new place. Hedy had built a strong identity as a person of value within the figured worlds of Mill County and MCHS, particularly as a leader in the FFA program and as a community and family contributor. Hedy drew upon this identity as a source of strength for existing in a figured world where she did not see herself as fitting. Despite not fitting well with the figured world of college, Hedy was able to draw on the fossilized artifacts of her identity that positioned her as a valuable person, translating these into valuable capital that helped her through these struggles.

While othered capital did serve as a support, other times when the students moved out of the figured world of Mill County, such as to the figured world of college, and engaged with students who had dominant middleclass capital, their "othered capital," became less helpful. As students attempted to shift between figured worlds, the doxic effects of class were reinforced because different kinds of globalizing communities did not fully share the script of what postsecondary education and life could be. These doxic effects were particularly challenging as students moved through the worlds of higher education where dominant cultural capital is highly prized. For example, despite Hedy being an honors student in Mill County, a symbol of dominant institutionalized capital, she scored low enough on the state university's entrance exam that she had to take a remedial math course, positioning her as inadequate in math, institutionally speaking. Hedy's academic capital from Mill County had not transferred into the figured world of the university. 
Within the field of education, middleclass people and institutions are privileged in that they are not required to understand people from whom they are different. Because of their privilege, often middleclass educators and institutions do not see, or refuse to see, that othered students have access to capital, it just looks different from their own. As those in the middleclass frame discourses within the field of education, because they are more powerful, their discourses become dominant and are fossilized into artifacts representing success and ability. When students from lower class background do not have their capital recognized by those in positions of power, these actions limit the way students' capital can be activated (Rios-Aguilar, Kiyama, Gravitt, \& Moll, 2011).

This work provides empirical evidence that supports the call in critical educational research for a broader view of capital (Graue \& Oen, 2009; Schnee \& Bose, 2010; Tveit, 2009). Students possessing othered capital opens an opportunity for educators to draw on already existing strengths. Within this study the students and parents often positioned themselves as very resourced, or at least trying hard to use the resources they had, even when they may have been less powerful within the postsecondary transition process. These heteroglossic discourses push against dominant discourses that position lower class families as inadequate and are an opportunity for middleclass institutions and educators to draw on already existing capital. Conceptualizing othered capital as assets that are valuable, despite the value changing in various fields, further supports the need to understand class contextually. When educators and institutions do not recognize diverse strengths, it contributes to inequitable educational outcomes. In the next section, I detail the ways that inequities are built into the structure of the postsecondary transition process. 


\section{Social Reproduction: A Flawed System Reproduces Social Inequalities}

Bourdieu (2000) posits that students and families "invest in education" (p. 216) in congruence with how well they think these investments will pay off. Bourdieu is referencing the differences between investments by people of different classes, where those from the higher classes invest more in education than those from the lower classes. My research complicates this picture as all students and families from across the class spectrum were highly invested in education. However, what they knew about the postsecondary transition process and how to navigate it positioned them differently from one another.

All of the participating students and families were dedicated to transitioning on to college. Across the board, participants were depending on the school systems, at the secondary and postsecondary levels, for giving them accurate and adequate information to help them navigate this very technical process. A successful transition to college would put the participants on the road to valuable institutionalized capital, baccalaureate degrees that would help them achieve the futures they envisioned and a life without struggle. To use Bourdieu's terminology, families and students from higher classes did not invest in education more than families and students from lower classes, rather they had better knowledge of how to invest in ways that could support their children through this system.

Families from higher class backgrounds, particularly those who possessed artifacts of college going knowledge, were positioned as more competent actors within the postsecondary transition process. These families knew that overall GPA was important and they knew that taking advanced courses were important for college preparation. However, students from lower class and first generation backgrounds were not privy to these discourses. They had learned that if they finished high school with a decent (think B-) GPA, that they could go to college and reach 
their dream job, a doxa specific to their classed positions. The dominant discourses these students had access to did not position them well in the postsecondary transition process. The lower class and first generation students were not privy to the implicit knowledge that academic planning and high scores need to be strived for starting freshman year in order to be the best prepared for desirable programs. There was also privileged knowledge of the planning involved for getting scholarships and awards and orchestrating other funding sources. While all students and families were investing in and depending on the school as an institution to make these things happen, some were positioned better to navigate the figured world of the postsecondary transition.

While all of the participants were able to successfully matriculate to their college of choice, other than Selene who was not accepted to her top-choice fashion school, the students who were first generation college students and from working-class and lower class backgrounds had the most tenuous paths. Because of the lack of advice they had received from the schools, institutions that are gatekeepers of institutionalized capital, these students struggled the most with meeting grade requirements and fulfilling the financial burden of paying for college. Additionally, parents were keenly aware of the costs of college, especially those from lower income backgrounds, which speaks back to work that positions low income parents as ignorant of this information. In their work, Galotti and Mark (1994) blame parents' lack of knowledge of college costs on why their children attend college less and suggest that if parents knew more about saving money they would be able to better help their children. A more effective tool for helping to negotiate college costs, would be to give parents and their children more complete advice during the early years in high school regarding grades and curricular choices that could help in securing scholarships and lessen the barriers to paying for college. For example, both 
Gregg and Fantasia shared that they did not realize how much their grades early in high school mattered when looking at long term outcomes. As a result, when it came time to pay for college, both struggled with meeting grade requirements for scholarship applications and for the golden carrot PROMISE Scholarship.

As I mentioned in the literature review, the PROMISE Scholarship is funded by the West Virginia State Lottery, and is a "universal" access scholarship that offers $\$ 4,750$ towards college tuition for any qualifying West Virginia student. However, as college costs have risen, the requirements to qualify for the PROMSIE have also steadily increased, making it less of a universal and more of a merit scholarship. Policies like this are problematic as they most benefit students from more economically privileged backgrounds who are more likely to meet higher achievement standards than lower income students (Cornwell \& Mustard, 2007). Similar to the research, the participants in my project qualified for the PROMISE Scholarship exclusively along class lines. Selene and Camilla easily qualified, while Hedy, the student most in the middle, took the ACT 4 times before she finally reached the score to qualify. Robbie, Fantasia, and Gregg, the students most in need of tuition assistance, did not qualify for the PROMISE Scholarship. Robbie met the core and overall GPA requirements, as well as the overall ACT score, however his reading sub-score did not meet standards so he was denied this "universal access." Robbie shared about his disappointment and what happened, "I'm just a slow reader, I couldn't get through everything" (Robbie, MCHS Focus Group 3, 2014). Gregg met all test scores and the overall GPA, but not the core GPA requirements. Fantasia did not meet the overall GPA requirement and so was automatically excluded. A recent report from the West Virginia Higher Education Policy Commission showed that nearly half (44\%) of all first time PROMISE 
recipients come from families who made $\$ 90 \mathrm{~K}$ or more (Speciale, 2015). My work, and this recent data, show the inequity of how "universal" access is offered, as $\$ 90 \mathrm{~K}$ is a very high income in a state with a median income of \$36K (U.S. Census, 2013).

Even though some students appeared adept at navigating the postsecondary transition, it was not without uncertainty and a lack of understanding. For instance, Camilla, who took on the entire process virtually on her own and was very successful, described it as a "secret process" that no one talked about. Similarly, Fantasia, who was in a much more vulnerable position than Camilla, described the process with frustration, that it was "like people know these steps, but they just won't tell you" (Fantasia, Personal Conversation, 2014). In these cases, both students saw that while helpful information for the postsecondary transition existed, it was not made available in a way that was supportive in moving through the postsecondary transition process. The participants' stories fit with the literature on social reproduction (Bourdieu \& Passeron, 1990; Brantlinger, 2003; Schubert, 2012) where students who are already socially and educationally advantaged are much more likely to achieve their goals, precisely because they have the knowledge that the school requires for success but does not provide (Anyon, 1981; Willis, 1976). For students and families with access to those who have college going knowledge, i.e. social capital and cultural capital, they indirectly learn about this information allowing them to more competently complete this process. Families and students without this access to social capital, miss out on this important knowledge and cultural capital. Students' match and previous knowledge with the figured world of the postsecondary transition helps to show the imperative of making the pathways to postsecondary education more accessible. 


\section{Academic preparation translated to institutionalized capital. Because of the}

inequities in the American K-12 system, particularly in how schools are funded through property taxes, many students are not served equitably. Like other research (Buras et al., 2010), there were clear differences that funding between MCHS and CHS played out. Differences in academic preparation between CHS and MCHS provided a very clear way that inequality was reproduced along social class lines, which is in line with research that points to this inequity (Auerbach, 2007; Brantlinger, 2003; Delpit, 2006). This is another important aspect to consider when thinking about how social class may be contextualized.

For instance at MCHS, while Hedy was in some AP and advanced courses, she was also in the general track for math. She was a member of the National Honor Society and had high grades in math throughout her high school career, positioning her with the identity of a strong student. However when she went to college, her math preparation was inadequate and because of her score on the placement test, she had to take remedial math courses, as did 29 of the 32 other students from MCHS who attended the same university. In contrast, at CHS, Fantasia had been in the applied level math courses but scored high enough on the college math entrance exam that she did not have to take the "bonehead" math courses (Fantasia, Personal Conversation, 2014). Likewise, Gregg, who had been in all general math courses at CHS did not have to take remedial math in college. This points to the difference in the quality of preparation that can differ between schools, particularly those with different income profiles.

While Hedy appeared to have the dominant capital within the figured world of MCHS, this did not translate or 'pay out' when she had to use it in other figured worlds where more dominant capital held power. The opposite was true for the CHS students when they went to college, particularly for Gregg and Fantasia. While they appeared to lack academic- 
institutionalized capital within the figured world of CHS, they had actually acquired dominant capital in the form of adequate test scores that allowed them avoid remedial courses. This observation points to hidden inequities between worlds of schooling that can be masked by course tracks and labels (Brantlinger, 2003).

This relativity of class, and particularly academic capital, means that students who move on to postsecondary schooling, especially college, may be differently prepared for engaging with the figured world of higher education not only culturally but also academically. Academic and cultural differences highlight the need for programs for first generation college students or those from places where social class and access may have different meanings. Just as support that recognizes contextual factors is important at the individual level, the same is true when thinking about how schools and communities can be mutually supportive. In the following section, I examine how current schooling practices of only supporting college pathways can be detrimental to the local community.

\section{Reproducing the Decline of Rural Communities}

While the state language and national push has changed from a focus on college for all to college and career readiness, this has not translated to practice in schools. In this study, both CHS and MCHS were standardly steering all students towards college. While not all students are served well by the college for all model, as the guidance counselors at MCHS recognized and spoke about, this is the model still being implemented. Because all of my participants were on the college path, this was not a part of their stories; however, through this work I saw how the college for all model was detrimental for small, rural communities like those in Mill County. 
It is important to me personally and professionally that West Virginia's small communities stabilize and become sustainable. An imperative of this goal is that these communities have young people who are able to work and live within them. However, when schools are organized to support only students who are on the college pathway, in a de facto manner, they are preparing these students to leave their small communities because, as Carr and Kefalas (2009) point out, there are so few jobs that require college degrees. For example, one Millsdale community member shared pride that her young son wanted to be an engineer, and then followed this with the sadness that "he'll have to leave here" as she had already experienced three children who had graduated from MCHS and then moved away to find living wage work.

I say this hollowing out is de facto because it was happening differently in Mill County than is described in other literature like Hollowing Out the Middle (Carr \& Kefalas, 2009). In Hollowing Out the Middle the educators and community seem to be in agreement that success is somewhere other than where they are, which is why high achieving students are sent to find that elsewhere. However, in Mill County, the exodus of students to college and careers elsewhere was more heavily influenced by the economic and employment profile of the area. The prevailing culture at MCHS, perhaps as a result of state and federal influence, was that the most desirable educational choice was college. Then, as a natural course of events, when students successfully completed college and wanted a job and pay commensurate with their education, returning to Mill County to do this was difficult. While people recognized the result, that young people were leaving and not returning home, they seemed to see no available ways to change that. 
All three of the students at MCHS realized that it would be unlikely that they could live in Mill County with their desired professions. However, it did not seem as if they had considered this consequence in conjunction with their expressed commitments to their families and to Mill County as their "home." Rather, it was just a fact of reality for students that in order to make it in the world, they had to move to places where there were options to have an interesting job that paid a living wage. Parents, however, seemed more concerned about their children leaving the area and moving away from local benefits, such as the tight-knit community and good place to raise a family. While Camilla's mother expressed her tie to the area for these same reasons, she was less concerned about Camilla leaving the area. While family was very important for Camilla's family, they had managed to maintain strong connections with family who were, literally, spread over the United States and the world. Camilla's family had experience in maintaining the family bond over long distances, while Hedy and Robbie's families were much more locally based. The Mill County students and families expressed that ties to place and family were very important for them. However, for Hedy and Robbie's families, it was as if they would have to sacrifice some of this connection due to the economic realities of the area. While these connections to family and place were relevant for students and families, they were not barriers to these students making plans to attend college as some research suggests (Ali \& Saunders, 2009; Brown, et al., 2009; Chenoweth \& Galliher, 2004; Wallace \& DieKroger, 2000).

This de facto hollowing out eliminates, or lessens, the possibilities for young people to remain in the area and support the communities. In the case of small, rural places like Mill County these are areas that are struggling economically and as more young people leave, the likelihood that diversified economic and community revitalization will happen also lessens. In 
addition, this fragmentation of families and relationships, in the forms of ties to family and place, is seen negatively by those who must negotiate these unwanted consequences of the local context.

As these previous sections look at the implications of my work within the stories of the students and families, the next section shifts gears as I frame the broad goals for this work within my own story. I explore the ways that my identity as a scholar-activist have developed across this project. I then relate this to how I hope positive change will come from this work.

\section{The Circuitry of an Activist Identity}

Working on this project for the past two years has broadened my perspective on theory, research, scholarship, and activism. In addition to the research on my dissertation, I was also teaching critically oriented courses, as well as completing a course that studied critical theory through the use of empirical studies. While in the past I have been supportive of broad social justice goals, I have always been more interested in classed inequalities because of my personal experience. However, the combination of my dissertation research, teaching, and student-ing at the same time worked in cohesion to help me understand the intersectionality of identities and oppression and how these things are connected across figured worlds. Through these experiences, I have come to understand that all identities are important when considering dismantling systems of oppression and that all oppression is related (hooks, 2000).

Gaining this deeper understanding of how different types of privilege and oppression are linked has shown me the need to listen to all voices, not only those of the economically oppressed. It is important to listen to the stories of women, from women, hearing about their struggles; to listen to queer folk and think about the discrimination they face and what that means for them; and for seeing the effects of the system of racism in our country and how that 
influences us all. Discrimination of all sorts leads to not seeing people as people, but as stereotypes of people. "Seeing" the real life stories of the first generation students and economically marginalized through my work has allowed me see more clearly that even though discrimination takes different forms, it happens in similar ways—by dehumanizing the targets, silencing their stories and points of view, and not listening to when they disagree, which serves to keep them in positions without power.

In my work, broadly speaking, I continued to recognize the powerful difference between knowing theory and seeing theory in action. Across my research and course experiences, I was seeing the intersectionality of identities and how oppression in one can lead to the other and how privilege with one identity can lead to privilege in others. However, while the privilege of some identities crosses over into others, there are spaces where these roles are reversed. Seeing these things in action allowed me to see how my conceptual identity, who I conceptualize myself to be internally, plays a role in my procedural identities, of how I enact these beliefs (Urietta, 2007b). In the following section, I detail more closely the processes of interaction that have shaped my identities during this project including my work as a student, teacher, and researcher.

\section{Becoming and Doing and Becoming...}

Urietta (2007b) detailed the processes of conceptual and procedural identities in his work on how Mexican Americans became Chicano activists. This process began as people learned about their cultural history as many of them had attended majority White schools where their history had been suppressed. The activists' new knowledge of oppression began their steps towards activism. Their conceptual identities of who they were as Mexican Americans and their histories changed first, then later their procedural identities changed as they began to enact their identities as activists. I would describe my processes as similar. 
The concepts of conceptual and procedural identity are useful when thinking about how my identities as an advocate and activist have changed from early in the doctoral program to where I am now as I finish this project (Urrietta, 2007b). Early in the doctoral program, when I first began to learn about inequality and its structural causes, the conceptual identity of a social justice advocate was born. At first, I just had this knowledge sitting inside of me; I identified myself as someone on the side of justice but not really as an activist. Though I would not have named it as such at the time, this conceptual identity shaped the way that I sought out information that supported this identity. My discourses and practices began to change as I looked for pathways to learn about fostering positive change, particularly within Appalachia and West Virginia, as was my goal when I entered the Ph.D. program. As I learned more about inequality, its actual causes, and not just the neoliberal, racist myths that circulate in popular culture, these artifacts strengthened my identity of advocate and activist; my conceptual identity supported actions that positioned me as a social justice advocate. Through my various experiences of learning about oppression, I realized that simply being on the side of justice was not enough. I felt I needed to be able to speak about and enact these things because if I do not, who will?! My first forays into enacting my identity as a social justice advocate, began as I started teaching courses from a critical perspective. As I dug into my own learning so that I could facilitate others' learning, I began to negotiate the discourses of social justice and equity at a more personal and not just academic level; I also realized how much I do not know. This realization propelled me to continue learning so that I would not be complacent nor reproductive of systemic inequalities. Within my role of advocate and activist, despite not naming it as such at the time, I continued to learn and act as the knowledge that I was doing meaningful work grew. 
The course I took during my data collection examined empirical research coupled with theory, as well seminal works that pushed the theory forward. As I worked in the field by day, trying to see how theory worked for my participants, one afternoon a week I was learning about theory that focused on identity negotiation and production. Exploring the course content that joined theory and empirical research made it more clear for me how to "see" the theoretical in my own research. I began to be able to pick out instances where my participants were working out their identities. Sometimes this happened in defensive ways to protect themselves from those who would position them as less than, other times, when power was available, the participants positioned themselves as better than others. Sometimes there were spaces in between where participants were just working out their identities in day-to-day actions. Through the critical lens of this course, I also learned to see power differences between people, at the day-to-day level, and how those affected identity presentation and production. As I translated this coursework and experience into my figured world of critical ethnographer, it was like a little window had opened that enabled me to see practice in relation to theory.

The experiences of the critical course, teaching, and my dissertation changed my views on how I should and can engage with various structures of inequality. As I did my field work, I was influenced by my participants and their experiences which shaped how I participated in life and where I hope to see my future work. Had I not done this project, and had the students, educators, and communities not shared their lives with me, my social justice stance would be as activated. Though I would never stop believing in social justice and that inequality exists, without the data collection experience I would not have seen how necessary it is for people who do see these inequalities and who have voices that people are willing to listen to, to actively engage with systems of oppression. As I have become a more competent actor within my role as 
a social justice advocate and activist within the figured world of academia, I have come to identify more with this figured world and role. This ongoing process has also shaped my desire to expand this role of advocate and activist as I have continued to learn about and started connecting with grassroots organizations in West Virginia, entering the figured world of community activism.

While my identities remained, they have also changed as I negotiated my new role of a critical ethnographer working to disrupt inequitable structures within the figured worlds of Mill County and Covington. Clear instances of this for me were acts such as collecting information on scholarships and community college programs for Robbie, sitting down with Fantasia and Gregg and working through scholarship searches and application information, helping Fantasia through some of the administrative tasks with the postsecondary transition, and working with the guidance counselors at MCHS by just lending an extra hand. The research experience moved me into the space of negotiating my identity differently, from a person who knows about social justice issues and can talk about it at an academic level to seeing (un)just power relations happening on a day-to-day basis and having to figure out how to insert social justice activism into places where people do not necessarily see any problems. By intentionally searching out inequities during the study, I gained an understanding of how invisible inequities are in everyday life, a part of the fabric of living.

As I conclude this dissertation, I have had an extended epiphany, that it is good to be angry about injustices, but unless I have the tools to engage people who participate in systems of oppression, I cannot be as helpful as I would like. I would like to be skilled enough to meet people where they are and not only where I want them to be. I have to be able to effectively engage in a way that does not shut me or them down. Further, this is not to say that I do not also 
participate in systems of oppression, because that is the nature of American society; however, I try to be conscious of when this happens and to address it. As I have developed this more active social justice stance, at times, some aspects of my identities are more salient than others. In the following section I share about how I negotiated the identities I brought to the dissertation project within the figured worlds of Covington and Mill County.

\section{Identity Positions and Listening}

As I entered these communities and schools, thinking about my identities was important in positioning myself as an authentic listener. This brought to the fore identities that are still, as always, in process. It was interesting to be in Mill County, a place very similar to the place where I grew up as I have been out of rural West Virginia for almost as long as I lived there. For most of these years I have worked in academia with mostly academic people, shaping the ways that I have become more middleclass. Though I keep in close contact with home, over the years I have become less like people at home. However, being immersed within the figured world of Mill County made me very cognizant of how significant some of these changes have been; I had just not noticed because they happened so gradually.

For instance, dialect made me stand out in Mill County. However, I easily slipped back into a more "country" dialect and less academic register; it was like putting on a pair of soft, comfy sweatpants I had forgotten I had. I was surprised at the ease with which I could switch between dialects. I did not realize how much my speech had changed until I was immersed within the world of language in Mill County. In Covington my language patterns were different, as speaking 'country' there may have made me seem like I was performing, or at least I felt that way. But because of the range of dialects present in the town and "vanilla" flavor of most of the speech, my academic accent did not make me stand out there, to my knowledge. 
My identity as a first generation college student is linked to my identity as a person from a blue-collar background. Going into the project, I thought that this identity would be more salient in my relationships with participants than it was. Though I did struggle with adjusting to life at West Virginia Wesleyan, a private, liberal arts school and thought that this may be helpful to share with participants, this was not a part of my identity that was salient for them. Despite telling each of the student and parent participants at least some of my own story when I explained the project, to them I was a university researcher working on a Ph.D. My position as an academic was much more salient for who I was to them than a part of me that they had never known nor experienced. Thus, I built relationships with participants differently than I had expected, as my being first generation and blue-collar ended up not being relevant commonalities in the work.

Doing this project has helped me to see how I am always in dialogue with the external, negotiating my various identities. As I stepped back into rural communities during this project, I renegotiated relics from my past that are still very much in me. I am picking and choosing the artifacts and discourses I like and discarding what I do not like, just as I also do within the figured world of middleclass academics. In part, this project has given me an awareness of the heteroglossic voices within and around me, particularly as I remain in dialogue with my historical spaces while negotiating my identity within academia and activism in West Virginia. Further, my actions and future are being shaped by these identities as I engage with a discourses for a sustainable and hopeful future for West Virginia. 
In the hope that West Virginia will have a sustainable future, I want to put as much of my efforts towards that as possible. To those ends, I have treated this project as a way to forward these activist goals. However, because the original design of the project was focused on impact after completion rather than during, negotiating how I performed as an activist within the figured worlds was challenging at times. In the following section, I detail these challenges and triumphs.

\section{Negotiating an Activist Stance in Research}

As I entered these communities as an educator/activist, I wanted to connect with my participants in a way that provided safe spaces for them to share their stories. However, as a researcher I want to see change happen, so I also went into this project with an agenda. I felt very self-conscious about my agenda at times, particularly when there were problematic things going on around race, class, and gender, etc. that participants did not recognize as problematic.

For example, I shared in the data a time sitting with guidance counselors and staff in Mill County when they were having a conversation about diversity, busing, and "bad, urban" schools. I recognized the racism in the conversation and knew that it would be a part of how I built the context of the figured world of Mill County. However, I did not engage with the people at the table in a way that let them know I saw racism in their conversation. This happened for multiple reasons: (1) This was one of my first visits to Mill County and I was still establishing very new relationships with people. I did not want them to feel like I was an intruder on their space who was judging them as, perhaps, less than; and (2) I felt unprepared to engage the conversation in a way that might be productive in helping them to understand why their conversation was racist without them feeling that I was posing that they were racist. Part of feeling unprepared to engage stems from my own lack of knowledge and training in how to effectively engage conversations like this, particularly with people I have just met outside of an academic setting; this is indicative 
of the systemic racism in our society. As a person who teaches critically on inequality, outside of an academic setting, where a person does not have to listen to me as an instructor, I lack the tools to meet them where they are to engage race critically. A goal for after this project, because of my experiences in this project, is to prepare myself to engage White people, particularly outside of academic settings, in productive conversations about privilege, racism, and inequality. So, back to the conversation, I eventually was able to steer the conversation out of its problematic frame by sharing about my own experiences with diversity and how wonderful and helpful those had been, enabling us to move the conversation out of such a problematic place.

Despite not being able to be "activist" oriented in all of my engagements with participants, there were times when I was more fully able to express this identity. I did help Gregg, Fantasia and Robbie find scholarship information in various capacities; sometimes I met with them and other times I just passed on information. I also helped Fantasia quite a bit with various administrative tasks related to transitioning from high school to college. I have also helped the participants with college projects, giving them editing feedback and writing a letter of recommendation for Robbie when he re-applied for his camp leadership position after his first year of college. I loved these spaces where I was able to supplement the strengths of the participants as they invited me into their lives.

As I went through the processes of listening to and working with other authors within these figured worlds, my approaches changed depending on the contexts and participants. At times I was able to use approaches I had planned, while at other times I had to discard what I had thought would be helpful. As I moved through the project, little of the work was like I had imagined it would be; though the unexpected complexity of the work brings me hope that the project can provide insight towards local and policy change. While I listened to, and worked 
with, others from an advocate/activist standpoint, I did not always work with people to try to implement change as often as I would have liked. For example, in the experience I shared with the guidance counselors and staff at MCHS, it would have been nice to be able to build on our conversation and make it a productive project around race and racism. However, some of that work was not feasible within the scope of this project. At these junctures, where I would have liked to be doing more education and advocacy work, I had to reimagine my role as activist so that I would not be too discouraged, and also reconsider how working through the process will hopefully lead to productive change in time. In future projects, I would like to embed a stronger dialogue of change or helping within the process of the project and not as only a final goal of the project. At times, I felt almost like a voyeur and I did not like that feeling, particularly when I was seeing or hearing problematic things. At times during this project, it was more like I was working alongside other authors rather than with them. However, some of the best parts of the project were just sharing time with people and learning about their lives, which taught me an incredible amount. In the following section I detail what I learned from participants that directed me towards looking at structures that contribute to inequitable outcomes.

\section{Local Knowledge for Larger Change}

I am thankful to have learned much from the people who participated in my study. What I learned from working with the low income, or lower class but not necessarily lower income families, like Robbie, Gregg, and Fantasia, was how much of a struggle it was for them to sometimes work around meeting basic needs, particularly Robbie's family. Their classed spaces and experiences, and for Gregg and Fantasia, knowledge of the postsecondary transition, made their postsecondary paths tenuous. As I mentioned earlier, reading about topics, like how lower 
income and first generation students make the transition to college and believing them is one thing. However, actually seeing the process and watching people struggle, structures knowing in a different and more profound way.

Likewise, I learned much from listening to the teachers and counselors as they shared about their difficulties in serving students within the neoliberal pushdown of standardization and unrealistic achievement standards. Mirroring the literature, I learned from the guidance counselors that they were not put into a position by the system to systematically support students through the postsecondary transition process, in multiple ways. Counselors at both schools had very high student loads, approximately 200:1 at MCHS and 360:1 at CHS (Blumberg Corwin, et al., 2004; Klasik, 2012; McDonough, 2005; Perna, et al., 2008). Additionally, counselors were often tasked with many administrative duties, as well as testing, which further limited their time with students (Blumberg Corwin, et al., 2004; McDonough, 2005). Similar to McDonough's work $(1997,2005)$, at the collegiate training level, school counselors had been trained as mental health counselors, rather than for the work that transpired in their day-to-day duties. This is a systemic change that could happen that would serve counselors and students better. The counselors felt ill-equipped to do everything they had been tasked with, because of lack of training and also because of their lack of time.

Policy makers need to listen to educators. While some teachers at CHS shared their concerns about students, there was much more time at MCHS for educators to speak to me, and for me to see the negative impacts of policy. Listening to what the practitioners said was much different from what the policymakers were doing. It was heartening to see that the majority of teachers I encountered seemed to have genuine concern for their students and the students' 
learning. These experiences of seeing the practices of educators as so much different from how they are often described, as inadequate and lazy, gave me the hope to re-imagine how teachers can be drawn upon as allies in positive educational change.

\section{The Limitations of Structures}

After spending time in both communities and schools, I learned how limiting structures can be to agency. Even with great initiative, if structures that are supposed to provide access are, in fact, barriers, opportunities for agency is going to be muted. For instance, I saw in this research many instances of structures and institutions intended to provide access to schools and citizens, preventing access to adequate educational tools and work. I encountered schools that do not provide adequate postsecondary planning, a government that does not provide a milieu where jobs are available, nor even basic services for residents.

Change that facilitates shared power and access is challenging within structures that are set up to prevent change. Particularly in West Virginia, where the "fields of power" (Grenfell, 2012), economics and politics, are often corruptly controlled. In West Virginia, industry has an ideological and literal grip on the state economically, politically, and even within the general population (Bell \& York, 2010; Blaacker, 2012). At a broader level, structures of neoliberalism and globalization affect politics in ways that trickle down to education. These include the Koch Brothers' influence with politicians (Opensecrets, 2015) and West Virginia University (Levinthal, 2014), industry influence, and the GOP takeover of West Virginia's statehouse (Kabler, 2015).

I have also learned that despite the best intentions of policymakers, educational policy is often political, changes frequently depending on which party is in control, and, at West Virginia's state level, is often controlled by people given positions due to nepotism and corporate 
bankrolling rather than because of actual qualifications. At the local school level, educators are not pleased with how policy "interferes." Educators in this work found it problematic that policy makers construct policy without knowledge of how things work at the day-to-day level, in the complexity of real school lives and within contexts that are not standardized.

Though educators, from administrators to teachers to counselors, were able to criticize the system that they placed as not helpful, they lacked a critical framework for how to activate and mobilize these criticisms into systemic pushback. While people did name problematic occurrences and even push back on individual instances, these places of agency happened separately and individually, without a concerted effort to look at problems and change more systemically. In a way, the lack of systematic pushback was similar to the problems that disguise the systemic nature of racism; while educators addressed individual acts as unacceptable, they were unable to address the system that allowed these problematic acts to continue to turn up.

Just as faculty, counselors, and schools, found policy problematic, the implementation of policy that focused on the postsecondary transition was problematic. While policy makers discursively position postsecondary preparation and transition policy as doing one thing, the practices I observed at CHS and MCHS, as these policies were enacted were very different. For example, the policy language changes that purport to support college and career readiness have not led to change in practices at the school level (WVDE, 2013a). Importantly, the counselors at MCHS voiced a desire to provide more career and technical pathways in line with policy, but felt unable to do this because of the pushdown of increasingly unrealistic requirements. The rhetoric from state officials, and the national education forum, is that students need to be either college or career ready at graduation (Rosenbaum, 2001). However, in practice, schools are very narrowly focused on supporting the college pathways, despite the changed rhetoric. This push, on paper 
but not in practice, leaves out students who may not want to or cannot go to college from accessing viable career training and paths. Further, these practices serve to prepare those students who do go to college for jobs that do not exist in West Virginia (U.S. Department of Labor, 2013), often leading either to underemployment or leaving the state.

These difficulties are compounded when state leaders say that West Virginia needs a more educated workforce, while they make business and economic moves that (1) limit access to higher education by reducing funding and (2) promote businesses that bring few jobs that require baccalaureate degrees by continuing to focus on industry as what will change the economy of the state. If those in power in the state actually want to see the state at large thrive, then changes need to happen, such as: (1) Changing tax policies that place the burden of public services on the people and draw little from larger businesses and natural resource extraction so that basic services (like education, healthcare, roads) can be funded; and (2) Making sure that students have realistic access to technical education programs.

The policies and practices detailed here best serve and are most adeptly navigated by the most powerful. These practices and policies interrupt people's agency in attempting to build good lives for themselves. As the powerful are unlikely to share their power, these policies indicate the need for local activism to push back against these people and policies so that West Virginia can be a sustainable place and not a place that people abandon (Bryson, 2015).

\section{Local Knowledge for Local Change}

At the local school levels in Covington and Mill County, there were instances of misrecognition that hid the ways that structures are maintained by those in power that serve some better than others. At both schools, the postsecondary transition process was set up to be navigated best by those who had information gained outside of school; this was true for both 
college and technical track students. While both schools provided the most assistance towards attending college, even this facilitation required students to use information that was often not provided to make these transitions happen. When students did not have access to outside information, often through their social networks, these processes were made very difficult, as Fantasia experienced at CHS. At CHS, these processes were often hidden because the students were, by and large, matriculating to college; however, this seemed to have more to do with social class and social networks rather than the school's efforts at facilitating this transition.

In comparison to MCHS, CHS had more visible and accessible information for making the postsecondary transition, as well as more representatives who visited the school, for both technical and college pathways. However, despite these "opportunities," my participants often lacked very important knowledge that would position them as successful in the postsecondary transition. At MCHS the landscape looked slightly different, though the processes limiting knowledge of and facilitating the postsecondary transition were similar, overall. MCHS had fewer "opportunities" for students to come in contact with institutions of higher education and there was little information available for students if they did not directly visit the guidance office. At MCHS and CHS, the students who "slipped through the cracks" were often silenced as their stories went untold. Despite these structural barriers, students showed great agency throughout this process; they were making the postsecondary transition with whatever amount (or lack) of facilitation the structures offered. However, for those students whose backgrounds were less of a match with the structures, they had to exhibit even stronger tenacity, and not necessarily more agency but rather different agency, to make these things happen. 


\section{Future Directions}

Though my goals for this project were multi-layered, I want to bring the structural changes I have suggested back to my desire for activism with locals and listening more deeply. Even though the participants showed incredible agency, discourses for the postsecondary transition are very limited, particularly for those without prior knowledge of making the transition to their chosen pathway (i.e. college, technical school, direct work). Not only are these discourses limited for students and families, but because of standardization and the pushdown of accountability, educators were often unable to fully engage hoped for possibilities in facilitating these pathways for students. The voices of students, parents, and local educators speak to the need to be heard by those in more powerful positions.

From my research and learning within the activist community during the Appalachian Studies Association conferences, it seems that the most effective activism comes from below. When activism comes from below, from a grass-roots level, it is the regular people's agenda that will hopefully benefit regular people. When initiatives start from the ground up, people are likely to have a stake in the outcomes and be vested in seeing work succeed.

Despite the dominance of the narratives, and lived realities, that paint the choice for life after high school as stay and struggle or leave and not struggle, there are alternatives. For instance, schools and communities can talk about community, school, and student struggles and successes openly, considering options in the area for students who may want to go to college and remain or return home. These options work to push against middleclass standards of success that can be limiting for those from lower classes (Brantlinger, 2003; Delpit, 2006; Graue \& Sherfinski, 2011; Howley \& Howley, 2010). Further, developing options locally for students who would like to remain is similar to the very successful work done in Wright's (2012) work 
where a community college paired with the local town to construct programming around the town's needs. This would be an easy segue for students to be taught about entrepreneurship to build growth locally, which could connect with current inchoate work in West Virginia. There is a current push from young people in West Virginia and West Virginian expats in other states who want to come back to build, from the ground up, sustainable communities. There are multiple groups working towards these goals: Generation West Virginia (see www.GenerationWV.org), Create West Virginia (www.CreateWV.org), and the West Virginia Community Development Hub (www.WVHub.org) and I hope to work with these groups on bringing positive change to West Virginia after this project.

\section{Limitations}

While, overall, the stories of the participants and schools are compelling and show the spaces where their stories can elaborate on educational trends, it is important to discuss some limitations. Many of these limitations are related to the data collection process and stem from a lack of resources to be able to more robustly support the project, as well as the scheduling and access issues caused by the winter weather.

First, I would recommend, next time, a more in-depth method for recruiting and screening students. Initially I had intended to do a small interview with a larger pool of potential participants and then choose those who fit the study best based on those interactions. However, we decided to forego the interviews and do a brief chat with a few students, which resulted in participants who did fit well with the purposes of the study, although the interviews would have been preferable. Part of the challenge in determining students who fit the criteria was that at CHS the information the guidance counselor shared about students was somewhat inaccurate and a brief interview may have helped to uncover this information earlier. 
Related to this, I would have liked to include a student from each school who was not on the college pathway. I had initially hoped for this at the beginning of the study and shared that with the guidance counselors at both schools when recruiting students. However, the counselors found it difficult to think of students they knew well to suggest who were not on the college pathway; which is telling in itself, indicating the lack of contact they had with students not on the college pathway. Also, it would have been interesting to include a powerful, popular student from each school to capture that viewpoint of the school dynamics. I did not have a student from the power group in either school.

Secondly, all of my participants at CHS were outsiders to the community of Covington. Because the majority group in Covington seemed so powerful and so separate from those who did not belong, it would have been helpful to have a student from that group to tell that portion of the story. In preparation for the project I did not realize there would be such a distance between groups at CHS. As such, this project does not reflect the full dynamics of belonging in Covington.

Thirdly, I would have liked to be able to offer a stipend or some small remuneration to students and families to make participation more enticing. This was particularly true for parents, as at times it was difficult to arrange meetings for interviews and a stipend may have helped in making their time with me more appealing.

Fourthly, I would have liked to better plan and time observations. Because of the weather cancellations, delays, and my other commitments, I often missed classroom instruction time that I would have liked to observe. For example, I often ended up in classes on test days or independent work days, and these times did not give great insight into the class dynamics. 
Additionally, I was not able to observe the AP classes at CHS until April, by which time they had transitioned entirely to self-study and test preparation.

In addition, I would have made the details of what I was looking for in the social class status of the families more clear, particularly at CHS. At CHS the actual class status of the students was fairly different from what the guidance counselor had perceived. For example, she had indicated that Gregg would be a middle income student and Fantasia would fit the low income student profile; however these were reversed as Fantasia's family had a significantly higher income than Gregg's. It seemed that the counselor had used appearance as a large factor in figuring out social class, particularly as she did not have access to free and reduced lunch status; according to appearances, how she positioned Gregg and Fantasia would have been more accurate. However, this deeper information still may not have been available as the counselor seemed to only know well the students who had been office aides. At some point, all three of my participants had been office aides, which is how the counselor knew about their stories.

Also related to social class, I would have constructed more nuanced ways to involve parents in conversations about social class. I eventually stopped asking directly about social class because people were so reluctant to talk about it openly. A more nuanced approach to addressing this sensitive topic would have been helpful to have a more authentic understanding of family's views of social class. However, through the context of other aspects of the interviews, I did gain some insight into social class.

Contrastingly, being more explicit with the students about what I was working on across the project, reminding them of my goals and intentions, seems like it would have been helpful. For example, one day while helping Fantasia with administrative tasks, I shared that I wanted to use this information to help people progress better through the postsecondary process and she 
elaborated on her view of the process and how it could be made better. While I told the students at the beginning of the project what my goals were, we did not directly re-visit these topics across the study. It seems like, in some cases, if I would have reiterated these goals more in conversations I may have gotten more information. In this case, being direct may have been more fruitful.

Lastly, perhaps at MCHS the "culture of warmth" was so visible because the students were on the college path and had there been a participant who was on the non-college track, perhaps they would not have been as warmly supported. However, there was evidence that students not on the college track were supported and valued, particularly by the Agriculture teacher. This evidence was supported by the fact that students often chose to forego vocational training at TCTS, which could have placed them very well career-wise, so they would not miss FFA classes.

\section{Concluding Remarks}

At a basic level, I want this work to make systems of inequality less damaging. To these ends, it is important for me, professionally and personally, to listen to the voices of those who are often silenced. As I listened to the stories of students and families, and saw their struggles and triumphs, it made clear that the present system is not equitably serving all students. This became even clearer as I learned about structural level barriers that are presented as opportunities for all, like the PROMISE Scholarship and other state educational policies.

Seeing the "possibilities" for pathways to the postsecondary transition, like the PROMISE Scholarship, that more closely resemble optical illusions in their limited access makes it essential to listen to the stories of those who are denied these possibilities. These illusions necessitate identifying who actually has access, which means considering the positionality and 
power of the students and families as individuals and groups within classed, raced, gendered, and placed (Appalachian) spaces. Additionally, the position of the school as a powerful institution that is charged with successfully transitioning students to adequate postsecondary positions, but that yet does not support the students and families' needs to be addressed. This work provides the material from which I plan to collaborate with stakeholders on a framework that provides guidance for educators and policymakers on this important topic. 


\section{References}

Ali, S. R., \& Saunders, J. L. (2006). College expectations of rural Appalachian youth: An exploration of social cognitive career theory factors. Career Development Quarterly, $55(1), 38-51$.

Ali, S. R., \& Saunders, J. L. (2009). The career aspirations of rural Appalachian high school students. Journal of Career Assessment, 17(2), 172-188.

American Federation of Teachers. (2015). AFT-West Virginia 2015 Legislative Update. Retrieved November 5, 2015.

Anglin, M. K. (2002). Lessons from Appalachia in the 20th century: Poverty, power, and the "grassroots." American Anthropologist, 104(2), 565-582.

Anglin, M. K. (2004). Erasures of the past: Culture, power, and heterogeneity in Appalachia. Journal of Appalachian Studies, 10(1-2), 73-84.

Anyon, J. (1981). Social class and school knowledge. Curriculum Inquiry, 11(1), 3-42.

Appalachian Regional Commission. (2013). Distressed designation and county economic status classification system, FY 2007-FY 2014. Retrieved from www.arc.gov

Apple, M. and A. Oliver (1996). Becoming right: Education and the formation of conservative movements. Cultural Politics and Education (42-67). M. Apple (Ed.). New York, NY: Teachers College Press.

Associated Press (2013). West Virginia Higher Ed Panel approves tuition increases. Diverse Issues in Higher Education.

Atkinson, W. (2010). Phenomenological additions to the Bourdieusian toolbox: Two problems for Bourdieu, two solutions from Schutz. Sociological Theory, 28(1), 1-19. 
Atkinson, W. (2011). From sociological fictions to social fictions: Some Bourdieusian reflections on the concepts of 'institutional habitus' and 'family habitus'. British Journal of Sociology of Education, 32(3), 331-347.

Auerbach, S. (2007). From moral supporters to struggling advocates: Reconceptualizing parent roles in education through the experience of working-class families of color. Urban Education, 42, 250-283.

Back, M. D., Stopfer, J., Vazire, S., Gaddis, S., Schmukle, S., Egloff, B., \& Gosling, S. (2010). Facebook profiles reflect actual personality, not self-idealization. Psychological Science, 20, 1-3.

Baldwin, F. D. ( 2000). The family-school connection. Appalachia: Journal of the Appalachian Regional Commission, 33(January-April), 2-7.

Batteau, A. W. (1990). The Invention of Appalachia. Tucson, AZ: The University of Arizona Press.

Bell, S. E., \& York, R. (2010). Community economic identity:The coal industry and ideology construction in West Virginia. Rural Sociology, 75(1), 111-143.

Berger, L. (2001). Inside out: Narrative autoethnography as a path toward rapport. Qualitative Inquiry, 7(4), 504-518.

Bickel, R., \& McDonough, M. (1997). Opportunity, community, and reckless lives: Social distress among adolescents in West Virginia. Journal of Social Distress and the Homeless, 6(1), 29-44.

Billings, D. B., Norman, G., \& Ledford, K. (Eds.). (1999). Confronting Appalachian stereotypes: Back talk from an American region. Lexington, KY: The University of Kentucky Press. 
Blaacker, D., Woods, J., \& Oliver, C. (2012). How big is Big Coal? Public perceptions of the coal industry's economic impact in West Virginia. Organization and Environment, 25, $385-401$.

Boettner, T. (2013a). Growing Working-class Economic Insecurity at the Heart of West Virginia Woes. Charleston, WV: West Virginia Center on Budget and Policy.

Boettner, T. (2013b). Why don't business tax cuts pay off? Charleston, WV: West Virginia Center on Budget and Policy.

Bomer, R., Dworin, J. E., May, L., \& Semingson, P. (2008). Miseducating teachers about the poor: A critical analysis of Ruby Payne's claims about poverty. Teachers College Record, $110(12), 2497-2531$.

Bond, A. (2013). The energy state: Mountain state leads in advanced energy research and resources. Edge, 2, 30-34.

Bourdieu, P. (1977a). Cultural reproduction and social reproduction. In J. H. Karabel (Ed.), Power and ideology in education (487-511). New York, NY: Oxford University Press.

Bourdieu, P. (1977b). Outline of a Theory of Practice. Cambridge, UK: Cambridge University Press.

Bourdieu, P. (1984). Distinction: A social critique of the judgment of taste (R. Nice, Trans.). Cambridge, MA: Harvard University Press.

Bourdieu, P. (2000). Pascalian meditations. Stanford, CA: Stanford University Press.

Bourdieu, P. (2011). The forms of capital. In A. R. Sadovnik (Ed.), Sociology of Education: A Critical Reader (83-96). New York, NY: Routledge: Taylor \& Francis Group.

Bourdieu, P., \& Passeron, J. (1990). Reproduction in education, society and culture. London: Sage Publications. 
Bradner, A. (2008). Teaching modernity in Appalachia. Teaching Philosophy, 31(3), 229-247.

Brantlinger, E. (2003). Dividing classes: How the middleclassnegotiates and rationalizes school advanatage. New York, NY: RoutledgeFalmer.

Brown, E. R. (2010). A critical perspective on human development: Implications for adolescence, classroom practice, and middle school policy. In K. Lee \& M. Vagle (Eds.), Developmentalism in Early Childhood and Middle Grades Education: Critical conversations on readiness and responsiveness (183-207). New York, NY: Palgrave Macmillan.

Brown, R., Copeland, W. E., Costello, E. J., Erkanli, A., \& Worthman, C. M. (2009). Family and community influences on educational outcomes among Appalachian youth. Journal of Community Psychology, 37(7), 795-808.

Bryan, E., \& Simmons, L. A. (2009). Family involvement: Impacts on post-secondary educational success for first-generation Appalachian college students. Journal of College Student Development, 50(4), 391-406.

Bryson, K. (2015). A Regional Rhetoric for Activism in Appalachia: The West Virginia Water Crisis. Paper presented at the Appalachian Studies Association Annual Conference. Johnson City, TN.

Buras, K. L., Randels, J., Salaam, K. Y., \& SAC. (2010). Pedagogy and policy in the privatized city: Stories of dispossession and defiance from New Orleans. New York, NY: Teachers College Press.

Burnell, B. (2003). The "real world" aspirations of work-bound rural Students. Journal of Research in Rural Education, 18(2), 104-113. 
Burns, S. Scott, S., \& Thompson, D. (2006). Family and community. Encyclopedia of Appalachia (149-154). Abramson \& Haskell (Eds.). Knoxville, TN: The University of Tennessee Press.

Cabrera, A. F., \& La Nasa, S. M. (2001). On the path to college: Three critical tasks facing America's disadvantaged. Research in Higher Education, 42(2), 119-149.

Calabrese Barton, A. C., Drake, C., Perez, J. G., St. Louis, K., \& George, M. (2004). Ecologies of parental engagement in urban education. Educational Researcher, 33(4), 3-12.

Carr, P. J., \& Kefalas, M. J. (2009). Hollowing out the middle: The rural brain drain and what it means for America. Boston, MA: Beacon Press Books.

Carspecken, P. F. (1996). Critical ethnography in educational research. New York, NY: Routledge.

Cassell, J. A., \& Nelson, T. (2013). Exposing the effects of the "Invisible Hand" of the neoliberal agenda on institutionalized education and the process of sociocultural reproduction. Interchange, 43(3), 245-264.

Chambers, E. (2000). Applied ethnography. In N. K. Denzin \& Y. S. Lincoln (Eds.), Handbook of qualitative research (851-869). Thousand Oaks, CA: Sage Publications.

Chenoweth, E., \& Galliher, R. V. (2004). Factors influencing college aspirations of rural West Virginia high school students. Journal of Research in Rural Education, 19(2), 1-14. College Foundation of West Virginia. (2012). Homepage. Retrieved from www.cfwv.com College Foundation of West Virginia. (2013a). Homepage. Retrieved from www.cfwv.com College Foundation of West Virginia. (2013b). PROMISE Scholarship program eligibility requirements. Retrieved from www.cfwv.com 
Conklin, H. G., \& Lee, K. (2010). Walking the borderland. In K. Lee \& M. Vagle (Eds.), Developmentalism in Early Childhood and Middle Grades Education: Critical conversations on readiness and responsiveness (233-254). New York, NY: Palgrave Macmillan.

Cooper, C. W. (2009). Parent involvement, African American mothers, and the politics of educational care. Equity and Excellence in Education, 42(4), 379-394.

Cornwell, C., \& Mustard, D. B. (2007). Merit-based college scholarships and car sales. Education Finance and Policy, 53(4), 133-151.

Blumberg Corwin, Z., Venegas, K. M., Maya Oliverez, P., \& Colyar, J. E. (2004). School counsel: How appropriate guidance affects educational equity. Urban Education, 39(4), $442-457$.

Crossley, N. (2012). Social class. In M. Grenfell (Ed.), Pierre Bourdieu: Key concepts (85-97). Durham, UK: Acumen Publishing Limited.

Cunningham, R. (2012). The valley so low: Kristeva, Frued, Mori, and Appalachian uncanniness. Paper presented at the Appalachian Studies Association, Indiana, PA.

Deer, C. (2012). Doxa. In M. Grenfell (Ed.), Pierre Bourdieu: Key concepts (14-125). Durham, UK: Acumen Publishing Limited.

Delpit, L. (2006). Other people's children: Cultural conflict in the classroom. New York, NY: The New York Press.

Deyoung, A. J. (2007). Constructing and staffing the cultural bridge: The school as change agent in rural Appalachia. In P. J. Obermiller \& M. E. Maloney (Eds.), Appalachia: Social context past and present (Vol. 5, 157-172). Dubuque, IA: Kendall/Hunt Publishing. Disch, L. (2012). The Tea Party: A "White Citizenship" movement? STEEP (133-151). In 
Rosenthal \& Trost (Eds.). Berkley, Los Angeles: University of California Press.

Doucet, F. (2011). (Re)Constructing home and school: Immigrant parents, agency, and the (un)desirability of bridging multiple worlds. Teachers College Record, 113(2), 27052738.

Doucet, F., \& Vukovic, R. (2011). R-E-S-P-E-C-T: Find out what it means to immigrant families. Teachers College Record.

Downey, L., \& Anyaegbunam, C. (2010). Your lives through your eyes: Rural Appalachian youth identity community needs and assets through the use of photovoice. Journal of Appalachian Studies, 16(1-2), 42-60.

Edvantia, Inc. (2011). A Chronicle of West Virginia's Global21 Initiative: 2004-2010. Charleston, WV: West Virginia Department of Education.

Ellis, C. (1999). Heartful autoethnography. Qualitative Health Research, 9(5), 669-683.

Ellis, C. (2004). The ethnographic I: A methodological novel about autoethnography. Walnut Creek, CA: AltaMira.

Emerson, R. M., Fretz, R. I., \& Shaw, L. L. (1995). Writing ethnographic fieldnotes. Chicago, IL: The University of Chicago Press.

Engberg, M. E., \& Wolniak, G. C. (2010). Examining the effects of high school contexts on Postsecondary Enrollment. Research in Higher Education, 51, 132-152.

Epstein, J. L. (2007). Improving family and community involvement in secondary schools. Principal Leadership, 16-22.

Ewald, W., \& Lightfoot, A. (2001). I wanna take me a picture. Boston, MA: Beacon Press. 
Fann, A., McClafferty Jarsky, K., \& McDonough, P. M. (2009). Parent involvement in the college planning process: A case study of P-20 collaboration. Journal of Hispanic Higher Education, 8, 374-393.

Farnell, B. (2000). Getting out of the habitus: An alternative model of dynamically embodied social action. The Journal of the Royal Anthropological Institute, 6(3), 397-418.

Galotti, K. M., \& Mark, M. C. (1994). How do high school students structure an important life decision? A short-term longitudinal study of the college decision-making process. Research in Higher Education, 35(5), 589-607.

Gonzalez, N., Moll, L. C., \& Amanti, C. (Eds.). (2005). Funds of knowledge: Theorizing practices in households, communities, and classrooms. Mawah, NJ: Lawrence Erlbaum Associates, Inc.

Gorski, P. (2006). The classist underpinnings of Ruby Payne's framework. Teachers College Record.

Gorski, P. (2008). Peddiling poverty for profit: Elements of oppression in Ruby Payne's framework. Equity and Excellence in Education, 41(1), 130-148.

Graue, M. E., Kroeger, J., \& Prager, D. (2001). A Bakhtinian analysis of particular home-school relations. American Educational Research Journal, 38(3), 467-498.

Graue, M. E., \& Sherfinski, M. (2011). The view from the lighted schoolhouse: Conceptualizing home-school relations wtihin a class size reduction reform. American Journal of Education, 117(2), 267-297.

Grenfell, M. (Ed.). (2012). Pierre Bourdieu: Key concepts (2 ed.). Durham, UK: Acumen Publishing Limited. 
Groenke, S. L., \& Nespor, J. (2010). "The drama of their daily lives": Racist language and struggles over the local in a rural high school. In Schafft \& Jackson (Eds.), Rural education in the twenty-first century (51-71). University Park, PA: The Pennsylvania State University Press.

Gutmann, A. (1987). Democratic education. Princeton, NJ: Princeton University Press.

Hallinan, M. T., \& Oakes, J. (2011). Tracking and more than misplaced technology. In Sadovnik (Ed.), Sociology of education: A critical Reader (347-358). New York, NY: Routledge.

Hammersley, M., \& Atkinson, P. (1995). Ethnography: Principles in practice. London: Routledge.

Hazen, K., P. Butcher, \& King, A. (2010). Unvernacular Appalachia: an empirical perspective on West Virginia dialect variation. English Today, 26(4), 13-22.

Headley, J. (2012). Dear West Virginia. The Revivalist: Word from the Appalachian South. Retrieved from http://therevivalist.info/dear-west-virginia/

Hektner, J. M. (1995). When moving up implies moving out: Rural adolescent conflict in the transition to adulthood. Journal of Research in Rural Education, 11(1), 3-14.

Holland, D., Lachicotte Jr., W., Skinner, D., \& Cain. (1998). Identity and agency in cultural worlds. Cambridge, MA: Harvard University Press.

Holt, N. L. (2003). Representation, legitimation, and autoethnography: An autoethnographic writing story. International Journal of Qualitative Methods, 2(1), 18-28.

hooks, b. (2000). Where we stand: Class matters. Psychology Press.

Hossler, D., \& Gallagher, K. S. (1987). Studying student college choice: A three-phase model and the implications for policymakers. College and University, 62(3), 207-221. 
Hossler, D., \& Stage, F. (1992). Family and high school experience influences on the postsecondary educational plans of ninth-grade students. American Educational Research Journal, 29(2), 425-451.

Howley, C. (2006). Purpose and place: Schooling and Appalachian residence. Journal of Appalachian Studies, 12(1), 58-78.

Howley, C. B., \& Howley, A. (2010). Poverty and school achievement in rural communities: A social-class interpretation. In Schafft \& Jackson (Eds.), Rural education in the twentyfirst century ( 34-50). University Park, PA: The Pennsylvania State University Press.

Isenberg, E. J. (2007) What Have We Learned About Homeschooling? Peabody Journal of Education, 82(2-3), 387-409.

Jones, A. (2013). Alabama Republican wants to ban Toni Morrison's The Bluest Eye from schools. The Atlantic Wire. Retrieved November 1, 2015.

Jones, C. (2013). Writing right: A conversation about the demands of Standard English in Composition. Paper presented at the Appalachian Studies Association Conference, Boone, NC

Kabler, P. (2015) GOP takeover to overshadow Tomblin Speech. Charleston Gazette. Charleston, WV.

Kahn, S., \& Minnick, E. (2005). Privatizing against equality. The fox in the henhouse: How privatization threatens democracy ( 127-137). Williston, VT: Berrett-Koehler Publishers.

Kay, T. (2011, Fall). Great Kanawha Textbook War. Goldenseal, 34-41.

Keefe, S. E. (1998). Appalachian Americans: The formation of "reluctant" ethnics. In G. R. Campbell (Ed.), Many Americas: Critical perspectives on race, racism, and ethnicity (129-153). Dubuque, IA: Kendall/Hunt. 
Keefe, S. (2005). Appalachian cultural competency: A guide for medical, mental health, and social service professionals. Keefe (Ed.). Knoxville, TN: The University of Tennessee Press.

Kersey, L. (2012). West Virginians are 'hardly working'. The Charleston Gazette.

Klasik, D. (2012). The college application gauntlet: A systematic analysis of the steps to fouryear college enrollment. Research in Higher Education, 53, 506-549.

Kvale, S., \& Brinkmann, S. (2009). Interviews: Learning the craft of qualitative research interviewing. Thousand Oaks, CA: Sage.

Lamont, M. (1992). Money, morals, and manners: The culture of the French and the American upper middleclass. University of Chicago Press.

Latimer, M. (2006). "We have never asked for help that was not desperately needed": Patterns of stigma management among former welfare recipients in West Virginia. Journal of Appalachian Studies, 12(2), 88-109.

Lauen, D. (2011). False promises: The school choice provisions in No Child Left Behind. In A. R. Sadovnik. (Ed.), Sociology of education: A critical reader (487-512). New York, NY: Routledge.

Lareau, A. (2003). Unequal childhoods: Class, race, and family life. Berkley and Los Angeles, CA: University of California Press.

Lee, K., \& Vagle, M. (2010a). General introduction: Developmentalism and the need for critical conversations within and across the fields. In Lee \& Vagle (Eds.), Developmentalism in early childhood and middle grades education: Critical conversations on readiness and responsiveness (1-10). New York, NY: Palgrave Macmillan. 
Lee, K., \& Vagle, M. (Eds.). (2010b). Developmentalism in early childhood and middle grades education: Critical conversations on readiness and responsiveness. New York, NY: Palgrave Macmillan.

Lesko, N. (2012a). Introduction: Troubling teenagers. Act your age! A cultural construction of adolescence (1-15). New York, NY: Routledge.

Lesko, N. (2012b). Time matters in adolescence. Act your age! A cultural construction of adolescence (91-115). New York, NY: Routledge.

Levinthal, D. (2014). Inside the Koch brothers' campus crusade. Center for Public Integrity, Washington, DC. Retrieved November 5, 2015.

Lewis, R. L. (1999). Beyond isolation and homogeneity: Diversity and the history of Appalachia. Confronting Appalachian stereotypes: Back talk from an American region (21-43). Billings, Norman \& Ledford (Eds.). Lexington, KY: The University of Kentucky Press.

Lightfoot, D. (2001). "Some parents just don't care:" Decoding the meanings of parental involvement in urban schools. Urban Education, 39, 91-107.

Locklear, E. A. (2011). Negotiating a perilous empowerment: Appalachian women's literacies.Athens, $\mathrm{OH}$ : Ohio Unviersity Press.

Lowndes, J. (2012). The past and future of race in the Tea Party movement. STEEP (21-43). Rosenthal \& Trost (Eds.). Berkley, CA: University of California Press.

Ludke, R., Obermiller, P., \& Rademacher, E. W. (2012). Demographic change in Appalachia: A tentative analysis. Journal of Appalachian Studies, 18(1-2), 48-92.

Luisa Méndez L, M. (2008). Middleclass identities in a neoliberal age: tensions between contested authenticities. The Sociological Review, 56(2), 220-237. 
Marcus, G. E. (1995). Ethnography in/of the world system: The emergence of multi-sited ethnography. Annual Review of Anthropology, 24, 95-117.

Mason, C. (2009). Reading Appalachia from left to right: Conservatives and the 1974 Kanawha county textbook controversy. Ithaca, NY, Cornell University Press.

Maton, K. (2012). Habitus. In Grenfell (Ed.), Pierre Bourdieu: Key concepts (48-64). Durham, UK: Acumen Publishing Limited.

McCarthy Brown, K. (1991). Mama Lola: A vodou priestess in Brooklyn. Berkeley, CA: Univeristy of California Press.

McDonough, P. (1997). Choosing colleges: How social class and schools structure opportunity. Albany, NY: State University of New York Press.

McDonough, P. (2005). Counseling and college counseling in America's high schools. Alexandria, VA: National Association for College Admission Counseling.

McDonough, P., Gildersleeve, R. E., \& McClafferty Jarsky, K. (2010). The golden cage of rural college access: How higher education can respond to the rural life. In Schafft \& Jackson (Eds.), Rural education for the 21st century: Identity, place, and community in a globalizing world (191-209). University Park, PA: The Pennsylvania State University Press.

McMahan, I. (2009). Adolescence. Boston, MA, Pearson.

Marcellus Drilling News. (2015). WV Gov Tomblin continues to cheerlead for Wood Co. cracker plant [sic]. Retrieved November 5, 2015.

Méndez, M. L. (2008). Middle class identities in a neoliberal age: Tensions between contested authenticities. The Sociological Review, 56(2), 220-237. 
Meyer, M. (2013). Protecting kids against 'toxic stress.' The Wheeling Intelligencer/New Register.

Miller, D. (2012). Johnson Newlon Camden, The West Virginia Encyclopedia. Charleston, WV: West Virginia Humanities Council. Retrieved from http://www.wvencyclopedia.org/articles/815

Miller, T. (2013). Legislators hear about poverty's impact on West Virginia children. The Herald-Dispatch. Huntington, WV.

Moore, R. (2012). Capital. In Grenfell (Ed.), Pierre Bourdieu: Key concepts (98-113). Durham, UK: Acumen Publishing Limited.

National Center for Children in Poverty. (2013). West Virginia demographics of poor children. New York, NY.

National Center for Education Statistics. (2012). The Condition of Education 2012. Washington, DC.

Newbury, J., \& Hoskins, M. L. (2008). A meaningful method: Research with adolescent girls who use crystal methamphetamine. Child Youth Care Forum, 37, 227-240.

Noe, K. W. (1999). Deadened Color and Colder Horror: Rebecca Harding Davis and the Myth of Unionist Appalachia. Confronting Appalachian Stereotypes: Backtalk from an American Region. Billings, Norman \& Ledford (Eds.). Lexington, KY, The University of Kentucky Press: 67-97.

O'Leary, S. (2013). With 3.8 million job openings last month, is there a skills gap? Charleston, WV: West Virginia Center on Budget and Policy.

O'Leary, S., \& Boettner, T. (2012). The State of Working West Virginia. Charleston, WV: West Virginia Center on Budget and Policy. 
Oakes, J., \& Guiton, G. (1995). Matchmaking: The dynamics of high school tracking decisions. American Educational Research Journal, 32(1), 3-33.

Oberhauser, A. (2005). Scaling gender and diverse economies: Perspectives from Appalachia and South Africa. Antipode, 37(5), 863-874.

Obermiller, P. (1977). Appalachians as an urban ethnic group: Romanticism, renaissance, or revolution? Appalachian Journal, 5(1), 145-152.

Obermiller, P. J., \& Maloney, M. E. (2011). The uses and misuses of Appalachian culture. Urban Appalachian Council Working Paper. Cincinatti, OH. Urban Appalachian Council.

Obermiller, P. J., \& Maloney, M. E. (2007). “We ain’t a goin’ back”: A retrospective look at urban Appalachians in greater Cincinnati. Appalachia: Social context past and present. Obermiller \& Maloney (Eds.). Dubuque, IA: Kendall/Hunt Publishing Company.

Office of the Governor. (2015). Governor Tomblin announces reduction in Fiscal 2016 budget. Retrieved November 5, 2015.

Opensecrets.org. (2015). Koch Industries, West Virginia Recipients. Retrieved November 5, 2015.

Packard, B., Ellison, K., \& Sequenzia, M. (2004). Show and tell: Photo-interviews with urban adolescent girls. International Journal of Education and the Arts, 5(3), 1-19.

Parker, L. (2014). A century of controversy, accidents in West Virginia's chemical valley in lead up to spill. National Geographic. Retrieved January 16, 2015.

Patton, M. Q. (2002). Qualitative research and evaluation methods (3 ed.). Thousand Oaks, CA: Sage. 
Perna, L.W., Rowan-Kenyon, H. T., Thomas, S. L., Bell, A., Anderson, R., \& Li, C. (2008). The role of college counseling in shaping college opportunity: Variations across high schools. The Review of Higher Education, 31(2), 131-159.

Plank, S. B., \& Jordan, W. J. (2001). Effects of information, guidance, and actions on postsecondary destinations: A study of talent loss. American Educational Research Journal, 38(4), 947-979.

Public Works LLC. (2012). Education efficiency audit of West Virginia's primary and secondary education system. West Virginia Department of Education.

Rasmussen, B. (1996). The politics of property tax in West Virginia. Journal of Appalachian Studies, 2(1), 141-147.

Reay, D. (2005). Beyond consciousness? The psychic landscape of social class. Sociology, 39(5), 911-928.

Reay, D. (2004). 'It's all becoming a habitus': Beyond the habitual use of habitus in educational research. British Journal of Sociology of Education, 25(4), 431-444.

Reimer, V. (2014). Who is in charge of the family? Religious mothering, neoliberalism, and REAL women of Canada. Mothering in the Age of Neoliberalism. M. V. Giles. Bradford, ON: Demeter.

Rice, Bill. (2011). Mountain State Forest Festival. Goldenseal, 37(3), 9-19.

Rios-Aguilar, C., Kiyama, J. M., Gravitt, M., \& Moll, L. C. (2011). Funds of knowledge for the poor and capital for the rich? A capital approach to examining funds of knowledge. Theory and Research in Edcuation, 9(2), 163-184.

Rist, R. (2000). Student social class and teacher expectations: The self-fulfilling prophecy. Harvard Educational Review, 40(3), 411-450. 
Rosenbaum, J. E. (2001). Beyond college for all: Career paths for the forgotten half. New York, NY: Russell Sage Foundation.

Rosenbaum, J. E. (2011). The complexities of college for all: Beyond fairy-tale dreams. Sociology of Education, 84(2), 113-117.

Rosenbaum, J. E., Muller, S. R., \& Krei, M. S. (1996). Gatekeeping in an era of more open gates: High school counselors' views of their influence on students' college plans. American Journal of Education, 104(4), 257-279.

Rosenberg, A. (2013). The most disturbing argument in the attempt to ban The Bluest Eye from Alabama high schools. ThinkProgress.org. Retrieved October, 8, 2015.

Rosenthal, L., \& Trost, C. (2012). STEEP: The precipitous rise of the Tea Party. Berkley, CA: University of California Press.

Rowe, W., Bennett, S. K., \& Atkinson, D. R. (1994). White racial identity models: A critique and alternative proposal. The Counseling Psychologist, 22, 129-146.

Rubin, B. C. (2003). Unpacking detracking:When progressive pedagogy meets students' social worlds. American Educational Research Journal, 40(2), 539-573.

Sayer, A. (2005). Class, moral worth and recognition. Sociology, 39(5), 947-963.

Schafft, K. A., \& Jackson, A. Y. (Eds.). (2010). Rural education in the twenty-first century. University Park, PA: The Pennsylvania State University Press.

Schnee, E., \& Bose, E. (2010). Parents don't do nothing: Reconceptualizing parental null actions as agency. The School Community Journal, 20(2), 91-114.

Schubert, J. D. (2012). Suffering/Symbolic violence. In Grenfell (Ed.), Pierre Bourdieu: Key concepts (179-212). Durham, UK: Acumen Publishing Limited. 
Schwartzman, G. (2015). Where Appalachia went right: Pro-Coal Politics in the Era of Climate Change. Paper presented at the Appalachian Studies Association Annual Conference, Johnson City, TN.

Scott-Clayton, J. (2011). On money and motivation: A quasi-experimental analysis of financial incentives for college achievement. Journal of Human Resources, 46(3), 614-646.

Shelby, A. (1999). The "R" word: What's so funny (and not so funny) about redneck jokes. In Billings, Norman \& Ledford (Eds.), Confronting Appalachian stereotypes: Back talk from an American region (153-160). Lexington, KY: The University of Kentucky Press.

Slocum, A., \& Weekley, B. S. (2013). From where I stand: Rural Appalachian adolescents claim epistemic privilege. Paper presented at the Appalachian Studies Association Conference, Boone, NC.

Smith, B. E., Fisher, S., Obermiller, P., Whisnant, D., Satterwhite, E., \& Cunningham, R. (2010). Appalachian identity: A roundtable discussion. Appalachian Journal, 38(1), 56-76.

Smith, C. (2005). Epistomological intimacy: A move to autoethnography. International Journal of Qualitative Methods, 4(2), 1-7.

Special, S. (2015). Promise Scholars more likely to come from wealthy families. Charleston Gazette-Mail: Charleston, WV. Retrieved on November 27, 2015.

Stanley, T. (2012). The Poco Field: An American story of place. Urbana, IL: University of Illinois Press.

Stephan, J. L. (2013). Social capital and the college enrollment process: How can a school program make a difference. Teachers College Record, 115, 1-39.

Stephan, J. L., Rosenbaum, J. E., \& Person, A. E. (2009). Stratification in college entry and completion. Social Science Research, 38, 572-593. 
Tedlock, B. (2005). The observation of participation and the emergence of public ethnography. In Denzin \& Lincoln (Eds.), Handbook of qualitative methods (467-481). Thousand Oaks, CA: Sage Publications.

Terman, A. (2015). Community and Mobility Working Together: The New Mobilities Paradigm and Young Adults in Appalachia. Paper presented at the Appalachian Studies Association Annual Conference, Johnson City, TN.

Theobald, P. \& K. Wood (2010). Learning to be rural: Identity lessons from history, schooling, and the U.S. corporate media. Rural education in the twenty-first century (1733). Schafft \& Jackson (Eds.). University Park, PA: The Pennsylvania State University Press.

Thompson, P. (2012). Field. In Grenfell (Ed.), Pierre Bourdieu: Key concepts (65-78). Durham, UK: Acumen Publishing Limited.

Tinnell, S. C. (2013). Francis H. Pierpont father of West Virginia. Goldenseal, 39, 24-25.

Towers, G. (2005). West Virginia’s lost youth: Appalachian stereotypes and residential preferences. The Journal of Geography, 104(2), 74-84.

Turley, R. N. L. (2006). When parents want children to stay home for college. Research in Higher Education, 47(7), 823-846.

Tveit, A. D. (2009). A parental voice: Parents as equal and dependent - rhetoric about parents, teachers, and their conversations. Educational Review, 61(3), 289-300.

United States Census Bureau. (2010). 2006-2010 American Community Survey West Virginia. United States Department of Education. (2013). Race to the Top Fund. 2013. Retrieved from http://www2.ed.gov/programs/racetothetop/index.html 
United States Department of Labor (2013). Occupations with the most openings: West Virginia. Retrieved from www.careerinfonet.org

Vagle, M., \& Parks, A. N. (2010). A schismatic family and a gated community? In Lee \& Vagle (Eds.), Developmentalism in early childhood and middle grades education: Critical conversations on readiness and responsiveness (213-232). New York, NY: Palgrave Macmillan.

Wall, S. (2006). An autoethnography on learning about autoethnography. International Journal of Qualitative Methods, 5(2), 146-160.

Wall, S. (2008). Easier said than done: Writing an autoethnography. International Journal of Qualitative Methods, 7(1), 38-53.

Wallace, L. A., \& DieKroger, D. K. (2000). "The ABCs in Appalachia": A descriptive view of perceptions of higher education in Appalachian culture. Paper presented at the Annual Conference of the Women of Appalachia, Zanesville, $\mathrm{OH}$.

Webster, L., \& Mertova, P. (2007). Using narrative inquiry as a research method. New York, NY: Routledge.

Werner, O., \& Schoepfle, G. M. (1987). Systematic fieldwork: Foundations of ethnography and interviewing Newbury Park, CA: Sage.

West Virginia Department of Education. (2013). Educate West Virginia Overview. Retrieved from http://wvde.state.wv.us/educatewv/overview.html

West Virginia Department of Education. (2013). State Board of Education Members: Gayle Manchin. Retrieved from http://wvde.state.wv.us/boe/manchin.html

West Virginia Higher Education Policy Commission. (2007). Charting the future 2007-2012: A master plan for West Virginia higher education. Charleston, WV. 
West Virginia Higher Education Policy Commission. (2011). West Virginia College Going Rates by County and High School. Charleston, WV.

West Virginia Higher Education Policy Commission. (2013). Leading the Way. Access. Success. Impact 2013-2018 Master Plan. Charleston, WV.

West Virginia Partnership to Assure Student Success. (2013a). Leadership Board. Retrieved from http://wvpass.org/leadershipboard.html

West Virginia Partnership to Assure Student Success. (2013b). Ruby Payne Training. Retrieved from http://wvpass.org/partners/rubypayne.html

Whisnant, D. E. (1983). All that is native and fine. Chapel Hill, NC: The University of North Carlina Press.

Willis, P. (1977). Learning to labor: How working-class kids get working-class jobs. New York, NY: Columbia University Press.

Wolcott, H. (1975). Criteria for an ethnographic approach to research in schools. Human Organization, 34(2), 111-127.

Wolcott, H. (1997a). Ethnographic research in education. In Jaegar (Ed.), Complementary methods for research in education (155-172). Washington, DC: American Educational Research Association.

Wolcott, H. (1997b). On ethnographic intent. In Spindler \& Spindler (Eds.), Interpretive ethnography of education: At home and abroad (37-51). Hillsdale, NJ: Erlbaum.

Woodman, S. (2012). Labor takes aim at Walmart-Again. Nation, 294, 20-25.

Wright, C. J. (2012). Becoming to remain: Community college students and postsecondary pursuits in central Appalachia. Journal of Research in Rural Education, 27(6), 1-11. 
Yonezawa, S., Wells, A. S., \& Serna, I. (2002). Choosing tracks: "Freedom of choice" in detracking schools. American Educational Research Journal, 39(1).

Zhao, S., Grasmuck, S., \& Martin, J. (2008). Identity construction on Facebook: Digital empowerment in anchored relationships. Computers in Human Behavior, 24, 1816-1836. 


\section{Appendix 1: Student Interview 1}

Introduction: I'm interested in how students from a range of backgrounds choose what they do after high school and what factors lead them to these choices. I want to learn a little about your life and the things that are helping you to make those decisions.

Question: Pretend you are on a game show and you have to describe yourself to the audience and give them the best picture of who you are, what would you say?

Follow up: If I asked your friends to describe you what would they say?

Follow up: If I asked your friends to describe you what would they say?

Question: I want to get a picture of your home life generally speaking - so pretend your life is TV show for a minute and have this episode be a typical day at home - tell me how that episode would go.

Follow up: When you're at home who else is there?

Follow up: When you're at home what do you spend time doing?

Question: Tell me about where you do live, not your house per se, but the area where you live. Follow up: What do you think about where you live?

Follow up: What do others think about where you live?

Question: If you could live anywhere around this area that you wanted to, where would you live?

Follow up: What makes you want to live there?

Question: Think about your larger community here... what do you like about your community? Follow up: What do you not like about your community?

Follow up: What kind of activities are there for someone your age to do here?

Follow up: What do you wish your community had that it doesn't?

Question: Tell me about the different groups of people around where you live.

Follow up: What makes these groups different from one another?

Follow up: How do you fit with these groups?

Follow up: How does your family fit with these groups?

Question A: If I ask you to think of West Virginia, what comes to mind?

Question B: If I ask someone from California to think of West Virginia what do you think they would think about?

Follow up: Tell me about those differences.

Follow up: What makes people have these different views?

Follow up: Where do you see yourself as fitting into these views?

Follow up: What do you like about West Virginia?

Follow up: What do you not like about West Virginia? 
Question: Tell me what school is like for you.

Follow up: What do you like about school?

Follow up: What do you not like?

Follow up: What classes do you do well in?

Follow up: What helps you do well?

Follow up: What classes do you have a hard time with?

Follow up: What makes those classes hard?

Question: Think about the different groups/cliques at school and pretend you're making a

brochure for people who might transfer to your school, how would you describe those groups?

Follow up: Tell me what makes each group distinct?

Follow up: How do you place yourself in those groups?

Follow up: How do others place you?

Follow up: Tell me about what your friends are like inside school.

Follow up: Tell me about what your friends are like outside school.

Follow up: What do you spend your time outside of school doing?

Question: What are your plans after graduation?

Follow up: What made you decide to do that?

Follow up: What are things you think may keep you from doing that?

Follow up: How worried are you about those things?

Follow up: What are things that may help you achieve your goal?

Question: Pretend that you could do anything you wanted to do after school, no limits or barriers on anything, what would you do?

Follow up: What makes you want to do that?

Follow up: What's the reason for the difference between what you are doing and your no limits idea? 


\section{Appendix 2: Parent Interview Outline}

Question: Tell me about your own experience as a student in school.

Follow up: What was high school like for you?

Follow up: How far did you go in school?

Question: Tell me your story about how you got to where you are in life now....from the time you finished your final year of schooling.

Follow up: What do you do for work now?

Follow up: What have you done in the past that is different?

Question: As 's family/guardians, what have your experiences interacting with the school been like? Example?

Follow up: Who interacts with the school the most on 's behalf?

Follow up: In what ways do you interact with the school?

Follow up: In what ways has the school been open or accessible if there was a concern or issue that needed addressed? Example?

Follow up: In what ways has the school been closed or inaccessible if there was a concern or issue that needed addressed? Example?

Question: What are the things you/the family does to support 's education?

Follow up: What do you wish you/the family could do differently to support 's education?

Follow up: What do you see as assets in you/the family supporting schooling/education?

Follow up: What do you see as barriers to you/the family supporting ___ 's schooling/education?

Question: In what ways is the school doing a good job of supporting 's education. Example?

Follow up: In what ways is the school not doing a good job of supporting 's education? Example?

Question: Tell me how you view as a student.

Follow up: What things have led you to come to this view?

Follow up: What are ___ 's strengths as a student?

Follow up: What are things you'd like to see them change?

Question: Describe how you think the school views as a student.

Follow up: What has the school done to lead you to this belief?

Question: Describe how you think sees themselves as a student.

Follow up: What do you think influences that view? 
Question: What are your hopes for 's educational path?

Follow up: How did you arrive at this goal?

Follow up: How do you think feels about this goal?

Follow up: What are your concerns for reaching this goal?

Question: What are your hopes for 's work/career path?

Follow up: How did you arrive at this goal?

Follow up: How do you think feels about this goal?

Follow up: What are your concerns for reaching this goal?

Question: Describe how you see as a person.

Follow up: What are their strengths?

Follow up: What are things you'd like to see them change?

Question: Tell me about 's friends

Follow up: How do you feel about Follow up: What has led you to these feelings?

Question: Think about your larger community here...what are strengths of your community? Follow up: What things about your community would you change if you could?

Follow up: What kind of activities are there for someone your kids age to do here?

Follow up: What do you wish your community had that it doesn't?

Question: Tell me about the different groups of people around where you live.

Follow up: What makes these groups different from one another?

Follow up: How does your family fit with these groups?

Follow up: How does your child fit with these groups?

Question A: If I ask you to think of West Virginia, what comes to mind?

Question B: If I ask someone from CA to think of WV what do you think they would think about?

Follow up: Tell me about how you believe people construct those views.

Follow up: Where do you see your family as fitting into these views?

Follow up: What do you like about West Virginia?

Follow up: What do you not like about West Virginia? 


\section{Appendix 3: Student Interview 2}

Question: These are the things that I have learned about you and your schooling over the past year. What are your thoughts on these results?

Follow up: What is interesting for you about these results?

Follow up: What surprised you?

Follow up: Is there anything that you see differently than what I have written about?

Follow up: What, if anything do you think I missed in my analysis?

Follow up: What do you think would be the best way for me to use this information?

Question: Now that you have graduated, tell me about what you are doing?

Follow up: (if different from previous plans) What made you decide to do this instead of...

Follow up: What were things you dealt with in getting here that you didn't expect to encounter? (barriers/helps)

Follow up: Who influenced you in this process?

Follow up: How do you feel about where you are at?

Question: What do you wish you would have known in high school that you know now? (that you would maybe share with other students)

Question: Now I'm going to ask you to think about 5 years in the future... What do you see yourself doing 5 years from now?

Follow up: What makes you want to do that?

Follow up: What do you think is going to help you get there?

Follow up: What are any barriers you see that might stop you from getting there?

Question: Are there any other things you want to tell me about that I haven't asked about or touched on?

Follow up: What are your questions for me about your data?

Follow up: What are your questions for me about this project?

Follow up: What was participating in this project like for you?

Follow up: Any suggestions for what I should do differently if I do something like this again? 


\section{Appendix 4: CHS Focus Group 1, Appalachian Identity}

Question: What were your experiences with Buckwild — did you watch it, what did you think about it, what did you like, what did you not like?

Follow up: What were your friends' reactions to the show? Family?

Follow up: What do you think about the different reactions to the show?

Watch the opening credits of the $1^{\text {st }}$ episode of Buckwild ( 2 minutes-I tunes)

Question: What do these opening scenes say about what people from West Virginia are like?

Follow up: How are those things true?

Follow up: How are they not true?

Follow up: In what ways are they too complicated to say they are true/not true?

Watch Buckwild stars on the Access Hollywood Clip then show photos from Jimmy Fallon

Question: What do each of the Buckwild actors' clothes say about them from New York?

Follow up: Shae?

Follow up: Shain?

Follow up: How do their clothes in New York (on Jimmy Fallon and Access Hollywood) compare to their clothes on their piece of the opening credits?

Question: How does the host's voice change when mimic's Shain's words/accent? (opening credits through $1 \mathrm{~min}$ )

Follow up: What do you think about Shae's facial expression when the hosts mimic Shain's dialect during this segment?

Follow up: A 2:55-310 the hosts bring up the differences in accents... What do you think about Shae and Shain's responses?

Follow up: How do you think they are true/not true?

Follow up: What does that say about Shain?

Follow up: What does that say about Shae?

Question: At 3:52 When the hosts ask about the controversy of the show what do you think about Shae's response? Shains?

Question: At 4:40 When Shain offers the homemade candy to the hosts...

Follow up: What do the initial reactions of the hosts imply?

Follow up: How does this represent and not represent people from WV?

Watch a clip of Jennifer Garner on the Conan O’Brien show (2 min)

Question: How is this clip of Jennifer Garner different from the clip of the Buckwild actors? 
Question: How does she portray people from WV in comparison to the Buckwild actors?

Follow up: Similar?

Follow up: Different?

Question: Thinking about the dynamics between Jennfier Garner/Conan and Shain/Shae and the Access Hollywood hosts - what are the differences?

Follow up: Why do you think the host/gust dynamics are different on the 2 shows?

\section{Discuss the description of Buckwild:}

On the back of the video box this is the blurb- "Buckwild is an authentic comedic series following an outrageous group of childhood friends from the rural foothills of West Virginia who love to dodge grown-up responsibilities and always live life with the carefree motto, "whatever happens, happens." Money might be tight in their neck of the woods, but whether they're throwing a dump truck pool party or building their own human slingshot, nothing stops them from making their own entertainment. Love and relationships come and go, but their bond with family and friends is always at the core of this eccentric group where anything goes!

"Buckwild is an authentic comedic series"

Question: What does this statement say?

"An outrageous group of childhood friends who love to dodge grown-up responsibilities and always live life with the carefree motto, "whatever happens, happens."”

Question: What are the implied meanings of this statement?

Follow up: How does the drug arrest of Salwa fit in with this statement?

Follow up: How does Shain's death fit in with this statement?

Watch West Virginia high school students' responses to Shain's death from Death of Buckwild Star "Wake-Up Call” to West Virginia Students on PBS Newshour...

Question: What do you relate to from this video?

Follow up: What do you not relate to from this video?

Follow up: What do you think about these students' responses to the series?

Read the blurbs from the students about Shain's death

Follow up: To the death of Shain?

Question: When a show like Buckwild comes out (or a movie/book/whatever)...

How does that impact you as a person from West Virginia

Watch a clip from Hollow the Documentary of Josh Clevenger high school senior and his hopes for the community and what he would like to do

Question: How is Josh's presentation of life different than Buckwild?

Follow up: How are his experiences similar to yours?

Follow up: How are they different? 
We will watch a video clip from the Appalachian Media Institute "Searching for an Appalachian Accent" that discusses accents in Appalachia and people's experiences.

Watch beginning through $1: 06 ; 309-645 ; 714-740 ; 842-928 ; 958-1033 ; 1322-1350$

Question: What have you all's experience been in encountering people and your accent is different than theirs?

Follow up: What has their response to your accent been?

Follow up: How did you respond to that?

Follow up: Where do people's ideas come from?

Follow up: What do you feel like when people say things like that?

Follow up: How does that place you as a person?

Follow up: How does it place your place?

Follow up: What about when someone tells me, you don't sound like you're from West Virginia... what are they implying with that statement?

Watch a Buckwild clip where other cast members are chastising Shain to "speak English" (clip is episode 1 on iTunes: 11:01-12:30)

Question: When the cast members tell Shain to "speak English" - what are they really saying to him?

Follow up: What does that say about his accent?

Follow up: What do you think about Shain's response?

Question: How do you think his friends' actions impact him? How would those same actions impact him if they were coming from someone who was not his friend?

Watch Hollow video about 'belonging' in West Virginia (Alan Johnston 3 min)

Question: In what ways does this address home?

Follow up: How do you relate to this video?

We will watch a video clip from Coal Black Voices from the Affrilachian Poets. (Frank X Walker 2 min.)

Question: What does this video show about Appalachia?

Question: How does this connect to your own identity, who you are as a West Virginian/Appalachian?

Question: How do people in your life address race?

Crystal Wilkinson "Dear Johnny P" — video from Coal Black Voices from Affrilachian Poets. (2 min.)

Question: How do you relate to this video?

Question: What does this video say about race in Appalachia?

Follow up: What is race like in your lives?

Follow up: What is race like at school? 
Question: In what ways have your racial experiences been like or different to what she addresses in this poem?

\section{General Group Questions}

Question: In what ways are you different from media portrayals of West Virginians?

Question: In what ways are you similar to media portrayals of West Virginians?

Question: What voices seem to be the loudest in this process?

Question: How does that impact you-how you feel about yourself, your state, in comparison to others? 


\section{Appendix 5: CHS Focus Group 2, Photovoice, Dialect, and Race}

Discussion Points - each photo will be discussed by the photographer and then the group following the outline below.

- To the photographer of each photo

○ Tell us about this photo.

- What is important in/about this photo?

- What aspect of you/your identity does this photo represent?

- How is this photo a complete representation of this topic?

How does this photo not capture all of this topic?

- To the rest of the group

- What do you identify with in this photo?

- What do you not identify with in this photo?

- How have your experiences with this topic been?

- How is this photo a complete representation of this topic?

How does this photo not capture all of this topic?

\section{Dialect and Race Portion}

We will watch a video clip from the Appalachian Media Institute "Searching for an Appalachian Accent" that discusses accents in Appalachia and people's experiences.

Watch beginning through 1:06; 309-645; 714-740; 842-928; 958-1033; 1322-1350

Question: What have you all's experience been in encountering people and your accent is different than theirs?

Follow up: What has their response to your accent been?

Follow up: How did you respond to that?

Follow up: Where do people's ideas come from?

Follow up: What do you feel like when people say things like that?

Follow up: How does that place you as a person?

Follow up: How does it place your place?

Follow up: What about when someone tells me, you don't sound like you're from West Virginia... what are they implying with that statement?

Watch a Buckwild clip where other cast members are chastising Shain to "speak English" (clip is episode 1 on itunes: 11:01-12:30)

Question: When the cast members tell Shain to "speak English" -what are they really saying to him?

Follow up: What does that say about his accent?

Follow up: What do you think about Shain's response?

Question: How do you think his friends' actions impact him? How would those same actions impact him if they were coming from someone who was not his friend? 
Watch Hollow video about 'belonging' in West Virginia (Alan Johnston $3 \mathrm{~min}$ )

Question: In what ways does this address home?

Follow up: How do you relate to this video?

We will watch a video clip from Coal Black Voices from the Affrilachian Poets. (Frank X Walker 2 min.)

Question: What does this video show about Appalachia?

Question: How does this connect to your own identity, who you are as a West

Virginian/Appalachian?

Question: How do people in your life address race?

Crystal Wilkinson "Dear Johnny P"—-video from Coal Black Voices from Affrilachian Poets. (2 min.)

Question: How do you relate to this video?

Question: What does this video say about race in Appalachia?

Follow up: What is race like in your lives?

Follow up: What is race like at school?

Question: In what ways have your racial experiences been like or different to what she addresses in this poem?

General Group Questions

Question: In what ways are you different from media portrayals of West Virginians?

Question: In what ways are you similar to media portrayals of West Virginians?

Question: What voices seem to be the loudest in this process?

Question: How does that impact you - how you feel about yourself, your state, in comparison to others? 


\section{Appendix 6: MCHS Focus Group 1, Appalachian Identity}

Question: What were your experiences with Buckwild — did you watch it, what did you think about it, what did you like, what did you not like?

Follow up: What were your friends' reactions to the show? Family?

Follow up: What do you think about the different reactions to the show?

Watch the opening credits of the $1^{\text {st }}$ episode of Buckwild ( 2 minutes-I tunes)

Question: What do these opening scenes say about what people from West Virginia are like?

Follow up: How are those things true?

Follow up: How are they not true?

Follow up: In what ways are they too complicated to say they are true/not true?

Watch Buckwild stars on the Access Hollywood Clip then show photos from Jimmy Fallon

Question: What do each of the Buckwild actors' clothes say about them from New York?

Follow up: Shae?

Follow up: Shain?

Follow up: How do their clothes in New York (on Jimmy Fallon and Access Hollywood) compare to their clothes on their piece of the opening credits?

Question: How does the host's voice change when mimic's Shain's words/accent? (opening credits through $1 \mathrm{~min}$ )

Follow up: What do you think about Shae's facial expression when the hosts mimic Shain's dialect during this segment?

Follow up: At 2:55-310 the hosts bring up the differences in accents... What do you think about Shae and Shain's responses?

Follow up: How do you think they are true/not true?

Follow up: What does that say about Shain?

Follow up: What does that say about Shae?

Question: At 3:52 when the hosts ask about the controversy of the show what do you think about Shae's response? Shains?

Question: At 4:40 when Shain offers the homemade candy to the hosts...

Follow up: What do the initial reactions of the hosts imply?

Follow up: How does this represent and not represent people from WV?

Watch a clip of Jennifer Garner on the Conan O’Brien show (2 min)

Question: How is this clip of Jennifer Garner different from the clip of the Buckwild actors? 
Question: How does she portray people from WV in comparison to the Buckwild actors?

Follow up: Similar?

Follow up: Different?

Question: Thinking about the dynamics between Jennifer Garner/Conan and Shain/Shae and the Access Hollywood hosts - what are the differences?

Follow up: Why do you think the host/gust dynamics are different on the 2 shows?

\section{Discuss the description of Buckwild:}

On the back of the video box this is the blurb- "Buckwild is an authentic comedic series following an outrageous group of childhood friends from the rural foothills of West Virginia who love to dodge grown-up responsibilities and always live life with the carefree motto, "whatever happens, happens." Money might be tight in their neck of the woods, but whether they're throwing a dump truck pool party or building their own human slingshot, nothing stops them from making their own entertainment. Love and relationships come and go, but their bond with family and friends is always at the core of this eccentric group where anything goes!

"Buckwild is an authentic comedic series"

Question: What does this statement say?

"An outrageous group of childhood friends who love to dodge grown-up responsibilities and always live life with the carefree motto, "whatever happens, happens."”

Question: What are the implied meanings of this statement?

Follow up: How does the drug arrest of Salwa fit in with this statement?

Follow up: How does Shain's death fit in with this statement?

Watch West Virginia high school students' responses to Shain's death from Death of Buckwild Star "Wake-Up Call” to West Virginia Students on PBS Newshour...

Question: What do you relate to from this video?

Follow up: What do you not relate to from this video?

Follow up: What do you think about these students' responses to the series?

Read the blurbs from the students about Shain's death

Follow up: To the death of Shain?

Question: When a show like Buckwild comes out (or a movie/book/whatever)...

How does that impact you as a person from West Virginia?

Watch a clip from Hollow the Documentary of Josh Clevenger high school senior and his hopes for the community and what he would like to do.

Question: How is Josh's presentation of life different than Buckwild?

Follow up: How are his experiences similar to yours?

Follow up: How are they different? 


\section{Appendix 7: MCHS Focus Group 2, Dialect and Race}

We will watch a video clip from the Appalachian Media Institute "Searching for an Appalachian Accent" that discusses accents in Appalachia and people's experiences.

Watch beginning through 1:06; 309-645; 714-740; 842-928; 958-1033; 1322-1350

Question: What have you all's experience been in encountering people and your accent is different than theirs?

Follow up: What has their response to your accent been?

Follow up: How did you respond to that?

Follow up: Where do people's ideas come from?

Follow up: What do you feel like when people say things like that?

Follow up: How does that place you as a person?

Follow up: How does it place your place?

Follow up: What about when someone tells me, you don't sound like you're from West Virginia... what are they implying with that statement?

Watch a Buckwild clip where other cast members are chastising Shain to "speak English" (clip is episode 1 on iTunes: 11:01-12:30)

Question: When the cast members tell Shain to "speak English" -what are they really saying to him?

Follow up: What does that say about his accent?

Follow up: What do you think about Shain's response?

Question: How do you think his friends' actions impact him? How would those same actions impact him if they were coming from someone who was not his friend?

Watch Hollow video about 'belonging' in West Virginia (Alan Johnston 3 min)

Question: In what ways does this address home?

Follow up: How do you relate to this video?

We will watch a video clip from Coal Black Voices from the Affrilachian Poets. (Frank X Walker 2 min.)

Question: What does this video show about Appalachia?

Question: How does this connect to your own identity, who you are as a West Virginian/Appalachian?

Question: How do people in your life address race? 
Crystal Wilkinson "Dear Johnny P”_ - video from Coal Black Voices from Affrilachian Poets. (2 min.)

Question: How do you relate to this video?

Question: What does this video say about race in Appalachia?

Follow up: What is race like in your lives?

Follow up: What is race like at school?

Question: In what ways have your racial experiences been like or different to what she addresses in this poem?

General Group Questions

Question: In what ways are you different from media portrayals of West Virginians?

Question: In what ways are you similar to media portrayals of West Virginians?

Question: What voices seem to be the loudest in this process?

Question: How does that impact you-how you feel about yourself, your state, in comparison to others? 


\section{Appendix 8: MCHS Focus Group 3, Photovoice}

Discussion Points - each photo will be discussed by the photographer and then the group following the outline below.

- To the photographer of each photo

$\circ$ Tell us about this photo.

$\circ$ What is important in/about this photo?

- What aspect of you/your identity does this photo represent?

- How is this photo a complete representation of this topic?

- How does this photo not capture all of this topic?

- To the rest of the group

- What do you identify with in this photo?

$\circ$ What do you not identify with in this photo?

- How have your experiences with this topic been?

- How is this photo a complete representation of this topic?

- How does this photo not capture all of this topic? 


\section{Appendix 9: Student Questionnaire}

Personal \& Family Information

How old are you?

How do you identify racially/ethnically?

Who lives in your home (names/ages)

What do your parent/s do for work?

What are your siblings' names and ages?

What do your siblings do for work (if they work)?

How long have you lived in this area?

Where else have you lived?

How would you describe where you live (rural/town/suburban)?

School Information

What is your overall GPA at school?

If you've taken any college prep/college entrance exams (ACT/SAT/PSAT) what were your scores on those? 


\section{Appendix 10: Teacher Questionnaire}

What courses do you teach?

Please briefly state your teaching philosophy.

Where did you grow up?

Where did you go to college? Degree(s)?

How long have you lived in this community?

How would you describe where you live (rural/town/suburb)?

Who else lives in your home? Ages? Jobs?

How old are you?

How do you identify racially/ethnically?

What do you see as strengths of your school?

What are things you would like to change/improve in your school? 


\section{Appendix 11: Guidance Counselor Questionnaire}

What are your specific duties in your position?

How many students are you assigned/assisting?

Please briefly state your counseling philosophy.

Where did you grow up?

Where did you go to college? Degree (s)?

How long have you lived in this community?

How would you describe where you live (rural/town/suburban)?

Who else lives in your home? Ages? Jobs?

How old are you?

How do you identify racially/ethnically? 


\section{Appendix 12: Counseling Department Questionnaire}

How many counselors are at your school?

How many students at your school?

How are counselors assigned to students?

What are the informal and formal guidance events for each grade?

Freshman

Sophomore

Junior

Senior

How many graduates (\%) enroll in 4 year college?

How many graduates (\%) enroll in:

Vocational education?

Military?

Direct work?

What percent of students participate in:

National honor society?

Sports?

Other clubs/honoraries?

What do you see as strengths of your department?

What are things you would like to change/improve in your department? 